Prepared in cooperation with the Virginia Department of Environmental Quality and the Hampton Roads Planning District Commission

\title{
Groundwater-Quality Data and Regional Trends in the Virginia Coastal Plain, 1906-2007
}

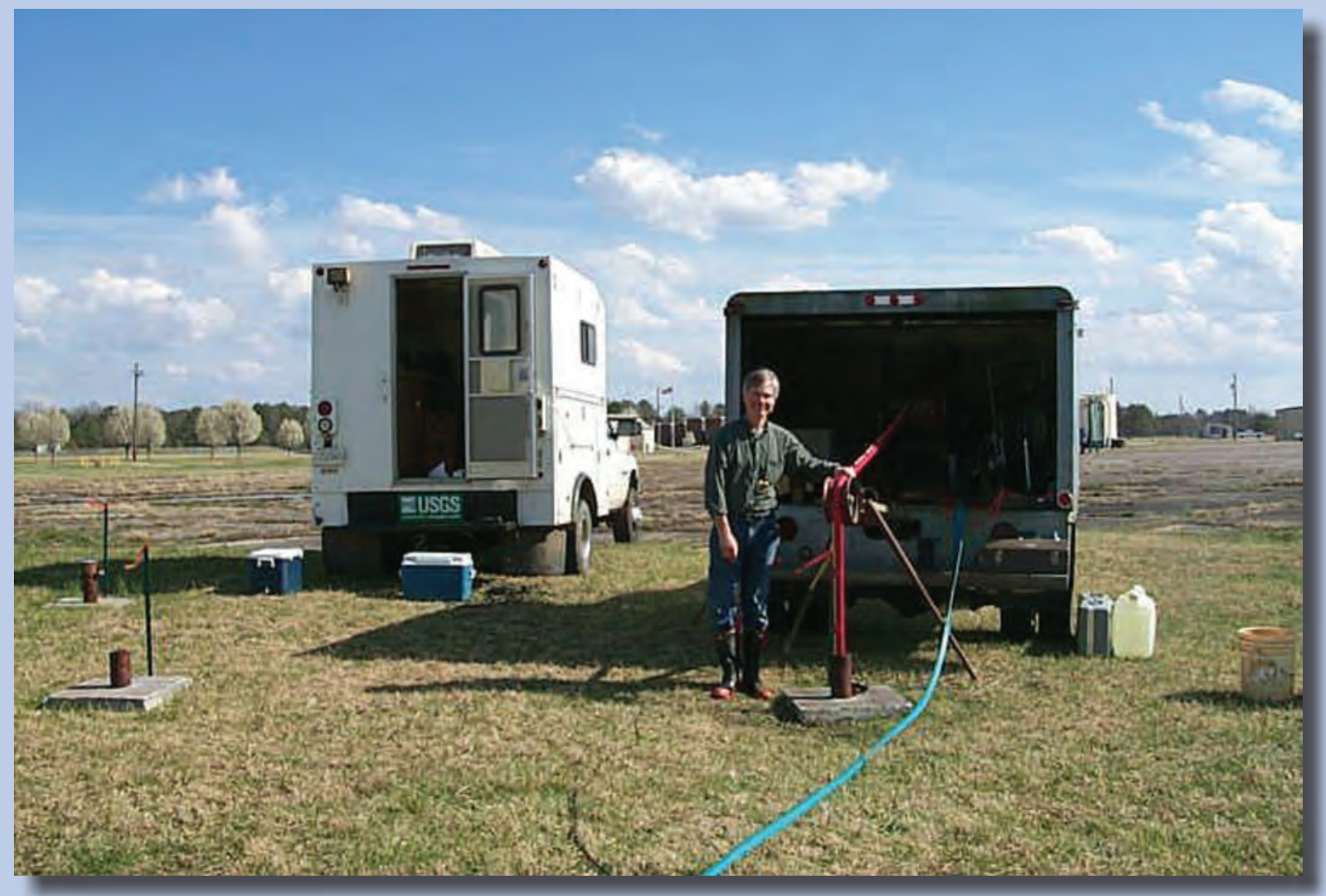

Professional Paper 1772 
Cover. Groundwater-quality samples being collected from research observation wells at Fentress, Virginia, during 2006. Truck-mounted submersible pumping system is being operated by a U.S. Geological Survey (USGS) hydrologic technician. Second vehicle is equipped for sample processing. Well being pumped and two wells to the left are among seven colocated wells completed in different aquifers. The wells constitute a groundwater-research station established by the Virginia Department of Environmental Quality (DEQ). The research station is part of a network of wells for monitoring saltwater intrusion in the Virginia Coastal Plain, from which groundwater samples are periodically collected and analyzed by the USGS in cooperation with DEO and the Hampton Roads Planning District Commission. (photograph by Roger M. Moberg, Hydrologic Technician, USGS) 


\section{Groundwater-Quality Data and Regional Trends in the Virginia Coastal Plain, 1906-2007}

By E. Randolph McFarland

Prepared in cooperation with the Virginia Department of Environmental Quality and the Hampton Roads Planning District Commission

Professional Paper 1772 


\title{
U.S. Department of the Interior \\ KEN SALAZAR, Secretary \\ U.S. Geological Survey \\ Marcia K. McNutt, Director
}

\author{
U.S. Geological Survey, Reston, Virginia: 2010
}

For more information on the USGS - the Federal source for science about the Earth, its natural and living resources, natural hazards, and the environment, visit http://www.usgs.gov or call 1-888-ASK-USGS

For an overview of USGS information products, including maps, imagery, and publications, visit http://www.usgs.gov/pubprod

To order this and other USGS information products, visit http://store.usgs.gov

Any use of trade, product, or firm names is for descriptive purposes only and does not imply endorsement by the U.S. Government.

Although this report is in the public domain, permission must be secured from the individual copyright owners to reproduce any copyrighted materials contained within this report.

Suggested citation:

McFarland, E.R., 2010, Groundwater-quality data and regional trends in the Virginia Coastal Plain, 1906-2007:

U.S. Geological Survey Professional Paper 1772, 86 p., 14 pls.

(available online at $h t t p: / / p u b s . u s g s . g o v / p p / 1772 /$ )

\section{Library of Congress Cataloging-in-Publication Data}

McFarland, E. Randolph.

Groundwater-quality data and regional trends in the Virginia coastal plain,

1906-2007 / by E. Randolph McFarland ; prepared in cooperation with the

Virginia Department of Environmental Quality and the Hampton Roads Planning

District Commission. -- Ist ed.

p. cm. -- (Professional paper ; 1772)

Includes bibliographical references.

ISBN 978-1-4113-2680-4

1. Groundwater--Quality--Virginia--History. 2. Hydrogeology--Virginia--History. 3. Water chemistry--Virginia--History. I. Virginia. Dept. of Environmental Quality. II. Hampton Roads Planning District Commission (Va.) III. Geological Survey (U.S.) IV. Title. V. Series: U.S.

Geological Survey professional paper ; 1772.

GB1025.V8M33 2010

551.4909755--dc22 


\section{Contents}

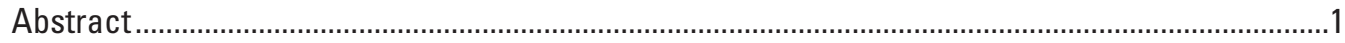

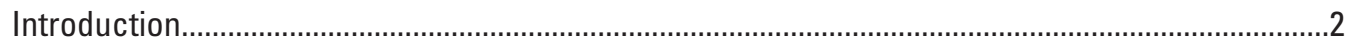

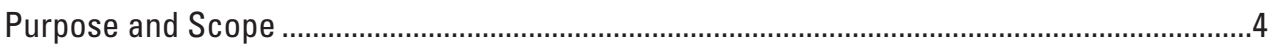

Description of the Study Area ..................................................................................................

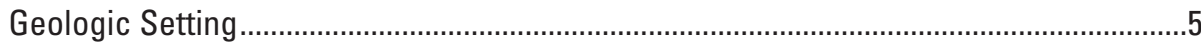

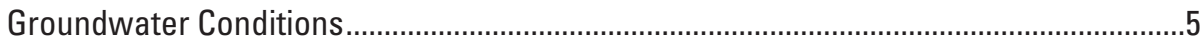

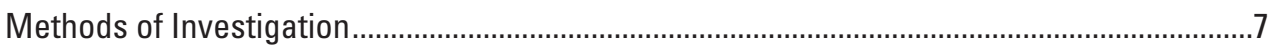

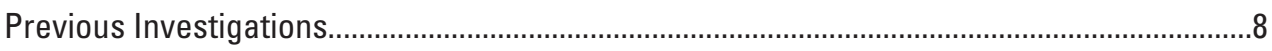

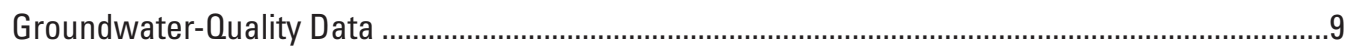

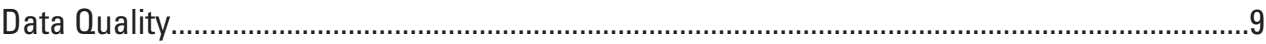

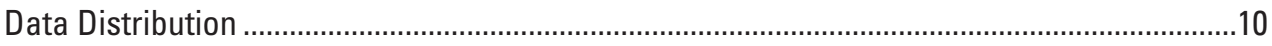

Data Use and Limitations.................................................................................................. 13

Regional Trends in Groundwater Quality ..................................................................................13

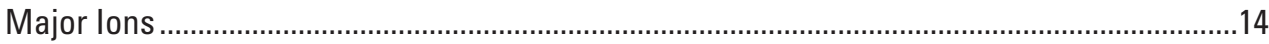

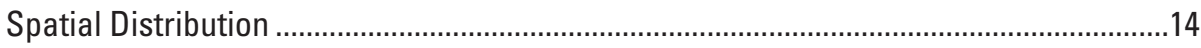

Hydrochemical Processes ................................................................................... 15

Saltwater-Transition Zone .................................................................................................. 17

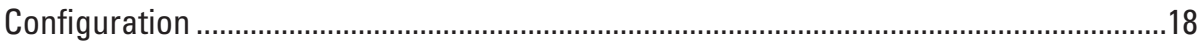

Chloride-Concentration Sections ...................................................................... 18

Chloride Iso-Concentration Surfaces.........................................................................19

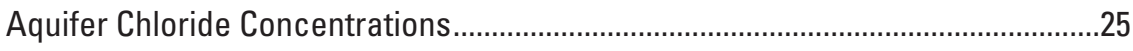

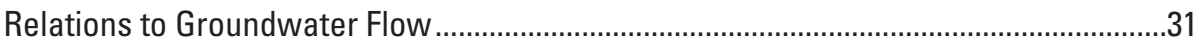

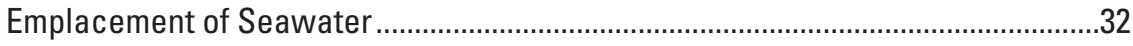

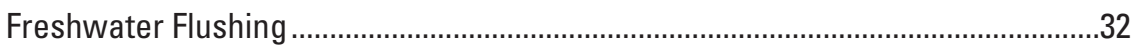

Brine and the Inner Chesapeake Bay Impact Crater................................................33

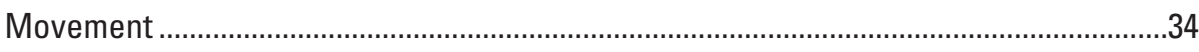

Rates of Change in Chloride Concentration ..............................................................

Patterns of Change in Chloride Concentration ........................................................42

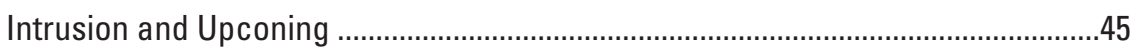

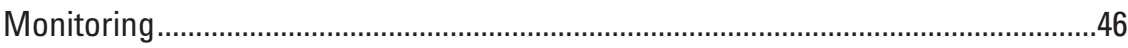

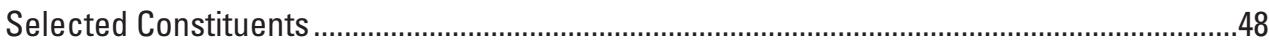

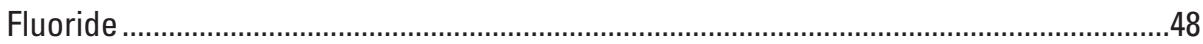

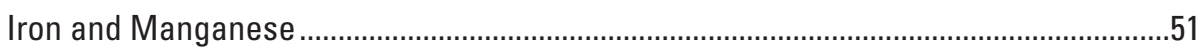

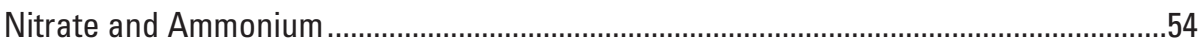

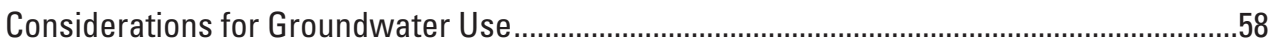

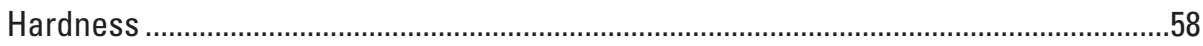

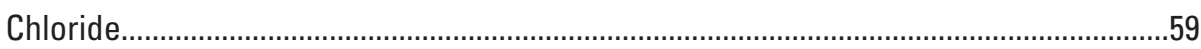

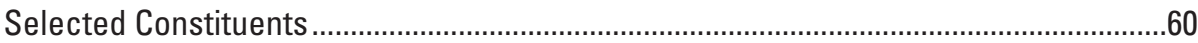

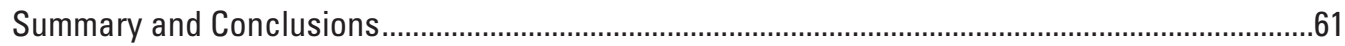

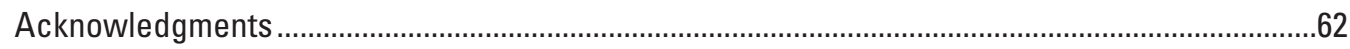

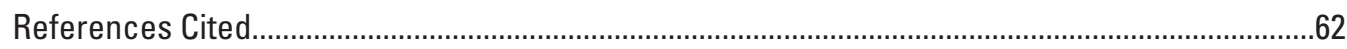

Attachment 1. - Chemical-constituent values and related data ...................................... in pocket

Attachment 2. - Summary of groundwater-quality constituent values ...........................................67 
Plates (In envelope)

1-3. Maps showing locations of sampled groundwater wells and boreholes in:

1. The northern part of the Virginia Coastal Plain

2. The southern part of the Virginia Coastal Plain

3. The Virginia Eastern Shore

4-9. Maps showing the major ion composition of groundwater in:

4. The surficial aquifer

5. The Yorktown-Eastover aquifer

6. The Piney Point aquifer

7. The Aquia aquifer

8. The Potomac aquifer

9. Basement bedrock

10-14. Dissolved chloride-concentration sections:

10. DD-DD' and ED-ED'

11. FD-FD' and GD-GD'

12. ID-ID' and JD-JD'

13. DS-DS' and ES-ES'

14. FS-FS' and GS-GS'

\section{Figures}

1. Map showing groundwater-sample locations and chloride-concentration

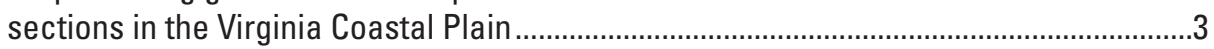

2. Generalized hydrogeologic section and directions of groundwater flow.........................

3. Diagram of stratigraphic relations among hydrogeologic units ........................................

4-8. Maps showing approximate altitude and configuration of:

4. The 50 milligram per liter chloride iso-concentration surface................................20

5. The 250 milligram per liter chloride iso-concentration surface...............................21

6. The 1,000 milligram per liter chloride iso-concentration surface............................22

7. The 10,000 milligram per liter chloride iso-concentration surface............................23

8. The 19,000 milligram per liter chloride iso-concentration surface..........................24

9-13. Maps showing groundwater chloride concentrations in:

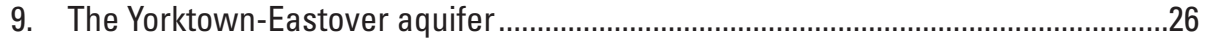

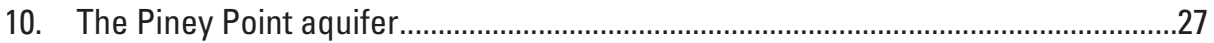

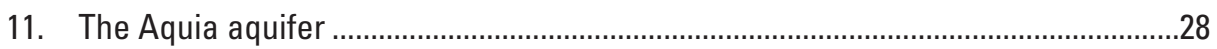

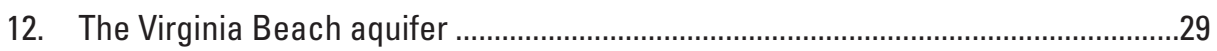

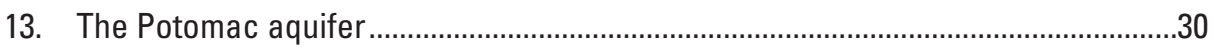

14. Graphs showing rates of change in concentrations of chloride in groundwater and yearly averaged rates of groundwater withdrawal ................................................35

15-19. Maps showing rates of change in concentrations of chloride in groundwater in:

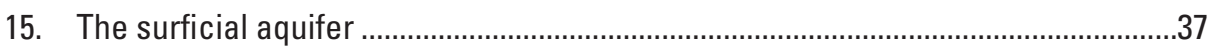

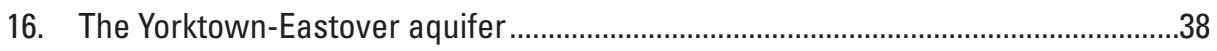

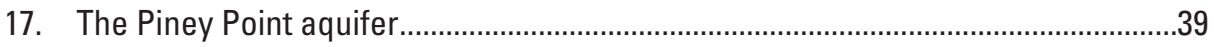

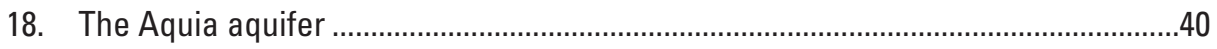

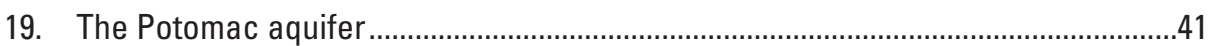


20-21. Graphs showing concentrations of chloride in groundwater and yearly averaged rates of groundwater withdrawal in:

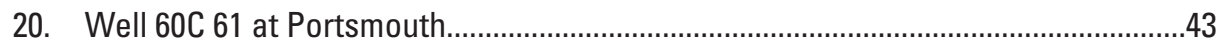

21. Selected wells on the central York-James Peninsula ...........................................44

22-26. Maps and generalized hydrogeologic sections showing distributions in groundwater of:

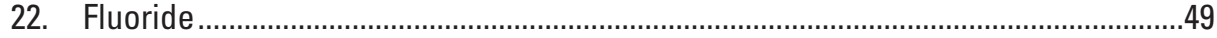

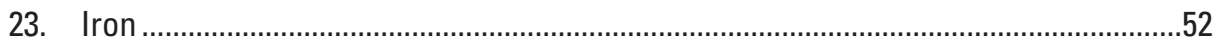

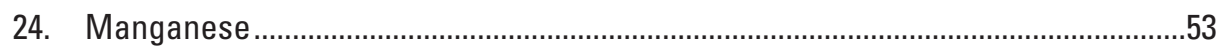

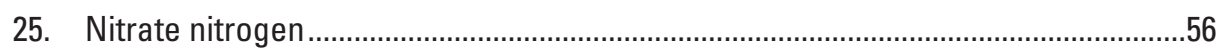

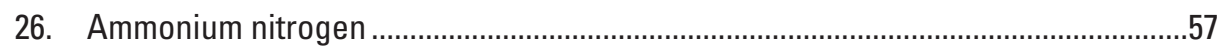

\section{Tables}

1. Numbers of sampled wells, water-quality samples, and chemical-constituent values.

2. Summary of sequentially collected groundwater samples ...............................................36

3. Municipalities operating brackish groundwater-development facilities..........................59 


\section{Conversion Factors}

Inch/Pound to SI

\begin{tabular}{|c|c|c|}
\hline Multiply & By & To obtain \\
\hline \multicolumn{3}{|c|}{ Length } \\
\hline inch (in.) & 2.54 & centimeter $(\mathrm{cm})$ \\
\hline inch (in.) & 25.4 & millimeter $(\mathrm{mm})$ \\
\hline foot (ft) & 0.3048 & $\operatorname{meter}(\mathrm{m})$ \\
\hline mile (mi) & 1.609 & kilometer (km) \\
\hline \multicolumn{3}{|c|}{ Area } \\
\hline square mile $\left(\mathrm{mi}^{2}\right)$ & 259.0 & hectare (ha) \\
\hline square mile $\left(\mathrm{mi}^{2}\right)$ & 2.590 & square kilometer $\left(\mathrm{km}^{2}\right)$ \\
\hline \multicolumn{3}{|c|}{ Volume } \\
\hline gallon (gal) & 3.785 & liter (L) \\
\hline \multicolumn{3}{|c|}{ Flow rate } \\
\hline million gallons per day (Mgal/d) & 0.04381 & cubic meter per second $\left(\mathrm{m}^{3} / \mathrm{s}\right)$ \\
\hline
\end{tabular}

SI to Inch/Pound

\begin{tabular}{lcl}
\hline \multicolumn{1}{c}{ Multiply } & By & \multicolumn{1}{c}{ To obtain } \\
\hline \multirow{2}{*}{ liter $(\mathrm{L})$} & Volume & \\
& 0.2642 & gallon (gal) \\
\hline milligram $(\mathrm{mg})$ & Mass & \\
& 0.00003527 & ounce $(\mathrm{oz})$ \\
\hline milligram per liter $(\mathrm{mg} / \mathrm{L})$ & Concentration & \\
\hline
\end{tabular}

Temperature in degrees Celsius $\left({ }^{\circ} \mathrm{C}\right)$ may be converted to degrees Fahrenheit $\left({ }^{\circ} \mathrm{F}\right)$ as follows:

$$
{ }^{\circ} \mathrm{F}=\left(1.8 \times{ }^{\circ} \mathrm{C}\right)+32
$$

Vertical coordinate information is referenced to the National Geodetic Vertical Datum of 1929 (NGVD 29).

Horizontal coordinate information is referenced to the North American Datum of 1927 (NAD 27).

Altitude, as used in this report, refers to distance above or below the vertical datum.

Specific conductance is given in microsiemens per centimeter at 25 degrees Celsius ( $\mu \mathrm{S} / \mathrm{cm}$ at $\left.25^{\circ} \mathrm{C}\right)$.

Concentrations of chemical constituents in water are given in milligrams per liter (mg/L) or micrograms per liter $(\mu \mathrm{g} / \mathrm{L})$. 


\title{
Groundwater-Quality Data and Regional Trends in the Virginia Coastal Plain, 1906-2007
}

\author{
By E. Randolph McFarland
}

\section{Abstract}

A newly developed regional perspective of the hydrogeology of the Virginia Coastal Plain incorporates updated information on groundwater quality in the area. Local-scale groundwater-quality information is provided by a comprehensive dataset compiled from multiple Federal and State agency databases. Groundwater-sample chemical-constituent values and related data are presented in tables, summaries, location maps, and discussions of data quality and limitations.

Spatial trends in groundwater quality and related processes at the regional scale are determined from interpretive analyses of the sample data. Major ions that dominate the chemical composition of groundwater in the deep Piney Point, Aquia, and Potomac aquifers evolve eastward and with depth from (1) "hard" water, dominated by calcium and magnesium cations and bicarbonate and carbonate anions, to (2) "soft" water, dominated by sodium and potassium cations and bicarbonate and carbonate anions, and lastly to (3) "salty" water, dominated by sodium and potassium cations and chloride anions. Chemical weathering of subsurface sediments is followed by ion exchange by clay and glauconite, and subsequently by mixing with seawater along the saltwatertransition zone. The chemical composition of groundwater in the shallower surficial and Yorktown-Eastover aquifers, and in basement bedrock along the Fall Zone, is more variable as a result of short flow paths between closely located recharge and discharge areas and possibly some solutes originating from human sources.

The saltwater-transition zone is generally broad and landward-dipping, based on groundwater chloride concentrations that increase eastward and with depth. The configuration is convoluted across the Chesapeake Bay impact crater, however, where it is warped and mounded along zones having vertically inverted chloride concentrations that decrease with depth. Fresh groundwater has flushed seawater from subsurface sediments preferentially around the impact crater as a result of broad contrasts between sediment permeabilities. Paths of differential flushing are also focused along the inverted zones, which follow stratigraphic and structural trends southeastward into North Carolina and northeastward beneath the chloride mound across the outer impact crater.
Brine within the inner impact crater has probably remained unflushed. Regional movement of the saltwater-transition zone takes place over geologic time scales. Localized movement has been induced by groundwater withdrawal, mostly along shallow parts of the saltwater-transition zone. Short-term episodic withdrawals result in repeated cycles of upconing and downconing of saltwater, which are superimposed on longerterm lateral saltwater intrusion. Effective monitoring for saltwater intrusion needs to address multiple and complexly distributed areas of potential intrusion that vary over time.

A broad belt of large groundwater fluoride concentrations underlies the city of Suffolk, and thins and tapers northward. Fluoride in groundwater probably originates by desorbtion from phosphatic sedimentary material. The high fluoride belt possibly was formed by initial adsorbtion of fluoride onto sediment oxyhydroxides, followed by desorbtion along the leading edge of the advancing saltwater-transition zone.

Large groundwater iron and manganese concentrations are most common to the west along the Fall Zone, across part of the saltwater-transition zone and eastward, and within shallow groundwater far to the east. Iron and manganese initially produced by mineral dissolution along the Fall Zone are adsorbed eastward and with depth by clay and glauconite, and subsequently desorbed along the leading edge of the advancing saltwater-transition zone. Iron and manganese in shallow groundwater far to the east are produced by reaction of sediment organic matter with oxyhydroxides.

Large groundwater nitrate and ammonium concentrations are mostly limited to shallow depths. Most nitrate and ammonium is recycled near the land surface, but some can also be produced by decomposition of sediment organic matter, by ion exchange along the leading edge of the advancing saltwatertransition zone, and possibly from site-specific human sources.

Groundwater is a heavily used water-supply resource throughout the study area, and its suitability for various uses is largely determined by its chemical quality. Whereas soft water in deep aquifers generally is suitable for a wide variety of uses, hard water can require ion-exchange treatment. Salty water in deep aquifers in the eastern part of the study area is undergoing increasingly widespread production for drinkingwater supplies. Treatment operations use desalination and blending. Saltwater intrusion can potentially be mitigated by 
redirecting locations and operation of wells producing shallow freshwater and by conjunctive freshwater/saltwater groundwater development close to and within the saltwater-transition zone. Groundwater with large fluoride concentrations is blended with water from different sources in the city of Suffolk. An array of methods can treat large groundwater iron and manganese concentrations, and associated hydrogen sulfide concentrations, depending on the level of treatment needed. Large groundwater nitrate concentrations can potentially be mitigated by various treatment methods or management of groundwater withdrawals.

\section{Introduction}

Groundwater in the Atlantic Coastal Plain Physiographic Province in eastern Virginia (fig. 1) is a heavily used resource. During the late 1800 s, the rate of groundwater withdrawal is estimated to have been close to zero, but the withdrawal rate has increased continuously during the $20^{\text {th }}$ century (Harsh and Laczniak, 1990). During 1992, major groundwater users regulated by the Virginia Department of Environmental Quality (DEQ) reported withdrawal rates totaling approximately 94 million gallons per day (Mgal/d) from Coastal Plain aquifers (Hammond and Focazio, 1995); additional unregulated withdrawals at that time were unknown. By 2000, the combined regulated and estimated unregulated withdrawals totaled 137.4 Mgal/d (Pope and others, 2008).

As a result of long-term withdrawals, groundwater levels in the Coastal Plain aquifers have declined by as much as 200 feet (ft) near large withdrawal centers, and flow gradients have been reversed from a previously seaward direction to a landward direction (Harsh and Laczniak, 1990), creating the potential for saltwater intrusion. Increasing withdrawals are projected, which could result in further water-level declines and intrusion potential, thereby limiting continued use of the groundwater resource.

To manage the groundwater resource, the DEQ regulates groundwater withdrawals in the most heavily used parts of the Virginia Coastal Plain, designated as Groundwater Management Areas, which include areas south of the York and Mattaponi Rivers, and the Virginia Eastern Shore. Withdrawals greater than 300,000 gallons per month in these areas must be approved under the DEQ Groundwater Withdrawal Permit Program, which requires groundwater users to submit withdrawal-related information that is needed to evaluate the potential effects of the withdrawals on the groundwater system.

The DEQ relies on a sound scientific understanding of Virginia Coastal Plain geology and hydrology to provide a valid context within which to make groundwater-management decisions. The U.S. Geological Survey (USGS) has been advancing knowledge of the geology and hydrology of the Virginia Coastal Plain since the beginning of the $20^{\text {th }}$ century. A widely recognized description of the hydrogeology of the
Virginia Coastal Plain resulted from the USGS Regional Aquifer-System Analysis (RASA) and related investigations completed during the 1980s. A hydrogeologic framework was developed by Meng and Harsh (1988) to provide a basis for construction of a digital computer model of groundwater flow (Harsh and Laczniak, 1990). The RASA framework and model were updated and adopted by the DEQ as an aid in managing the groundwater resource, by evaluating the potential effects of existing and proposed withdrawals (McFarland, 1998). Among subsequent followup investigations, the chemical quality of groundwater was summarized based on the RASA framework (Focazio and others, 1993).

Following the RASA investigation and related efforts, additional findings provided a basis for major changes in the definition of hydrogeologic conditions, with the most significant being discovery of the world's sixth largest meteorimpact crater beneath the lower Chesapeake Bay (Powars and Bruce, 1999; Powars, 2000). Knowledge of the impact crater and other recently recognized geologic features resulted in the need for a complete redefinition of the groundwater system. Additionally, locations and rates of groundwater withdrawals increased following the RASA investigation and related efforts, which further complicated understanding of the flow system.

In order for resource-management efforts to adequately address these developments, a comprehensive effort was begun in 2000 by the USGS, in cooperation with the DEQ and the Hampton Roads Planning District Commission (HRPDC), to develop a new, regional perspective of the hydrogeology of the Virginia Coastal Plain that reflects current groundwater conditions and incorporates updated knowledge of the geology and hydrology of the area. During 2000-2004, a refined hydrogeologic framework was formulated that provides an enhanced level of detail on the geologic relations, configuration, composition, and hydrologic aspects of a stratified series of 19 aquifers, confining units, and confining zones (collectively termed hydrogeologic units) (McFarland and Bruce, 2006). In turn, these findings were applied to development of a revised digital computer model of the groundwater-flow system that is consistent with present-day (2008) hydrologic conditions and can be used to project future conditions (Heywood and Pope, 2009).

The newly revised framework and model address many aspects of the presence and movement of groundwater in the Virginia Coastal Plain. Knowledge of the chemical quality of groundwater is equally critical to sound management of the resource, but was not incorporated into the framework and model. Concentrations of various chemical constituents should be known in order to effectively plan for possible limitations and treatment requirements for groundwater use. Groundwater quality in the Virginia Coastal Plain, however, is more variable than in any other part of the State (Heller, 2008). Moreover, groundwater chemical-constituent data are most useful when individual sample values are accurately associated with the hydrogeologic unit from which each sample was collected. The most recent detailed characterization of groundwater 


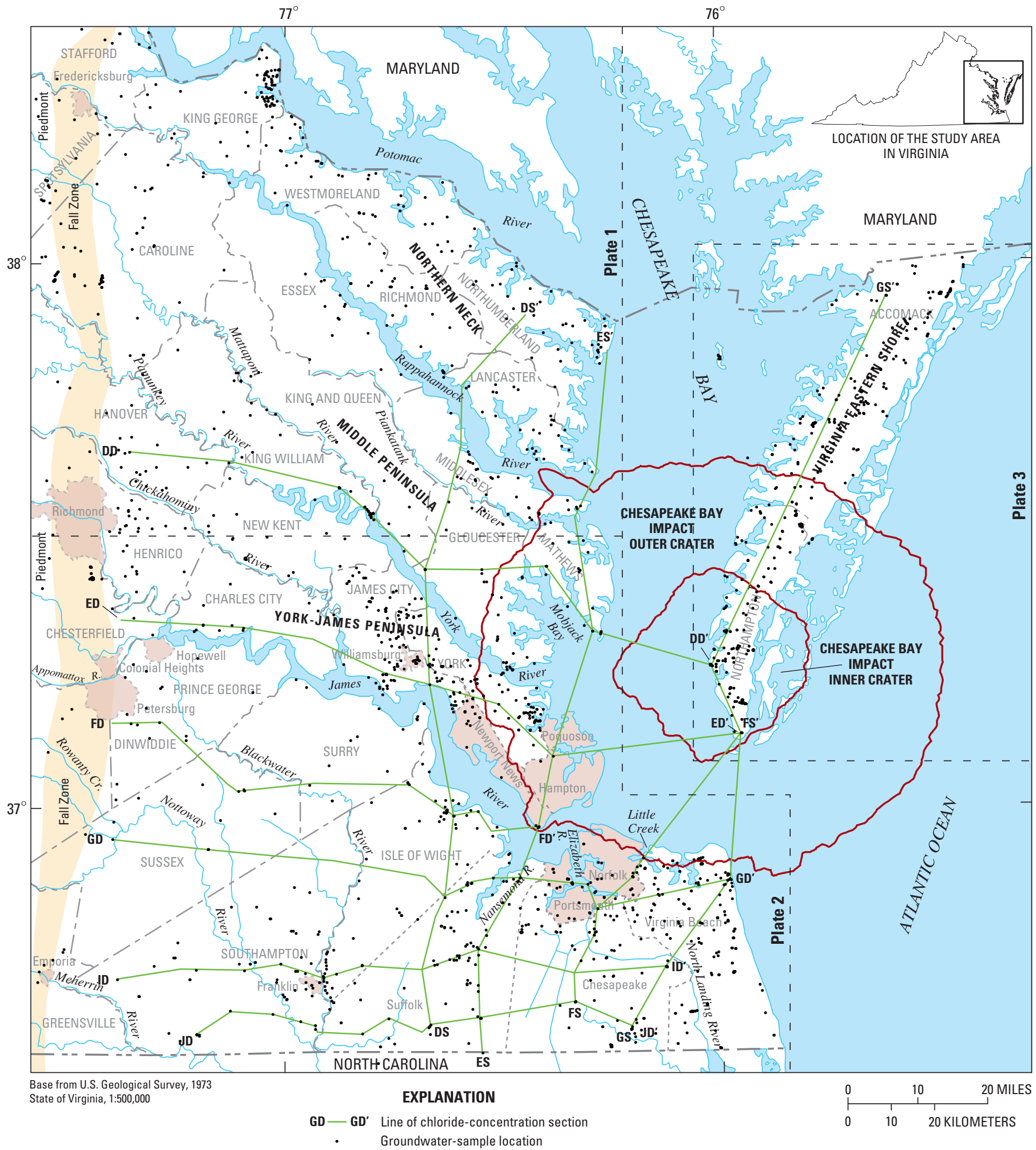

Figure 1. Groundwater-sample locations and chloride-concentration sections in the Virginia Coastal Plain. Location of Chesapeake Bay impact crater from Powars and Bruce (1999). Further detail shown on plates 1-3. 
Groundwater-Quality Data and Regional Trends in the Virginia Coastal Plain, 1906-2007

quality in the Virginia Coastal Plain was based on the RASA framework (Focazio and others, 1993), which has since been substantively revised to incorporate the impact crater and other geologic features. Hence, application of the newly revised hydrogeologic framework is required to understand the groundwater quality of the Virginia Coastal Plain in the context of current knowledge of the aquifer system.

Knowledge of the chemical quality of groundwater supports resource-management efforts at two distinct levels. First, well drillers and owners, environmental consultants, and water-resource managers have short-term, practical needs for local-scale information on groundwater quality in making case-by-case estimates of constituent concentrations for the development and operation of water-supply wells, waste-management facilities, and other groundwater related activities. Second, informed long-term decisions by planners and policy makers are contingent upon a regional understanding of groundwater-quality trends and related processes.

Toward this end, a perspective that encompasses the entire Virginia Coastal Plain as an integrated hydrochemical system can be provided by a synthesis of groundwater constituent concentrations and related data. Certain constituents represent resource-management issues of particular interest and thereby warrant in-depth interpretive analysis, such as concentrations of chloride associated with areas of brackish groundwater along the saltwater-transition zone.

To address these needs, an investigation was undertaken during 2006-08 by the USGS, in cooperation with the DEQ and the HRPDC, which incorporates updated knowledge of groundwater quality into the newly developed regional perspective of the hydrogeology of the Virginia Coastal Plain. An expanded and comprehensive set of groundwater constituent values and related data was compiled from multiple Federal and State agency databases. Associations of samples with hydrogeologic units were determined based on the revised hydrogeologic framework. Chemical-constituent values and related data were summarized and interpreted to serve both local and regional scale resource-management needs.

\section{Purpose and Scope}

The chemical quality of groundwater in the Virginia Coastal Plain is documented herein. Data retrieved from multiple Federal and State agency databases represent 10,165 groundwater samples collected from 1,991 wells and boreholes during 1906 to 2007. Analytical results are presented for 37 chemical constituents, for which 73,610 individual sample constituent values are reported. Constituent values are electronically tabulated, along with corresponding well and borehole identification and location information, collection date and time, collection-interval altitude, and associations among hydrogeologic units. Sample locations and hydrogeologic unit associations are also presented on maps.

This report serves as a companion document to a newly revised hydrogeologic framework of the Virginia Coastal Plain
(McFarland and Bruce, 2006; available at http://pubs.usgs. gov/pp/2006/1731/). The hydrogeologic framework provides the basis for hydrogeologic associations among the groundwater samples. Moreover, the two reports are designed to be used together, such that groundwater quality can be directly integrated with other hydrologic and geologic information needed for sound management of the resource.

This report is organized to convey two distinct levels of information. The first part of the report provides groundwatersample data to aid in estimating groundwater quality at the local scale. Tabulated chemical-constituent values and related data, and mapped sample locations and hydrogeologic unit associations are presented. The number of wells and boreholes, samples, and chemical-constituent analyses among hydrogeologic units and descriptive statistics of constituent values are summarized. Estimation of local-scale groundwater quality is enabled by cross-referencing mapped sample locations with tabulated data. Use of the groundwater-sample data is supported by discussions of data quality and limitations.

The second part of the report presents a conceptual understanding of spatial trends in groundwater quality and related processes at the regional scale. Variations in the concentrations of major ions that dominate the chemical composition of groundwater are summarized by maps of major water-supply aquifers. Hydrochemical processes that control groundwater composition are described. In addition, chemical constituents of particular resource-management interest are individually addressed. Based on spatial variations in chloride concentration, the saltwater-transition zone is portrayed three-dimensionally using maps and sections. Relations of the configuration of the saltwater-transition zone to groundwater flow are discussed. A summary of wells that exhibit changes in chloride concentration over time also is tabulated, and selected examples of chloride-concentration changes that result from different groundwater conditions are illustrated. In addition to chloride, regional trends for other selected constituents are summarized by maps and sections of concentrations of fluoride, iron and manganese, and nitrate and ammonium. Lastly, considerations for the use of groundwater related to various chemical constituents are discussed.

\section{Description of the Study Area}

The Virginia Coastal Plain occupies an area of approximately 13,000 square miles $\left(\mathrm{mi}^{2}\right)$ between approximately latitude $36^{\circ} 30^{\prime}$ and $38^{\circ} 30^{\prime} \mathrm{N}$. and longitude $75^{\circ} 30^{\prime}$ and $77^{\circ} 30^{\prime} \mathrm{W}$. (fig. 1). The climate is temperate and humid, with annual precipitation of more than 40 inches (in.; National Weather Service, 1996), and the region is generally heavily vegetated. Major urban centers along the western margin of the area include Fredericksburg and Richmond. A large metropolitan area, collectively referred to as Hampton Roads, occupies the southeast and consists of 16 localities, including the counties of Gloucester, Isle of Wight, James City, Southampton, Surry, and York, and the cities of Franklin, 
Hampton, Newport News, Norfolk, Poquoson, Portsmouth, Williamsburg, Chesapeake, Suffolk, and Virginia Beach. The latter three cities are large and comparable to the counties in land area, and these cities encompass rural as well as urban land uses. The rest of the Virginia Coastal Plain is mostly rural and fairly evenly divided between cropland and forest. Small towns are widely scattered, many of which serve as county seats. Residential development is increasing by conversion of farmland in proximity to urban centers and along waterfronts.

The Virginia Coastal Plain is characterized by rolling terrain and deeply incised stream valleys in the northwestern part, and gently rolling-to-level terrain, broad stream valleys, and extensive wetlands in the eastern and southern parts. Topography is dominated by valleys of the major rivers, including the Potomac, Rappahannock, Piankatank, Mattaponi, Pamunkey, York, Chickahominy, James, Appomattox, Blackwater, Nottoway, Meherrin, Nansemond, Elizabeth, and North Landing (fig. 1). Lowlands consisting of terraces, flood plains, and wetlands occupy valley floors and are flanked by broad uplands along basin boundaries. The uplands and lowlands are bounded by relict erosional scarps associated with the rivers (Johnson and Ramsey, 1987); these scarps are obscured in places by the present-day tributary drainage pattern. Land-surface altitude ranges from over $300 \mathrm{ft}$ across some western uplands to $0 \mathrm{ft}$ along the Atlantic coast.

The major rivers receive flow from dense and extensive networks of tributaries that extend across their entire drainage basins. These rivers collectively drain to the east and southeast into Chesapeake Bay, a large estuary formed by submersion of the Susquehanna River Valley as a result of rising sea level. Major rivers draining from the west also become estuarine upon entering the Coastal Plain. Chesapeake Bay separates most of the Virginia Coastal Plain to the west from the Virginia Eastern Shore to the east, which makes up the southernmost part of the Delmarva Peninsula. The northernmost part of the Virginia Coastal Plain is hydraulically isolated by the Potomac River north of Fredericksburg and is excluded from this investigation.

\section{Geologic Setting}

The Coastal Plain is underlain by a seaward-thickening wedge of regionally extensive, generally eastward-dipping strata of unconsolidated to partly consolidated sediments of Cretaceous, Tertiary, and Quaternary age that unconformably overlie a basement of consolidated bedrock (fig. 2). The sediment wedge extends from Cape Cod, Massachusetts, southward to the Gulf of Mexico and offshore to the Continental Shelf. Sediment thickness in Virginia ranges from $0 \mathrm{ft}$ at its western margin to more than $6,000 \mathrm{ft}$ along the Atlantic coast (Onuschak, 1972). The sediments were deposited by seaward progradation of fluvial plains and deltas along the North American continental margin, followed by a series of transgressions and regressions by the Atlantic Ocean in response to changes in sea level. A thick sequence of nonmarine strata primarily of Cretaceous age is overlain by a much thinner sequence of marine strata of Tertiary age, which is in turn overlain by a veneer of nearly flat-lying terrace and flood-plain deposits primarily of Quaternary age (Meng and Harsh, 1988).

Coastal Plain sediments in Virginia were further affected during the Tertiary period by the impact of an asteroid or comet near the mouth of the present-day Chesapeake Bay (Powars and Bruce, 1999). The buried Chesapeake Bay impact crater is greater than 50 miles (mi) in diameter and extends across a large part of the southeastern Virginia Coastal Plain (fig. 1). The crater was formed within the preexisting sediments and contains a unique assemblage of impact-related material. Subsequent sediment deposition has buried the crater approximately $1,000 \mathrm{ft}$ below the present-day land surface.

The area to the west of the Coastal Plain is the Piedmont Physiographic Province (Piedmont) (figs. 1, 2), which is characterized by rolling terrain. Residual soils range from nearly 0 to $100 \mathrm{ft}$ thick and are underlain by igneous and metamorphic bedrock of late Proterozoic and early Paleozoic age, along with fault-bounded structural basins containing sedimentary and igneous bedrock of Triassic and Jurassic age. Shallow alluvial deposits of Quaternary age are localized in stream valleys. The transitional part of the Coastal Plain toward the Piedmont is designated as the Fall Zone. Numerous falls and rapids are present along streams across the Fall Zone, because gradients increase as the streams flow generally eastward from resistant bedrock onto more easily eroded sediments. From the Fall Zone, the Piedmont bedrock dips eastward beneath the sediment wedge to constitute the basement that underlies the Coastal Plain. The Fall Zone encompasses a belt several miles wide, along which the configuration of surface exposures of sediment and bedrock is intricate. Streams have eroded through Coastal Plain sediments to expose Piedmont bedrock in their valley floors, whereas interstream divides are capped by uneroded sediments overlying the bedrock (Mixon and others, 1989).

\section{Groundwater Conditions}

Sediments of the Virginia Coastal Plain are represented by a hydrogeologic framework of aquifers, confining units, and confining zones, collectively termed hydrogeologic units (fig. 3) (McFarland and Bruce, 2006). Permeable sediments that act as regionally extensive conduits for groundwater flow are designated as aquifers, and less permeable sediments that partly restrict flow are designated as confining units. Less distinct transitional intervals between aquifers and confining units are considered confining zones. Parts of some aquifers provide a widely used supply of water in Virginia.

A complex history of sediment deposition has produced numerous lateral variations in lithology. Consequently, the positions of unit margins are divergent, and their areal distribution has a complex, overlapping "patchwork" configuration. In particular, some units pinch out westward toward the Fall Zone, where the vertical sequence of sediments varies widely compared to other parts of the Coastal Plain. In addition, major discontinuities among units are present along 


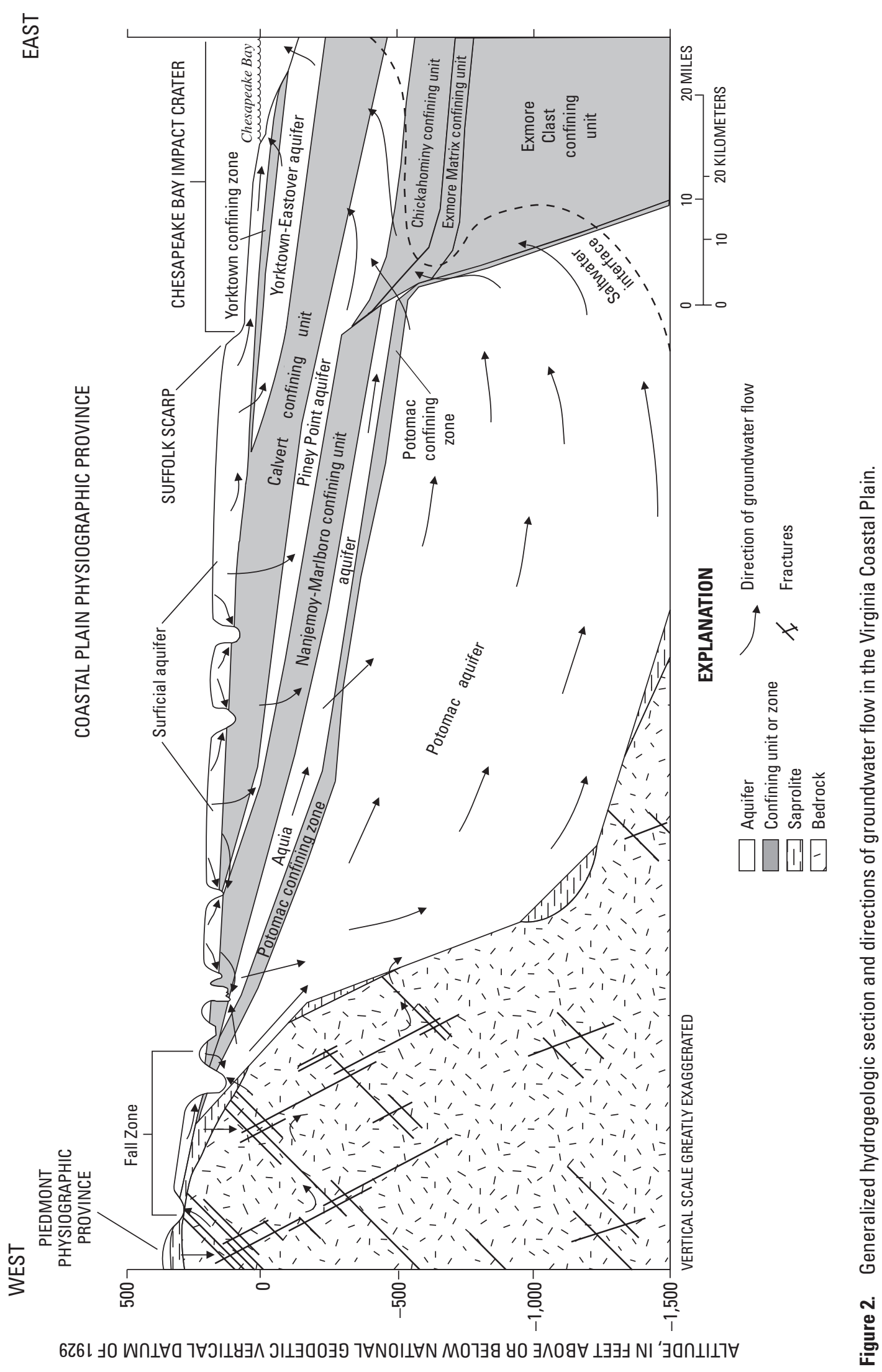




\begin{tabular}{|c|}
\hline surficial aquifer \\
\hline Yorktown confining zone \\
\hline Yorktown-Eastover aquifer \\
\hline Saint Marys confining unit \\
\hline Saint Marys aquifer \\
\hline Calvert confining unit \\
\hline Piney Point aquifer \\
\hline Chickahominy confining unit \\
\hline Exmore Matrix confining unit \\
\hline Exmore Clast confining unit \\
\hline Nanjemoy-Marlboro confining unit \\
\hline Aquia aquifer \\
\hline Peedee confining zone \\
\hline Peedee aquifer \\
\hline Virginia Beach confining zone \\
\hline Virginia Beach aquifer \\
\hline Upper Cenomanian confining unit \\
\hline Potomac confining zone \\
\hline Potomac aquifer \\
\hline Basement bedrock \\
\hline
\end{tabular}

Figure 3. Simplified composite stratigraphic relations among hydrogeologic units of the Virginia Coastal Plain (adapted from McFarland and Bruce, 2006). Not all hydrogeologic units are present at every location. Associations among some hydrogeologic units that cross stratigraphic boundaries also are not shown.

the margin of the Chesapeake Bay impact crater (fig. 2). None of the hydrogeologic units extends across the entire Virginia Coastal Plain.

Hydrogeologic conditions in the Coastal Plain are distinct from the Piedmont. In the Coastal Plain, groundwater is largely present in pores between the sediment grains. By contrast, groundwater in the Piedmont is present mostly in fractures in the bedrock and in pores in weathered residuum overlying the bedrock.

Groundwater in the Coastal Plain is recharged principally by precipitation that infiltrates the land surface and percolates to the water table. Most of the unconfined groundwater flows relatively short distances and discharges to nearby streams, but a small amount flows downward to recharge the deeper confined aquifers (fig. 2), primarily along the Fall Zone and beneath surface-drainage divides between major river valleys
(Harsh and Laczniak, 1990). Because aquifers in the Fall Zone are shallow and subcrop along major rivers, flow interactions with the rivers result from direct hydraulic connections to the land surface (McFarland, 1999). The basement bedrock imposes a relatively impermeable underlying boundary. Localized flow interaction is theorized to occur between bedrock fractures and the overlying sediments, but the extent and magnitude of such interaction are not well known.

Because of stratification of the Coastal Plain sediments, horizontal hydraulic conductivity generally is greater than vertical hydraulic conductivity. Hence, flow through the confined aquifers primarily is lateral in the down-dip direction to the east (fig. 2) and toward large withdrawal centers and major discharge areas along large rivers and the Atlantic coast. Contrasting density between freshwater and saltwater to the east causes the confined groundwater to discharge by upward flow across intervening confining units. In addition, hydraulic boundaries along the Chesapeake Bay impact crater have been theorized to cause a lateral divergence of flow to either side of the impact crater (McFarland and Bruce, 2005).

\section{Methods of Investigation}

The investigation presented herein was undertaken during 2006-08. A newly expanded and comprehensive set of groundwater quality and related data was compiled from multiple Federal and State agency databases. Chemicalconstituent values and corresponding well and borehole identification, location, sample-collection date and time, and collection-interval altitude information were retrieved during 2006 from the Quality of Water Data Base (QWDATA) and Groundwater Site Inventory (GWSI) database maintained by the USGS. These data were augmented during 2007 primarily with data retrieved from the Storage and Retrieval (STORET) database maintained by the U.S. Environmental Protection Agency (USEPA). Smaller amounts of data were also provided by the DEQ, the Virginia Department of Health (VDH), and the USGS National Research Program (NRP).

The dataset represents groundwater-quality samples collected from wells and boreholes located in the Virginia Coastal Plain and a few miles to the west, along the easternmost part of the Piedmont (fig. 1; pls. 1-3). Individual sample values were included only for chemical constituents that are present naturally and generally represent ambient groundwater composition (although some of these constituents can be artificially increased above natural concentrations). Concentration values for artificial chemicals that are not present naturally and originate solely from human contamination (for example, synthetic organic compounds) were excluded. Likewise, any samples known to represent treated water were not included. Samples also were excluded for which collection-interval altitudes could not be determined, primarily those from wells having inadequate construction information.

For consistency of the dataset, all groundwater samples are identified using the well and borehole 
identification-numbering system used at the USGS Virginia Water Science Center, which is based on the USGS 7.5-minute topographic quadrangle maps on which the wells and boreholes are located. Different well and borehole identificationnumbering systems, however, are used among the non-USGS data sources. Moreover, some wells and boreholes have been sampled multiple times. Because the different samples from an individual well or borehole can originate from different data sources, they can be associated with different well or borehole identification numbers. Accordingly, a combination of automated data-relational operations and manual screening was used to distinguish multiple samples collected from a single well or borehole. For wells and boreholes already represented in the USGS databases, the existing USGS identification number was assigned to any samples originating from non-USGS data sources. Conversely, samples determined to have been collected from wells and boreholes that were not represented in USGS databases were assigned new USGS identification numbers.

Groundwater-quality data are most useful when chemical-constituent values are accurately associated with the hydrogeologic unit from which each sample was collected. Accordingly, the newly revised hydrogeologic framework of the Virginia Coastal Plain (McFarland and Bruce, 2006) was applied so that the groundwater-quality dataset would reflect current knowledge of the aquifer system. Each groundwater sample was associated with one of the 19 aquifers, confining units, or confining zones delineated by the framework.

A geographic information system (GIS), developed as part of the hydrogeologic framework investigation, was used to locate each sample three-dimensionally among the hydrogeologic units. Approximate configurations of the top surfaces of all hydrogeologic units are represented in the GIS by raster datasets. Groundwater-quality sample locations and related data were added to the GIS as georeferenced points. GIS operations were then performed to identify the regionally estimated altitudes of hydrogeologic unit top surfaces at each sample location. Subsequently, a series of data-relational operations was performed to determine from which hydrogeologic unit each sample was collected, based on the collection-interval altitude. Resulting sample hydrogeologic unit associations were incorporated with the compiled chemical-constituent values and related data.

\section{Previous Investigations}

Evolving knowledge of groundwater in the Virginia Coastal Plain is documented by a large and diverse body of literature. Some of the most important historical contributions to the geologic and hydrologic aspects are summarized by McFarland and Bruce (2006).

The chemical quality of groundwater in the Virginia Coastal Plain has also been addressed by many published investigations. Most of these studies were of limited geographic extent, and relatively few encompass the entire
Virginia Coastal Plain. In the past, groundwater quality typically was treated as a subtopic among other geologic and hydrologic aspects of a particular study. Other publications are limited to a specific issue related to groundwater quality, most widely chloride and other aspects of groundwater salinity.

Individual works are cited throughout this report to reference information supporting particular discussions. Continued development of groundwater resources has entailed many additional investigations of a site-specific nature for individual water-supply systems, which are not widely published or referenced herein. The following review is not intended to be wholly inclusive, but to highlight some of the efforts that have had regional significance. They are organized here chronologically and by broadness of scope.

Pioneering work on groundwater quality in the Virginia Coastal Plain was achieved during the early and middle parts of the $20^{\text {th }}$ century. Sanford (1913) made probably the earliest description of groundwater quality, which was treated as a subtopic on groundwater in the entire Virginia Coastal Plain and also in individual counties, described by separate chapters. A series of publications by Cederstrom followed, again treating groundwater quality as a subtopic in reports on groundwater in southeastern Virginia $(1939,1945)$, the YorkJames Peninsula (1957), and the Middle Peninsula (1968), and also including separate chapters on individual counties. More indepth assessments of the entire Virginia Coastal Plain, however, were also made of chloride concentrations in relation to groundwater salinity (Cederstrom, 1943) and of hydrochemical processes that control groundwater composition (Cederstrom, 1946a, b).

Some major advances in understanding groundwater quality in the Virginia Coastal Plain were made during the middle and later parts of the $20^{\text {th }}$ century. A scientific milestone was established by Back (1966), who developed the concept of hydrochemical facies to describe the sequence by which groundwater composition evolves along regional flow paths across the entire Northern Atlantic Coastal Plain (Virginia northward through New Jersey). Further understanding was gained of groundwater salinity within the Virginia Coastal Plain by Larson (1982) and across the entire Northern Atlantic Coastal Plain by Meisler (1989). Both of these works present spatial distributions of groundwater chloride concentrations to depict the configuration of the saltwater-transition zone and to theorize processes related to emplacement of saltwater within the aquifer system.

A detailed systematic compilation of groundwater-quality information from throughout the Virginia Coastal Plain was presented by Focazio and others (1993). Descriptions are given of selected individual chemical constituents and of variations in overall groundwater composition. Summary statistics are tabulated for groundwater-sample data from five major water-supply aquifers for 16 chemical constituents. A series of maps also presents areal concentration distributions for nine constituents in each of the aquifers.

Statewide studies that incorporate the Virginia Coastal Plain include Powell and Hamilton (1988), who described 
Virginia as part of a nationwide summary of groundwater quality. Nelms and others (2003) used trace-level hydrochemical tracers to estimate apparent groundwater ages throughout Virginia. Heller (2008) related groundwater quality to characteristics of wells located across Virginia.

Several additional groundwater investigations took place during the later part of the $20^{\text {th }}$ century that, as in earlier efforts, generally treat groundwater quality as a subtopic among other geologic and hydrogeologic aspects of particular subregional areas, including

- the Northern Neck-Sinnott, 1969; Newton and Siudyla, 1979

- the Middle Peninsula—Siudyla and others, 1977

- the York-James Peninsula-Commonwealth of Virginia, 1973; Laczniak and Meng, 1988

- southeastern Virginia - Commonwealth of Virginia, 1974; Siudyla and others, 1981

- the Eastern Shore-Commonwealth of Virginia, 1975; Fenema and Newton, 1982; Richardson, 1994; Speiran, 1996; Sanford and others, 2009a, b

- the James River Basin—Lichtler and Wait, 1974

- Hanover County_Ellison and Masiello, 1979

- Henrico County-Wigglesworth and others, 1984

- James City County-Harsh, 1980

- York County-Richardson and Brockman, 1992

- Dahlgren (King George County) - Harlow and Bell, 1996; Bell, 1996

- city of Virginia Beach—Smith, 2003

Some of these reports include details of chloride in groundwater and(or) other aspects of groundwater salinity. Other investigations focused specifically on groundwater salinity. Brown and Silvey (1977) evaluated the feasibility of underground injection as a means of freshwater storage in the brackish part of the aquifer system at Norfolk, Virginia. Smith used numerical simulation to estimate the potential for saltwater intrusion on the York-James Peninsula (1999) and in Virginia Beach (2003).

The most recent efforts to characterize groundwater salinity were undertaken as part of a larger investigation of the Chesapeake Bay impact crater. McFarland and Bruce (2005) analyzed chemical tracers and other constituents in samples of pore water extracted from cores of crater-fill and overlying sediments drilled at three locations along the landward margin of the outer crater. Based on these data, along with existing groundwater-sample data from several nearby wells, the configuration of the saltwater-transition zone was described, and its relations to the impact event, groundwater flow, sea-level fluctuation, and groundwater withdrawal were theorized. Subsequently, Sanford and others (2009b) extracted and analyzed additional sediment pore-water samples from two coreholes drilled within the inner crater. A large sediment thickness was found to contain brine having salinity levels greatly exceeding that of seawater, as well as those of groundwater along the outer crater margin and beyond. The earlier interpretations of McFarland and Bruce (2005) were expanded by Sanford and others (2009b) to include possible origins of the brine, water/mineral chemical reactions, and alternative relations to groundwater flow.

\section{Groundwater-Quality Data}

In order to aid in estimating groundwater quality at the local scale, a newly expanded and comprehensive set of groundwater quality and related data was compiled from multiple Federal and State agency databases. Associations of groundwater samples among 19 hydrogeologic units and basement bedrock were determined based on a newly revised hydrogeologic framework (McFarland and Bruce, 2006).

\section{Data Quality}

A dataset is electronically tabulated (Attachment 1), consisting of individual groundwater-sample chemicalconstituent values along with corresponding well and borehole identification and location information, collection date and time, collection-interval altitudes, and associations among hydrogeologic units. Sample locations and hydrogeologic unit associations are also presented with detailed base-map information (pls. 1-3). Sample-collection dates range from 1906 to 2007. Additional aspects of the sample data are described below, generally in the order tabulated (Attachment 1).

The well or borehole from which each groundwater sample was collected is identified by a USGS identification number. Multiple samples collected from a single well or borehole are identified by different collection dates and(or) times. Multiple samples collected from a finished well typically exhibit identical or similar collection-interval altitudes, as well as the same hydrogeologic unit association. By contrast, multiple samples have sometimes been collected at varying depths in a borehole, generally by zone testing of a borehole, or by pore-water extraction from a sediment core. Such samples represent widely varying collection-interval altitudes and different hydrogeologic units (see "Data Distribution").

Well and borehole locations are presented as latitude and longitude coordinates, referenced to the North American Datum of 1927 (NAD 27), which currently (2009) is the datum used on all published USGS 7.5-minute topographic quadrangle maps within the Virginia Coastal Plain. Coordinates of a minority of locations have been determined independently (not part of this study) using satellite-based global positioning systems (GPS) to within fractions of a second. Most locations, 
however, were likely estimated from topographic maps and should generally be regarded as accurate to no more than plus or minus (+/-) 5 seconds. Likewise, only the locations of those wells sampled by the USGS are known to have been verified in the field.

Collection-interval altitudes are referenced to the National Geodetic Vertical Datum of 1929 (NGVD 29), as calculated from reported interval top and bottom depths below the altitudes of land surface at the well and borehole locations. Collection intervals of finished wells having multiple screened intervals were designated using the top of the uppermost screen and the bottom of the lowermost screen. Although a minority of location land-surface altitudes have been leveled independently to within a hundredth of a foot, most altitudes were likely estimated from topographic maps accurate to $+/-5 \mathrm{ft}$. In addition, measured collection-interval depths commonly can vary by several feet, depending on whether the measurement was taken from true land surface, the top of surface casing, or some other datum usually not recorded. Hence, collection-interval altitudes generally should be regarded as accurate to no more than $+/-10 \mathrm{ft}$.

Associations of groundwater samples with hydrogeologic units are presented directly as they were determined by a GIS developed as part of a revised hydrogeologic framework investigation (see "Methods of Investigation"). The GIS provided an efficient means of associating the large number of samples with the hydrogeologic units. The associations are based on regionally estimated hydrogeologic unit altitudes, however, which can vary from actual altitudes at any specific location by several feet or more. Altitudes of hydrogeologic units were directly determined at 403 geophysically logged sites that serve as control points for structural contour maps developed for the framework (McFarland and Bruce, 2006). Based on stratigraphic correlation, altitudes were interpolated between logs at all other locations, including those of most sampled wells and boreholes. As a result, samples having collection intervals within a few feet of the actual top or bottom of a hydrogeologic unit can potentially be associated by the GIS with a nearby adjacent unit. Particularly, some samples associated with a confining unit or a confining zone may actually have been collected from an adjacent aquifer (see "Data Distribution").

Tabulated groundwater-sample data include values for 37 chemical constituents. Chemical-constituent values are presented essentially as they were reported and were retrieved directly from the original data sources. Because of the broad range of numerical values, dataset cells are formatted to four decimal places to preclude rounding or truncating of values. The constituent values represent the results of groundwatersample collection and analysis by numerous individuals and diverse organizations spanning a century-long period. Limits of analytical precision are not fully documented, but likely vary widely for each constituent, both among the different data sources and possibly over time. Hence, reported values should not be assumed to represent analytical precision limits or other measures of accuracy (see "Data Use and Limitations"). In addition, only a very few obvious errors among the chemicalconstituent values were corrected or deleted here (for example, dates set in the future). Based on visual examination and summary statistics of the compiled dataset, a small number of apparently erroneous values possibly remain (see "Data Use and Limitations"), but information is not adequate to evaluate them definitively for correction or deletion.

\section{Data Distribution}

No groundwater samples in the compiled dataset (Attachment 1) include values for every chemical constituent, and most samples have values for only a few constituents. Constituent values among individual hydrogeologic units also alternately exhibit spatial gaps, lateral and vertical variability at local scales, and(or) non-uniform areal trends at the regional scale. Likewise, constituent values are not representative of the entire regional extent of those hydrogeologic units from which samples were collected over a limited area, because the chemical composition of groundwater varies regionally.

Because of the large volume of the compiled groundwater-quality data, summaries are presented to describe their distribution. The data represent 1,991 wells and boreholes, from which 10,165 groundwater samples were collected (table 1). Results of sample analysis consist of 73,610 chemical-constituent values. The numbers of wells and boreholes, samples, and constituent values vary among the hydrogeologic units, primarily in relation to their importance to water-resource management. The largest numbers are exhibited by the Potomac aquifer, which provides approximately 75 percent of groundwater withdrawal in the Virginia Coastal Plain (McFarland and Bruce, 2006). Many water-quality sampling programs have focused on the Potomac aquifer for various evaluations of public drinking-water systems and heavy industry.

Large numbers of wells and boreholes, samples, and constituent values also represent the Yorktown-Eastover aquifer and the surficial aquifer (table 1). The YorktownEastover aquifer is the second most heavily used groundwater source in the Virginia Coastal Plain, providing 13 percent of the total withdrawal (McFarland and Bruce, 2006) and serving diverse small businesses and public drinking-water systems, rural domestic and agricultural uses, and low-density residential developments. The surficial aquifer provides only 4 to 5 percent of the total groundwater withdrawal, but is the principal source for many thousands of private domestic supply wells at widely dispersed rural locations. Additional wells in the surficial aquifer have been sampled as part of various investigations of near surface contamination.

Relatively few wells and boreholes, samples, and constituent values represent the Piney Point aquifer, Aquia aquifer, and basement bedrock (table 1), which are locally important groundwater supplies. The Piney Point and Aquia aquifers provide approximately 5 percent and 3 percent, respectively, of groundwater withdrawal in the Virginia 
Table 1. Numbers of sampled wells, water-quality samples, and chemical-constituent values among hydrogeologic units of the Virginia Coastal Plain.

\begin{tabular}{|c|c|c|c|}
\hline Hydrogeologic unit ${ }^{1}$ & $\begin{array}{l}\text { Sampled wells } \\
\text { and boreholes }\end{array}$ & $\begin{array}{l}\text { Water-quality } \\
\text { samples }\end{array}$ & $\begin{array}{c}\text { Chemical- } \\
\text { constituent } \\
\text { values }\end{array}$ \\
\hline Surficial aquifer & 469 & 2,231 & 13,054 \\
\hline Yorktown confining zone & 84 & 298 & 2,806 \\
\hline Yorktown-Eastover aquifer & 444 & 2,361 & 18,112 \\
\hline Saint Marys confining unit & 30 & 220 & 1,644 \\
\hline Saint Marys aquifer & 3 & 19 & 193 \\
\hline Calvert confining unit & 7 & 26 & 187 \\
\hline Piney Point aquifer & 94 & 417 & 2,519 \\
\hline Chickahominy confining unit & 7 & 26 & 200 \\
\hline Exmore matrix confining unit & 1 & 22 & 180 \\
\hline Exmore clast confining unit & 6 & 97 & 456 \\
\hline Nanjemoy-Marlboro confining unit & 43 & 183 & 1,217 \\
\hline Aquia aquifer & 28 & 62 & 736 \\
\hline Peedee confining zone & 1 & 7 & 87 \\
\hline Peedee aquifer & 3 & 13 & 173 \\
\hline Virginia Beach confining zone & 0 & 0 & 0 \\
\hline Virginia Beach aquifer & 5 & 13 & 153 \\
\hline Upper Cenomanian confining unit & 7 & 25 & 289 \\
\hline Potomac confining zone & 28 & 85 & 903 \\
\hline Potomac aquifer & 618 & 3,234 & 27,495 \\
\hline Basement bedrock & 105 & 826 & 3,206 \\
\hline Multiple hydrogeologic units ${ }^{2}$ & 8 & included above & included above \\
\hline Total & 1,991 & 10,165 & 73,610 \\
\hline
\end{tabular}

Coastal Plain (McFarland and Bruce, 2006), whereas use of the basement bedrock has not been quantified. Remaining aquifers include the Saint Marys, Peedee, and Virginia Beach, which are only minor groundwater supplies and exhibit among the smallest numbers of wells and boreholes, samples, and constituent values.

Samples from eight wells and boreholes were collected from multiple hydrogeologic units (table 1). The numbers of samples and chemical-constituent values are included among those separately listed for each hydrogeologic unit. At some of these locations, samples were collected from different aquifers during borehole zones tests conducted prior to completion of permanent wells. At other locations, samples were collected from different aquifers, as well as confining units and confining zones, as part of a larger study of the Chesapeake Bay impact crater in which pore water was extracted from cores of crater-fill and overlying sediments (McFarland and Bruce, 2005; Sanford and others, 2009b) (see "Previous Investigations").
Although the majority of groundwater samples are associated with aquifers, some samples are associated with a confining unit or a confining zone (table 1), for example sediment-core pore water collected within the Chesapeake Bay impact crater as described previously and primarily from the Saint Marys, Chickahominy, Exmore matrix, and Exmore clast confining units. Elsewhere, wells are rarely completed in a confining unit or confining zone. Hence, potentially many of the samples associated with a confining unit or confining zone were actually collected from an adjacent aquifer. Because of the limited accuracy of regionally estimated hydrogeologic unit altitudes, samples having collection intervals within a few feet of the top or bottom of an aquifer can potentially be associated with a nearby adjacent confining unit or a confining zone (see "Data Quality"). Most notably among these, many of the relatively large number of wells and boreholes, samples, and constituent values associated with the NanjemoyMarlboro confining unit are likely from the underlying Aquia aquifer. In many areas, only gradational differences in 
texture and lithologic composition distinguish the NanjemoyMarlboro confining unit from the Aquia aquifer, and both hydrogeologic units are relatively thin across much of their extents. Similar relations exist between the Calvert confining unit and underlying Piney Point aquifer, and between the Yorktown, Peedee, Virginia Beach, and Potomac confining zones and each of their respective underlying aquifers.

Locations of sampled wells and boreholes are not uniformly distributed (fig. 1; pls. 1-3). The largest concentration of wells and boreholes is on the York-James Peninsula, southeastern Virginia, and the Virginia Eastern Shore, corresponding to the greatest and most widespread use of groundwater. Localized concentrations of wells are also present at two large industrial withdrawal centers at Franklin and West Point. Smaller groupings are associated with various local-scale investigations of groundwater at locations along the Fall Zone and in the eastern parts of King George, Hanover, and Henrico Counties. The remaining wells and boreholes are generally located at widely dispersed rural locations.

Locations of groundwater samples among hydrogeologic units are also not uniformly distributed geographically (fig. 1; pls. 1-3). The most numerous and widespread samples are from the heavily used Potomac aquifer and span most of the Virginia Coastal Plain with varying density. Potomac aquifer samples are largely absent, however, in the far southeastern parts of the Middle and York-James Peninsulas, and most of the city of Virginia Beach and the Virginia Eastern Shore. Here, the Potomac aquifer is several hundred feet or more deep and is largely unused because of increased salinity. Correspondingly, most groundwater samples in these areas are from the surficial and Yorktown-Eastover aquifers, which are comparatively shallow, contain freshwater, and locally dominate the groundwater supply. Whereas samples from the Yorktown-Eastover aquifer are for the most part only in these areas, additional samples from the more widely used surficial aquifer span much of the rest of the Virginia Coastal Plain with varying density.

Most samples from the Piney Point and Aquia aquifers are clustered around the northwestern part of the York-James Peninsula centered in eastern New Kent County and western James City County, from which additional samples are scattered to the north and northeast across the Middle Peninsula and Northern Neck (pls. 1-3). Most samples from basement bedrock are along the Fall Zone and in the eastern Piedmont. Small numbers of samples from other hydrogeologic units are at widely dispersed locations.

Groundwater-sample chemical constituents are organized among six groups (Attachment 2), including general parameters, major cations, major anions, nutrients, secondary constituents, and radiochemical constituents. General parameters, major cations, and major anions are individually listed in commonly published order. Nutrients are listed in order of general interest to resource management. Secondary constituents are listed loosely on a combined basis of hydrochemical associations and general prevalence in groundwater. Radiochemical constituents are listed alphabetically. Summary statistics for all constituents are tabulated for samples collected from all hydrogeologic units collectively, as well as for samples collected from each hydrogeologic unit individually. Statistic values include the number of analyses for each constituent, followed by constituent value minima, maxima, means, and medians. Minima and maxima are cited directly from the compiled groundwater-sample dataset (Attachment 1) and are subject to the same qualifications (see "Data Quality"). Conversely, means and medians were calculated from the individual constituent values and are limited to no more than three significant figures.

For samples collected from all hydrogeologic units collectively and for samples collected from each hydrogeologic unit individually, the largest numbers of analyses are generally represented for the general parameters, major cations, and major anions (Attachment 2). The most widely analyzed general parameter is $\mathrm{pH}$. Whereas the numbers of analyses among the major cations are generally evenly divided, bicarbonate is more widely analyzed than the other major anions for samples from most hydrogeologic units. Generally fewer analyses are represented for nutrients and secondary constituents. Relatively very few analyses are represented for radiochemical constituents, which are wholly lacking from several hydrogeologic units. Radon 222, however, is more widely analyzed than the other radiochemical constituents, mostly from the surficial, Yorktown-Eastover, Piney Point, and Potomac aquifers. Among the radiochemical and other constituents represented by few analyses, more samples are known to have been collected and analyzed from some wells, but were excluded from the compiled groundwater-quality data because well-construction information was inadequate to determine sample collection-interval altitudes (see "Methods of Investigation").

Ranges and central tendencies among the chemicalconstituent values are partly dependent on the locations of sampled wells and boreholes, because the chemical composition of groundwater varies regionally, and sampled locations are not uniformly distributed across the entire extent of every hydrogeologic unit. Minimum values are at or close to zero for many constituents (Attachment 2). Analytical detection limits likely vary among the different data sources and over time (see "Data Quality"). Maxima represent extreme values for some constituents, which in some cases are potentially suspect of being erroneous (see "Data Use and Limitations"). Substantial differences are apparent between mean and median values for some constituents, which can result from a small number of extreme values. Median values are based on a ranking of the samples and, in such cases, are generally considered more representative of most of the samples than mean values. 


\section{Data Use and Limitations}

Local-scale knowledge of the chemical quality of groundwater is required by well drillers and owners, environmental consultants, and water-resource managers who have short-term, practical needs in making case-by-case estimates of chemical-constituent concentrations for diverse groundwater-related activities. Accordingly, the complete groundwater-sample dataset is presented here (Attachment 1). In order to access local-scale groundwater-quality information, mapped sample locations can be readily cross-referenced with tabulated groundwater-sample data to estimate specific chemical-constituent values.

Valid application of the compiled groundwater-sample data requires an understanding of the previously described data quality and associated limitations. The data originate from diverse sources having long and potentially complex but not fully documented histories. Potential data errors range from well construction and sample collection, preservation, and analysis, to typographic mistakes and other reporting problems. (Some samples of treated or otherwise chemically altered water possibly are also represented, although known cases were excluded during compilation.) Moreover, reported chemical-constituent values vary widely among the original sources, and do not necessarily reflect analytical precision limits. In practical terms, most values should be considered no more accurate than three significant figures. Some erroneous values also likely remain in the compiled dataset, for example, the overall maximum temperature and dissolved-oxygen values of 210 degrees Celsius $\left({ }^{\circ} \mathrm{C}\right)$ and 16.1 milligrams per liter ( $\mathrm{mg} / \mathrm{L})$, respectively (Attachment 2 ), which could actually represent more realistic measurements of $21.0^{\circ} \mathrm{C}$ and $1.61 \mathrm{mg} / \mathrm{L}$.

For interpretive analyses presented later in this report, the compiled groundwater-quality data were screened to exclude inappropriate values. Techniques used included calculations of major ion charge balance (see "Major Ions") and correlation between chloride-concentration and specific conductance values (see "Saltwater-Transition Zone"). The rationale that was applied is described in the relevant report sections.

Users of this report are advised to use judgment in their application of individual groundwater-sample data, based on the limitations described previously. Sampled well and borehole locations should be verified in the field whenever possible. Moreover, the likely representativeness of chemicalconstituent values at any given location should be evaluated, using sound hydrogeologic experience and common sense. Extreme data values are particularly considered as suspect. Lastly, sample hydrogeologic unit associations are to be viewed with due regard for limitations in the accuracy of the hydrogeologic framework GIS. Collection-interval altitudes should be examined to evaluate whether any particular samples have potentially been collected from a nearby part of an adjacent hydrogeologic unit.

\section{Regional Trends in Groundwater Quality}

Local-scale information on the chemical quality of groundwater in the Virginia Coastal Plain is provided in a previous section of this report (see "Groundwater-Quality Data"). Individual groundwater-sample data can be applied in making case-by-case estimates of chemical-constituent concentrations. A conceptual understanding of groundwaterquality trends and related processes at the regional scale, however, is also required by planners and policy makers in making informed long-term resource-management decisions. Accordingly, a synthesis of groundwater constituent concentrations is presented herein, to provide a perspective that encompasses the entire Virginia Coastal Plain as an integrated hydrochemical system.

Among the general parameters (Attachment 2), $\mathrm{pH}$ is the most widely analyzed property. Other than a small number of extremes, most $\mathrm{pH}$ values are relatively close to the mean and median, both slightly above 7 collectively. Among most individual hydrogeologic units, $\mathrm{pH}$ is generally maintained from approximately 7 to slightly above 8 , in association with congruent dissolution of calcium-magnesium carbonates (see "Hydrochemical Processes"). Two notable exceptions are the surficial aquifer and basement bedrock, within which $\mathrm{pH}$ is closer to 6 , possibly reflecting relatively direct recharge with precipitation.

Most values for groundwater temperature are close to the mean and median (Attachment 2), both in the mid to upper teens (degrees Celsius) collectively and among individual hydrogeologic units. Subsurface temperatures are effectively controlled by the geothermal gradient.

Mean and median values for concentrations of dissolved oxygen are both relatively low (Attachment 2), close to or less than $1 \mathrm{mg} / \mathrm{L}$ collectively and among most individual hydrogeologic units. Dissolved oxygen is widely consumed by chemical weathering reactions involving iron-bearing and associated minerals (see "Iron and Manganese"). Higher values for some hydrogeologic units are probably a result of collection procedures that allowed sample contact with the atmosphere. Within the surficial aquifer, however, actual concentrations are possibly close to the approximately $3 \mathrm{mg} / \mathrm{L}$ indicated, as a result of contact with the atmosphere across the water table.

Some extreme individual values of $\mathrm{pH}$, temperature, and dissolved oxygen are possibly the result of sample-collection, analysis, and(or) reporting errors (see "Data Use and Limitations"). By contrast, the relatively large ranges exhibited by specific conductance, total dissolved solids, and filtered residue more likely result from large difference among the total ion concentrations of the groundwater samples (see "Major Ions"). 


\section{Major Ions}

Regional trends in groundwater quality are determined largely by variations in the concentrations of major ions that dominate the chemical composition of groundwater. Although groundwater potentially contains many chemical constituents, the major ions typically are at the greatest concentrations and are considered here to include the cations calcium $\left(\mathrm{Ca}^{2+}\right)$, magnesium $\left(\mathrm{Mg}^{2+}\right)$, sodium $\left(\mathrm{Na}^{+}\right)$, and potassium $\left(\mathrm{K}^{+}\right)$, and the anions bicarbonate $\left(\mathrm{HCO}_{3}^{-}\right)$, carbonate $\left(\mathrm{CO}_{3}^{-}\right)$, sulfate $\left(\mathrm{SO}_{4}{ }^{2-}\right)$, and chloride $\left(\mathrm{Cl}^{-}\right)$. Summary statistics of compiled major ion concentration values are tabulated for groundwater samples collected from all hydrogeologic units collectively, as well as for samples collected from each hydrogeologic unit individually (Attachment 2), and include the number of analyses for each major ion, followed by its minimum, maximum, mean, and median.

Accurately determined concentrations of all of the major ions are needed for groundwater samples to reliably indicate regional trends in groundwater quality. For many of the samples, however, concentrations of some or all major ions are not included among the compiled chemical-constituent values, and the accuracy of those that are included is uncertain.

Accordingly, samples having complete and accurate major ion concentrations were identified by categorizing the samples on the basis of charge-balance values calculated for each sample.

Charge balance represents the relative difference in an aqueous solution between the amounts of positively charged cations and negatively charged anions, in terms of the milliequivalents per liter (meq/L) of each ion, which accounts for their different electrical charges and molecular weights. Because groundwater is thermodynamically stable and electrically neutral, the total positive electrical charge resulting from all cations equals the total negative charge from all anions, and the true charge balance is zero percent. Only an approximate charge balance, however, was calculated here from the compiled chemical-constituent values for each groundwater sample. Calculations included only the concentrations of major ions and not other chemical constituents that are probably at smaller concentrations. In addition, all concentration values are not exact, but rather are limited within various ranges of analytical accuracy.

Groundwater samples were categorized by charge balance into three groups: (1) those having values within 5 percent of zero, (2) those having values between 5 and 10 percent from zero, and (3) those having values greater than 10 percent from zero. Based on the known limitations described previously, the first group of samples was considered to have acceptably complete and accurate major ion concentration values.

Examination of major ion concentrations of the second group of samples indicated trends that generally followed those of the first group and likely also represent complete and accurate values. Thus, the first and second groups were combined to include 2,289 samples having complete major ion concentrations from which regional trends in groundwater quality can be determined. The third group of samples was considered to have incomplete and(or) inaccurate major ion concentration values.

\section{Spatial Distribution}

Spatial variations in the groundwater quality of the Virginia Coastal Plain are exhibited among the primary regional water-supply aquifers and basement bedrock (pls. 4-9), as reflected by the relative dominance among the major ions. Groundwater samples having complete major ion analyses were categorized by predominant ion type, based on 50 percent or greater of a particular cation or anion (or ion pair in some cases), which make up the total cations or anions, as milliequivalents per liter. Designated cation types are the pairs calcium plus magnesium $\left(\mathrm{Ca}^{2+}+\mathrm{Mg}^{2+}\right)$ and sodium plus potassium $\left(\mathrm{Na}^{+}+\mathrm{K}^{+}\right)$. Anion types are bicarbonate plus carbonate $\left(\mathrm{HCO}_{3}^{-}+\mathrm{CO}_{3}^{-}\right)$, sulfate $\left(\mathrm{SO}_{4}{ }^{2-}\right)$, and chloride $\left(\mathrm{Cl}^{-}\right)$. The ion pairs calcium plus magnesium and bicarbonate plus carbonate are associated by chemical weathering of subsurface sediments, and sodium plus potassium by cation exchange and saltwater mixing (see "Hydrochemical Processes"). Samples in which no cation or anion (or pair) is 50 percent or greater than the total are categorized as a mixed type. The overall major ion type for a sample is the combination of the cation and anion type, for example $\left(\mathrm{Ca}^{2+}+\mathrm{Mg}^{2+}\right)+\left(\mathrm{HCO}_{3}^{-}+\mathrm{CO}_{3}^{-}\right)$.

Contrasting sample-location colors distinguish the major ion type of each groundwater sample among the primary regional water-supply aquifers and basement bedrock (pls. 4-9). Base map content and scaling are identical to that used in a revised hydrogeologic framework of the Virginia Coastal Plain (McFarland and Bruce, 2006; available at http://pubs.usgs.gov/pp/2006/1731/) to enable direct comparison of groundwater quality to other aspects of the aquifers. Some groundwater samples that were associated by the hydrogeologic framework GIS with confining units or confining zones were likely actually collected from an adjacent aquifer (see "Data Quality") and are included here with the corresponding aquifer as appropriate. Other hydrogeologic units include relatively few samples.

Conventional contouring of the concentration of each major ion within every hydrogeologic unit is not feasible because of spatial data gaps, regionally non-uniform concentration gradients, and local-scale concentration variability (either laterally or vertically) within some hydrogeologic units. Likewise, presentation of spatial variations in groundwater quality by contouring is not practical because of the very large number of maps that would result.

Although sample major ion types do not convey specific concentrations of individual ions, values for filterable residue do reflect the total ion concentrations of the samples. Accordingly, estimated total ion concentration is contoured based on values for filterable residue for aquifers that include a sufficient number of adequately distributed samples (pls. 6-8), with some generalization at locations where vertical variations 
are present. Contours were manually generated to be consistent with the sample values but not wholly constrained by them. To accommodate abrupt lateral changes in total ion concentration, contour intervals range from $100 \mathrm{mg} / \mathrm{L}$ toward the west to $5,000 \mathrm{mg} / \mathrm{L}$ toward the east. For aquifers and basement bedrock in which local-scale variations preclude contouring, total ion concentrations are portrayed by scaling the size of open sample-location symbols proportionately to values for filterable residue (pls. $4,5,9$ ). The locations of some additional samples that lack values for filterable residue are shown by single-sized solid symbols. Major ion type, together with estimated total ion concentration, provides an efficient spatial summary of the compiled major ion concentrations and a generally coherent depiction of spatial variations in groundwater quality.

Most of the groundwater samples are categorized as one of three major ion types:

1. $\left(\mathrm{Ca}^{2+}+\mathrm{Mg}^{2+}\right)+\left(\mathrm{HCO}_{3}^{-}+\mathrm{CO}_{3}^{-}\right)$type water, dominated by calcium and magnesium cations, bicarbonate and carbonate anions, and commonly referred to as "hard" water,

2. $\left(\mathrm{Na}^{+}+\mathrm{K}^{+}\right)+\left(\mathrm{HCO}_{3}^{-}+\mathrm{CO}_{3}^{-}\right)$type water, dominated by sodium and potassium cations, bicarbonate and carbonate anions, and commonly referred to as "soft" water, and

3. $\left(\mathrm{Na}^{+}+\mathrm{K}^{+}\right)+\mathrm{Cl}^{-}$type water, dominated by sodium and potassium cations, chloride anions, and commonly referred to as "salty" water.

In addition, some samples of $\left(\mathrm{Na}^{+}+\mathrm{K}^{+}\right)+$mixed anion type water were collected from the Potomac aquifer (pl. 8). Relatively small numbers of additional samples are generalized here as "other," which are categorized among the remaining major ion types dominated by other ion combinations or as a mixed type in which no cation or anion (or pair) is 50 percent or greater than the total.

The degree to which spatial variations among major ion type and total ion concentration indicate regional trends in groundwater quality differs among the aquifers and basement bedrock. No trend at a regional scale is apparent from the compiled sample data from the surficial aquifer, Yorktown-Eastover aquifer, and basement bedrock (pls. 4, $5,9)$. Relatively few groundwater samples having complete major ion analyses were collected from either of these aquifers or bedrock, with most samples located within areas of limited extent and leaving large expanses with few or no samples. Moreover, the chemical composition of groundwater in these units is highly variable locally, with samples exhibiting contrasting major ions types and total ion concentrations.

In contrast to the preceding aquifers and basement bedrock, regional trends in groundwater quality are apparent in the Piney Point, Aquia, and Potomac aquifers (pls. 6-8). Trends are most clearly exhibited by the Potomac aquifer, from which groundwater samples were widely collected across the entire Virginia Coastal Plain except for the Virginia Eastern Shore. Locations of samples from the Piney Point aquifer are limited to the Northern Neck, Middle Peninsula, and York-James Peninsula eastward to the southern tip of the Virginia Eastern Shore. Locations of samples from the Aquia aquifer span most of its extent in Virginia except its western margin.

Total ion concentration in the Piney Point, Aquia, and Potomac aquifers increases generally eastward (pls. 6-8). Although areas to the west exhibit some local-scale variability, a consistent and abrupt eastward increase in total ion concentration in all three aquifers conforms to the outer margin of the Chesapeake Bay impact crater. In addition, a spatial sequence is apparent in the relative dominance among the major ions. $\left(\mathrm{Ca}^{2+}+\mathrm{Mg}^{2+}\right)+\left(\mathrm{HCO}_{3}^{-}+\mathrm{CO}_{3}^{-}\right)$type "hard" water is present generally toward the west. $\left(\mathrm{Na}^{+}+\mathrm{K}^{+}\right)+\left(\mathrm{HCO}_{3}{ }^{-}+\mathrm{CO}_{3}{ }^{-}\right)$type "soft" water primarily occupies a broad north-south trending belt spanning much of the central part of the Virginia Coastal Plain. Toward the east, $\left(\mathrm{Na}^{+}+\mathrm{K}^{+}\right)+\mathrm{Cl}^{-}$type "salty" water (along with some samples of $\left(\mathrm{Na}^{+}+\mathrm{K}^{+}\right)+$mixed anion type water in the Potomac aquifer) conforms closely to the abruptly increasing total ion concentration along the outer crater margin.

\section{Hydrochemical Processes}

Diverse processes can potentially affect the chemical composition of groundwater in coastal aquifers, including mixing, ion exchange, diagenesis, and oxidation-reduction reactions (Jones and others, 1998). Water composing almost all of the groundwater samples presented herein likely originated as precipitation that infiltrated the land surface and has undergone processes that controlled its chemical composition as it flowed through the subsurface. One possible exception is a sample located in the southwestern part of the city of Suffolk, which is from basement bedrock and composed of $\left(\mathrm{Na}^{+}+\mathrm{K}^{+}\right)+\mathrm{Cl}^{-}$type "salty" water of relatively high total ion concentration (pl. 9). Bedrock at this location is composed of Jurassic- to Triassic-age sedimentary rock. The chemical composition of this water possibly was produced by diagenetic processes associated with lithification of the bedrock.

Alternatively, relatively large chloride concentrations have been observed in groundwater in bedrock near Fredericksburg (Subitzky, 1961), which is likely of $\left(\mathrm{Na}^{+}+\mathrm{K}^{+}\right)+\mathrm{Cl}^{-}$type and is attributed to the presence of residual seawater (see "SaltwaterTransition Zone").

Regional trends in the groundwater quality of the Virginia Coastal Plain were first recognized about 70 years ago (Cederstrom, 1939), from which time an understanding has been sought of how hydrochemical processes control groundwater composition. The concept of hydrochemical facies (Back, 1966) remains the most widely accepted fundamental description of the sequence by which groundwater composition evolves along regional flow paths throughout the entire Northern Atlantic Coastal Plain and is generally described below. 
Water infiltrating the land surface combines with carbon dioxide originating from soil organic material to form carbonic acid (hydrogen ions and bicarbonate anions):

$$
\mathrm{H}_{2} \mathrm{O}+\mathrm{CO}_{2} \rightarrow \mathrm{H}^{+}+\mathrm{HCO}_{3}^{-} \text {(Drever, 1988). }
$$

With downward percolation to the water table, followed by flow through the saturated zone, water and hydrogen ions react with minerals making up subsurface sediments. These chemical weathering reactions are as highly varied as the many mineral species with which the water can come in contact. One of the most widespread reactions, however, is the dissolution of calcium-magnesium carbonates:

$$
\mathrm{Ca}, \mathrm{MgCO}_{3}+\mathrm{H}^{+} \rightarrow \mathrm{Ca}^{2+}, \mathrm{Mg}^{2+}+\mathrm{HCO}_{3}^{-}
$$
(Freeze and Cherry, 1979),

by which the chemical composition of groundwater becomes dominated by calcium and magnesium cations and bicarbonate anions to produce $\left(\mathrm{Ca}^{2+}+\mathrm{Mg}^{2+}\right)+\left(\mathrm{HCO}_{3}^{-}+\mathrm{CO}_{3}^{-}\right)$type "hard" water. This type of reaction is termed congruent dissolution, because consumption of the solid mineral results entirely in dissolved chemical constituents. As a result of a continued supply of carbon dioxide under "open system" conditions (Freeze and Cherry, 1979), pH varies over a relatively small range, generally between 7 and 8 .

Other widely occurring chemical weathering reactions include those involving diverse minerals collectively termed aluminosilicates. As one example, orthoclase feldspar reacts with hydrogen ions and water to produce potassium ions, dissolved silica, and the solid clay mineral kaolinite:

$$
2 \mathrm{KAlSi}_{3} \mathrm{O}_{8}+2 \mathrm{H}^{+}+9 \mathrm{H}_{2} \mathrm{O} \rightarrow 2 \mathrm{~K}^{+}+4 \mathrm{H}_{4} \mathrm{SiO}_{4}+\mathrm{Al}_{2} \mathrm{Si}_{2} \mathrm{O}_{5}(\mathrm{OH})_{4}
$$$$
\text { (Drever, 1988). }
$$

This type of reaction is termed incongruent dissolution, because consumption of the original solid mineral results in both dissolved chemical constituents and a newly formed solid mineral. Diverse dissolved constituents can be produced, depending on the composition of the original aluminosilicate mineral. Such reactions, however, commonly take place at relatively slow rates because the produced clay forms coatings around the aluminosilicate grains, reducing contact with water. Thus, the dissolved constituents are produced in relatively small amounts that are less apt to dominate the chemical composition of groundwater. Similarly, small concentrations of various constituents can also result from other chemical weathering reactions (see "Selected Constituents").

Following recharge at the water table, groundwater in the Virginia Coastal Plain continues to flow generally eastward through the saturated zone as far as several tens of miles, to depths as great as several hundred feet or more, and remains in contact with subsurface sediments for as long as several tens of thousands of years (Nelms and others, 2003) or more (McFarland and Bruce, 2005; Sanford and others, 2009b). Ion concentrations increase along regional flow paths, as more dissolved ions in groundwater are produced by continued chemical weathering. Other processes, however, also act to alter the relative dominance among the major ions. In water flowing to sufficiently great distances and depths, calcium and magnesium cations are adsorbed by the sediments onto grains of clay and glauconite, displacing previously adsorbed sodium and potassium cations into solution to thereby become the dominant cations. Bicarbonate anions remain unaffected. Thus, the earlier formed $\left(\mathrm{Ca}^{2+}+\mathrm{Mg}^{2+}\right)+\left(\mathrm{HCO}_{3}^{-}+\mathrm{CO}_{3}^{-}\right)$type "hard" water evolves to a $\left(\mathrm{Na}^{+}+\mathrm{K}^{+}\right)+\left(\mathrm{HCO}_{3}^{-}+\mathrm{CO}_{3}^{-}\right)$type "soft" water.

Lastly, and farther east toward the coast, groundwater mixes along a broad transition zone with seawater that occupies the sediments beneath the Atlantic Ocean. Cations remain dominated by sodium and potassium, but the concentration of chloride originating from seawater increases markedly and supersedes bicarbonate as the dominant anion. Thus, $\left(\mathrm{Na}^{+}+\mathrm{K}^{+}\right)+\left(\mathrm{HCO}_{3}^{-}+\mathrm{CO}_{3}^{-}\right)$type "soft" water evolves once more to a $\left(\mathrm{Na}^{+}+\mathrm{K}^{+}\right)+\mathrm{Cl}^{-}$type "salty" water. The total ion concentration of groundwater also increases abruptly into the brackish range, as a result of mixing with seawater. The saltwater-transition zone has a complex configuration resulting from changes in groundwater flow over time (see "SaltwaterTransition Zone"). In addition, changes in the major ion composition of groundwater along the saltwater-transition zone are associated with variations among the concentrations of various other constituents (see "Selected Constituents").

Hydrochemical processes that control groundwater quality are strongly reflected by regional trends in major ion type and total ion concentration exhibited by the Potomac aquifer (pl. 8) and to a lesser extent by the Piney Point and Aquia aquifers (pls. 6, 7). The sequence by which groundwater composition evolves along regional flow paths is best developed in the Potomac aquifer, which is the thickest and deepest among the hydrogeologic units (fig. 2) and through which the greatest volume of groundwater flows. The hydrochemical sequence is also best discerned by the numerous and widespread groundwater samples collected from the Potomac aquifer.

Recharge to the Potomac aquifer directly from infiltration at the land surface takes place primarily along the westernmost margin of the aquifer, as indicated by $\left(\mathrm{Ca}^{2+}+\mathrm{Mg}^{2+}\right)+\left(\mathrm{HCO}_{3}^{-}+\right.$ $\mathrm{CO}_{3}^{-}$) type "hard" water being almost wholly constrained to that area (pl. 8). By contrast, the widespread presence of $\left(\mathrm{Na}^{+}+\mathrm{K}^{+}\right)+\left(\mathrm{HCO}_{3}^{-}+\mathrm{CO}_{3}^{-}\right)$type "soft" water in much of the aquifer farther east infers that any additional recharge to that part of the aquifer has first leaked downward through a substantial thickness of sediments of overlying hydrogeologic units and thereby exchanged much of the calcium and magnesium cations for sodium and potassium cations. The complete absence of any groundwater samples of mixed composition between these two types of water reflects the abrupt shift in the relative concentrations among the cations and indicates the efficiency with which cation exchange by the sediments alters dominance among the cations. (Two locations along the western margin of the Potomac aquifer of samples 
of $(\mathrm{Na}+\mathrm{K})+\mathrm{Cl}$ type "salty" water and another two locations of samples of $(\mathrm{Na}+\mathrm{K})+$ mixed anion type water possibly reflect human solute sources.)

Still farther east, the presence of $\left(\mathrm{Na}^{+}+\mathrm{K}^{+}\right)+\mathrm{Cl}^{-}$type "salty" water in the Potomac aquifer conforms closely to a marked increase in total ion concentration along the saltwater-transition zone (pl. 8). In addition, mixed composition between this and $\left(\mathrm{Na}^{+}+\mathrm{K}^{+}\right)+\left(\mathrm{HCO}_{3}{ }^{-}+\mathrm{CO}_{3}{ }^{-}\right)$type "soft" water to the west is indicated by an appreciable number of $\left(\mathrm{Na}^{+}+\mathrm{K}^{+}\right)+$mixed anion type groundwater samples. Hence, in contrast to the abrupt effect of cation exchange to the west, freshwater/seawater mixing along the transition zone is relatively gradational.

Hydrochemical processes are reflected similarly in the Piney Point and Aquia aquifers (pls. 6, 7), although not as fully as in the Potomac aquifer. Eastwardly increasing total ion concentrations and evolving major ion types are generally apparent in both aquifers, although limited in detail and extent because of the scarcity of groundwater samples to the west and south. In addition, some samples of $(\mathrm{Ca}+\mathrm{Mg})+\left(\mathrm{HCO}_{3}+\mathrm{CO}_{3}\right)$ type "hard" water from both aquifers are located on the York-James Peninsula (farther east than generally found in the Potomac aquifer), because of differences in both of the aquifers' sediment composition and depth. Sediments making up the Piney Point and Aquia aquifers contain much greater amounts of calcium-magnesium carbonates than those of the Potomac aquifer, which upon dissolution likely increase the relative dominance of calcium and magnesium cations in groundwater. Both aquifers are also shallower than the Potomac aquifer (fig. 2). Groundwater has flowed a shorter distance - and is less chemically evolved - than in the Potomac aquifer at the same geographic location.

In contrast to the Piney Point, Aquia, and Potomac aquifers, regional groundwater-flow paths do not exist in the surficial aquifer, Yorktown-Eastover aquifer, and basement bedrock. The surficial aquifer and Yorktown-Eastover aquifer are shallowest among the regional water-supply aquifers (fig. 2). Likewise, all but one of the samples from bedrock are located along the Fall Zone (pl. 9) and are also shallow. Shallow groundwater is divided among many localized and poorly known flow cells that encompass short flow paths between closely located recharge and discharge areas. The locations of groundwater samples having complete major ion analyses are too widely dispersed to discern spatial variations in groundwater quality within individual flow cells.

Shallow groundwater in the surficial aquifer, YorktownEastover aquifer, and basement bedrock also does not flow to sufficiently great distances and depths to undergo the complete sequence of chemical evolution reflected by the regional trends in major ion type and total ion concentration of deeper aquifers. For example, most groundwater samples from the Yorktown-Eastover aquifer are of either $(\mathrm{Ca}+\mathrm{Mg})+\left(\mathrm{HCO}_{3}+\mathrm{CO}_{3}\right)$ type "hard" water of relatively low total ion concentration or $(\mathrm{Na}+\mathrm{K})+\mathrm{Cl}$ type "salty" water of higher total ion concentration (pl. 5). Only a few samples of $(\mathrm{Na}+\mathrm{K})+\left(\mathrm{HCO}_{3}+\mathrm{CO}_{3}\right)$ type "soft" water are present.
"Hard" water is produced by dissolution of large amounts of calcium-magnesium carbonates that compose the aquifer sediments, but then evolves directly to "salty" water by mixing with seawater, either laterally along discharge areas at the Atlantic coast, Chesapeake Bay, and tidal streams and rivers, or vertically with the regional saltwater-transition zone. Most groundwater-flow paths are too short for cation exchange by the sediments to effectively "soften" the water.

Lastly, shallow groundwater of major ion types other than "hard," "soft," or "salty" can result locally from nearby human solute sources. Shallow groundwater in many areas has entered the subsurface within human timeframes and can potentially contain solutes originating from human sources (Nelms and others, 2003). Some groundwater samples at widely spaced locations from the surficial aquifer, YorktownEastover aquifer, and basement bedrock are categorized as "other" (pls. 4, 5, 9) and include $(\mathrm{Ca}+\mathrm{Mg})+\mathrm{SO}_{4},(\mathrm{Ca}+\mathrm{Mg})+\mathrm{Cl}$, and $(\mathrm{Ca}+\mathrm{Mg})+$ mixed anion major ion types. Various aspects of closely located samples of shallow groundwater have been previously documented at Dahlgren (King George County) (Bell, 1996; Harlow and Bell, 1996) and on the Virginia Eastern Shore (Speiran, 1996). Solute sources at other sample locations potentially include a wide variety of both rural and urban activities, but are beyond the scope of the regional analysis here to consider in detail.

\section{Saltwater-Transition Zone}

The saltwater-transition zone in the Virginia Coastal Plain exhibits a marked eastward increase in the total ion concentration of groundwater along the outer margin of the Chesapeake Bay impact crater and a coincident evolution of its major ion type from a $\left(\mathrm{Na}^{+}+\mathrm{K}^{+}\right)+\left(\mathrm{HCO}_{3}{ }^{-}+\mathrm{CO}_{3}^{-}\right)$type "soft" water to a $\left(\mathrm{Na}^{+}+\mathrm{K}^{+}\right)+\mathrm{Cl}^{-}$type "salty" water (pls. 6-8) (see "Major Ions"). Chloride supersedes bicarbonate as the dominant anion as a result of mixing of groundwater with seawater that occupies the sediments beneath the Atlantic Ocean.

Chloride is a chemical constituent of particular resourcemanagement interest in the Virginia Coastal Plain, and its concentration is of primary concern in association with the saltwater-transition zone. Chloride concentrations below the U.S. Environmental Protection Agency (1990) secondary maximum contaminant level of $250 \mathrm{mg} / \mathrm{L}$ are commonly referred to as "fresh." Concentrations between freshwater and that of seawater $(19,000 \mathrm{mg} / \mathrm{L})(\mathrm{Hem}, 1985)$ are referred to as "brackish" and are widespread in large parts of the major water-supply aquifers across the eastern part of the Virginia Coastal Plain. Concentrations above that of seawater constitute "brine." Chloride concentrations of brackish groundwater across the saltwater-transition zone are a major issue regarding the use of groundwater (see "Considerations for Groundwater Use").

Spatial variations in groundwater chloride concentration are used herein to depict the saltwater-transition zone in a manner that most directly relates to resource-management 
interests. The compiled dataset (Attachment 1) includes 6,650 chloride concentrations (Attachment 2), of which 2,289 samples were considered to be acceptably accurate based on charge balance of major ions (see "Major Ions"). The accuracy of the chloride concentrations of other groundwater samples having incomplete analyses of major ions is uncertain and cannot be evaluated by charge balance. Paired values of chloride concentration and specific conductance, however, can be used to evaluate the accuracy of chloride concentration. Accordingly, a LOWESS smooth regression (Helsel and Hirsch, 2002) of specific conductance versus chloride concentration was performed on 1,683 samples that have values for both chloride concentration and specific conductance. Regression residual values were within 3 standard deviations of the mean for 1,658 of the samples, which were thereby designated as having acceptably accurate chloride concentrations. These samples were combined with those accepted based on charge balance, for a total of 3,947 chloride concentrations used to depict the saltwater-transition zone. Residual values of 25 samples were greater than 3 standard deviations of the mean and were considered to reflect unreliable chloride concentrations that were not used.

\section{Configuration}

Initial understanding of the physical principles governing the transition from freshwater to saltwater in coastal aquifers has been widely attributed to Ghyben (1888) and Herzberg (1901). In a homogeneous unconfined aquifer under hydrostatic conditions, freshwater is separated from the more dense seawater by a landward sloping interface. Hubbert (1940) elaborated that with steady-state outflow to the sea, the interface is displaced seaward. Henry (1960) described the transition as a dispersive mixing zone rather than a sharp boundary, which Pinder and Cooper (1970) further characterized with transient movement in a confined aquifer. In the Atlantic Coastal Plain from New Jersey through North Carolina, Meisler (1989) described a relatively broad transition zone between freshwater and saltwater.

\section{Chloride-Concentration Sections}

In characterizing groundwater salinity associated with the Chesapeake Bay impact crater, McFarland and Bruce (2005) depicted the vertical configuration of part of the saltwatertransition zone by a single hydrogeologic section across the lower part of the Middle Peninsula, upon which variations in groundwater specific conductance are represented by contours. A similar approach has been modified and expanded on for this report. Ten chloride-concentration sections, collectively spanning most of the Virginia Coastal Plain, depict the vertical configuration of the entire saltwater-transition zone by representing variations in groundwater chloride concentrations with point values and contours (pls. 10-14).

Chloride-concentration section point values alternately represent (1) the chloride concentration of a single groundwater sample or (2) a generalized groundwater chloride concentration, based on multiple samples collected from a single well or borehole at different times and(or) from multiple closely located wells or boreholes. Some samples are located directly on a section, whereas other samples are projected onto the section from locations in general proximity to the section.

Chloride-concentration section contours represent lines of equal groundwater chloride concentration that interpolate across areas between point values and, in some instances, extrapolate beyond the area spanned by point values. Contours were manually generated to be consistent with the point values but not wholly constrained by them. In addition, because the sections intersect at multiple locations, contoured features that were apparent from some sections were extrapolated onto adjacent sections to maintain consistency among the sections. To accommodate a general downward acceleration in chloride concentration, contour intervals range from $100 \mathrm{mg} / \mathrm{L}$ at shallow depths to as much as $6,000 \mathrm{mg} / \mathrm{L}$ below.

In order to enable direct comparison of chlorideconcentration variations to other aspects of the aquifers, chloride-concentration section letter designations, content, and scaling used here are identical to those used for hydrogeologic sections in a revised hydrogeologic framework of the Virginia Coastal Plain (McFarland and Bruce, 2006; available at http://pubs.usgs.gov/pp/2006/1731/). A full description is given there of construction of the hydrogeologic sections. The chloride-concentration sections have been extended to greater depth, to encompass the full span of groundwater-sample locations. Sections DD-DD' and ED-ED' (pl. 10), FD-FD' and GD-GD' (pl. 11), and ID-ID' and JD-JD' (pl. 12) are oriented along the general regional stratigraphic dip of the hydrogeologic units. Among these, sections DD-DD' and ED-ED' (pl. 10) span the Chesapeake Bay impact crater. Sections DS-DS' and ES-ES' (pl. 13) and FS-FS' and GS-GS' (pl. 14) are oriented along stratigraphic strike. All of these sections span the impact crater, except DS-DS', which is positioned several miles to the west (pl. 13). Seven additional hydrogeologic sections, mostly spanning the northern and western parts of the Virginia Coastal Plain, were constructed for the hydrogeologic framework, but are not included here because groundwater samples located in those areas do not span sufficient ranges of chloride concentration and depth.

Chloride-concentration sections oriented along dip exhibit an eastward and downward trend in increasing groundwater chloride concentration, which reflects a broad but generally landward-dipping saltwater-transition zone between fresh groundwater to the west and saltwater to the east (pls. 10-12). The altitude of the $250 \mathrm{mg} / \mathrm{L}$ contour line separating fresh and brackish groundwater is as deep as $-1,000 \mathrm{ft}$ in some western areas, but is higher than $-100 \mathrm{ft}$ toward the east. The $19,000 \mathrm{mg} / \mathrm{L}$ contour is equivalent to the chloride concentration of seawater and extends westward below $-2,000 \mathrm{ft}$ before truncating against basement bedrock, but to the east is higher at $-1,000 \mathrm{ft}$ beneath parts of the Virginia Eastern Shore (pl. 10). At greater depths, brine having chloride concentrations greater than seawater is beneath the 
Virginia Eastern Shore and the lower Chesapeake Bay, as well as the northern part of Virginia Beach (pl. 11).

Chloride-concentration sections oriented along strike also exhibit groundwater chloride concentrations that increase downward, but that are also positioned at relatively high altitudes across the Chesapeake Bay impact crater (pls. 13, 14). Both the $250 \mathrm{mg} / \mathrm{L}$ contour and $19,000 \mathrm{mg} / \mathrm{L}$ contour are steeply dipping and displaced upward by as much as $1,000 \mathrm{ft}$ across the impact crater relative to adjacent areas (section GS-GS', pl. 14). This chloride "mound" extends outside the impact crater several miles to the west beneath the York-James Peninsula, where the $250 \mathrm{mg} / \mathrm{L}$ contour is displaced upward by more than $600 \mathrm{ft}$ (section DS-DS', pl. 13). The chloride mound is most elevated within confining units composed of low-permeability sediments deposited over the impact crater, which thicken and deepen into the impact crater (sections DD-DD' and ED-ED', pl. 10; section GD-GD', pl. 11).

In addition to broad regional trends described previously, local-scale variations in groundwater chloride concentration take the form of concentration inversions. The downward increasing concentration trend is locally reversed across some vertical intervals having sufficient numbers of adequately distributed point values, including within and slightly outside of the Chesapeake Bay impact crater (sections DD-DD' and ED-ED', pl. 10; section ES-ES', pl. 13), but also well outside the impact crater to the south (section JD-JD', pl. 12; section ES-ES', pl. 13).

Contours depict possible relations of the concentration inversions to regional groundwater flow and associated chloride-concentration trends. The inversions correlate along distinct zones that partly follow stratigraphic dip (sections DD-DD' and ED-ED', pl. 10; section JD-JD', pl. 12). Parts of some inverted zones are extrapolated up-dip to areas exhibiting irregular altitudes among contrasting chloride concentrations, as well as onto adjacent sections. The inverted zones also follow a regional north-south structural trend, represented by an eastward plunging ridge in basement bedrock located south of the James River, termed the Norfolk arch (section ES-ES', pl. 13). Inverted zones parallel the flanks of the Norfolk arch that dip northward into the Salisbury embayment across the Virginia Coastal Plain into Maryland and southward into North Carolina. Thus, the three-dimensional trend of the inverted zones is the resultant of the dip-oriented and flank-oriented components represented on the chlorideconcentration sections. The inverted zones are inferred to reflect paths of differential flushing of fresh groundwater (see "Freshwater Flushing").

The different aspects of variations in groundwater chloride concentration described previously combine to make up the overall configuration of the saltwater-transition zone. The generally eastward and downward increasing groundwater chloride concentrations are displaced upward to form a mound across the Chesapeake Bay impact crater, across which zones of inverted chloride concentration are superimposed. Thus, the generally landward-dipping saltwater-transition zone has a convoluted configuration, which can loosely be described as being warped around the impact crater along the inverted zones.

\section{Chloride Iso-Concentration Surfaces}

In order to gain additional perspectives on the configuration of the saltwater-transition zone, the representations of groundwater chloride concentration on chloride-concentration sections were expanded by a series of groundwater chloride iso-concentration surfaces. Each contour appearing on a section represents a three-dimensional trace, resulting from the intersection of the vertical plane of the section with a sloping surface of equal groundwater chloride concentration that is projected through the section. Five of these iso-concentration surfaces, corresponding to section contours ranging from $50 \mathrm{mg} / \mathrm{L}$ to $19,000 \mathrm{mg} / \mathrm{L}$, were delineated by correlating among the sections (figs. 4-8). The altitude of each isoconcentration surface was identified at various points along the sections directly from the section contours. Contours in map view were then drawn manually to interpolate altitudes across areas between sections. The contours represent lines of equal altitude that depict the configuration of each iso-concentration surface. Contour intervals are variable, as small as $50 \mathrm{ft}$ at high altitudes to reflect subtle features of the shallowest parts of the surfaces, and as much as $250 \mathrm{ft}$ at lower altitudes where the surfaces are steeply dipping. Section alignments are indicated, so that particular features of the iso-concentration surfaces can be cross referenced with the sections, to be seen in side view.

The extent of each groundwater chloride isoconcentration surface is limited by those of the corresponding chloride-concentration section contours and is greatest for the relatively shallow $50 \mathrm{mg} / \mathrm{L}$ surface (fig. 4) and least for the deep 19,000 mg/L surface (fig. 8). The iso-concentration surfaces are further limited to depicting broad regional groundwater chloride-concentration trends. Subjective judgment was required in manually generating contours to depict plausible surface configurations, which are consistent with the section contours but not wholly constrained by them. Moreover, because contouring is constrained to a planer view, the surfaces cannot depict vertically inverted groundwater chloride-concentration zones. In such areas, contours are generalized across the inverted parts of the surfaces.

Groundwater chloride iso-concentration surfaces provide a general indication of different groundwater chloride concentrations at various altitudes within the Coastal Plain sediments, which has practical use for site-specific activities such as locating and constructing groundwater wells. Accounting for variations in land-surface altitude, groundwater having a particular chloride concentration would be encountered at relatively shallow depths at locations where the corresponding iso-concentration surface is at a high altitude and at greater depths where the surface is at a low altitude. (Evaluation of the possibility of encountering inverted chlorideconcentration zones would entail examination of the chlorideconcentration sections.) 


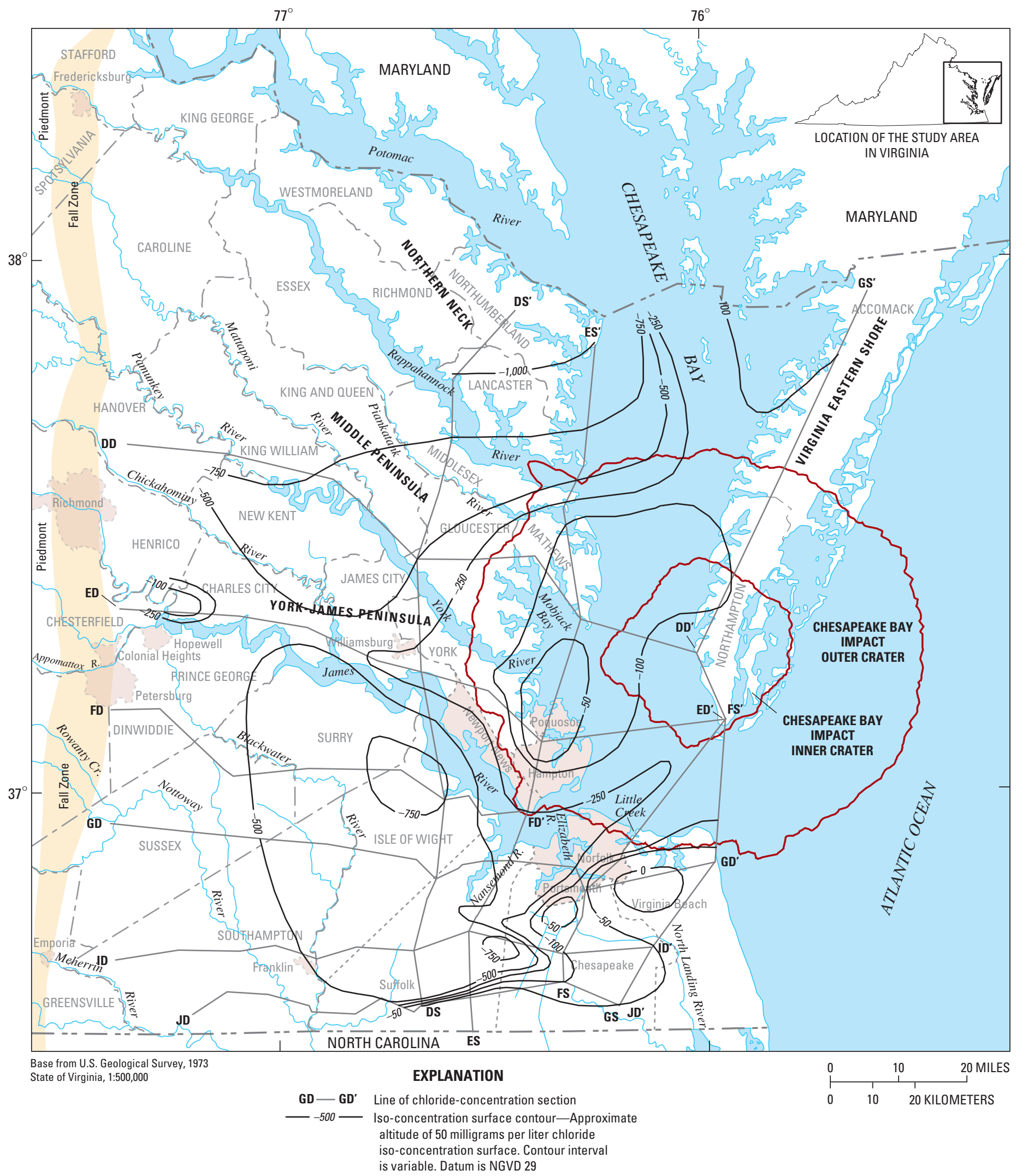

Figure 4. Approximate altitude and configuration of the 50 milligrams per liter chloride iso-concentration surface in the Virginia Coastal Plain. Surface is delineated on the basis of correlation among chloride-concentration sections (pls. 10-14). Mapped extent of surface is limited to that of section contours. Location of Chesapeake Bay impact crater from Powars and Bruce (1999). 


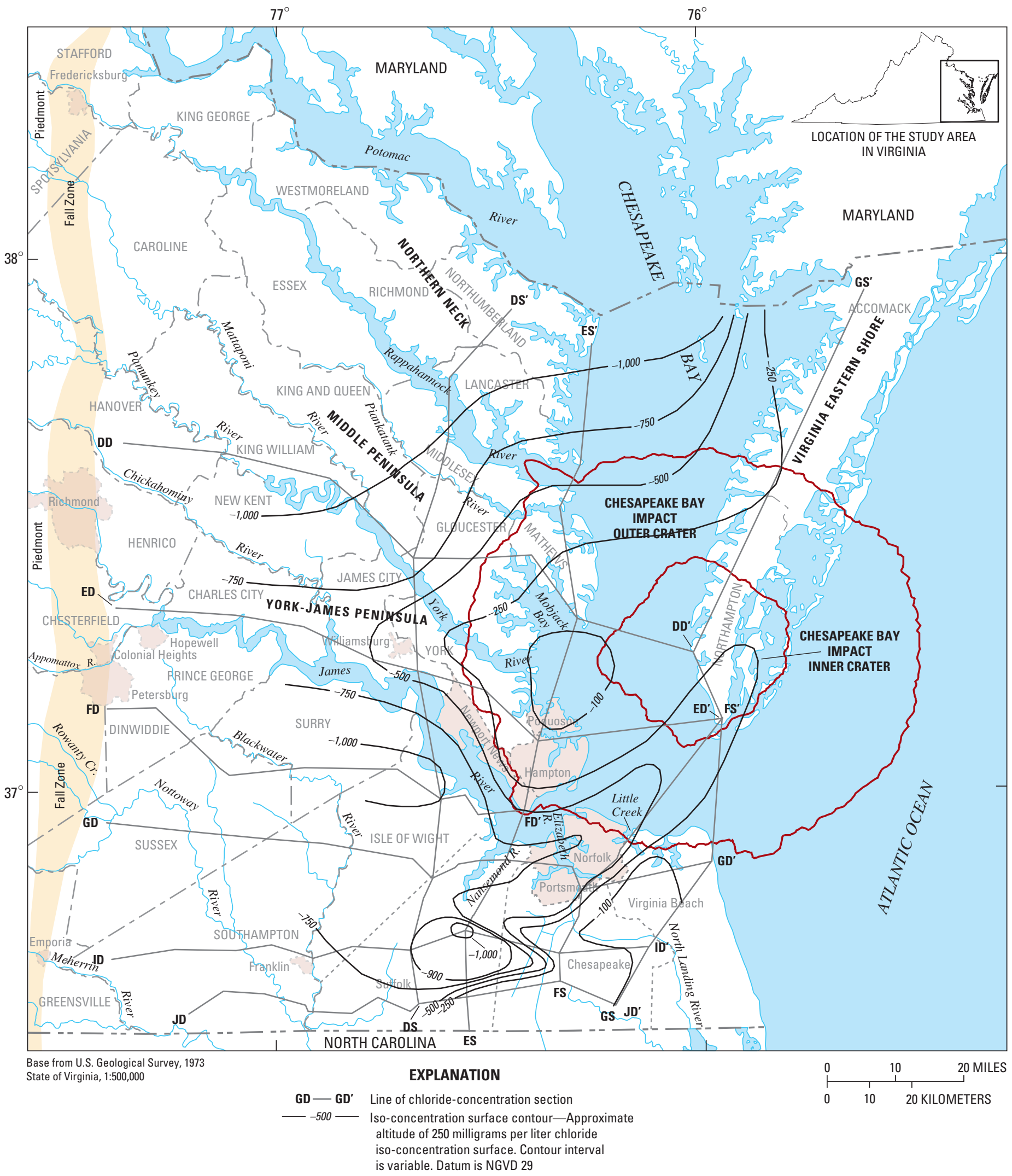

Figure 5. Approximate altitude and configuration of the 250 milligrams per liter chloride iso-concentration surface in the Virginia Coastal Plain. Surface is delineated on the basis of correlation among chloride-concentration sections (pls. 10-14). Mapped extent of surface is limited to that of section contours. Location of Chesapeake Bay impact crater from Powars and Bruce (1999). 


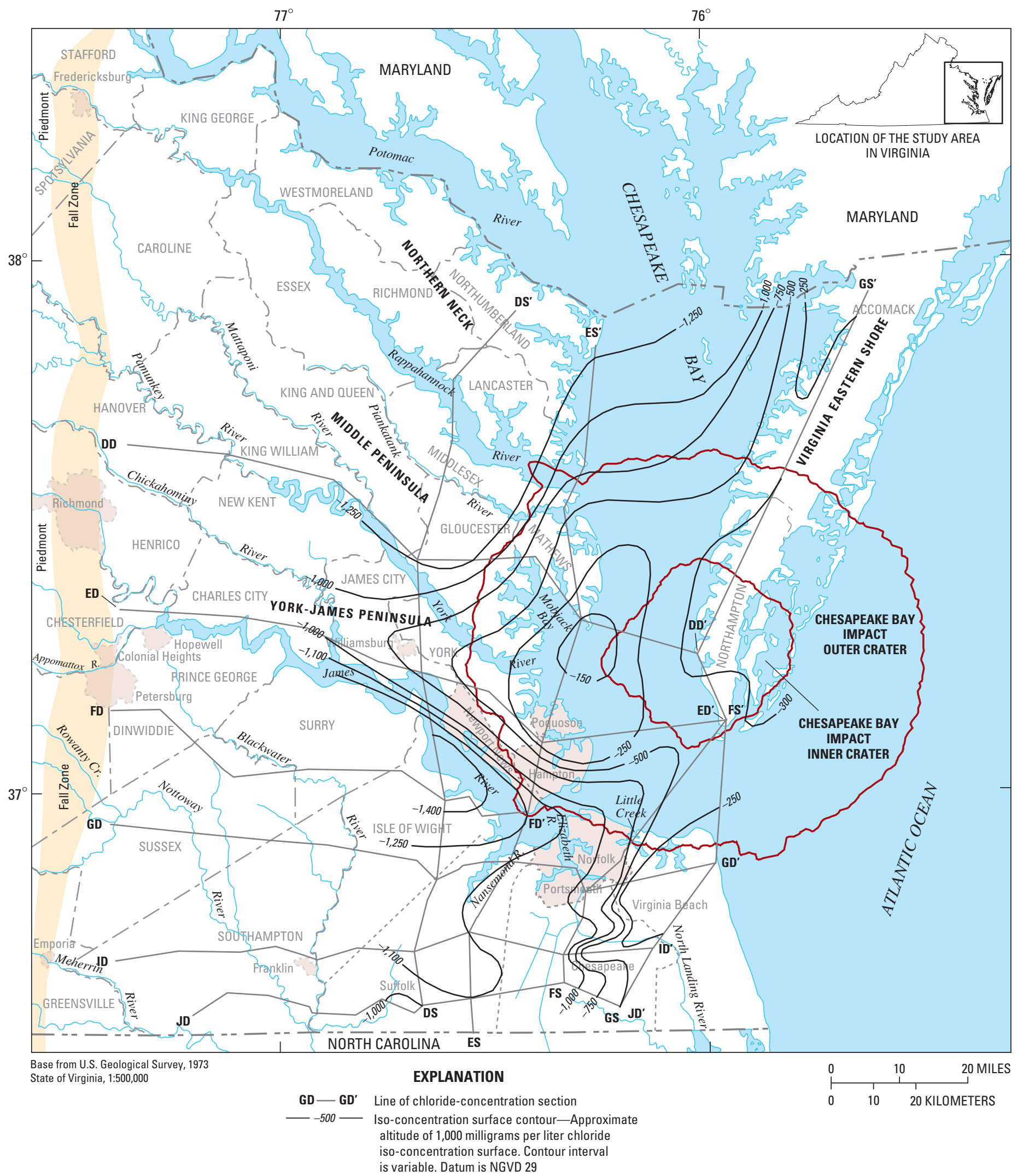

Figure 6. Approximate altitude and configuration of the 1,000 milligrams per liter chloride iso-concentration surface in the Virginia Coastal Plain. Surface is delineated on the basis of correlation among chloride-concentration sections (pls. 10-14). Mapped extent of surface is limited to that of section contours. Location of Chesapeake Bay impact crater from Powars and Bruce (1999). 


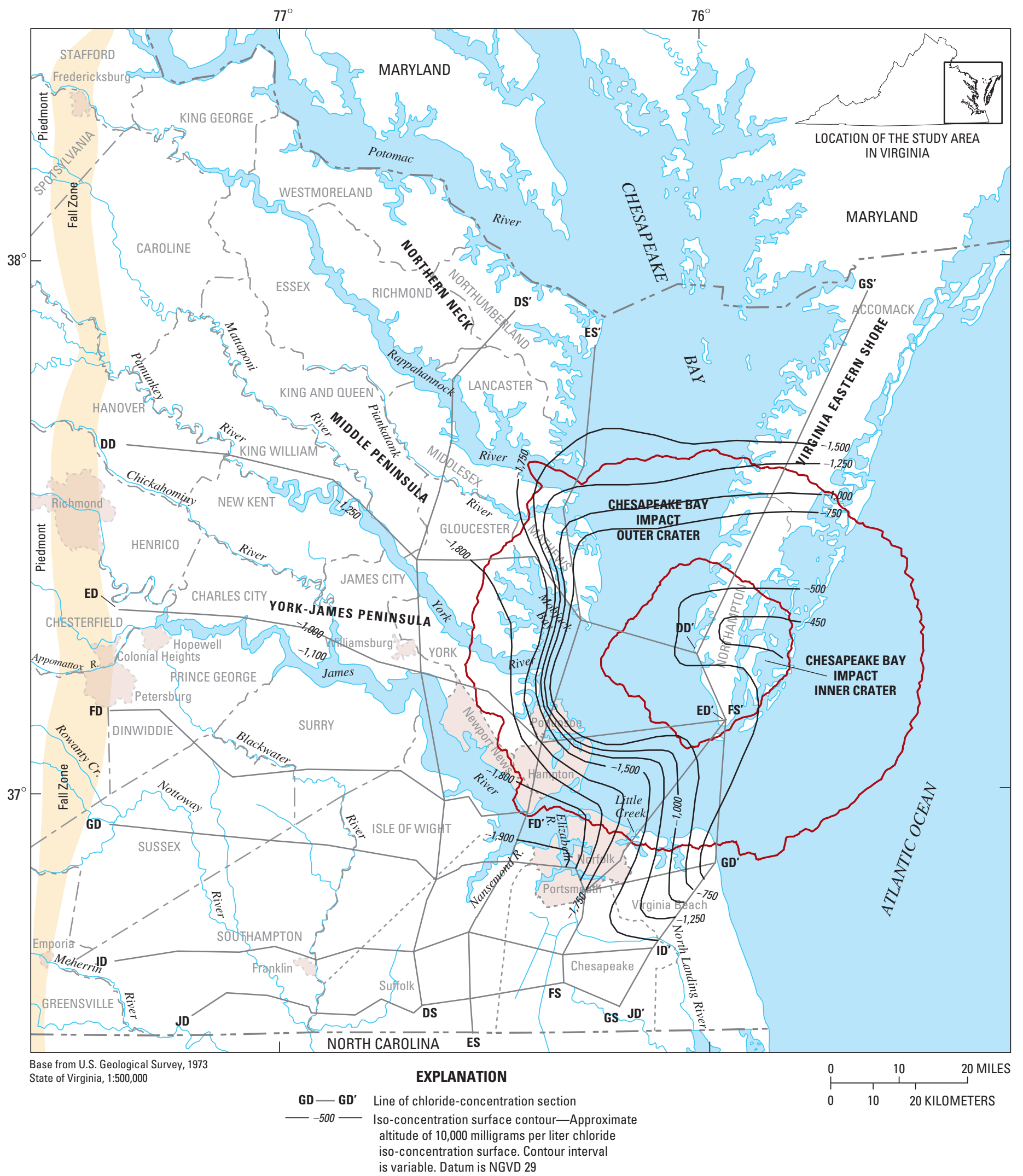

Figure 7. Approximate altitude and configuration of the 10,000 milligrams per liter chloride iso-concentration surface in the Virginia Coastal Plain. Surface is delineated on the basis of correlation among chloride-concentration sections (pls. 10-14). Mapped extent of surface is limited to that of section contours. Location of Chesapeake Bay impact crater from Powars and Bruce (1999). 


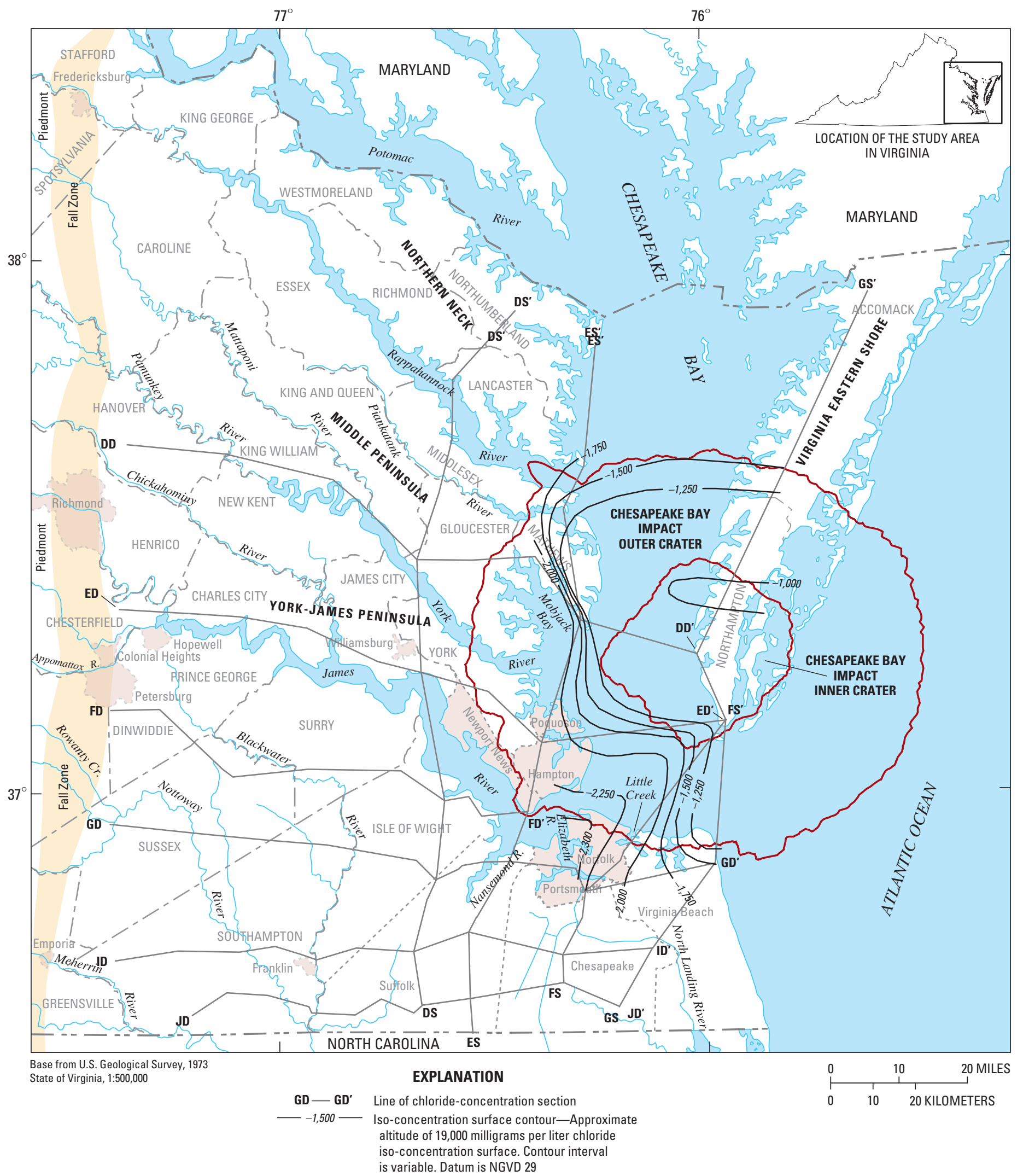

Figure 8. Approximate altitude and configuration of the 19,000 milligrams per liter chloride iso-concentration surface in the Virginia Coastal Plain. Surface is delineated on the basis of correlation among chloride-concentration sections (pls. 10-14). Mapped extent of surface is limited to that of section contours. Location of Chesapeake Bay impact crater from Powars and Bruce (1999). 
The groundwater chloride iso-concentration surfaces also have practical use for analyses of the groundwater-flow system (see "Relations to Groundwater Flow"), by collectively depicting various features making up the three-dimensional configuration of the saltwater-transition zone. As exhibited by the relatively shallow $50 \mathrm{mg} / \mathrm{L}, 250 \mathrm{mg} / \mathrm{L}$, and 1,000 mg/L iso-concentration surfaces (figs. 4-6), the earlier described chloride mound across the Chesapeake Bay impact crater (see "Chloride-Concentration Sections") exhibits a broad dome shape and is centered along the western to southwestern side of the outer impact crater. These surfaces also exhibit a westward plunging spur ridge projecting from the mound beneath the York-James Peninsula. The ridge on the $50 \mathrm{mg} / \mathrm{L}$ surface extends fully to the Fall Zone (fig. 4), rising in altitude to take on a saddle-like shape. Flank areas of the mound and ridge on all three surfaces dip evenly northwestward beneath the Middle Peninsula and Northern Neck, and southwestward beneath Surry and Isle of Wight Counties. Farther south, a second, more irregularly shaped ridge plunges westward beneath the cities of Suffolk and Chesapeake. This ridge is separated from the mound by a southwestward plunging trough, trending from the southern tip of the Virginia Eastern Shore across the lowermost parts of Chesapeake Bay and the James River.

Overall similar configurations are exhibited at greater depth by the $10,000 \mathrm{mg} / \mathrm{L}$ and $19,000 \mathrm{mg} / \mathrm{L}$ iso-concentration surfaces (figs. 7, 8), although across smaller extents. The chloride mound exhibits a more plug-like shape, however, with a level plateau and precipitously dipping flanks and is centered farther eastward into the inner crater.

\section{Aquifer Chloride Concentrations}

In addition to the groundwater chloride-concentration sections and chloride iso-concentration surfaces, further perspective on the configuration of the saltwater-transition zone is provided by a series of chloride-concentration maps of water-supply aquifers (figs. 9-13). Chloride-concentration sections depict the configuration of the saltwater-transition zone only across discrete vertical profiles of the hydrogeologic units (pls. 10-14), and iso-concentration surfaces depict only broad regional trends of chloride concentrations at various altitudes, independent of their positions within hydrogeologic units (figs. 4-8). Some resource-management information needs are specific to individual hydrogeologic units, typically one or more of the major water-supply aquifers. Accordingly, chloride concentrations were delineated within the YorktownEastover, Piney Point, Aquia, Virginia Beach, and Potomac aquifers. All of these hydrogeologic units represent major regional water-supply resources except for the Virginia Beach aquifer, which is of local importance in the city of Suffolk, where it can be favored over the deeper Potomac aquifer because of its higher groundwater levels (McFarland and Bruce, 2006).

Conventional contouring of groundwater chloride concentration is not feasible for some aquifers, because of spatial data gaps, regionally non-uniform concentration gradients, and local-scale concentration variability (either laterally or vertically). Instead, the GIS developed as part of the newly revised hydrogeologic framework of the Virginia Coastal Plain (McFarland and Bruce, 2006) (see "Methods of Investigation") was applied to delineate chloride concentrations among the aquifers. GIS raster datasets that represent the approximate configurations of the top surfaces of all hydrogeologic units were used in conjunction with the chloride iso-concentration surfaces. Each iso-concentration surface is a sloping surface of equal groundwater chloride concentration (see "Chloride Iso-Concentration Surfaces") that projects through the space occupied by the various hydrogeologic units.

GIS operations were performed to delineate a series of three-dimensional traces that result from intersections of the hydrogeologic unit top surfaces with the iso-concentration surfaces. Each trace is a projected contour line of equal chloride concentration along the top surface of the hydrogeologic unit. Segments of chloride-concentration contours were combined from among various hydrogeologic unit surfaces to construct continuous contours across both the bottom and top surfaces of the water-supply aquifers. The chloride-concentration value of each contour corresponds to each of the iso-concentration surfaces, resulting in a variable contour interval. Likewise, the extents of the contours are limited by those of the iso-concentration surfaces. Also like the iso-concentration surfaces, the contours represent broad regional trends of chloride concentrations that do not include all local-scale features, such as vertically inverted groundwater chloride-concentration zones.

The Piney Point, Aquia, and Virginia Beach aquifers are thin (fig. 2), and vertical variations in chloride concentration within these aquifers are small relative to lateral variations. The relatively steep dips of the chloride iso-concentration surfaces result in little difference between the projected positions and alignments of the top-surface chloride-concentration contours and those of the bottom-surface contours. Accordingly, a single set of chloride-concentration contours was manually generated for each of these aquifers that closely approximates the positions and alignments of both their top-surface and bottom-surface contours (figs. 10-12).

In contrast to the Piney Point, Aquia, and Virginia Beach aquifers, the Yorktown-Eastover aquifer and especially the Potomac aquifer are thick (fig. 2). Vertical variations in chloride concentration within these aquifers are comparable in magnitude to lateral variations. Chloride iso-concentration surface dips are shallow enough that the projected positions and alignments of the top-surface chloride-concentration contours differ substantially from those of the bottom-surface contours. Accordingly, both the top-surface and bottom-surface chloride-concentration contours serve together to delineate chloride concentrations within the Yorktown-Eastover and Potomac aquifers (figs. 9, 13, respectively). For each aquifer, the two sets of projected contours are distinguished by different colors. For added clarity, the different areas spanned by the two sets of contours are also shaded using corresponding colors. 


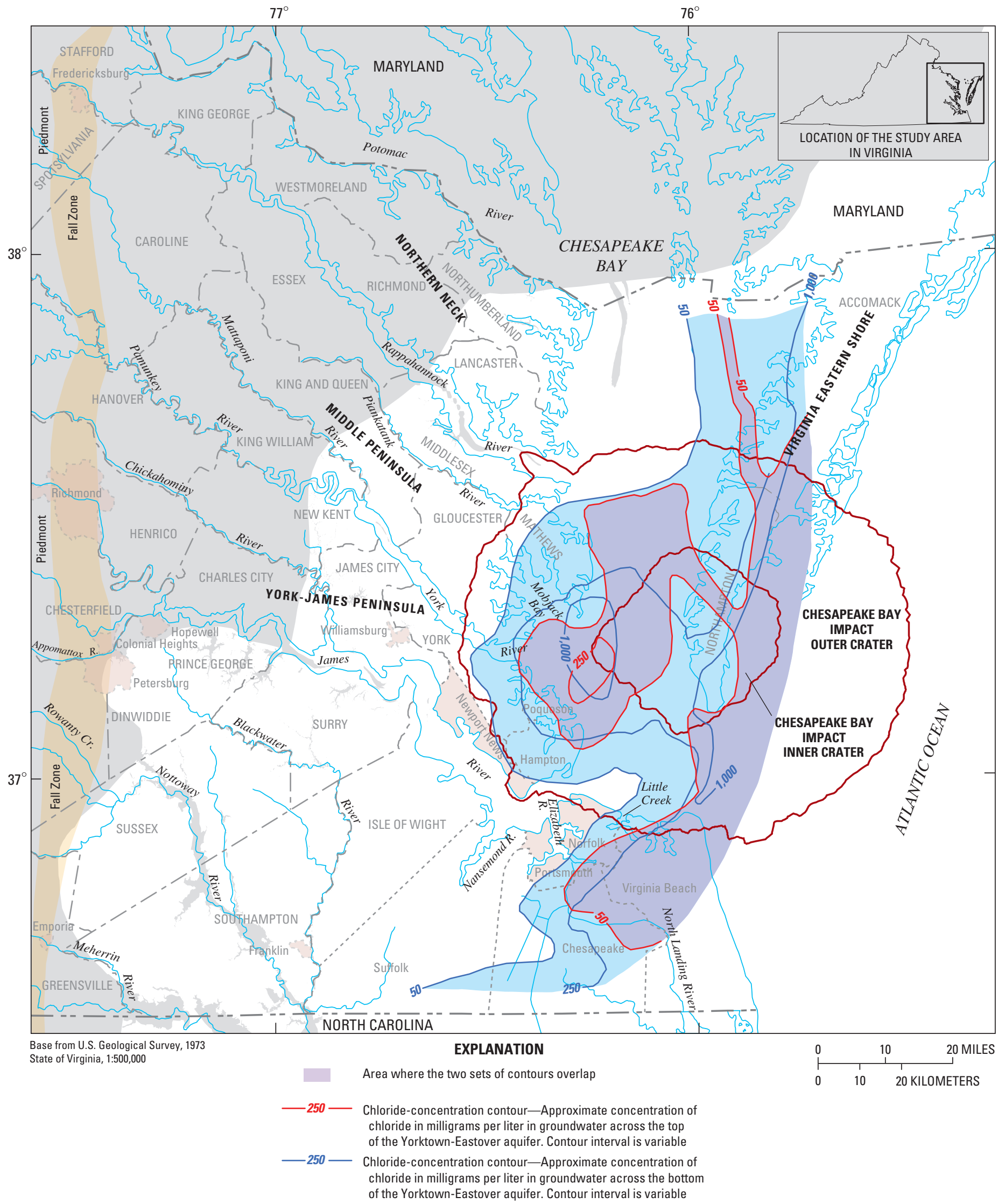

Figure 9. Approximate groundwater chloride concentrations, in milligrams per liter, across the top (red) and bottom (blue) of the YorktownEastover aquifer in the Virginia Coastal Plain. Areas spanned by alternate sets of contours are shaded in corresponding colors. Mapped extents of contours are limited to those of chloride iso-concentration surfaces (figs. 3-7). Area outside extent of aquifer is shaded gray. Location of Chesapeake Bay impact crater from Powars and Bruce (1999). 


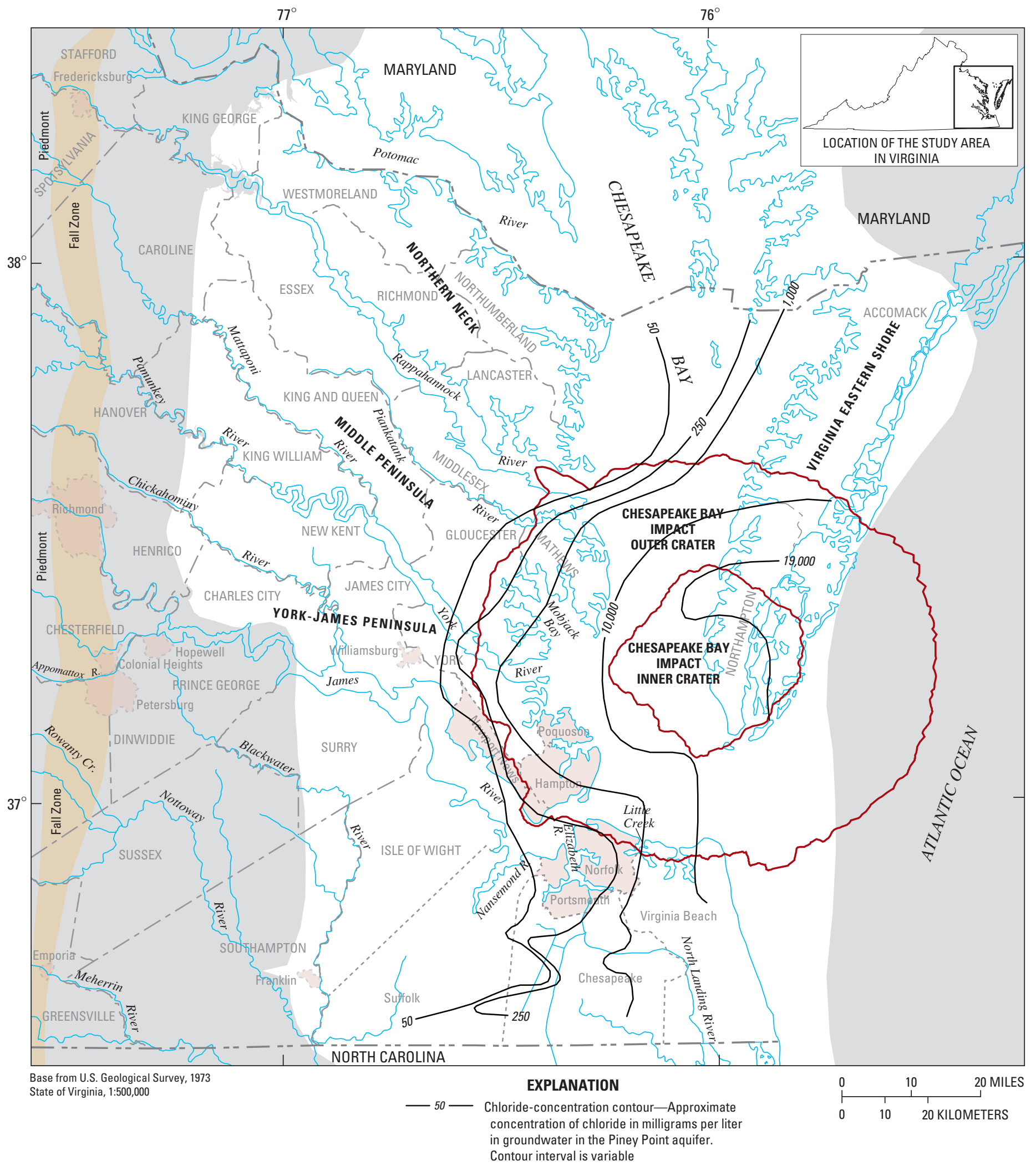

Figure 10. Approximate groundwater chloride concentrations, in milligrams per liter, in the Piney Point aquifer in the Virginia Coastal Plain. Mapped extent of contours is limited to that of chloride iso-concentration surfaces (figs. 3-7). Area outside extent of aquifer is shaded gray. Location of Chesapeake Bay impact crater from Powars and Bruce (1999). 


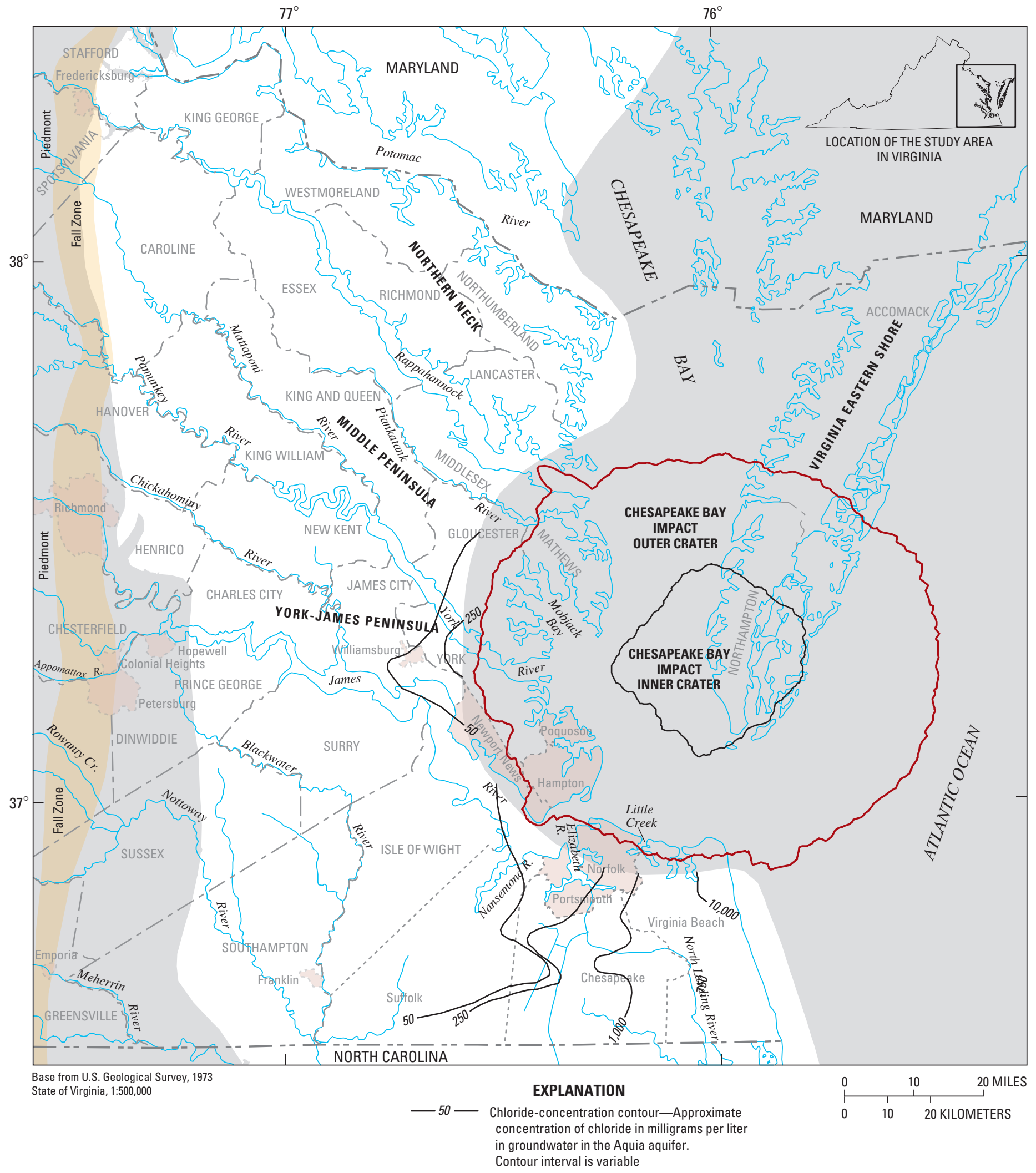

Figure 11. Approximate groundwater chloride concentrations, in milligrams per liter, in the Aquia aquifer in the Virginia Coastal Plain. Mapped extent of contours is limited to that of chloride iso-concentration surfaces (figs. 3-7). Area outside extent of aquifer is shaded gray. Location of Chesapeake Bay impact crater from Powars and Bruce (1999). 


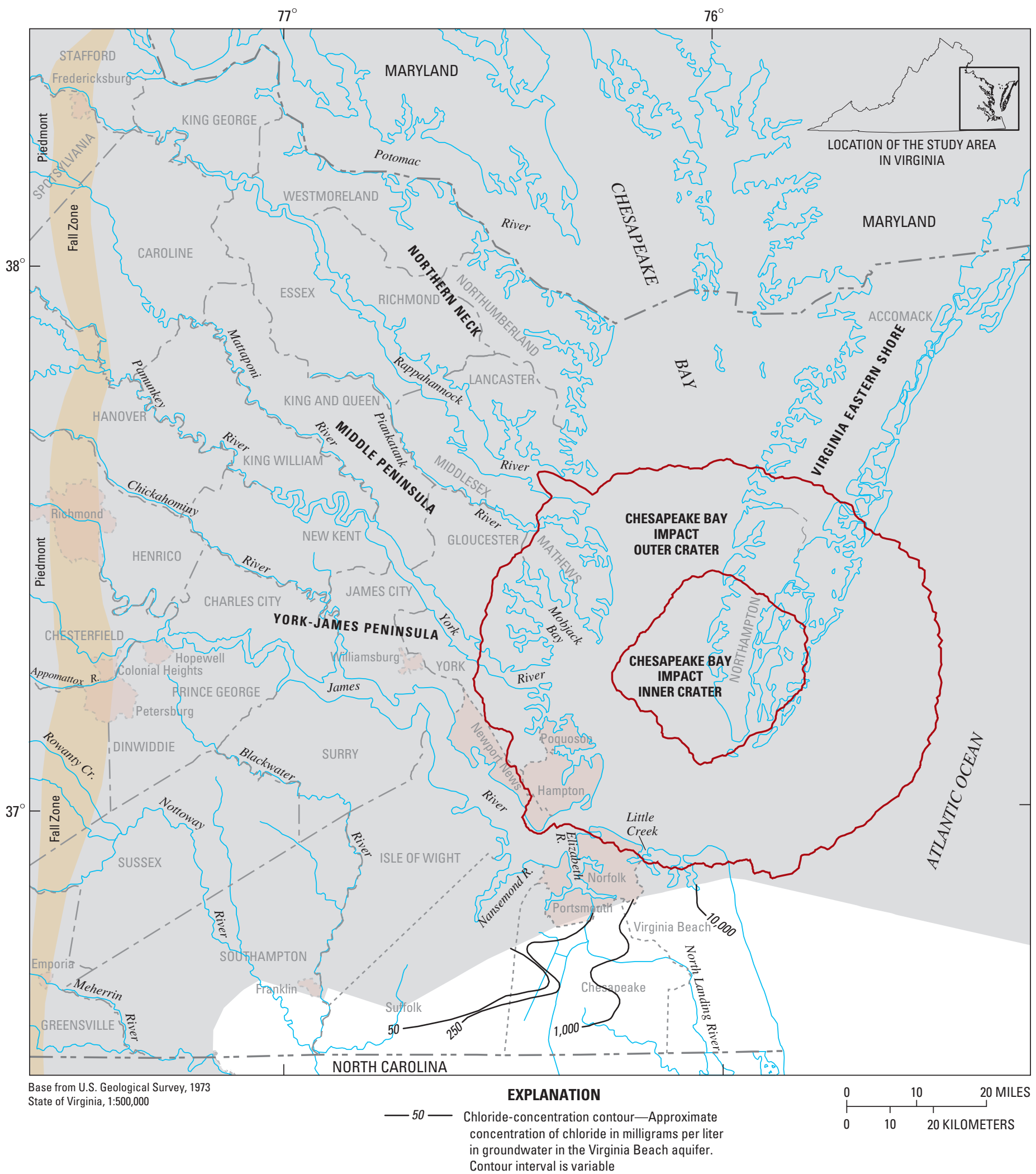

Figure 12. Approximate groundwater chloride concentrations, in milligrams per liter, in the Virginia Beach aquifer in the Virginia Coastal Plain. Mapped extent of contours is limited to that of chloride iso-concentration surfaces (figs. 3-7). Area outside extent of aquifer is shaded gray. Location of Chesapeake Bay impact crater from Powars and Bruce (1999). 


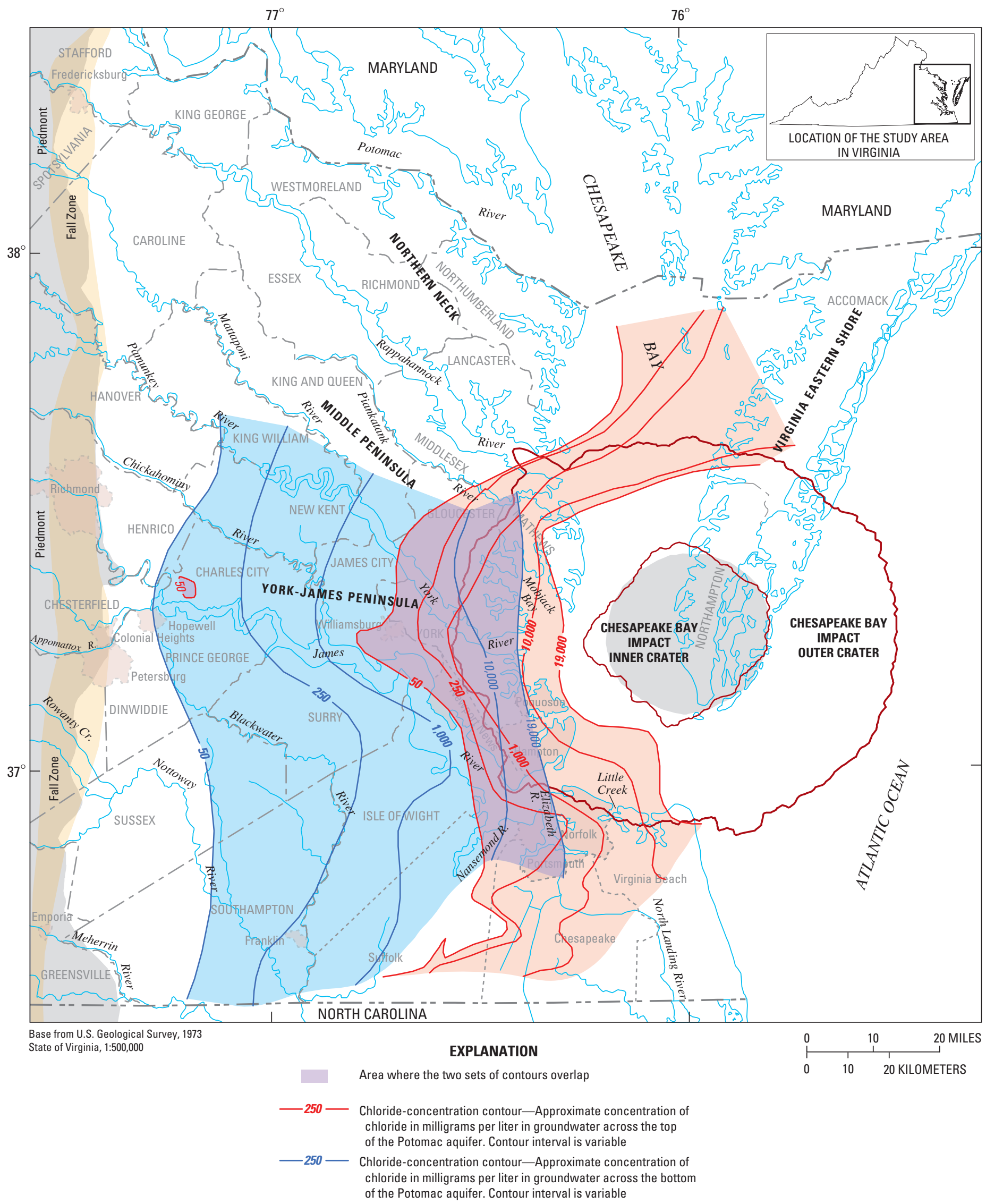

Figure 13. Approximate groundwater chloride concentrations, in milligrams per liter, across the top (red) and bottom (blue) of the Potomac aquifer in the Virginia Coastal Plain. Areas spanned by alternate sets of contours are shaded in corresponding colors. Mapped extents of contours are limited to those of chloride iso-concentration surfaces (figs. 3-7). Area outside extent of aquifer is shaded gray. Location of Chesapeake Bay impact crater from Powars and Bruce (1999). 
Groundwater chloride concentrations across the entire thickness of the Yorktown-Eastover aquifer (fig. 9) are less than $50 \mathrm{mg} / \mathrm{L}$ beneath the lower Northern Neck, upper Middle Peninsula and York-James Peninsula, and areas south of the James River across most of the city of Suffolk and westward. Conversely, greater chloride concentrations are projected beneath the lower Middle Peninsula and York-James Peninsula, areas south of the James River across the southeastern city of Suffolk, most of the city of Chesapeake and eastward, and the Virginia Eastern Shore. The area across the bottom of the aquifer where concentrations exceed $50 \mathrm{mg} / \mathrm{L}$ extends farther west than the area across the top of the aquifer, reflecting the generally landward dip of the saltwater-transition zone. Middle parts of the aquifer where concentrations exceed $50 \mathrm{mg} / \mathrm{L}$ are positioned between these two areas. The chloride "mound" (see "Chloride-Concentration Sections" and "Chloride Iso-Concentration Surfaces") is exhibited along the western part of the Chesapeake Bay impact crater, where concentrations exceed $250 \mathrm{mg} / \mathrm{L}$ across part of the top of the aquifer and $1,000 \mathrm{mg} / \mathrm{L}$ across part of the bottom of the aquifer. Concentrations greater than $50 \mathrm{mg} / \mathrm{L}$ are also projected across the city of Virginia Beach southwestward as far as the southeastern city of Suffolk, corresponding to the chloride "ridge." Additionally, beneath Chesapeake Bay and the Virginia Eastern Shore, concentrations exceeding $50 \mathrm{mg} / \mathrm{L}$ are projected across the top of the aquifer along two narrow belts, where the top of the aquifer has been incised by paleochannels (McFarland and Bruce, 2006).

Groundwater chloride concentrations are projected similarly among the Piney Point, Aquia, and Virginia Beach aquifers (figs. 10-12). Within the extent of each aquifer, concentrations are generally less than $50 \mathrm{mg} / \mathrm{L}$ beneath the lower Northern Neck, upper Middle Peninsula, and areas south of the James River across most of the city of Suffolk and westward. Greater concentrations are projected beneath the lower Middle Peninsula, most of the York-James Peninsula, areas south of the James River across the southeastern city of Suffolk, most of the city of Chesapeake and eastward, and the Virginia Eastern Shore. The chloride mound is exhibited by the conformance of large chloride concentrations in the Piney Point aquifer with the Chesapeake Bay impact crater, where concentrations exceed $19,000 \mathrm{mg} / \mathrm{L}$ (seawater concentration) within the inner crater beneath the Virginia Eastern Shore. (The Aquia aquifer does not span the Virginia Eastern Shore and the lowermost parts of the Middle Peninsula and YorkJames Peninsula, and the Virginia Beach aquifer is present only from the city of Virginia Beach westward into Southampton County.) Large concentrations in all three aquifers are also projected across the city of Virginia Beach southwestward as far as the southeastern city of Suffolk, corresponding to the chloride ridge.

Because of the large thickness of the Potomac aquifer (fig. 2) and corresponding vertical variations in groundwater chloride concentration, projected concentrations differ substantially between the top and the bottom of the aquifer (fig. 13). Across the top of the Potomac aquifer, concentrations are projected similarly to the overlying aquifers, encompassing areas as far east as the lower Northern Neck, upper Middle Peninsula, and areas south of the James River across most of the city of Suffolk with concentrations of less than $50 \mathrm{mg} / \mathrm{L}$. Farther east and also similar to overlying aquifers, greater concentrations across the top of the Potomac aquifer reflect conformance of the chloride mound with the Chesapeake Bay impact crater, where concentrations exceed 19,000 mg/L (seawater concentration) generally beneath Chesapeake Bay, and the chloride ridge across the city of Virginia Beach southwestward into the southeastern city of Suffolk.

Groundwater chloride concentrations projected across the bottom of the Potomac aquifer are greater than across the top of the aquifer and extend farther inland, exceeding $50 \mathrm{mg} / \mathrm{L}$ in proximity to the Fall Zone (fig. 13). (At an isolated location along the Fall Zone in the southwestern corner of Charles City County, chloride concentrations exceeding $50 \mathrm{mg} / \mathrm{L}$ are also projected to the top of the aquifer.) Concentrations across the bottom of the aquifer continue eastward to increase uniformly to $19,000 \mathrm{mg} / \mathrm{L}$ along the western margin of the Chesapeake Bay impact crater beneath the lowermost parts of the Middle Peninsula and York-James Peninsula, and southward into the city of Chesapeake. Thus, the area across the bottom of the Potomac aquifer where concentrations exceed $50 \mathrm{mg} / \mathrm{L}$ extends farther west by roughly $30 \mathrm{mi}$ than the area across the top of the aquifer, reflecting the broad landward dip of the saltwater-transition zone through the large thickness of the aquifer. Middle parts of the aquifer where concentrations exceed $50 \mathrm{mg} / \mathrm{L}$ are positioned between these two areas. Also, unlike the top of the Potomac aquifer, concentrations projected across the bottom of the aquifer do not reflect the chloride mound across the Chesapeake Bay impact crater, but rather exhibit a north-south trending planer configuration that results from chloride iso-concentration surfaces being truncated against basement bedrock. Although chloride concentrations greater than $50 \mathrm{mg} / \mathrm{L}$ across the bottom of the Potomac aquifer likely span much of Middle Peninsula and Northern Neck farther to the north than shown, the extent of chloride-concentration contours is constrained by that of the corresponding iso-concentration surfaces.

\section{Relations to Groundwater Flow}

The saltwater-transition zone is a major regional boundary on the groundwater-flow system. Fresh groundwater originating from recharge at the water table leaks downward into confined aquifers and, prior to large groundwater withdrawals, flowed downgradient to the east. Upon encountering dense saltwater along the coast, groundwater leaks back upward to discharge to the Atlantic Ocean, major rivers, and Chesapeake Bay. The saltwater-transition zone encompasses a volume of sediments within which dispersive mixing takes place between fresh and salty water across a density gradient.

Alternate mechanisms have been theorized to explain the origin and configuration of the saltwater-transition zone in the Virginia Coastal Plain and beyond. More than 60 years ago, 
Cederstrom (1943) described the irregular configuration of the saltwater-transition zone as a "saltwater wedge" and theorized "differential flushing" of groundwater around a "structural depression" in the area of the then-unknown Chesapeake Bay impact crater, which left residual seawater retained in the nowrecognized crater-fill sediments. Similarly, Meisler (1989) attributed large-scale lateral and vertical salinity variations across the entire North Atlantic Coastal Plain to variations in flow rates among different parts of the aquifer system and to variable sea-level fluctuations across the region. Alternatively, Manheim and Horn (1968) and Meisler (1989) cited upward diffusion of solutes from the dissolution of basement evaporite deposits for parts of the Atlantic Coastal Plain. Increases in salinity by membrane filtration (reversed osmotic movement of water between particles of clay) was also suggested by Larson (1982) for the Virginia Coastal Plain in general and by Powars and Bruce (1999) for the Chesapeake Bay impact crater specifically, as a result of loading, compaction, and dewatering of crater-fill sediments.

McFarland and Bruce (2005) reviewed the preceding works in detail and concluded on the basis of their own hydrochemical evidence that mixing of fresh groundwater and seawater has taken place along the outer margin of the Chesapeake Bay impact crater and that small amounts of brine that exceed seawater salinity by as much as 35 percent could result from a moderate degree of seawater evaporation. Subsequently using a similar approach, Sanford and others (2009b) concluded that seawater altered by heat-induced diagenesis has been retained within the inner crater since the time of the impact event and suggested that brine with concentrations as much as twice that of seawater was present in deep target sediments and(or) basement bedrock prior to the impact and were excavated to higher altitudes by the blast.

\section{Emplacement of Seawater}

Exclusive of brine (see "Brine and the Inner Chesapeake Bay Impact Crater"), both geologic and hydrochemical evidence indicates that much of the saltwater now present in Virginia Coastal Plain sediments originated from seawater, rather than evaporate dissolution or membrane filtration (McFarland and Bruce, 2005; Sanford and others, 2009b). The Atlantic Coastal Plain is contiguous with the offshore Continental Shelf, which together represent an approximately 160-mi-wide wedge of sediment that mantles the eastern margin of North America from the Fall Zone to the Atlantic Basin. Seawater has been repeatedly emplaced within various volumes of the sediment wedge as a result of partial to complete inundation by the Atlantic Ocean over the past approximately 65 million years (m.y.). The most recent complete inundation took place during the Pliocene Epoch approximately 1.8 to 5.3 m.y., when seawater likely occupied nearly the entire volume of sediments. Relatively large groundwater chloride concentrations have been attributed to apparently isolated residual seawater as far west as Fredericksburg (Subitzky, 1961).
Upon emergence of the sediment wedge, eastward and downward flowing fresh groundwater began flushing seawater from the sediments. Areas remained inundated as far west as the eastern city of Suffolk as recently as 115,000 years ago during interglacial periods of the Pleistocene Epoch, when sea levels were higher than at present by as much as $20 \mathrm{ft}$ (Bradley, 1999). Subsequently, nearly the entire sediment wedge emerged over the next approximately 95,000 years. Sea level declined as low as $390 \mathrm{ft}$ to $470 \mathrm{ft}$ below present day, during the Pleistocene glacial maximum from 18,000 to 21,000 years ago (Peltier, 1994; Bradley, 1999). The hydraulic gradient of fresh groundwater was two to four times greater than at present, and enhanced flushing emplaced freshwater throughout nearly the entire volume of sediment as the saltwater-transition zone was displaced eastward to the edge of the Continental Shelf (Heywood, 2003).

Since the Pleistocene glacial maximum, sea level has risen to its current position, and seawater has re-inundated the approximate eastern half of the sediment wedge, as well as the Pleistocene-age valley of the Susquehanna River to form Chesapeake Bay, and the valleys of several other major rivers to form large estuaries. Modern seawater is now reentering the sediments, and the saltwater-transition zone is migrating to the west. Eastward flushing by fresh groundwater, however, has continued beneath the still emergent part of the sediment wedge, but has been progressively truncated by the westward migrating saltwater-transition zone.

\section{Freshwater Flushing}

The manner in which seawater has been flushed from the sediments by fresh groundwater can be inferred from the position and configuration of the saltwater-transition zone. Although flow is currently redirected toward large withdrawal centers, the present-day saltwater-transition zone reflects pre-stress conditions because flow velocities are very slow, and groundwater has not yet been displaced over regionally appreciable distances in response to pumping.

The configuration of the saltwater-transition zone indicates that seawater has been flushed from the sediments by fresh groundwater in a complex three-dimensional fashion. The chloride "mound" that conforms with the Chesapeake Bay impact crater (see "Configuration") infers that flushing has been impeded across the impact crater as a result of broad contrasts between sediment permeabilities inside and outside the impact crater, including confining units composed of low-permeability sediments that thicken and deepen into the impact crater and(or) hydraulic barriers created by faults associated with the impact crater. Distinct zones of preferential flow, however, cannot be explicitly delineated solely on the basis of sediment composition and hydraulic properties. Individual strata within the chaotically mixed crater-fill sediments, as well as undisrupted but highly interbedded fluvial-deltaic sediments outside the impact crater, exhibit extreme compositional contrasts over very short distances (for example, as observed in sediment cores), but cannot be 
effectively correlated at a regional scale (McFarland and Bruce, 2006). Likewise, faults have been generally theorized to act alternately as either conduits or barriers to groundwater flow (Caine and others, 1996), but their distribution and structure across the impact crater have not been delineated in adequate detail to determine their hydraulic effect. Alternately, variations in groundwater chloride concentrations reflect the effective regional scale result of flushing, which has been integrated across smaller-scale hydraulic influences by mixing and dispersion.

A lateral divide of the generally eastward flow of fresh groundwater is indicated by the spur ridge on the $50 \mathrm{mg} / \mathrm{L}$, $250 \mathrm{mg} / \mathrm{L}$, and $1,000 \mathrm{mg} / \mathrm{L}$ iso-concentration surfaces that extends westward of the chloride mound beneath the YorkJames Peninsula (figs. 4-6) (see "Chloride Iso-Concentration Surfaces"). Seawater has been preferentially flushed around the Chesapeake Bay impact crater, either northeastward beneath the Middle Peninsula and Northern Neck or southeastward beneath the area south of the James River. Less flushing has taken place along the ridge where flow is divided, as also indicated by greater total ion concentrations (pl. 8). Chloride becomes the dominant anion, however, only east of Williamsburg (see "Major Ions").

Fresh groundwater deepens northeastward into the Salisbury embayment, where marked increases in the depth of basement bedrock and sediment thickness possibly provide the most transmissive path for lateral flow around the impact crater (figs. 3, 4). Fresh groundwater also deepens initially southeastward beneath Surry and Isle of Wight Counties and the city of Suffolk, but not farther beneath the cities of Chesapeake and Virginia Beach. Unlike the Salisbury embayment to the north, sediments to the south are relatively thin and shallow across the Norfolk arch, possibly precluding an effective lateral flow route. As a likely result, southeastward flushing has apparently been focused into distinct vertical intervals, as indicated by inverted chloride-concentration zones (section ES-ES', pl. 13) (see "Chloride-Concentration Sections"). Paths of differential flushing are inferred by the inverted zones, which are bounded vertically by stagnant intervals within which seawater is relatively unflushed, probably as the result of broad contrasts in sediment permeabilities.

A vertical flow divide coincides with the Norfolk arch (section ES-ES', pl. 13), from which differential flushing has either (1) continued southeastward along one path into North Carolina or (2) has been redirected northeastward into the Salisbury embayment along two parallel paths that pass beneath and undercut the chloride mound along the outer margin of the Chesapeake Bay impact crater. These latter two paths partly align in proximity to contacts between hydrogeologic units, possibly as a result of broad contrast in permeability between the units. The two paths have also entrained differential flushing from north of the spur ridge projecting from the chloride mound (section DD-DD', pl. 10). Hence, fresh groundwater originating from both north and south of the spur ridge has contributed to differential flushing along these paths across the outer crater. The two paths also are positioned at a similar altitude and are possibly contiguous with a broad and thick groundwater salinity inversion described as a "deep freshwater wedge" (Meisler, 1989) that extends from the northern part of Chesapeake Bay northeastward across the Salisbury embayment, beneath the Delmarva Peninsula to the Continental Shelf off New Jersey. Differential flushing along the paths beneath the impact-crater chloride mound possibly has acted as a feeder to the larger salinity inversion to the northeast.

The inverted configuration of the saltwater-transition zone is probably a relict feature of Pleistocene-age freshwater flushing. Inverted chloride-concentration zones indicate unstable conditions, where relatively dense saltwater is not in equilibrium hydrodynamically with underlying fresher and less dense water. Fresh groundwater is theorized to have been overridden by the Atlantic Ocean and Chesapeake Bay as a result of rapid sea-level rise and inundation of the Continental Shelf (Meisler, 1989). Fresh groundwater now occupying the sediments has taken as long as 40,000 years to flow eastward to the present-day position of the saltwater-transition zone (Nelms and others, 2003). This water had travelled only about halfway to its present position, however, by the time of the Pleistocene glacial maximum, when flushing by older freshwater had displaced the saltwater-transition zone to the far edge of the Continental Shelf (see "Emplacement of Seawater"). Since then, freshwater has continued eastward, while the coastline migrated westward at an approximately three times faster rate. Seawater has infiltrated relatively shallow sediments beneath the inundated area, but has not had adequate time to fully displace underlying freshwater, which is effectively stalled at depth. Adjustment toward a stable saltwater-transition zone configuration could be made by continued seawater emplacement, but likely preceded by complex intermediate configurations lasting for centuries (Kooi and Groen, 2000). Alternatively, with continued climatic warming, sea-level rise, and inundation, seawater will continue to override and stall an ever greater volume of fresh groundwater, thereby further propagating inversion of the saltwater-transition zone.

\section{Brine and the Inner Chesapeake Bay Impact Crater}

In contrast to the outer margin of the Chesapeake Bay impact crater, the degree of flushing by fresh groundwater across the inner crater is less certain. Brine as concentrated as twice that of seawater salinity has been observed below $-2,200 \mathrm{ft}$ in corehole $63 \mathrm{G} 69$ (pl. 3) in the inner crater (Sanford and others, 2009b). Vertical chloride-concentration variations in brine between $-1,000 \mathrm{ft}$ and $-2,200 \mathrm{ft}$ possibly have resulted from blast-induced deposition of sediment clasts having contrasting pore-water chloride concentrations from before the impact (Sanford and others, 2009b). Although paths of differential flushing correlate along inverted chlorideconcentration zones across the northwestern side of the outer crater (section DD-DD', pl. 10), they are not continuous from south to north across the inner crater (section GS-GS', pl. 14). 
Moreover, the plug-like shape of the chloride mound in the inner crater generally infers that little or no flushing has taken place, either because of decreased sediment permeabilities toward the center of the impact crater or the density of the brine creates a barrier to flow. Any flushing across the inner crater has most likely been above $-2,200 \mathrm{ft}$ and along its northwestern side in continuity with flushing into the Salisbury embayment that generally has taken place preferentially northwest of the impact crater. Below $-2,200 \mathrm{ft}$, brine in the inner crater becomes uniformly more concentrated (Sanford and others, 2009b), precluding the likelihood of any degree of flushing.

Hydrochemical evidence (McFarland and Bruce, 2005; Sanford and others, 2009b) and estimates of solute advection and diffusion rates (Sanford, 2003) further indicate that some saltwater has been retained within the inner part of the Chesapeake Bay impact crater prior to the most recent inundation by seawater, possibly as long ago as the time of the impact event. Moreover, the presence of brine in the inner crater cannot be accounted for solely by the emplacement of seawater within the sediments. The brine is theorized to have essentially maintained its present position during repeated inundation and reemergence since the impact, being largely bypassed during periods of freshwater flushing, even during the Pleistocene glacial maximum when seawater from surrounding areas was displaced as far eastward as the edge of the Continental Shelf (see "Emplacement of Seawater"). Since then, modern seawater now reentering the sediments with the current sea-level rise has merged with the brine. The presence of the brine at its observed concentrations and apparent extent, however, has not yet been fully explained, and its origin remains largely conjectural.

\section{Movement}

Movement of the saltwater-transition zone over time is of resource-management interest in relation to potential increases in chloride concentration. An understanding of past changes in chloride concentration and their relations to groundwater withdrawal is needed to anticipate possible future changes.

Heath (1983) defines "saltwater encroachment" as any movement of the saltwater-transition zone toward fresh groundwater. "Lateral encroachment" denotes withdrawalinduced horizontal movement and is referred to here by the more widely used term "intrusion." "Upconing" is also defined as vertical movement to a pumping well from an underlying volume of salty groundwater. Because upconing can result from displacement of relatively small volumes of water, it is generally regarded as a more prevalent cause of increasing concentrations of chloride in groundwater than intrusion.

Barlow and Wild (2002) reviewed movement of the saltwater-transition zone throughout the Atlantic Coastal Plain that has been documented for more than 100 years and which varies widely in form and degree under different hydrogeologic conditions. Although in general only small parts of aquifers have been affected by saltwater intrusion, some more widespread instances have also occurred. One of the most thoroughly documented is at Cape May County, New Jersey, where a comprehensive, long-term data-collection effort provided estimates of intrusion rates ranging from 92 to $220 \mathrm{feet}$ per year ( $\mathrm{ft} / \mathrm{yr}$ ) over various multidecade periods during 1940-90 (Lacombe and Carleton, 2002).

In the Virginia Coastal Plain, the potential for widespread saltwater intrusion has been recognized for at least 35 years (Lichtler and Wait, 1974). Rates of groundwater withdrawal in the Virginia Coastal Plain have increased during the past century to greater than $140 \mathrm{Mgal} / \mathrm{d}$ (fig. 14) (J.P. Pope, U.S. Geological Survey, written commun., 2009). Consequently, regional (multicounty) hydraulic gradients have been approximately doubled by widespread water-level declines as great as $200 \mathrm{ft}$ (Hammond and others, 1994a, b, c) and redirected landward toward large withdrawal centers located at varying distances west of the saltwater-transition zone.

Both intrusion and upconing in the Virginia Coastal Plain have been investigated at varying scales. Among early efforts, Cederstrom (1943) described how the onset of a rapid withdrawal within or close to salty groundwater can result in increasing chloride concentrations (presumably as a result of upconing), generally until the pumping well reaches hydraulic equilibrium. Lichtler and Wait (1974) asserted that flow gradients altered by large long-term withdrawals have created the potential for area-wide intrusion, but also acknowledged that movement rates are likely very slow. Larson (1982) concluded that increases in groundwater chloride concentration are primarily of local extent.

Relatively recent investigations have focused on different parts of the Virginia Coastal Plain, based on observed changes in chloride concentration in combination with digital simulation of concentration change and movement of the saltwatertransition zone. On the Virginia Eastern Shore, Richardson's (1994) simulation indicated no intrusion within the YorktownEastover aquifer prior to 1989, but predicted slow intrusion during a future period of 50 years. Intrusion on the Virginia Eastern Shore was also recently investigated by Sanford and others (2009a). No area-wide increases in chloride concentration were discerned from groundwater samples collected between the early 1980s and 2003, but localized increases of as much as $300 \mathrm{mg} / \mathrm{L}$ during 2003-2050 were predicted by simulation. On the York-James Peninsula, Smith (1999) identified a concentration increase in only one well from a network of wells, from 2,000 to 2,400 mg/L between 1984 and 1996. Simulation indicated intrusion within the Potomac aquifer, however, at rates of approximately 7 to $115 \mathrm{ft} / \mathrm{yr}$ over various multidecade periods during 1890-1997. Upconing was also simulated to result from a typical hypothetical production well and was determined to occur within the volume of the aquifer within $100 \mathrm{ft}$ below the well. 

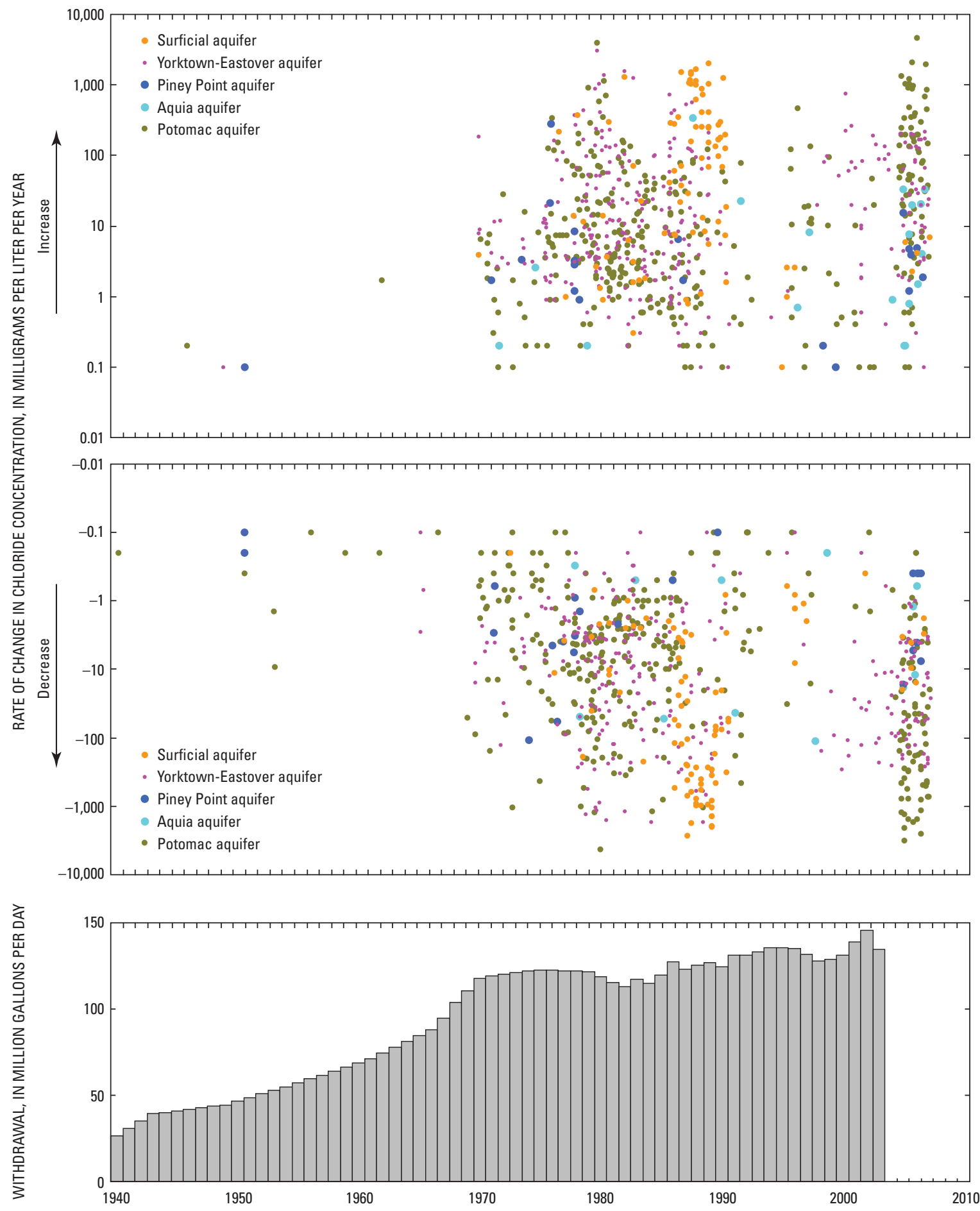

Figure 14. Rates of change in concentrations of chloride in groundwater and yearly averaged rates of groundwater withdrawal reported by regulated groundwater users. Rates of concentration change are based on samples from 518 wells used to calculate 1,749 rates and are plotted relative to the midpoint in time of two sequential samples having a collection interval of 90 days or greater. Withdrawal data are unavailable beyond 2003. 


\section{Rates of Change in Chloride Concentration}

The compiled groundwater-quality data were used to determine changes in the concentration of chloride in groundwater over time. Because groundwater samples from separate wells located in proximity can exhibit substantial differences in chloride concentration, samples collected multiple times from individual wells are needed to indicate concentration changes at specific geographic locations and depths. Of the 6,650 samples analyzed for chloride (Attachment 2), 5,565 represent two or more samples collected sequentially and from the same depth in 631 wells.

Chloride concentrations among sequentially collected groundwater samples vary widely, ranging from zero to $24,000 \mathrm{mg} / \mathrm{L}$ (table 2). Most concentrations, however, are relatively small: 70 percent are $234 \mathrm{mg} / \mathrm{L}$ or less, and the median concentration is $52 \mathrm{mg} / \mathrm{L}$. The number of samples collected from each well also varies widely, ranging from 2 to 266. Most wells, however, were sampled relatively few times: 70 percent of the wells were sampled 8 times or less, and the median number of samples per well is 4 .

The duration of sequential sample collection at each well ranges from zero to 62 years, with 70 percent of the wells sampled over a period of 10 years or less, and the median duration is 5.8 years (table 2). The frequency of sample collection at each well also varies widely. Some samples were collected on the same day, whereas others are separated by as much as 22,480 days (62 years). Most samples, however, were collected within relatively short timeframes: 70 percent of samples were collected within 141 days or less from the previous sample, and the median period between sequential pairs of samples is 96 days.

Samples collected from 518 wells were used to calculate 1,749 rates of change in groundwater chloride concentration, as the differences in concentration between each sequential pair of groundwater samples collected at each well, divided by the periods of time between sample collection. Rates of concentration change provide a consistent basis for comparing changes in groundwater chloride concentration over time, by accounting for the widely varying periods of time between the collection of sequential samples. Calculation of rates of concentration change included samples (1) designated as having acceptably accurate chloride concentrations (see
"Configuration"), based on major ion charge balance and correlation with specific conductance, and (2) collected sequentially from each well 90 days or more apart, to eliminate duplicate samples collected on the same day, concentration differences resulting primarily from sample collection and(or) analysis error, and unrealistically large rates of concentration change that exceed the range of observed concentrations.

Rates of change in groundwater chloride concentration range from increases as rapid as 4,603 milligrams per liter per year ( $\mathrm{mg} / \mathrm{L} / \mathrm{yr}$ ) to decreases as rapid as $-4,284 \mathrm{mg} / \mathrm{L} / \mathrm{yr}$ (a minus sign denotes a concentration decrease) (table 2). Most rates, however, are relatively small: 70 percent have magnitudes within plus or minus (+/-) $23 \mathrm{mg} / \mathrm{L} / \mathrm{yr}$, and the median rate magnitude is $+/-6 \mathrm{mg} / \mathrm{L} / \mathrm{yr}$.

Rates of concentration change vary widely and sporadically (fig. 14), both collectively and within major water-supply aquifers. Increases in chloride concentration coincide with decreases throughout the period of sample collection. Neither increases nor decreases appear to become more frequent, or to change in magnitude, as groundwater withdrawal increased during the period. Thus, the overall change in chloride concentration is small, with a mean rate of concentration change of $-3.4 \mathrm{mg} / \mathrm{L} / \mathrm{yr}$. The rates primarily represent changes in groundwater chloride concentration during 1970-2006, however, with only a few rates calculated for earlier periods. Most of the rates are calculated from a large number of samples collected during approximately $1970-90$ and again during 2004-06, with fewer samples collected during the intervening period.

Rates of change in groundwater chloride concentration exhibit some contrasts spatially among different parts of major water-supply aquifers (figs. 15-19). Across the sampled extent of each aquifer, both decreasing rates of concentration and increasing rates of moderate magnitude (up to $20 \mathrm{mg} / \mathrm{L} / \mathrm{yr}$ ) are generally widespread. More rapid rates of increasing chloride concentration, however, appear for some aquifers to be constrained to specific areas. Also noted, and of particular resource-management interest, are locations where an initial chloride concentration below the U.S. Environmental Protection Agency (1990) secondary maximum contaminant level of $250 \mathrm{mg} / \mathrm{L}$ has increased to above $250 \mathrm{mg} / \mathrm{L}$.

Table 2. Summary of sequentially collected groundwater samples.

[mg/L, milligram per liter; yr, year; $\mathrm{mg} / \mathrm{L} / \mathrm{yr}$, milligram per liter per year $]$

\begin{tabular}{lrrrr}
\hline & Minimum & Maximum & 70th percentile & Median \\
\hline Chloride concentration (mg/L) & 0 & 24,000 & 234 & 52 \\
Samples per well & 2 & 266 & 8 & 4 \\
Duration of sample collection (yr) & 0 & 62 & 10 & 5.8 \\
Frequency of sample collection (days) & 0 & 22,480 & 141 & 96 \\
Rate of chloride-concentration change $^{1}$ (mg/L/yr) & $-4,284$ & 4,603 & $+/-23$ & $+/-6$ \\
\hline
\end{tabular}

${ }^{1}$ Based on samples from 518 wells used to calculate 1,749 rates. 


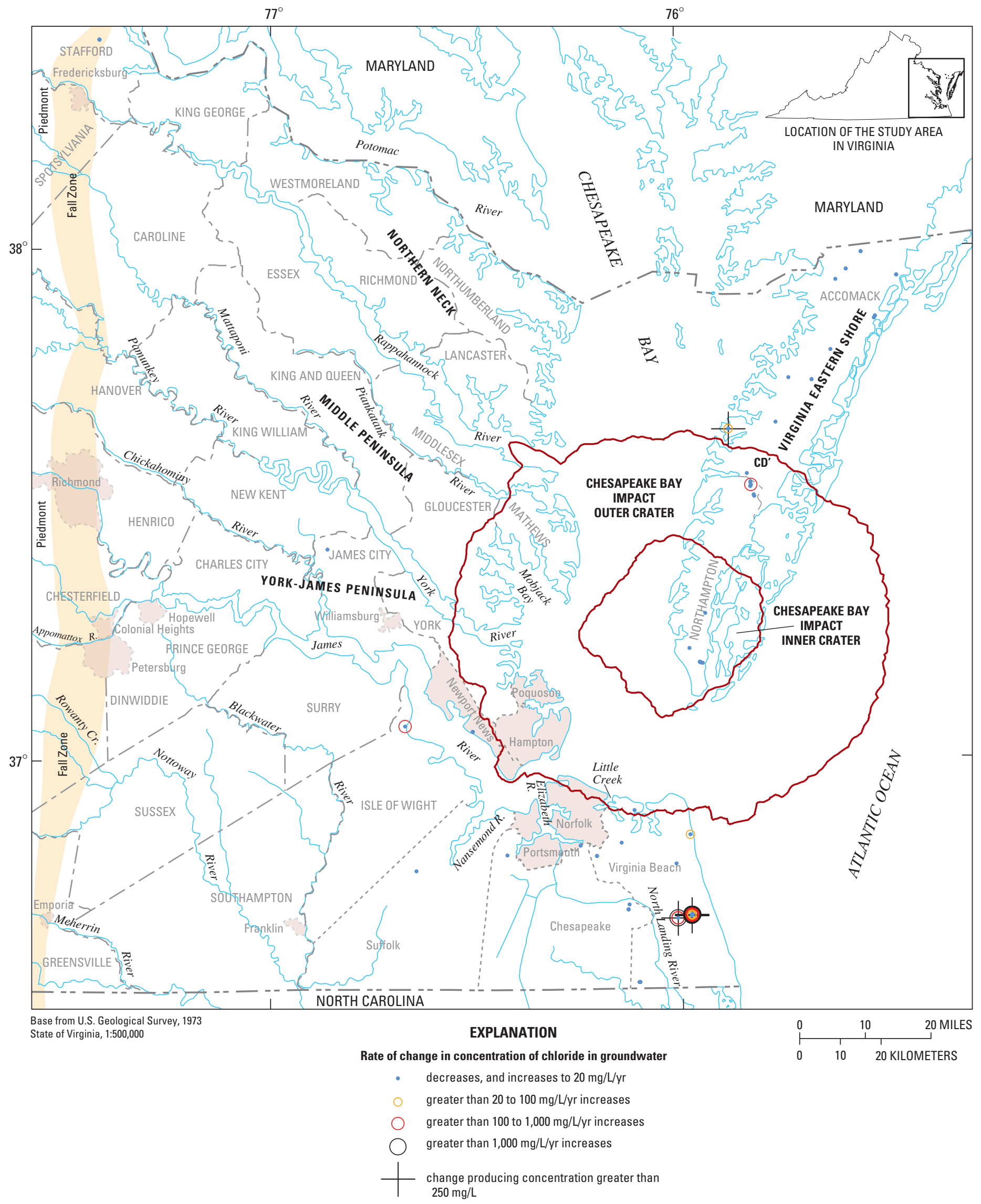

Figure 15. Rates of change in concentrations of chloride in groundwater in the surficial aquifer of the Virginia Coastal Plain. Rate values are calculated from 186 changes in chloride concentration over periods of 90 days or greater during 1970-2006 in 55 wells. Location of Chesapeake Bay impact crater from Powars and Bruce (1999). [mg/L, milligrams per liter; mg/L/yr, milligrams per liter per year] 


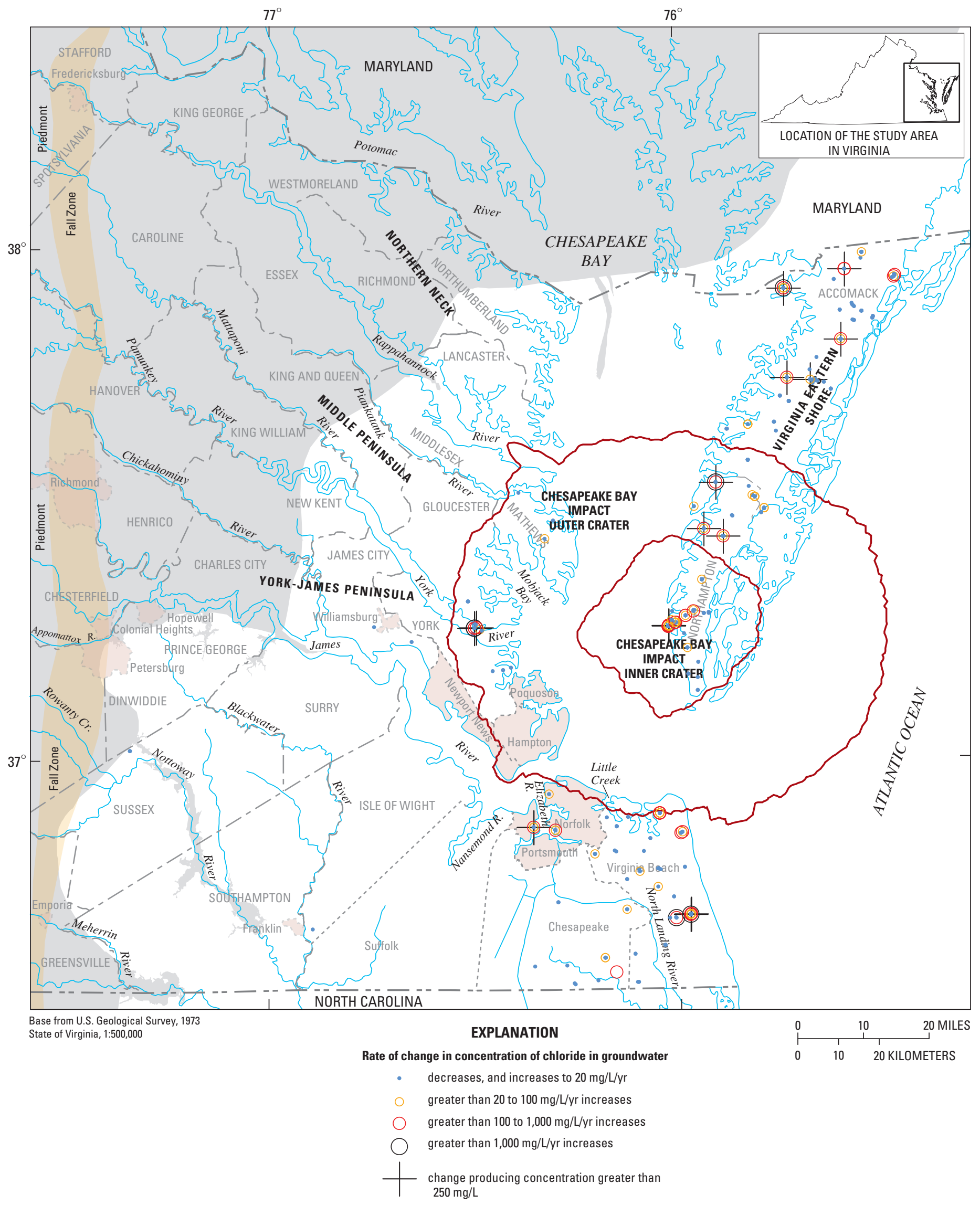

Figure 16. Rates of change in concentrations of chloride in groundwater in the Yorktown-Eastover aquifer of the Virginia Coastal Plain. Rate values are calculated from 634 changes in chloride concentration over periods of 90 days or greater during 1969-2006 in 174 wells. Area outside extent of aquifer is shaded gray. Location of Chesapeake Bay impact crater from Powars and Bruce (1999). [mg/L, milligrams per liter; mg/L/yr, milligrams per liter per year] 


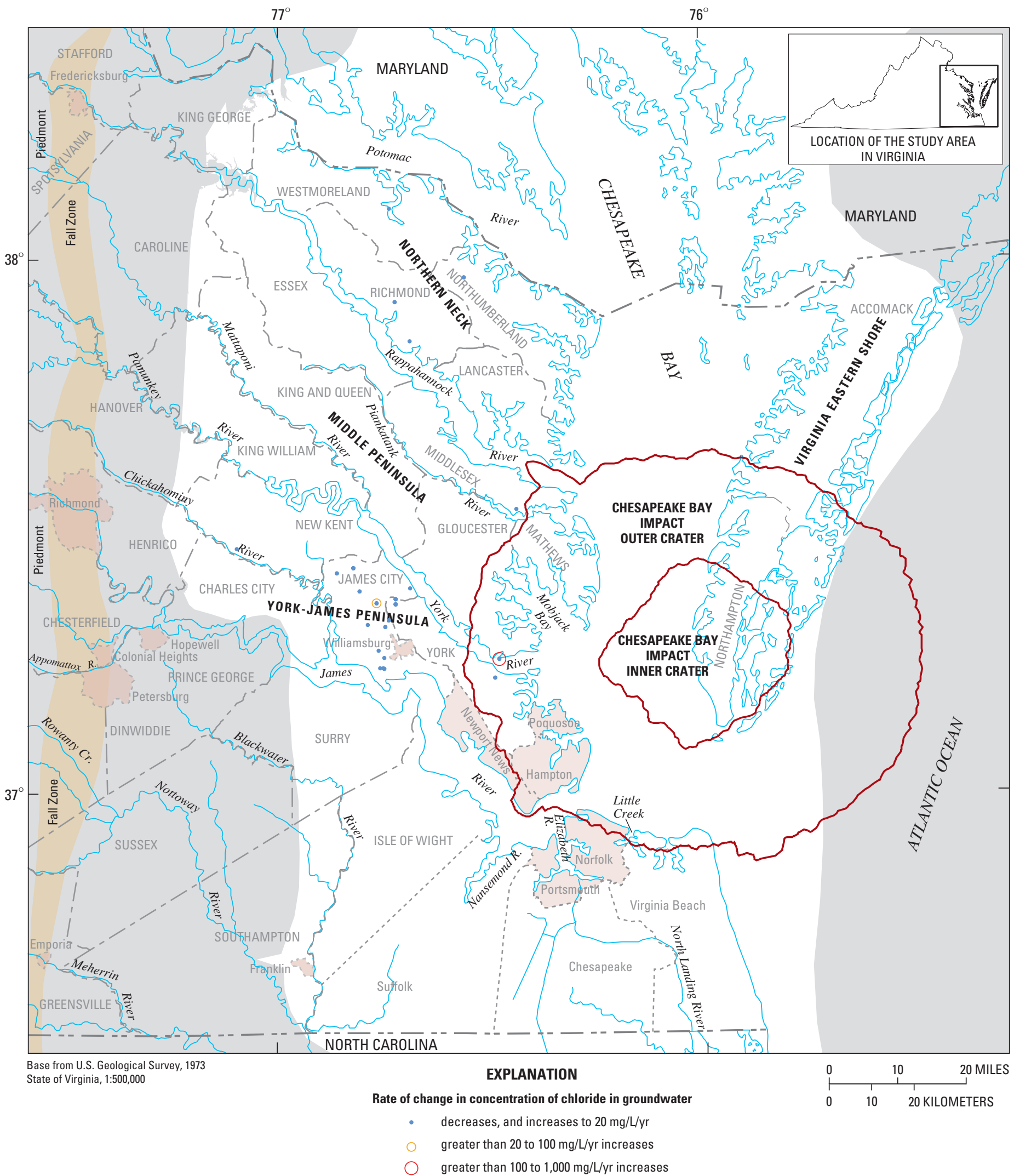

Figure 17. Rates of change in concentrations of chloride in groundwater in the Piney Point aquifer of the Virginia Coastal Plain. Rate values are calculated from 47 changes in chloride concentration over periods of 90 days or greater during 1953-2006 in 23 wells. Area outside extent of aquifer is shaded gray. Location of Chesapeake Bay impact crater from Powars and Bruce (1999). [mg/L/yr, milligrams per liter per year] 


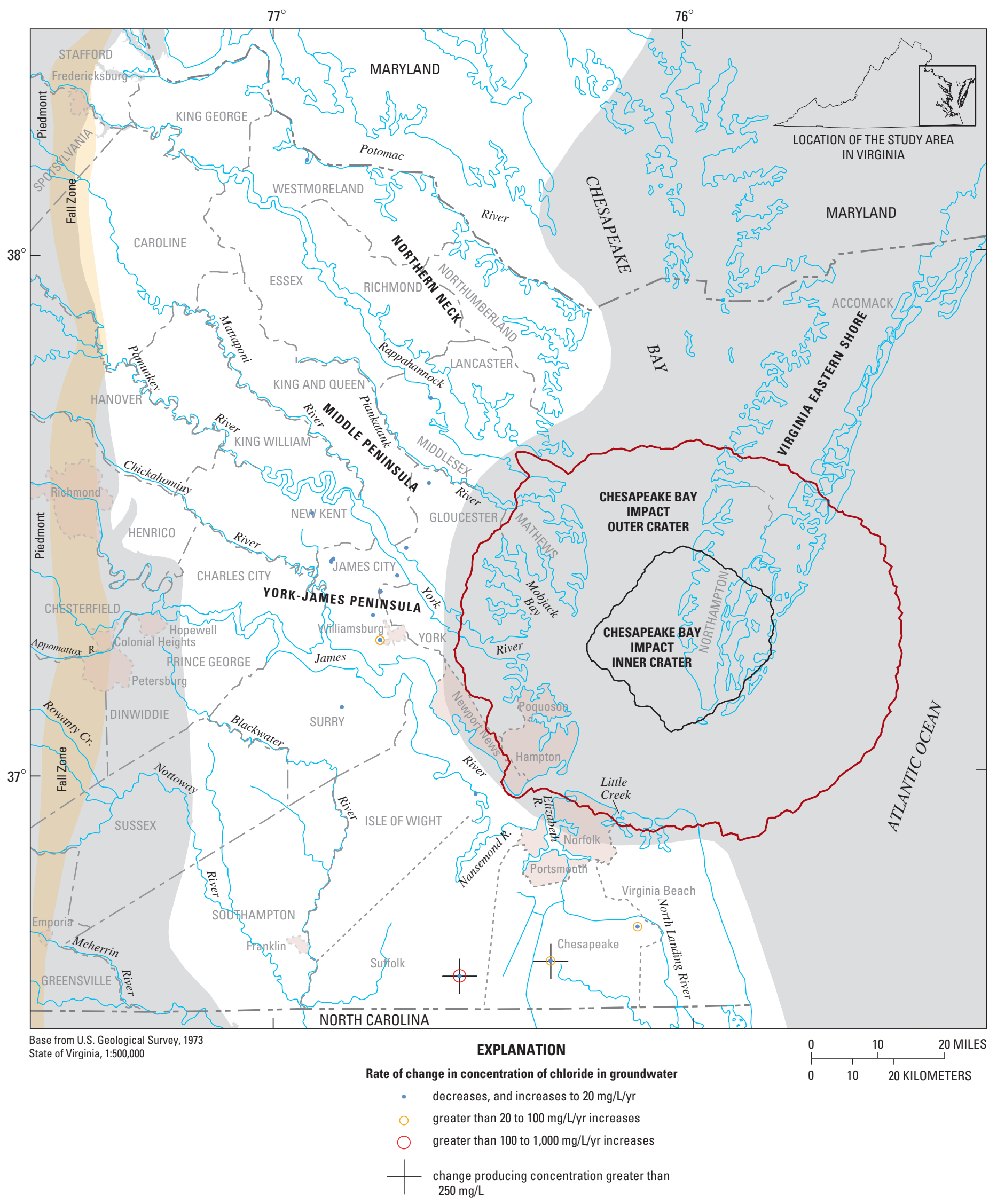

Figure 18. Rates of change in concentrations of chloride in groundwater in the Aquia aquifer of the Virginia Coastal Plain. Rate values are calculated from 39 changes in chloride concentration over periods of 90 days or greater during 1972-2006 in 16 wells. Area outside extent of aquifer is shaded gray. Location of Chesapeake Bay impact crater from Powars and Bruce (1999). [mg/L, milligrams per liter; mg/L/yr, milligrams per liter per year] 


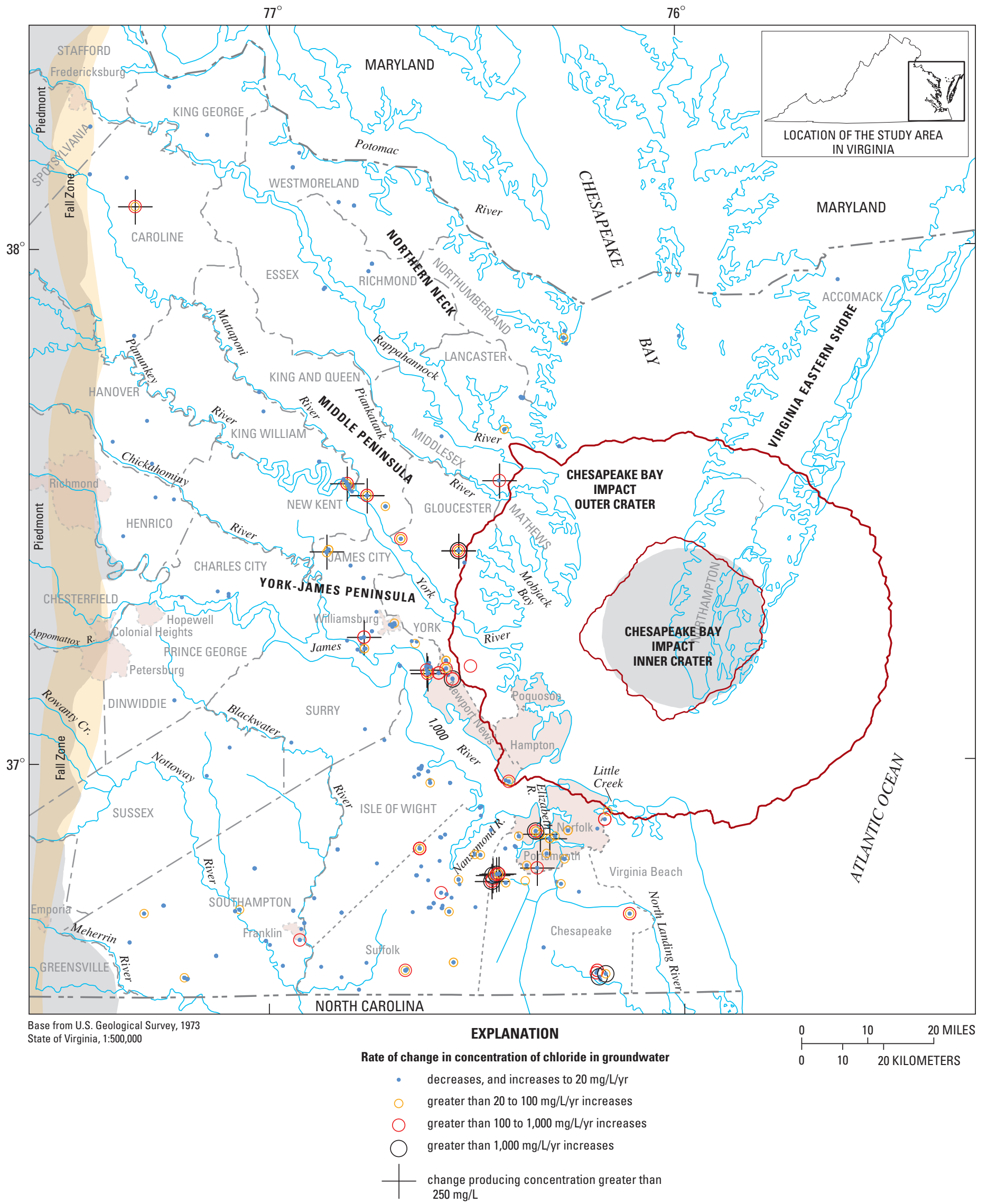

Figure 19. Rates of change in concentrations of chloride in groundwater in the Potomac aquifer of the Virginia Coastal Plain. Rate values are calculated from 807 changes in chloride concentration over periods of 90 days or greater during 1948-2006 in 229 wells. Area outside extent of aquifer is shaded gray. Location of Chesapeake Bay impact crater from Powars and Bruce (1999). [mg/L, milligrams per liter; mg/L/yr, milligrams per liter per year] 
At many locations exhibiting rapid rates of increasing chloride concentration, decreasing or moderately increasing rates of chloride concentration are also indicated (figs. 15-19). These contrasting colocated rates potentially reflect different changes in chloride concentration over time among samples collected from a single well, or alternatively among samples collected from different colocated wells, or some combination. Contrasting rates among samples collected from different wells potentially reflect different changes in chloride concentration within vertically separated parts of a single aquifer.

In the surficial aquifer, 186 rates of change in chloride concentration were calculated on the basis of samples collected during 1970-2006 from 55 wells, located mostly toward the coast (fig. 15). Decreasing rates and increasing rates of moderate magnitude are indicated across the sampled extent. Only a few rapid rates of increase are indicated at relatively isolated locations, including two on the Virginia Eastern Shore, another in far northern Isle of Wight County, and two more in proximity in the city of Virginia Beach. Three of these locations also correspond to increases in chloride concentration above $250 \mathrm{mg} / \mathrm{L}$.

In the Yorktown-Eastover aquifer, 634 rates of change in chloride concentration were calculated on the basis of samples collected during 1969-2006 from 174 wells, located mostly toward the coast (fig. 16). Decreasing rates and increasing rates of moderate magnitude are indicated across the sampled extent. Rapid rates of increase are also widespread, however, including several locations spanning much of the Virginia Eastern Shore, one location near the mouth of the York River, and several locations south of Chesapeake Bay. Several of these locations also correspond to increases in chloride concentration above $250 \mathrm{mg} / \mathrm{L}$.

In the Piney Point aquifer, 47 rates of change in chloride concentration were calculated on the basis of samples collected during 1953-2006 from 23 wells, located mostly within and near James City County on the York-James Peninsula (fig. 17). Almost all locations indicate decreasing rates or increasing rates of moderate magnitude. Only one location in James City County and another near the mouth of the York River indicates rapid rates of increase. No increases in concentration above $250 \mathrm{mg} / \mathrm{L}$ are indicated.

In the Aquia aquifer, 39 rates of change in chloride concentration were calculated on the basis of samples collected during 1972-2006 from 16 wells at widely scattered locations (fig. 18). Most locations indicate decreasing rates or increasing rates of moderate magnitude. Rapid rates of increase are indicated at solitary locations near Williamsburg, in southeastern city of Suffolk, and in central and far eastern city of Chesapeake. Two of these locations also correspond to increases in chloride concentration above $250 \mathrm{mg} / \mathrm{L}$.

In the Potomac aquifer, 807 rates of change in chloride concentration were calculated on the basis of samples collected during 1948-2006 from 229 widely located wells (fig. 19). Decreasing rates and increasing rates of moderate magnitude are indicated across the sampled extent. Rapid rates of increase are also indicated at many locations toward the coast, but spanning areas farther inland than the locations of rapid rates of increase in shallower aquifers. Locations of rapid rates of increase in the Potomac aquifer generally form two, broadly fan-shaped areas flanking the outer margin of the Chesapeake Bay impact crater: (1) from the upper parts of the Middle Peninsula and York-James Peninsula, extending to the east and south, and (2) from southern Southampton County, extending and broadening to the east and northeast across the cities of Suffolk, Chesapeake, Portsmouth, and Norfolk. The two areas are separated by a band of locations across Isle of Wight County, almost entirely indicating decreasing rates or increasing rates of moderate magnitude. A rapid rate of increase is also indicated at a solitary outlying location to the far northwest in Caroline County. Many of the locations of rapid rates of increase also correspond to increases in chloride concentration above $250 \mathrm{mg} / \mathrm{L}$.

\section{Patterns of Change in Chloride Concentration}

Temporal changes in chloride concentrations in individual wells were also examined to determine possible relations to groundwater withdrawal. Because most wells have been sampled only a few times over a short period and exhibit relatively small chloride concentrations, data from wells having the longest duration and greatest frequency of sample collection, as well as relatively large chloride concentrations, were examined. In some instances, other wells are in proximity to those selected, but have either not been extensively sampled or are completed in different aquifers having small chloride concentrations. Conversely, from the selected wells, chloride concentrations of all samples were included for examination to provide the most complete record possible for each well needed to discern patterns of concentration change. Yearly averaged rates of groundwater withdrawal, reported through 2003 to the DEQ by regulated groundwater users (J.P. Pope, U.S. Geological Survey, written commun., 2009), were used to determine possible relations to changes in chloride concentration.

Although variations among groundwater chloride concentrations at each well are unique, three patterns of change are generally apparent from examination, which are represented by two examples (figs. 20-21). The first example is represented by well $60 \mathrm{C} 61$, completed in the Yorktown-Eastover aquifer in the city of Portsmouth (pl. 2). Groundwater samples from well 60C 61 increased from less than $500 \mathrm{mg} / \mathrm{L}$ in 1990 to approximately $3,500 \mathrm{mg} / \mathrm{L}$ by 2000 (fig. 20). Chloride concentrations fluctuated moderately between sequential samples throughout the period and also fluctuated markedly but ephemerally during 1999 , with a sharp decrease followed by a similar increase. During 2000-2004, concentrations generally stabilized with moderate fluctuation between 3,000 and 3,500 $\mathrm{mg} / \mathrm{L}$.

All reported groundwater withdrawals in proximity to well 60C 61 are from the Yorktown-Eastover aquifer, and are from several locations across an approximately 2 -mi-wide area. Their combined withdrawal rate increased during 

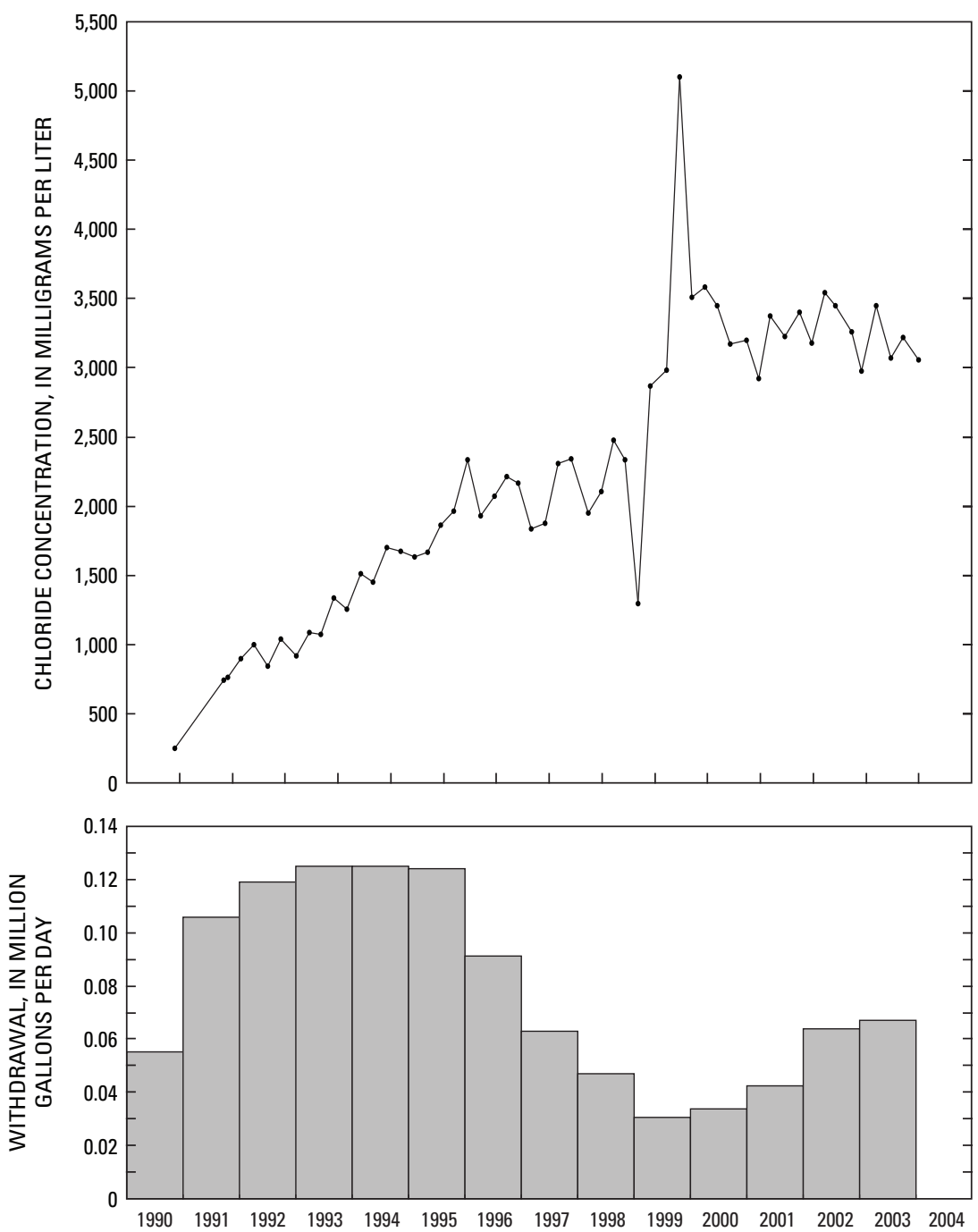

Figure 20. Chloride concentrations in groundwater in well 60C 61 at Portsmouth, Virginia, and yearly averaged rates of groundwater withdrawal reported by regulated groundwater users at nearby locations. Withdrawal data are unavailable beyond 2003.

1990-93, remained steady during 1994-95, decreased during 1996-99, and increased again during 2000-2003 but only to approximately half of the earlier rate (fig. 20). Groundwater chloride concentration in well 60C 61 generally increased during the periods of both increasing and steady withdrawal, and continued to increase during the period of withdrawal decrease. Chloride concentration then stabilized while withdrawal was moderately increased.

None of the other examined wells exhibit sustained and substantially increasing trends in chloride concentration similar to well 60C 61. Instead, either broad patterns of gradual, relatively small concentration change or punctuated patterns of numerous short-term fluctuations in concentration are indicated. Most of the examined wells are solitary and not in proximity to another examined well.

The most complete example of both broad and punctuated patterns of concentration change is represented by nine examined wells located in the central part of the York-James Peninsula. Groundwater samples having relatively large chloride concentrations were frequently collected during 1984-2006 (fig. 21) from these nine wells located within 1 to 2 mi of each other (pl. 2). All of the wells are completed in the Potomac aquifer and are colocated in groups of two or three at four different locations.

A broad pattern of concentration change is represented by the colocated wells $58 \mathrm{~F} 50,58 \mathrm{~F} 51$, and $58 \mathrm{~F} 52$, from each of which seven to eight samples were collected during 1984-99 (fig. 21). Samples from the deepest among these wells, 58F 50, have the greatest chloride concentrations, which gradually increased from approximately 2,100 to 2,600 mg/L. Samples from the shallower wells 58F 51 and 58F 52 have smaller concentrations that vary within less than $100 \mathrm{mg} / \mathrm{L}$.

A punctuated pattern of concentration change is represented by the other six wells, which are colocated in pairs at three locations, and from each of which approximately four samples per year were collected during 1998-2006 (fig. 21). Chloride concentrations fluctuate among these samples, some by as much as several $100 \mathrm{mg} / \mathrm{L} / \mathrm{yr}$. Samples from the 

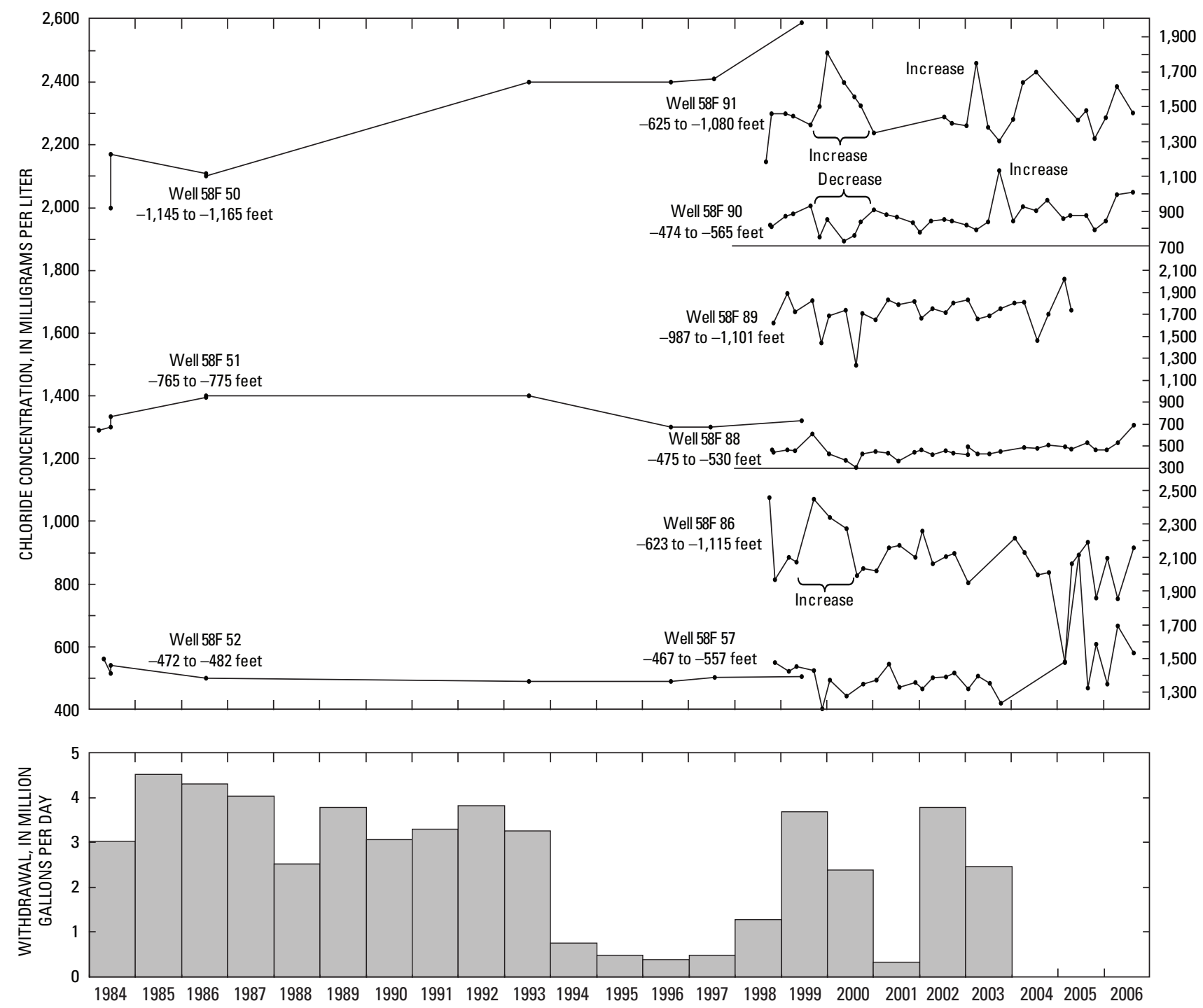

Figure 21. Chloride concentrations in groundwater in selected wells on the central York-James Peninsula, Virginia, and yearly averaged rates of groundwater withdrawal reported by regulated groundwater users at nearby locations. Colocated wells are grouped as shown. Withdrawal data are unavailable beyond 2003. Sample-collection interval altitude datum is National Geodetic Vertical Datum of 1929. 
deeper of the two wells at each location have both the greatest chloride concentrations and generally the largest fluctuations among samples.

Reported groundwater withdrawals in proximity to the nine examined wells in the central part of the York-James Peninsula are entirely from the Potomac aquifer and are located across an approximately 5-mi-wide area. Their combined withdrawal rate was relatively large during 1984-93, but decreased markedly during 1994-98 (fig. 21). Withdrawal then increased during 1999-2000, decreased markedly during 2001, and increased again during 2002-03. Groundwater chloride concentration in well 58F 50 increased during the initial period of large withdrawal, remained steady while withdrawal decreased, and increased again as withdrawal increased. Relations to withdrawal are less apparent from the small variations in chloride concentration in the two shallower colocated wells 58F 51 and 58F 52. Among the other six wells, chloride in the relatively deep wells 58F 91 and 58F 86 initially increased in concentration as groundwater withdrawal increased during 1999-2000, but then decreased to earlier concentrations. Conversely, a similarly ephemeral decrease in concentration occurred in the relatively shallow well 58F 90 during the same period. During the second withdrawal increase of 2002-03, concentrations in well 58F 86 fluctuated sporadically, while only a single sample collected from well 58F 91 in early 2003 had an increased chloride concentration, and well $58 \mathrm{~F} 90 \mathrm{had}$ a similar solitary increase later the same year. Relations to withdrawal are less apparent from the concentration fluctuations in wells $58 \mathrm{~F} 87,58 \mathrm{~F} 88$, and $58 \mathrm{~F} 89$ that were relatively small throughout 1998-2003. Withdrawal data are unavailable beyond 2003 with which to compare to later fluctuations in concentration.

The broad pattern of change in groundwater chloride concentration represented by the colocated wells $58 \mathrm{~F} 50$, $58 \mathrm{~F} 51$, and $58 \mathrm{~F} 52$ possibly is an artifact of the relatively low frequency of sample collection, as long as several years between sequential samples (fig. 21). Fluctuating concentrations similar to those in the other six wells in the central part of the York-James Peninsula likely would be observed, if sample collection was increased to a similar frequency.

\section{Intrusion and Upconing}

Based on general considerations, previous investigations, and results presented herein, primarily localized movement of the saltwater-transition zone resulting from groundwater withdrawal is most apparent in the Virginia Coastal Plain. Likewise, regional intrusion has probably not occurred. Large withdrawals that have steepened and redirected regional hydraulic gradients apparently have derived much of the water by release from storage and have not been imposed long enough to displace water across multicounty areas. Moreover, given current understanding of the emplacement of the saltwater-transition zone, its overall position and configuration have evolved over a geologic time scale of tens of thousands of years and, thus, will not establish a hydrodynamically stable configuration for centuries into the future (see "Relations to Groundwater Flow"). The amount of time needed under present conditions for regional intrusion to take place is uncertain, but could potentially be very long by human standards.

Within the preceding context, the compiled groundwaterquality data can provide a perspective on withdrawal-induced movement of the saltwater-transition zone. Implicit is that a change in groundwater chloride concentration reflects movement of the saltwater-transition zone in some form. Locations of rapid rates of increase in chloride concentration (figs. 15-19) indicate where movement toward a volume of relatively fresh groundwater likely has occurred. Where these locations have been determined with sufficient density and extent in the Yorktown-Eastover and Potomac aquifers (figs. 16, 19, respectively), they generally delineate areas where movement has been relatively prevalent. These areas primarily overlie or flank the chloride mound and ridges (see "Chloride Iso-Concentration Surfaces"), where the saltwatertransition zone is shallow and likely to be intercepted by production wells. Rapid rates of concentration increase in the Potomac aquifer, however, also extend northwestward to the upper Middle Peninsula and York-James Peninsula, and southwestward to southern Southampton County, where the saltwater-transition zone is relatively deep. Chloride concentrations can be as great as $1,000 \mathrm{mg} / \mathrm{L}$ toward the bottom of the Potomac aquifer in these areas (fig. 13), where pumping from sufficiently deep wells can cause concentrations to increase.

Lateral intrusion cannot be distinguished from vertical upconing based solely on the calculated rates of increase in groundwater chloride concentration. Instances of a sustained increasing trend, however, are possibly more likely to result from intrusion than upconing. As one example in the relatively shallow Yorktown-Eastover aquifer, well 60C 61 (fig. 20) is in proximity to a brackish water embayment of the James River (pl. 2). The aquifer is projected there to be incised along the shoreline (McFarland and Bruce, 2006) from which localized intrusion of brackish surface water has possibly been induced by nearby groundwater withdrawals. As another example in a deep part of the Potomac aquifer, gradual increases in chloride concentrations in well 58F 50 coincided with periods of large or increasing withdrawal (fig. 21). Common to both the Yorktown-Eastover and Potomac aquifer examples, chloride concentrations stabilized but did not decrease with the decrease in withdrawal, suggesting that lateral advancement of the saltwater-transition zone slowed or stopped, but was not followed by recession to its earlier position.

In contrast to the sustained increases in groundwater chloride concentration resulting from intrusion, upconing possibly is reflected by more ephemeral concentration increases. Both increases and decreases in chloride concentration are widely indicated at varying rates throughout the period of sample collection (fig. 14). Moreover, at many of the locations of rapid rates of increase, decreasing rates are also indicated (figs. 15-19). In individual wells, chloride concentration has commonly fluctuated among sequentially collected samples, 
including increases such as those in wells $58 \mathrm{~F} 91$ and $58 \mathrm{~F} 86$ that were followed by decreases to earlier concentrations

(fig. 21).

Upconing is at least partly accounted for by the relation originally described by Ghyben (1888) and Herzberg (1901) as:

$$
d_{s}=h_{f}\left(\rho_{f} d_{f} /\left(\rho_{s}-\rho_{f}\right)\right),
$$

where

$\begin{array}{ll}d_{s} & \text { is depth of saltwater below sea level, } \\ h_{f} & \text { is the freshwater head above sea level, } \\ \rho_{f} & \text { is density of freshwater, and } \\ \rho_{s} & \text { is density of saltwater. }\end{array}$

By this relation, and given approximate densities of freshwater and seawater, a decline in freshwater head of $1 \mathrm{ft}$ resulting from groundwater withdrawal would correspond proportionately to a rise in saltwater of $40 \mathrm{ft}$. Conversely, recovery of freshwater head upon decrease or cessation of withdrawal would result in a proportional deepening of saltwater. The freshwater in effect "floats" in dynamic equilibrium on the more dense saltwater beneath. Actual conditions are made more complex, however, by dispersion between the volumes of freshwater and saltwater, heterogeneities among sediment hydraulic properties, and groundwater being under flowing rather than static conditions (Heath, 1983).

In addition to fluctuating groundwater chloride concentrations, groundwater withdrawal at many locations in proximity to the saltwater-transition zone has historically been episodic (Focazio and Speiran, 1993). Pumping rates typically vary in response to high water demands, either seasonally or over longer periods during droughts, which are interrupted by extended periods of no withdrawal. Hence, the general prevalence of fluctuating chloride concentrations probably reflects numerous punctuated instances of withdrawal-induced upconing of salty groundwater, followed by its downward recession or "downconing" upon a decrease or cessation of withdrawal. Cycles of upconing and downconing can potentially occur repeatedly in proximity to a single production well. Although the relative prevalence of upconing versus intrusion is unknown, distances of vertical displacement are generally much smaller than those of horizontal displacement, and upconing is widely regarded as the more frequent cause of increasing groundwater chloride concentrations (Heath, 1983). Potentially, both intrusion and upconing can coincide in various combinations, although the overall amount of movement has so far remained localized.

Relations are not entirely apparent between the yearly averaged rates of reported groundwater withdrawals and all chloride-concentration fluctuations in the examined wells (see "Patterns of Change in Chloride Concentration"). Closely spaced production wells are commonly operated at different times by different water authorities and as a result have divergent pumping histories. Different wells can thereby make up the averaged rate from one year to the next. Moreover, the reported rates do not represent all withdrawals. The DEQ requires reporting of groundwater withdrawals only from those users of 300,000 gallons or more per month. Users of smaller amounts are exempt from reporting requirements, but are known anecdotally through local supply-well drillers to be numerous and widespread (T.S. Bruce, Virginia Department of Environmental Quality, oral commun., 2009). Thus, complex hydraulic interactions and associated changes in chloride concentration are likely to result from a continually varying array of supply wells taken in and out of production and which are only partly known.

\section{Monitoring}

Increases in groundwater chloride concentration in the Virginia Coastal Plain are often ephemeral, probably resulting from individual instances of localized upconing, and reversible to varying degrees with a decrease or cessation of the associated withdrawal (see "Intrusion and Upconing"). A greater concern exists for lateral intrusion, which potentially represents an essentially permanent repositioning of the saltwater-transition zone. Although the timing remains uncertain, intrusion in the Virginia Coastal Plain will eventually broaden as long as large groundwater withdrawals continue. Accordingly, some form of monitoring of intrusion is regarded as necessary to provide advanced detection of the likely threat to the water supply.

Intrusion monitoring throughout the Atlantic Coastal Plain has most widely entailed collection and analysis of groundwater samples over time from various networks of wells. In addition, geophysical methods in boreholes and at the land surface are continually being refined and increasingly applied, which have advantages in providing broad and cost-efficient indications of movement of the saltwatertransition zone. Geophysical methods generally entail various indirect measurements, however, and require some form of direct observation to interpret the results. Hence, groundwater sampling will likely continue to provide the baseline of information necessary for intrusion monitoring.

The compiled groundwater-quality data were used to indicate where movement of the saltwater-transition zone toward a volume of relatively fresh groundwater has likely occurred and been relatively frequent, and to determine some relations between groundwater withdrawal and different forms of movement (see "Intrusion and Upconing"). The data are a combined result, however, of numerous well-sampling programs undertaken at different times by various entities to achieve diverse objectives. Conversely, the sampled wells do not collectively make up a single consistent network designed and maintained for the express purpose of monitoring intrusion. Most wells have been sampled either once or only a few times over a short period and not in the coordinated fashion with other wells needed to systematically detect movement of the saltwater-transition zone. Likewise, most wells are not optimally located and designed for monitoring.

A minority of samples among the compiled groundwaterquality data were collected as part of a network for intrusion 
monitoring currently (2009) being maintained by the USGS in cooperation with HRPDC and the DEQ. A program of annual groundwater-sample collection in the Virginia Coastal Plain began in 1997. Initially, a network of approximately 90 wells was planned to be sampled on a rotating basis of 20 wells per year, with the entire network to begin a new cycle of sampling on a 5-year interval. The network has since been modified, with the addition of newly drilled wells and omission of wells damaged, destroyed, or otherwise becoming unavailable or deemed unsuitable. Sampling frequency has also been reduced, on average by half.

At present, the intrusion monitoring network includes 113 wells. Many of the wells are grouped among 24 locations, including from 2 to as many as 8 wells each. Groundwater chloride concentrations exceed $100 \mathrm{mg} / \mathrm{L}$ in 67 of the wells. Wells are currently prioritized for sampling based on those exhibiting relatively large chloride concentrations and possible increasing trends in concentration, although 20 of the wells have so far been sampled only once. None of the current network wells were constructed solely for intrusion monitoring. Rather, access for sampling has been gained to production wells and to observation wells located at or near production facilities that were constructed to satisfy various regulatory requirements. In addition, research observation wells grouped at several locations have been constructed and maintained by the DEQ.

Not all network wells are optimally located and designed for intrusion monitoring. Production wells typically have relatively long and often multiple screened intervals through which water from varying depths are mixed, thereby integrating and losing distinction among parts of the aquifer having contrasting chloride concentrations. Both regulatory and research observation wells generally have single, shorter screened intervals that effectively isolate a distinct part of the aquifer, but conversely have been constructed to serve a broad array of information needs, including description of the hydrogeologic framework and water-level monitoring. Optimal well locations and designs to address these needs do not necessarily coincide with those for intrusion monitoring. In addition, use of the observation wells for characterizing any aspects of water quality specifically requires development of the wells beyond that needed for other purposes. Construction of the wells necessarily entails hydraulic rotary drilling techniques in deep boreholes, which introduces large volumes of drilling fluid that substantially differs in chemical composition from groundwater. Sufficient removal of the drilling fluid to enable subsequent collection of representative groundwater-quality samples is time consuming and costly.

The current intrusion monitoring network in the Virginia Coastal Plain is in an early and relatively formative stage. By contrast, detailed descriptions of movement of the saltwatertransition zone in New Jersey were accomplished using a network of wells much more densely arrayed across a single county and extensively sampled over a 50-yr period (Lacombe and Carleton, 2002). A comparable effort will likely be needed in the Virginia Coastal Plain to detect intrusion during coming years and decades.

Relations between groundwater withdrawal and the saltwater-transition zone in the Virginia Coastal Plain present a substantial challenge for designing an effective intrusion monitoring network. Ideally, intrusion would be anticipated across a distinct front ahead of which all withdrawals are positioned within the freshwater part of the aquifer system and at some distance from the saltwater-transition zone. Observation wells constructed for collection of groundwater-quality samples could then be positioned in a straightforward manner across the intervening area. By contrast, in the Virginia Coastal Plain, large and increasing groundwater withdrawals are positioned close to and wholly within the saltwatertransition zone (see "Considerations for Groundwater Use"), which has a three-dimensionally complex configuration (see "Configuration"). Rather than a distinct front, multiple areas of potential intrusion are probably complexly distributed and are likewise specific to numerous individual production areas. Moreover, many withdrawals are not documented, and among those that are, individual supply wells are continually being taken in and out of production in response to varying demands (see "Intrusion and Upconing"). Numerous shortterm instances of localized upconing are thereby superimposed upon any longer-term intrusion trend, but cannot always be clearly distinguished or related to withdrawal based on changes in groundwater chloride concentration.

The effectiveness of intrusion monitoring in the Virginia Coastal Plain could be improved by collection of groundwaterquality samples from a network of wells designed specifically to address the issues discussed previously. Although sampling of wells at and near groundwater production facilities needs to be maintained, additional observation wells suitably positioned away from production areas are probably more critical toward providing advanced detection of intrusion. Appropriately designing an intrusion monitoring network would depend on a detailed hydrologic analysis that is beyond the scope of the current study, but would entail identifying multiple, complexly distributed areas of potential intrusion with the objective of determining locations at which observation wells would most likely intercept intrusion. Aspects of the saltwater-transition zone could be addressed using newly gained details presented herein (see "Configuration"). Also needed, however, would be as complete an account as possible of groundwater withdrawal locations and amounts or rates. Because of the episodic nature of withdrawal among production facilities, observation well locations need to be arrayed with sufficient extent and density to detect variations in intrusion resulting from changes in withdrawal among different facilities over time and also with regard to locations of projected future withdrawals. A largescale drilling program would then be needed for observation well construction and would specifically include extensive development of the wells prior to collection of groundwaterquality samples.

Collection of groundwater-quality samples from observation wells that compose the intrusion monitoring 
network needs to be frequent enough to distinguish shortterm fluctuations in chloride concentrations associated with upconing from sustained long-term concentration increases that indicate potential lateral intrusion. Although detection of intrusion is of greater concern than upconing, short-term fluctuations in chloride concentration can potentially obscure long-term concentration trends. Periods as long as several years between sequential samples produce broad patterns of change in chloride concentration, which cannot represent concentration fluctuations that are evident from samples collected as frequently as four times per year (see "Patterns of Change in Chloride Concentration"). As a result, infrequent sampling cannot provide the context within which to tell whether a concentration difference between two sequential samples is part of a long-term trend or alternatively is only one among a series of short-term fluctuations. An analysis of the durations of episodic withdrawals could potentially determine the appropriate frequency of sample collection from the monitoring network.

Lastly, intrusion could potentially take from years to decades of monitoring to detect. For example, substantial rates of intrusion determined in Cape May County, New Jersey, average approximately $170 \mathrm{ft} / \mathrm{yr}$ (Lacombe and Carleton, 2002). Put another way, however, 30 years of monitoring was required to detect $1 \mathrm{mi}$ of movement of the saltwater-transition zone.

\section{Selected Constituents}

Concentrations of 37 chemical constituents in groundwater are tabulated (Attachment 1) and summarized (Attachment 2). Many constituents can be present at generally smaller concentrations than the major ions that dominate the chemical composition of groundwater (see "Major Ions"). Some of these constituents are of particular resource-management interest, but not all of them are adequately represented among the tabulated concentration values to determine regional trends (see "Data Distribution"). Fluoride, iron, manganese, nitrate, and ammonium were selected for interpretive analysis, based both on having relevance to resource management and a sufficient number of adequately distributed samples. Concentration values for other constituents were deemed of less interest and(or) inadequate for effective analysis.

Concentrations of fluoride, iron, manganese, nitrate, and ammonium are presented in map and sectional views to convey a conceptual understanding of their distribution and related processes at the regional scale (figs. 22-26). Locations of samples collected from all hydrogeologic units are shown in a single map view for each constituent. Similarly, in sectional view, all sample locations are projected onto a single vertical plane along lines of longitude, which approximate geologic strike. Hydrogeologic-unit associations among samples in sectional view are generalized from McFarland and Bruce (2006) by approximate boundaries between basement bedrock, fluvial-deltaic sediments of the Potomac aquifer, and overlying hydrogeologic units dominated by marine sediments. (The location of the Chesapeake Bay impact crater within the Potomac aquifer is omitted for clarity.) Areas of contrasting groundwater major ion type and the saltwater-transition zone are also approximated. The maps and sections portray broad regional trends among concentrations of the selected constituents, within which local variations can be present.

All groundwater samples analyzed for the selected constituents were included from the compiled data, not just those included in other data analyses based on calculations of major ion charge balance (see "Major Ions") and correlation between chloride-concentration and specific conductance values (see "Saltwater-Transition Zone"). Fluoride, iron, manganese, nitrate, and ammonium concentrations of individual samples are separately tabulated (Attachment 1) and are subject to the same qualifications as other sample data (see "Data Quality").

\section{Fluoride}

Fluoride anions $\left(\mathrm{F}^{-}\right)$are the dominant form of fluorine dissolved in water. The enforceable drinking-water standard for fluoride is $4 \mathrm{mg} / \mathrm{L}$ (U.S. Environmental Protection Agency, 1990), based on consumption of water having larger concentrations leading to bone disease. In addition, to protect against dental fluorosis, a secondary standard is $2 \mathrm{mg} / \mathrm{L}$, above which brown staining and pitting of teeth can result. Conversely, smaller fluoride concentrations promote dental health.

Large fluoride concentrations pose a considerable limitation on groundwater use in parts of the Virginia Coastal Plain. Widespread fluorosis among children has been recognized in the area south of the James River as long as 70 years ago (Cederstrom, 1939). Recent drinking-water production has included blending of groundwater having large fluoride concentrations with water having small concentrations of fluoride (see "Considerations for Groundwater Use").

Tabulated groundwater-sample data include 3,845 fluoride-concentration values (Attachment 1). Mean and median values (Attachment 2 ) are below both primary and secondary drinking-water standards. Map and sectional views (fig. 22) indicate a large fluoride concentration of $18 \mathrm{mg} / \mathrm{L}$ in a sample from a well open to basement bedrock along the Fall Zone in central Henrico County, possibly as a result of the particular bedrock mineralogy there. Additional large concentrations ranging from 13 to $30 \mathrm{mg} / \mathrm{L}$ are present in 11 vertically aligned pore-water samples extracted from sediments at the center of the Chesapeake Bay impact crater. The thermal history of the impact crater has uniquely altered groundwater chemistry at that location (Sanford and others, 2009b), which is likely distinct from the rest of the Virginia Coastal Plain and remains an area of active research (see "Brine and the Inner Chesapeake Bay Impact Crater").

Most of the large fluoride concentrations are present in 671 groundwater samples having between 2 and $4 \mathrm{mg} / \mathrm{L}$, 216 samples having between 4 and $10 \mathrm{mg} / \mathrm{L}$, and one sample having $18 \mathrm{mg} / \mathrm{L}$. Most of these samples are from a broad belt 


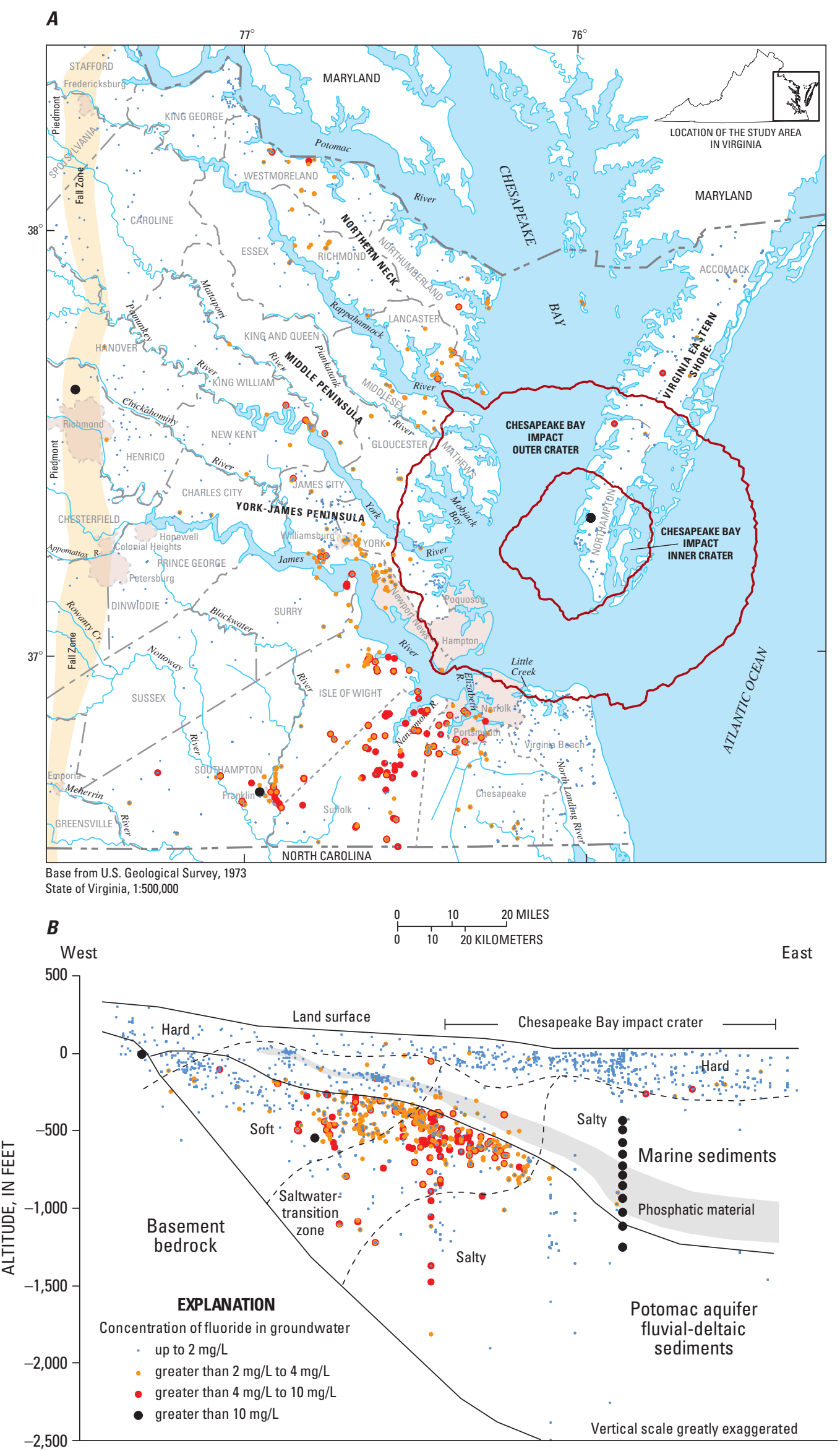

Figure 22. Distribution of fluoride in groundwater in the Virginia Coastal Plain in $(A)$ map view and $(B)$ generalized sectional view. Positions of groundwater major-ion types are approximate. Subsurface materials are generalized from McFarland and Bruce (2006). Location of the Chesapeake Bay impact crater is from Powars and Bruce (1999). Crater-fill sediment is not shown in sectional view. Altitude datum is National Geodetic Vertical Datum of 1929. [mg/L, milligrams per liter] 
(fig. 22A) that spans southeastern Virginia from the city of Franklin eastward across the city of Suffolk and the western city of Chesapeake, and that narrows northward parallel to the outer margin of the Chesapeake Bay impact crater across eastern Isle of Wight and Surry Counties, the central York-James Peninsula, and the lower Middle Peninsula and Northern Neck.

Vertically, the large concentrations across the high fluoride belt are near or within the uppermost part of the Potomac aquifer at elevations ranging from -300 to $-700 \mathrm{ft}$ (fig. 22B), with the greatest thickness of large concentrations to the south of the James River. Groundwater fluoride concentrations in shallower sediments are generally less than $2 \mathrm{mg} / \mathrm{L}$. Within the Potomac aquifer, concentrations also are generally less than $2 \mathrm{mg} / \mathrm{L}$ on either side of the high fluoride belt and likewise at greater depth beneath the belt. Thus in three dimensions, the belt consists of large concentrations clustered into a roughly lens-shaped mass that is centered approximately $500 \mathrm{ft}$ beneath the city of Suffolk and that thins and tapers northward.

The origin of the high fluoride belt has not been determined with certainty. The fluoride concentration of seawater is approximately $1.3 \mathrm{mg} / \mathrm{L}$ (Hem, 1985) and cannot directly account for the larger concentrations of fluoride in groundwater. Alternatively, fluorine is present in solid form within some marine sediments as phosphatic material composed of fluorapatite $\left(\mathrm{Ca}_{5}\left(\mathrm{PO}_{4}\right)_{3} \mathrm{~F}\right)$, which makes up fossil bones and teeth deposited as remains of marine animals (McFarland and Bruce, 2006). Fluorapatite releases dissolved fluoride to groundwater by ion exchange with hydroxyl $\left(\mathrm{OH}^{-}\right)$to form hydroxylapatite $\left(\mathrm{Ca}_{5}\left(\mathrm{PO}_{4}\right)_{3} \mathrm{OH}\right)$. Adsorbtion of hydroxyl results from an increase in its concentration in groundwater, thereby displacing adsorbed fluoride into groundwater and increasing its concentration. Dissolved hydroxyl concentration also varies directly with $\mathrm{pH}$ and bicarbonate concentration. Thus, increases in $\mathrm{pH}$ and bicarbonate concentration also correspond to desorbtion of fluoride.

Fluorapatite-bearing phosphatic material in the South Carolina Coastal Plain has been cited as the source for groundwater fluoride concentrations as large as $5.5 \mathrm{mg} / \mathrm{L}$ (Zack, 1980). In the Virginia Coastal Plain, however, spatial relations are not consistent with phosphatic material being a direct source of the high fluoride belt. Groundwater fluoride concentrations in the phosphatic material are generally less than $2 \mathrm{mg} / \mathrm{L}$ (fig. 22B), whereas underlying fluvial-deltaic sediments of the Potomac aquifer in which the high fluoride belt is positioned lack phosphatic material. The high fluoride belt appears to be essentially isolated within the upper part of the Potomac aquifer, separate from the phosphatic material, and lacking any plume or sheet of high fluoride groundwater that would reflect transport of fluoride between the two locations. Despite phosphatic material being the most obvious source of groundwater fluoride, hydroxyl concentrations there are apparently adequate to desorb only enough fluoride from fluorapatite to produce relatively low dissolved fluoride concentrations.
Other fluorite-bearing minerals have been suggested as possible sources of groundwater fluoride, including tourmaline and topaz (Sinnott and Whetstone, 1962), but if present are only trace components of the Potomac aquifer sediments. More abundant sediment components have also been cited, including mica and clay (Cederstrom, 1945; Sinnott and Whetstone, 1962; Maciuika, 1992). Incongruent dissolution of various mica minerals can potentially release a diverse variety of solutes to groundwater, including fluoride, but no direct relation has been established between mica and large groundwater fluoride concentrations. Moreover, clay minerals modify the composition of groundwater primarily by exchange of cations and do not affect fluoride anions. Oxyhydroxides of iron and manganese, however, can exchange both cations and anions (Drever, 1988), and are also abundant within Potomac aquifer sediments as amorphous colloidal particles and coatings on sediment grains (McFarland and Bruce, 2006) (see "Iron and Manganese"). Adsorbtion and desorbtion of fluoride onto oxyhydroxides can potentially take place alternately with hydroxyl as well as other anions in a manner similar to that described previously for fluorapatite.

In addition to its source, other aspects of the high fluoride belt are possibly related to its presence. Groundwater fluoride concentration has been directly related to $(\mathrm{Na}+\mathrm{K})+\left(\mathrm{HCO}_{3}+\mathrm{CO}_{3}\right)$ "soft" type groundwater (Cederstrom, 1945; Sinnott and Whetstone, 1962; Maciuika, 1992) and to bicarbonate concentration (Zack, 1980). In addition, the high fluoride belt aligns with the outer margin of the saltwatertransition zone (fig. $22 \mathrm{~B})$, where $(\mathrm{Na}+\mathrm{K})+\left(\mathrm{HCO}_{3}+\mathrm{CO}_{3}\right)$ "soft" type groundwater transitions eastward and with depth to $(\mathrm{Na}+\mathrm{K})+\mathrm{Cl}$ "salty" type groundwater (see "Major Ions"). Groundwater $\mathrm{pH}$ and bicarbonate concentrations are relatively high, and chloride concentrations increase from approximately $20 \mathrm{mg} / \mathrm{L}$ to as much as $1,000 \mathrm{mg} / \mathrm{L}$. Farther eastward and to greater depth beyond the high fluoride belt, chloride concentrations continue to increase, but fluoride concentrations generally decline to below $2 \mathrm{mg} / \mathrm{L}$.

Based on the preceding information, a hypothesis is proposed herein of how the high fluoride belt was possibly formed as a consequence of migration of the saltwatertransition zone. Fresh groundwater has flowed from the marine sediments eastward and downward into the underlying Potomac aquifer for the past approximately 1.8 m.y., following emergence from the most recent region-wide inundation by the Atlantic Ocean (see "Saltwater-Transition Zone"). During the Pleistocene glacial maximum from 18,000 to 21,000 years ago, fresh groundwater flowed nearly to the edge of the Continental Shelf, under a hydraulic gradient two to four times greater than at present. North-to-south trending belts of hard, soft, and salty type groundwater, and their corresponding total ion concentrations (see "Major Ions"), were displaced eastward proportionately. Fluoride was released from phosphatic material to groundwater across large areas at small concentrations of $2 \mathrm{mg} / \mathrm{L}$ or less that are generally widespread. Upon transport into the Potomac aquifer, however, some portion of the dissolved fluoride was adsorbed onto oxyhydroxides 
within the Potomac aquifer sediments. During the prolonged period of groundwater flow and transport, the oxyhydroxides acted in a filter-like manner to accumulate a large quantity of adsorbed fluoride potentially across a wide span of the Potomac aquifer as far east as the edge of the Continental Shelf.

With the subsequent rise in sea level, the Atlantic Ocean has reinundated the Continental Shelf, and the saltwater-transition zone has migrated westward to its present position. The belts of hard, soft, and salty type groundwater, and their corresponding total ion concentrations, have been displaced to the west proportionately. Under these conditions, oxyhydroxides within the Potomac aquifer sediments have become a source of fluoride, which is being desorbed back into solution by adsorbtion of hydroxyl, chloride, and(or) other anions, where soft $(\mathrm{Na}+\mathrm{K})+\left(\mathrm{HCO}_{3}+\mathrm{CO}_{3}\right)$ type groundwater transitions eastward and with depth to salty $(\mathrm{Na}+\mathrm{K})+\mathrm{Cl}$ type groundwater. Thus, much of the fluoride in groundwater probably originated from phosphatic material, but was adsorbed onto oxyhydroxides within the Potomac aquifer sediments and subsequently desorbed along the advancing saltwater-transition zone to result in the current position of the high fluoride belt.

Considering the possible relation of the high fluoride belt to the saltwater-transition zone, their present-day configurations are not static. Areas farther east likely first developed large groundwater fluoride concentrations, straddling the leading edge of the advancing saltwater-transition zone. Low fluoride seawater has since reentered the sediments in these areas, as sea level has risen to its current position. Thus, the high fluoride belt is a relatively transient feature associated with westward migration of the saltwater-transition zone.

\section{Iron and Manganese}

Iron and manganese are closely associated in groundwater and are primarily in the form of cations having a charge of $2\left(\mathrm{Fe}^{2+}\right.$ and $\mathrm{Mn}^{2+}$, respectively), although smaller amounts of differently charged cations, ion complexes, and other forms can also be present (Hem, 1985). Secondary drinking-water standards (U.S. Environmental Protection Agency, 1990) are $0.3 \mathrm{mg} / \mathrm{L}$ for total iron and $0.05 \mathrm{mg} / \mathrm{L}$ for total manganese, based primarily on aesthetic considerations. Water exceeding the standards can commonly have a rusty or brown to black color and metallic taste, and can produce sediment and reddish to orange or black staining. Conversely, both iron and manganese are essential elements for plant and animal life.

Iron and manganese are pervasive in groundwater throughout the Virginia Coastal Plain with highly variable concentrations at the local scale. Wells producing water with relatively small concentrations can often be in proximity to other wells exhibiting substantially larger and problematic concentrations. Removal of iron and(or) manganese is one of the most common necessary treatments of water from supply wells (see "Considerations for Groundwater Use").
Tabulated groundwater-sample data include 3,554 ironconcentration values and 2,581 manganese-concentration values (Attachment 1). (Note that tabulated values are in micrograms per liter $(\mu \mathrm{g} / \mathrm{L})$, equivalent to $0.001 \mathrm{mg} / \mathrm{L}$. Iron and manganese drinking-water standards are equivalent to $300 \mu \mathrm{g} / \mathrm{L}$ and $50 \mu \mathrm{g} / \mathrm{L}$, respectively.) Median iron and manganese concentrations (Attachment 2) are both below their drinking-water standards, but their mean concentrations are above. Large differences between the mean and median concentrations reflect small numbers of extreme large values.

Tabulated groundwater-sample iron- and manganeseconcentration values are summarized in map and sectional views (figs. 23, 24, respectively), and exhibit similar trends. Although some large concentrations are present throughout the Virginia Coastal Plain, a spatial sequence is apparent in relative differences among the concentrations. To the west along the Fall Zone, iron and manganese concentrations exceeding drinking-water standards are relatively common (figs. $23 \mathrm{~A}$, $24 A$ ). Eastward, concentrations at or below the drinking-water standards dominate a broad north-south trending belt spanning much of the central part of the Virginia Coastal Plain. The two areas generally correspond to those of $\left(\mathrm{Ca}^{2+}+\mathrm{Mg}^{2+}\right)+\left(\mathrm{HCO}_{3}^{-}+\right.$ $\left.\mathrm{CO}_{3}^{-}\right)$type "hard" water toward the west and $\left(\mathrm{Na}^{+}+\mathrm{K}^{+}\right)+$ $\left(\mathrm{HCO}_{3}^{-}+\mathrm{CO}_{3}^{-}\right)$type "soft" water toward the east (see "Major Ions"). Still farther east, iron and manganese concentrations increase widely to include many of the largest concentrations and generally correspond to the area of $\left(\mathrm{Na}^{+}+\mathrm{K}^{+}\right)+\mathrm{Cl}^{-}$type "salty" water.

Further aspects of the spatial sequence in groundwater iron and manganese concentrations are exhibited vertically (figs. 23B, 24B). As in map view, concentrations furthest updip to the west commonly exceed drinking-water standards where hard water is dominant, and eastward are more widely at or below the drinking-water standards where soft water is dominant. Farther east, however, two vertically separated trends are apparent. Within the Potomac aquifer and lower part of the marine sediments, iron concentrations widely exceed the drinking-water standard across the saltwater-transition zone and beyond, where soft water evolves to salty water. Manganese concentrations follow a similar trend, but only widely exceed the drinking-water standard farther east beyond the saltwater-transition zone.

Distinct from these findings, many additional iron and manganese concentrations exceed their drinking-water standards within the shallow part of the marine sediments (figs. $23 B, 24 B$ ), where hard water remains dominant far to the east. As seen in map view (figs. 22A, 23A), these large iron and manganese concentrations at shallow depths occupy a broad belt spanning the lower parts of the Middle Peninsula and York-James Peninsula northeastward across the Virginia Eastern Shore and southeastward across the cities of Chesapeake and Virginia Beach.

The origin of iron and manganese in groundwater is complex in detail. Both constituents can potentially take part in a broad array of chemical reactions with various sediment components. Speciation of iron and manganese among diverse 
$\boldsymbol{A}$

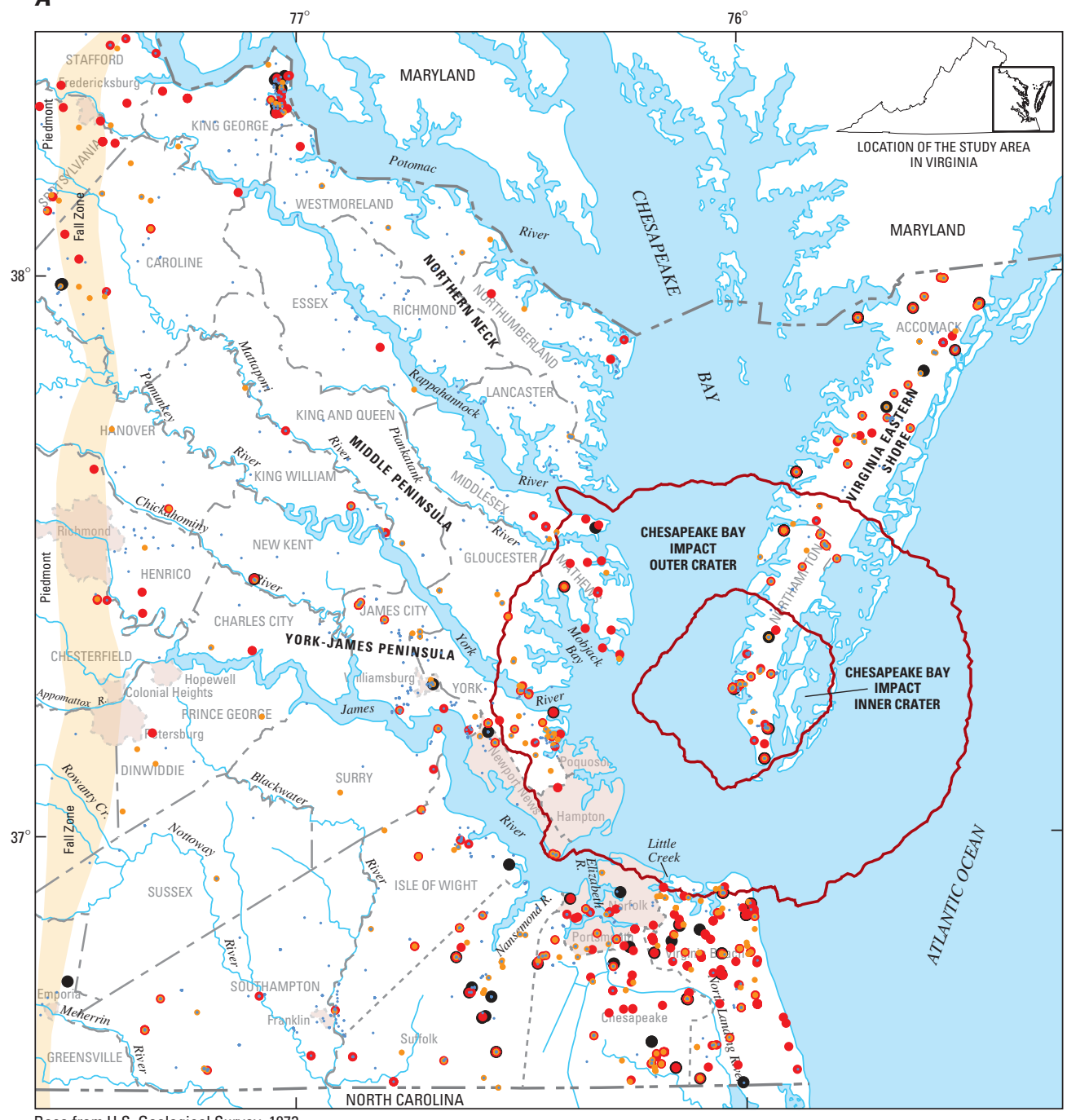

Base from U.S. Geological Survey, 1973

State of Virginia, 1:500,000

B

West

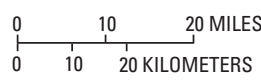

East

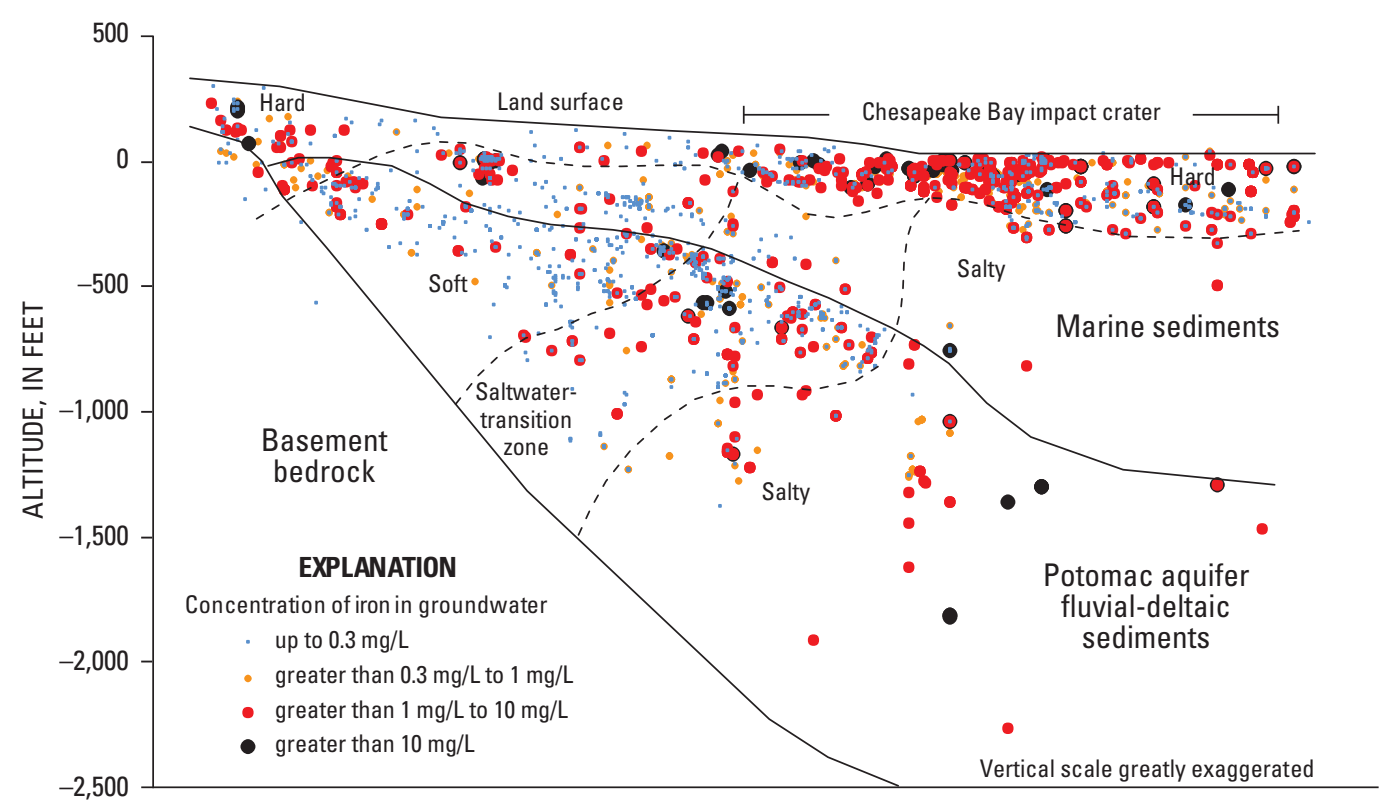

Figure 23. Distribution of iron in groundwater in the Virginia Coastal Plain in $(A)$ map view and $(B)$ generalized sectional view. Positions of groundwater major-ion types are approximate. Subsurface materials are generalized from McFarland and Bruce (2006). Location of the Chesapeake Bay impact crater is from Powars and Bruce (1999). Crater-fill sediment is not shown in sectional view. Altitude datum is National Geodetic Vertical Datum of 1929. [mg/L, milligrams per liter] 


\section{$\boldsymbol{A}$}

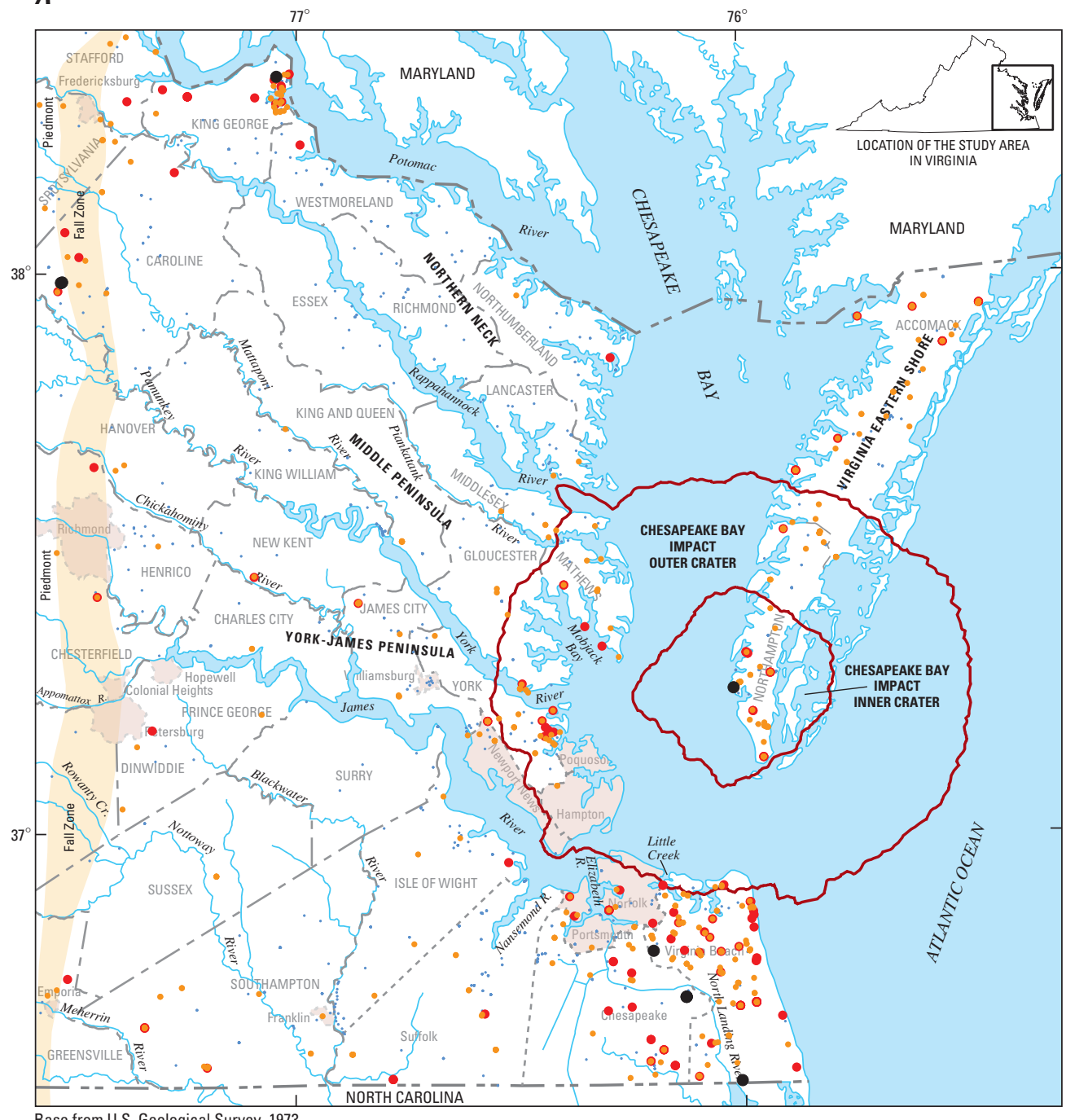

Base from U.S. Geological Survey, 1973 State of Virginia, 1:500,000

B
West

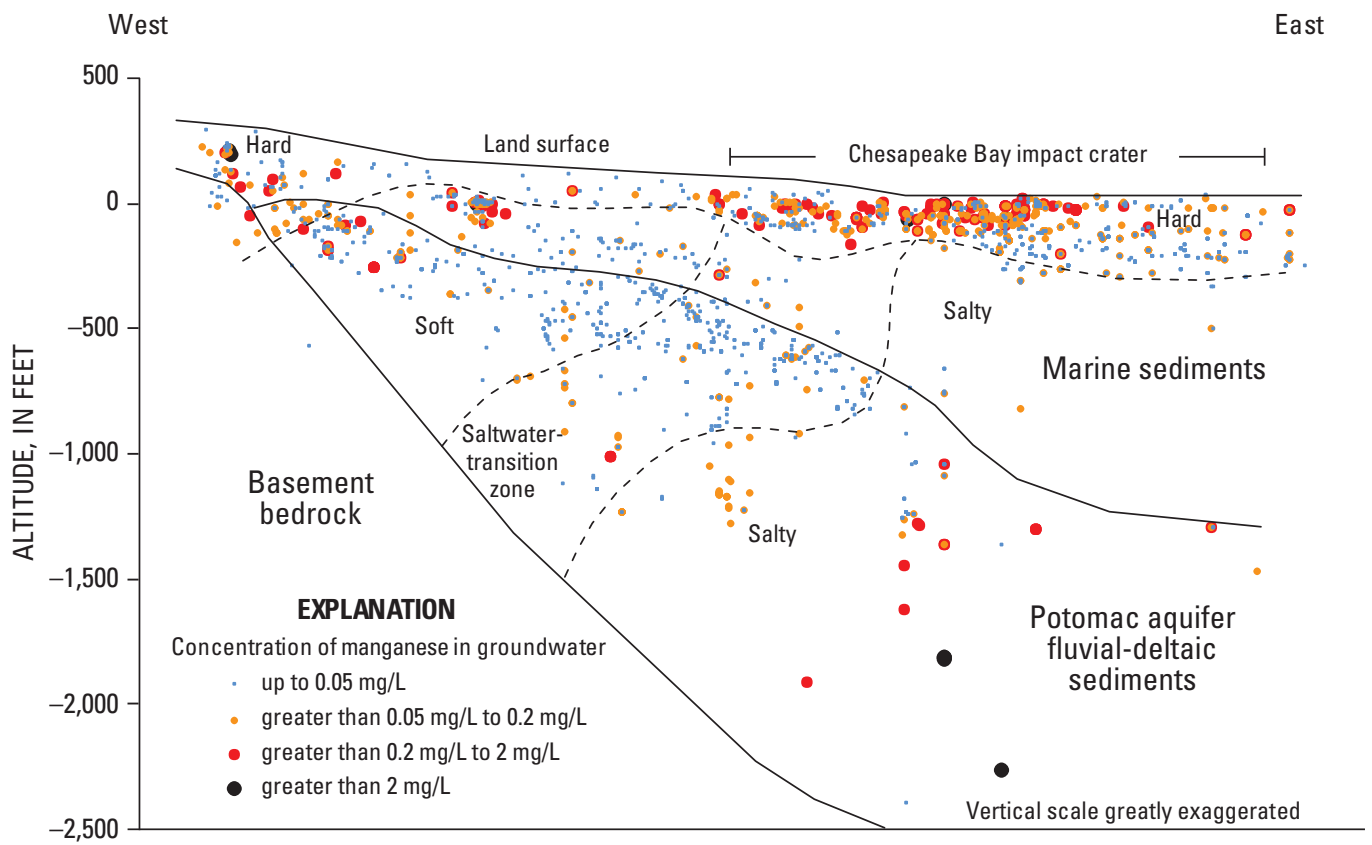

Figure 24. Distribution of manganese in groundwater in the Virginia Coastal Plain in $(A)$ map view and $(B)$ generalized sectional view. Positions of groundwater major-ion types are approximate. Subsurface materials are generalized from McFarland and Bruce (2006). Location of the Chesapeake Bay impact crater is from Powars and Bruce (1999). Crater-fill sediment is not shown in sectional view. Altitude datum is National Geodetic Vertical Datum of 1929. [mg/L, milligrams per liter] 
dissolved and solid-phase forms are functions of both $\mathrm{pH}$ and oxidation-reduction, or "redox," potential (Eh). Whereas $\mathrm{pH}$ is a measure of the activity of protons (hydrogen ions) transferred in acid-base reactions, Eh is a measure of the activity of electrons transferred in redox reactions. In practical terms, the Eh of groundwater is partly reflected by the presence or absence of dissolved oxygen. Iron and manganese will exist in more positively charged forms under oxidizing conditions and in less positively charged forms under less oxidizing (reducing) conditions. Moreover, oxidizing conditions generally correspond to relatively small concentrations of dissolved iron and manganese and reducing conditions to larger concentrations. Large concentrations of iron in groundwater in the Maryland Coastal Plain were shown to result from reducing conditions (Back and Barnes, 1965). Transformation reactions among various dissolved and solid-phase forms of both iron and manganese can also involve complex organic compounds and can be catalyzed by microorganisms (see "Considerations for Groundwater Use"). Further details of iron and manganese in water are subjects of a broad field of hydrochemical research, which is beyond the scope of this report.

Processes affecting groundwater iron and manganese in the Virginia Coastal Plain can be broadly generalized. In updip areas to the west, iron and manganese probably originate from the dissolution of various minerals. Clumps, nodules, and other massive forms of pyrite $\left(\mathrm{FeS}_{2}\right)$ are commonly associated with fossil plant debris and other organic material within some sediments of the Potomac aquifer. More finely disseminated pyrite is also present in some overlying sediments. Dissolved iron originating from dissolution of pyrite is also often associated with large concentrations of hydrogen sulfide in groundwater (see "Considerations for Groundwater Use"). In addition, basement bedrock is composed of a diverse assemblage of igneous and metamorphic minerals, many of which potentially contain both iron and manganese. Although mineral dissolution produces some dissolved iron and manganese, additional amounts are precipitated back into the sediments where dissolved oxygen is present as amorphous oxyhydroxides consisting of colloidal particles and coatings on sediment grains.

Concentrations of iron and manganese in groundwater decrease eastward and downward, where the major ion composition of groundwater evolves from hard to soft as a result of ion exchange (see "Major Ions"). Similar to calcium and magnesium, iron and manganese cations are adsorbed by clay and glauconite within the sediments to release previously adsorbed sodium and potassium cations into solution. Replenishment of dissolved iron and manganese by further dissolution of pyrite and(or) other minerals possibly is hindered by lack of a sustained supply of dissolved oxygen at depth.

Farther east, concentrations of iron and manganese in groundwater increase across and beyond the saltwatertransition zone, where the major ion composition of groundwater evolves from soft to salty as a result of mixing with seawater. The increases cannot be directly accounted for by emplacement of seawater, in which iron and manganese concentrations are small (approximately $3 \mu \mathrm{g} / \mathrm{L}$, and $2 \mu \mathrm{g} / \mathrm{L}$, respectively) (Hem, 1985). Instead, iron and manganese concentrations are increased by ion exchange, which is reversed from that taking place to the west. Sodium cations in large concentrations associated with seawater are adsorbed onto clay and glauconite to release previously adsorbed iron and manganese cations back into solution. In addition, iron and manganese cations are possibly exchanged for sodium cations by oxyhydroxides in a similar manner to fluoride anions for hydroxyl and chloride anions (see "Fluoride"). Unlike fluoride, however, large iron and manganese concentrations extend eastward beyond the saltwater-transition zone, indicating that their desorbtion persists as seawater is emplaced within the sediments.

Other processes take place in shallow, dominantly hard groundwater across the broad eastward belt of large iron and manganese concentrations. These sediments compose mostly the surficial and Yorktown-Eastover aquifers, consisting of sands and clays with large amounts of fossil shell material, but also substantial quantities of organic matter as fossil plant debris and peat. Organic matter reacts with iron and manganese oxyhydroxides to produce dissolved iron and manganese, generalized as (Freeze and Cherry, 1979):

$$
\begin{gathered}
\mathrm{CH}_{2} \mathrm{O}+4 \mathrm{Fe}(\mathrm{OH})_{3}+7 \mathrm{H}^{+} \rightarrow 4 \mathrm{Fe}^{2+}+\mathrm{HCO}_{3}^{-}+10 \mathrm{H}_{2} \mathrm{O} \text {, and } \\
\mathrm{CH}_{2} \mathrm{O}+2 \mathrm{MnO}_{2}+3 \mathrm{H}^{+} \rightarrow 2 \mathrm{Mn}^{2+}+\mathrm{HCO}_{3}^{-}+2 \mathrm{H}_{2} \mathrm{O} .
\end{gathered}
$$

The organic matter is also a potential source of ammonium (see "Nitrate and Ammonium") and hydrogen sulfide (see "Considerations for Groundwater Use").

\section{Nitrate and Ammonium}

Dissolved nitrogen takes several forms, including the anions nitrate $\left(\mathrm{NO}_{3}^{-}\right)$and nitrite $\left(\mathrm{NO}_{2}^{-}\right)$, the cation ammonium $\left(\mathrm{NH}_{4}^{+}\right)$, the gases nitrogen $\left(\mathrm{N}_{2}\right)$ and nitrous oxide $\left(\mathrm{N}_{2} \mathrm{O}\right)$, and diverse organic compounds. Primary drinking-water standards (U.S. Environmental Protection Agency, 1990) are $10 \mathrm{mg} / \mathrm{L}$ of nitrogen in the form of nitrate, and $1 \mathrm{mg} / \mathrm{L}$ in the form of nitrite, based on consumption of water having larger concentrations leading to acute methemoglobinemia (a blood disease) in infants and long-term diuresis and hemorrhaging of the spleen in adults. Although other forms of nitrogen in drinking water are unregulated, some can potentially be transformed into nitrate. In addition to effects on drinking water, transport of large amounts of nitrogen by both groundwater and streams has been cited as a major cause of eutrophication of Chesapeake Bay (Phillips, 2007). Conversely, ecologically balanced amounts of nitrogen are essential for plant and animal life.

Some forms of dissolved nitrogen are pervasive in groundwater throughout the Virginia Coastal Plain, with concentrations generally variable at the local scale. Wells producing water with relatively small concentrations can often be in proximity to other wells exhibiting substantially larger 
concentrations. Removal of nitrate and other forms of dissolved nitrogen are potential necessary treatments of water from some supply wells (see "Considerations for Groundwater Use").

Tabulated groundwater-sample data include 2,711 nitrateconcentration values and 2,293 ammonium-concentration values (Attachment 1). Concentrations are expressed as milligrams per liter of nitrogen to allow direct comparison among the two forms. No values are included for other forms of dissolved nitrogen. Nitrate-concentration mean and median values are both below the drinking-water standard by one and two orders of magnitude, respectively (Attachment 2). Ammonium-concentration maximum, mean, and median values are all about an order of magnitude greater than their corresponding nitrate-concentration values.

Groundwater nitrate- and ammonium-concentration values are summarized in map and sectional views (figs. 25, 26). For both constituents, concentrations at or below $1 \mathrm{mg} / \mathrm{L}$ are present throughout the Virginia Coastal Plain. The locations of larger nitrate concentrations are generally scattered (fig. 25A), including those of 33 samples that exceed the $10 \mathrm{mg} / \mathrm{L}$ drinking-water standard. By contrast, some larger ammonium concentrations are more clustered in one area around the lower part of the Northern Neck and in a second area around the city of Virginia Beach (fig. 26A).

Vertically, groundwater nitrate and ammonium concentrations at or below $1 \mathrm{mg} / \mathrm{L}$ are also widespread (figs. 25B, 26B). Nitrate concentrations greater than $1 \mathrm{mg} / \mathrm{L}$ span most of the area of shallow $\left(\mathrm{Ca}^{2+}+\mathrm{Mg}^{2+}\right)+\left(\mathrm{HCO}_{3}^{-}+\mathrm{CO}_{3}^{-}\right)$type "hard" water, although a few are also present at greater depth across the saltwater-transition zone. Ammonium concentrations follow similar trends, although those greater than $1 \mathrm{mg} / \mathrm{L}$ are generally at greater depths. Within the area of shallow hard water far to the east, ammonium concentrations greater than $1 \mathrm{mg} / \mathrm{L}$ generally underlie nitrate concentrations greater than $1 \mathrm{mg} / \mathrm{L}$. Some deeper ammonium concentrations are also substantially greater than nitrate concentrations across and beyond the saltwater-transition zone.

Processes affecting nitrogen in groundwater are complex in detail. Speciation of nitrogen among the various forms are functions of both $\mathrm{pH}$ and oxidation-reduction, or "redox," potential (Eh), and chemical transformation reactions are often mediated by microorganisms. In broad terms, groundwater nitrate generally originates from sources at or near the land surface (Freeze and Cherry, 1979). Decomposition of organic nitrogen from the remains of plants and animals initially produces ammonium. Where oxygen is available, ammonium is converted primarily to nitrate (nitrite is temporarily produced as an unstable intermediate form). Where vegetation is active, nitrate is largely taken back up by plants (Drever, 1988) to effectively recycle nitrogen near the land surface.

Ammonium and nitrate that is not recycled near the land surface can be transported in groundwater to greater depths. Excess amounts of both constituents in groundwater can originate from artificial sources, such as fertilizer-application and livestock-production areas, and buried sewer lines and septic systems. In addition, organic matter that was deposited within sediments at depth is a potential natural source. Ammonium can be removed from groundwater by ion exchange in a manner similar to other cations (see "Major Ions" and "Iron and Manganese"). Nitrate generally is more readily transported by groundwater flow, as long as oxygen is available, although some nitrate can potentially be adsorbed by iron and manganese oxyhydroxides. In addition, where oxygen becomes unavailable, nitrate can be partly converted by microbially mediated denitrification to nitrogen and(or) nitrous oxide gases, which are chemically stable and nonreactive, pose no detriment to drinking water, and can be removed from groundwater by vaporization.

The widespread presence of groundwater nitrate and ammonium concentrations at or below $1 \mathrm{mg} / \mathrm{L}$ is consistent with much of the nitrogen being recycled near the land surface throughout most of the Virginia Coastal Plain. In addition, nitrate transported to greater depth possibly undergoes denitrification, where dissolved-oxygen concentrations are generally small within confined aquifers and confining units and zones (Attachment 2).

Nitrate and ammonium concentrations greater than $1 \mathrm{mg} / \mathrm{L}$ in shallow groundwater indicate additional amounts not taken up by plants, which in many cases likely originate from human sources. Shallow groundwater in many areas has entered the subsurface within human timeframes (Nelms and others, 2003), and human sources possibly have locally altered the major ion type of shallow groundwater at widely spaced locations (see "Major Ions"). Removal of nitrate by denitrification is precluded by the relatively large dissolved-oxygen concentrations within the surficial aquifer (Attachment 2). Site-specific human sources of nitrate and(or) ammonium potentially include a wide variety of both rural and urban activities, but are beyond the scope of the regional analysis herein to consider in detail.

Some groundwater nitrate and ammonium concentrations greater than $1 \mathrm{mg} / \mathrm{L}$ possibly result from other processes. In shallow hard water far to the east, both constituents are possibly produced by decomposition of organic matter, which is present in substantial quantities as fossil plant debris and peat within sediments of the surficial and Yorktown-Eastover aquifers. Ammonium is more prevalent than nitrate at depths below which oxygen is available. The organic matter possibly also reacts with iron and manganese oxyhydroxides to produce dissolved iron and manganese (see "Iron and Manganese").

Across and beyond the saltwater-transition zone, groundwater nitrate and ammonium concentrations greater than $1 \mathrm{mg} / \mathrm{L}$ possibly result from ion exchange. The concentrations cannot be directly accounted for by emplacement of seawater, in which dissolved nitrogen is primarily in the form of nitrate at concentrations less than $1 \mathrm{mg} / \mathrm{L}$ (not including nitrogen gas) (Hem, 1985). Instead, sodium cations in large concentrations associated with seawater are adsorbed onto clay and glauconite, and also possibly onto iron and manganese oxyhydroxides to release previously adsorbed ammonium cations back into solution. Similarly to iron and manganese 


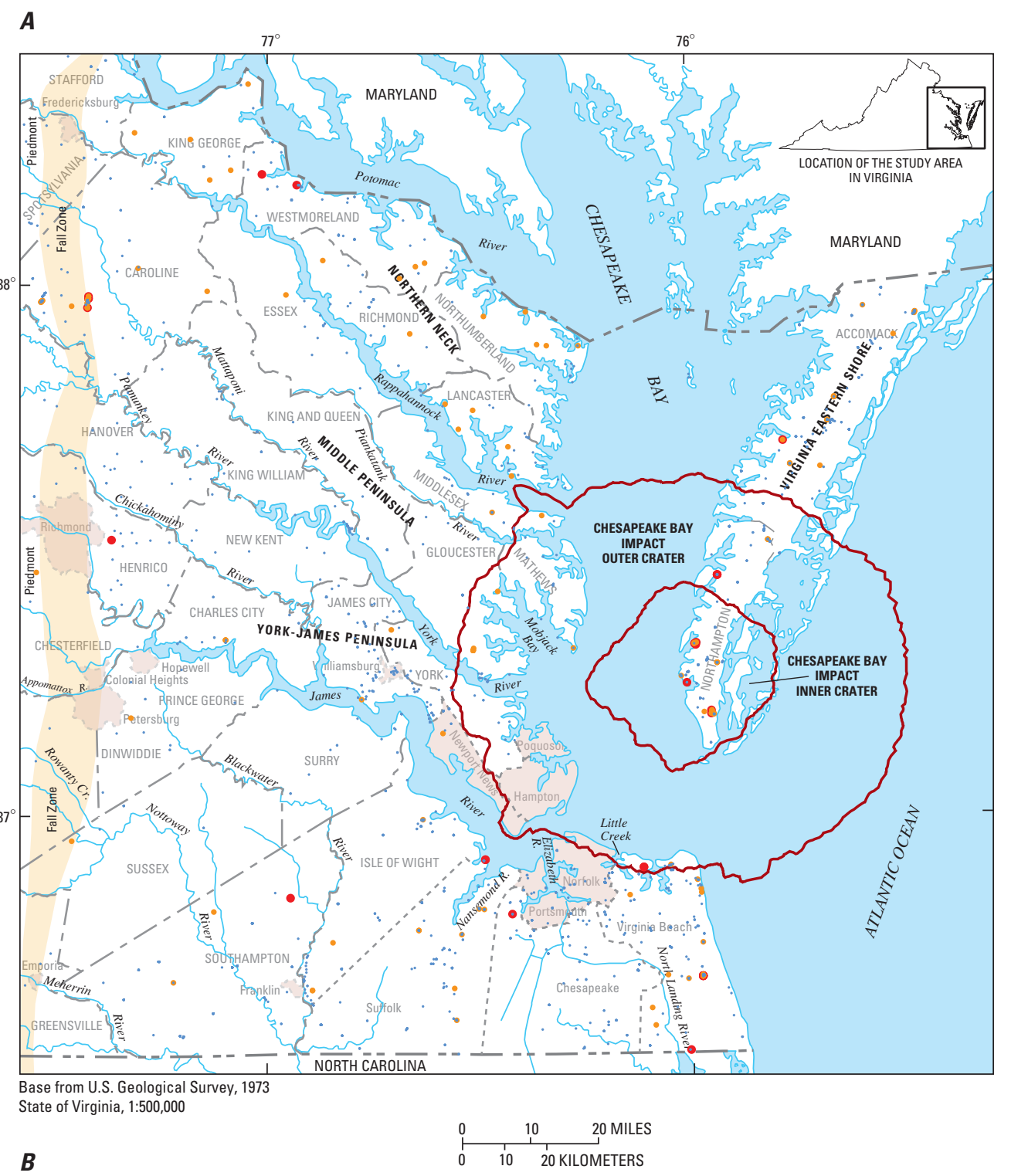

West

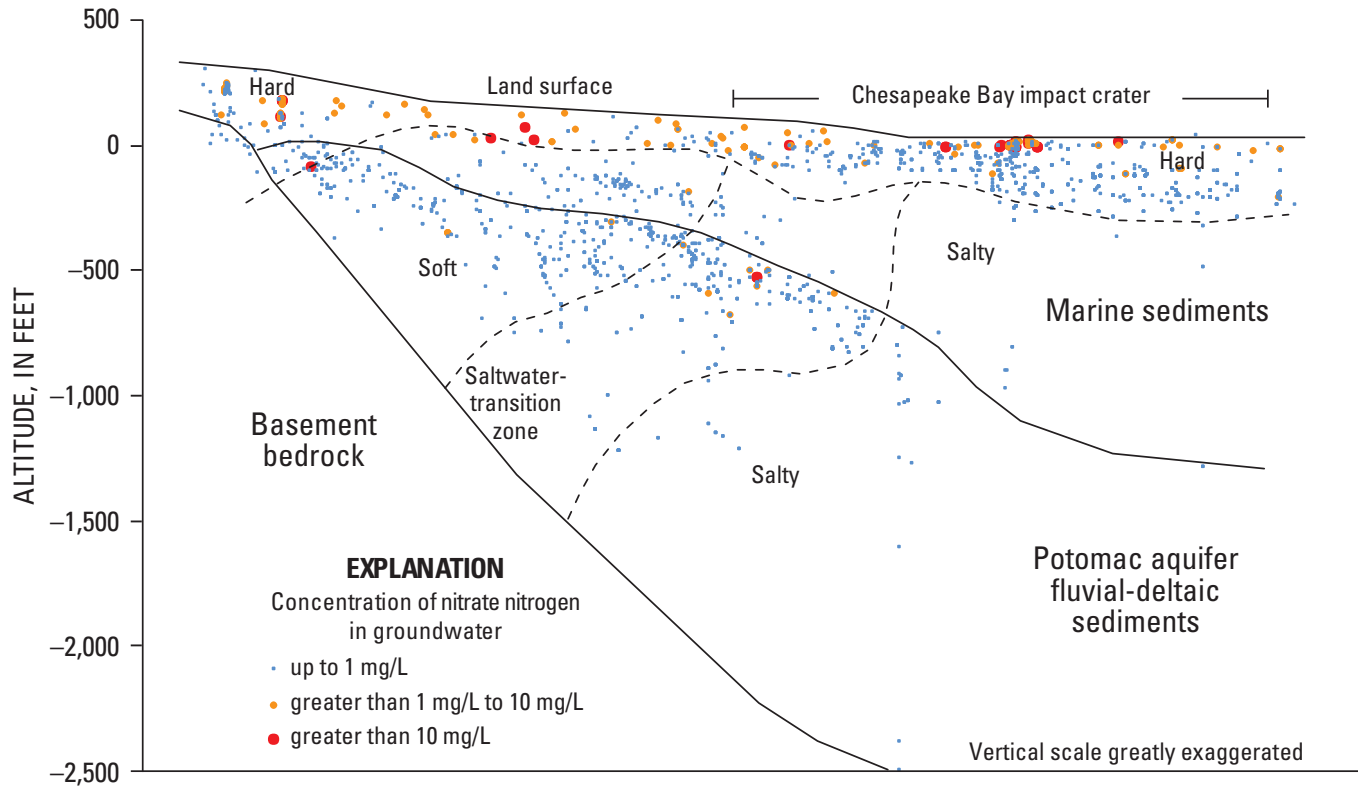

Figure 25. Distribution of nitrate nitrogen in groundwater in the Virginia Coastal Plain in $(A)$ map view and $(B)$ generalized sectional view. Positions of groundwater major-ion types are approximate. Subsurface materials are generalized from McFarland and Bruce (2006). Location of the Chesapeake Bay impact crater is from Powars and Bruce (1999). Crater-fill sediment is not shown in sectional view. Altitude datum is National Geodetic Vertical Datum of 1929. [mg/L, milligrams per liter] 


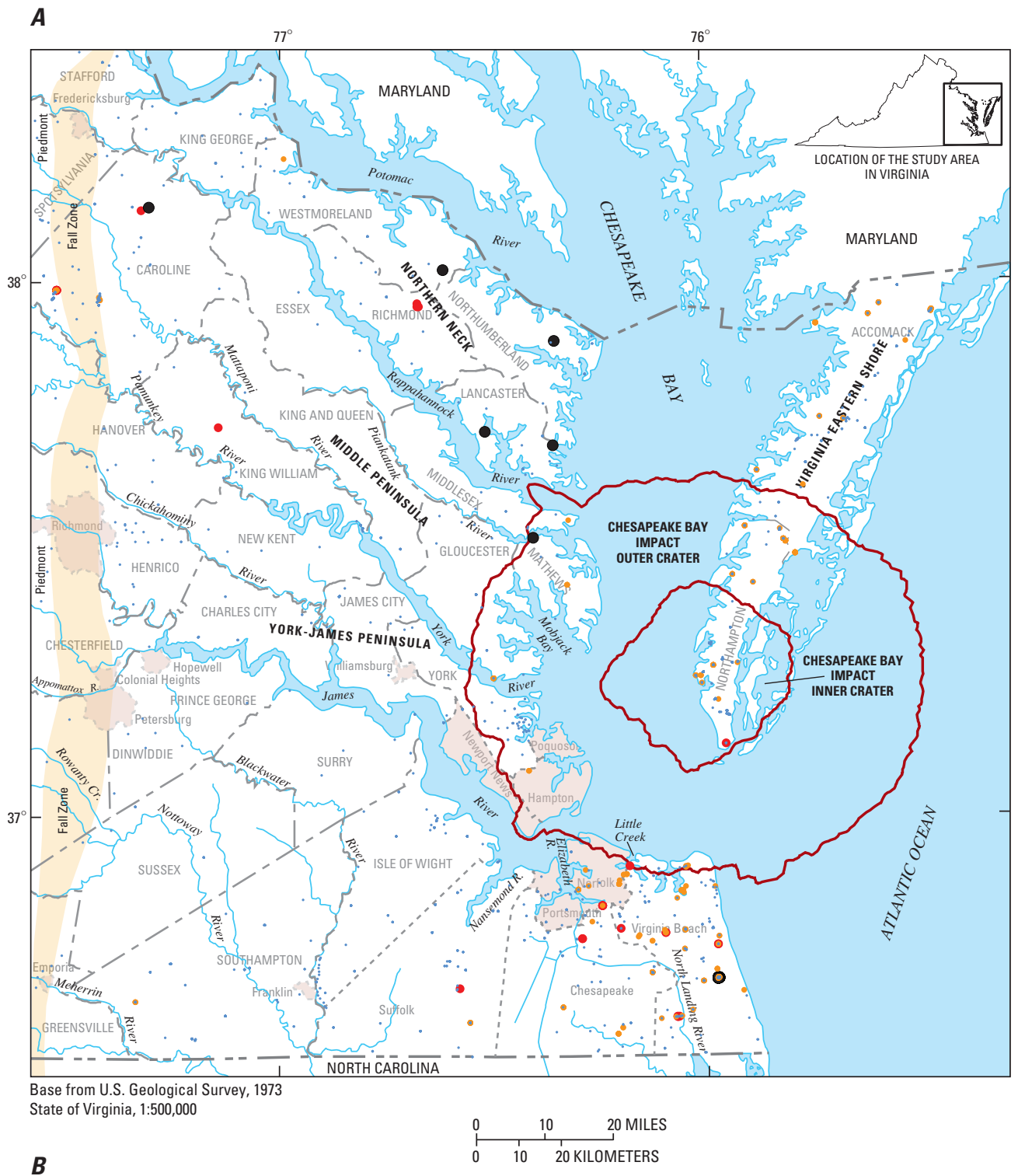

West

East

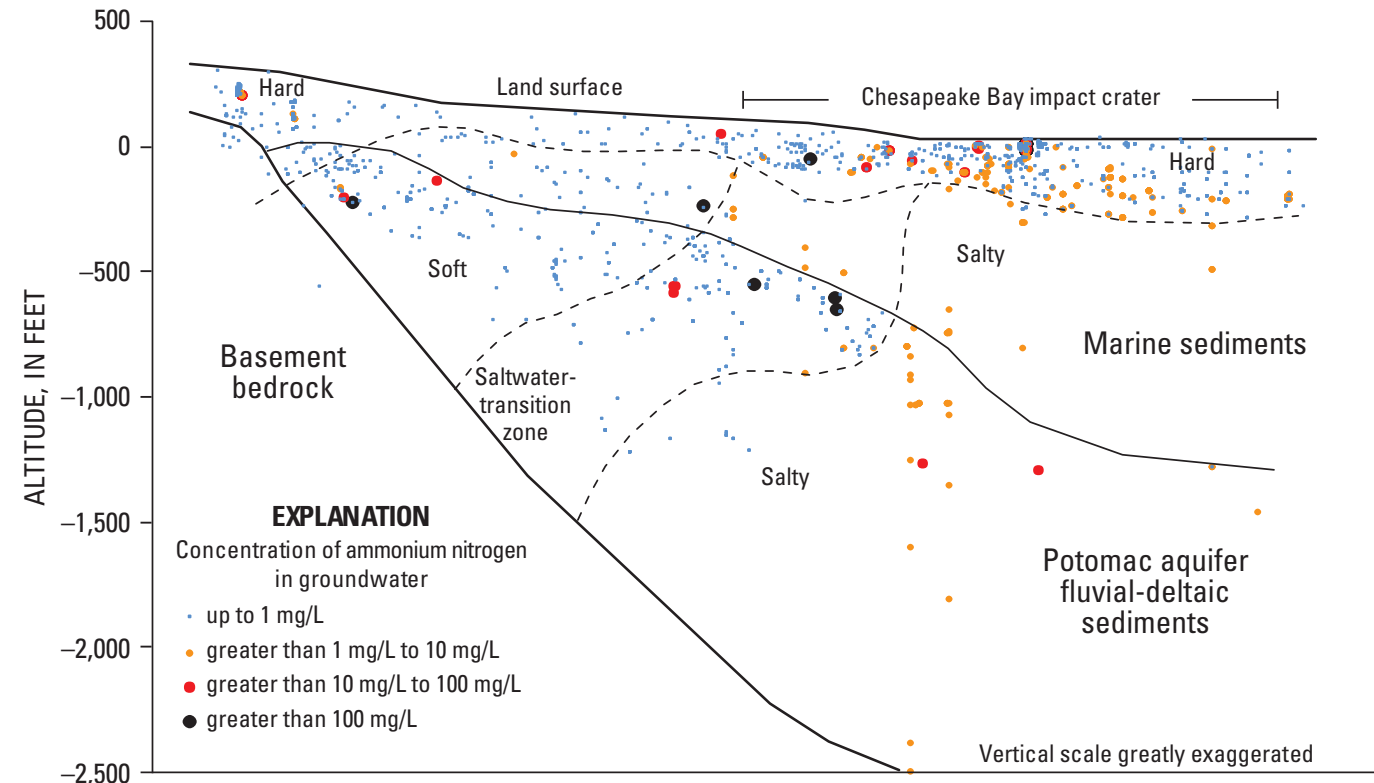

Figure 26. Distribution of ammonium nitrogen in groundwater in the Virginia Coastal Plain in $(A)$ map view and $(B)$ generalized sectional view. Positions of groundwater major-ion types are approximate. Subsurface materials are generalized from McFarland and Bruce (2006). Location of the Chesapeake Bay impact crater is from Powars and Bruce (1999). Crater-fill sediment is not shown in sectional view. Altitude datum is National Geodetic Vertical Datum of 1929. [mg/L, milligrams per liter] 
(see "Iron and Manganese"), large ammonium concentrations extend eastward beyond the saltwater-transition zone, indicating that their desorbtion persists as seawater is emplaced within the sediments. In addition, nitrate anions are possibly exchanged by oxyhydroxides for hydroxyl and chloride anions in a similar manner to fluoride anions (see "Fluoride").

\section{Considerations for Groundwater Use}

The suitability of groundwater for various uses is largely determined by its chemical quality. Concentrations of some chemical constituents can potentially impose limitations and treatment requirements for a particular use. Hence, a complete understanding of groundwater quality in the Virginia Coastal Plain includes knowledge of relations to its intended uses.

During 2000, groundwater use in the Virginia Coastal Plain was 137.4 Mgal/d (Pope and others, 2008), of which nearly half was used to supply major industries and diverse commercial enterprises. Urban municipalities withdrew nearly another quarter, to provide public drinking water in developed areas. More than another quarter of the water was withdrawn from small, privately owned domestic supply wells that are widely dispersed across large rural areas. Irrigation and other uses made up withdrawals equivalent to less than 3 percent of the total.

General relations between groundwater quality and use in the Virginia Coastal Plain are summarized on the basis of regional trends and related processes presented in earlier sections of this report. Discussion is limited to only some chemical constituents that are generally present naturally and does not address constituents that originate from human contamination. Water-treatment technology and groundwater remediation are broad and complex fields of engineering and environmental science. Major water-production facilities providing industrial, commercial, and public supplies commonly employ large and elaborate processing operations to achieve the required chemical quality for a particular use. In addition, the quality of water in the environment and produced for drinking involves diverse regulatory and public-policy issues. A full discussion of these topics is beyond the scope of this report.

Various groundwater-quality issues affect diverse uses, ranging among individual, privately owned domestic wells, small community or commercial water systems, and major water-production facilities. In addition to chemical treatment, sound planning and other resource-management strategies can potentially avoid the use of groundwater having an unsuitable quality for an intended use.

\section{Hardness}

The primary influence on the suitability of groundwater for various uses is exerted by the major ions that dominate its chemical composition (see "Major Ions"). $\left(\mathrm{Na}^{+}+\mathrm{K}^{+}\right)+\left(\mathrm{HCO}_{3}^{-}+\mathrm{CO}_{3}^{-}\right)$"soft" type water in deep aquifers beneath the central part of the Virginia Coastal Plain is generally suitable for a wide variety of uses. By contrast, $\left(\mathrm{Ca}^{2+}+\mathrm{Mg}^{2+}\right)+\left(\mathrm{HCO}_{3}^{-}+\mathrm{CO}_{3}^{-}\right)$"hard" type water in parts of these aquifers to the west, and at some locations in shallower aquifers and basement bedrock along the Fall Zone, can potentially require treatment for some uses.

The concept of water having properties described as either hard or soft has been traced as far back as Hippocrates (460-377 B.C.) (Hem, 1985). Distinct from the categorization used herein, an array of alternative definitions of hard water exists (Freeze and Cherry, 1979; Hem, 1985; Drever, 1988; Wilson and others, 1999a). Various semiquantitative measures are commonly reported, most widely in terms of equivalent concentration of calcium carbonate, but are inconsistently determined and generally not useful in providing a precise hydrochemical description. Many reported hardness values are actually calculated by different methods from the separately analyzed concentrations of individual chemical constituents (Hem, 1985). Similarly, from the chemical-constituent concentration values tabulated in this report (Attachment 1), hardness values can potentially be calculated by a variety of schemes.

Hardness is the most commonly reported water problem in the United States, and by some estimates, 85 percent of water nationwide is considered hard (Wilson and others, 1999a). Hard water is not associated with negative health effects, however, and is not regulated by drinking-water standards (U.S. Environmental Protection Agency, 1990). Problematic aspects of hard water include reaction with soap and detergent to form insoluble compounds and precipitation of solid deposits (Wilson and others, 1999a). The effectiveness of cleansing agents is hindered when combined in hard water mostly with calcium and magnesium cations to produce a waxy slime, scum, or other forms of residue. In addition, scaly deposits of calcium carbonate and other precipitates can accumulate with deleterious effects in plumbing, appliances, and other devices and systems through which hard water is conveyed.

The most common form of treatment for hard water is softening by ion exchange (Wilson and others, 1999a). Artificial water softening is analogous to the softening from ion exchange by subsurface sediments that takes place naturally in deep aquifers beneath the central part of the Virginia Coastal Plain (see "Major Ions"). Water-softening systems are made up of columns of small, densely packed synthetic resin beads, through which hard water is transmitted to adsorb calcium and magnesium cations in exchange for sodium cations. Water softening is commonly used by major water-production facilities, but smaller systems are also designed for individual domestic wells and small community or commercial water supplies. Appropriate system design depends on the required water-production capacity and other features, such as the desired method of column regeneration (manual versus automated). Required system maintenance entails periodic back-flushing with a concentrated sodium chloride solution followed by freshwater to regenerate the ion-exchange column 
by desorbing calcium and magnesium cations with a renewed supply of sodium cations.

Although generally considered superior to hard water for most uses, soft water possesses some limitations. For privately owned softening systems, the concentration of sodium produced should be evaluated by users for whom sodium consumption is a health concern. Some systems can use potassium instead of sodium, whereas others include a bypass feature to supply untreated water for drinking and cooking. In addition, as an aesthetic consideration, bathing with soft water (either treated or naturally present) can produce a slippery feel on skin. Alternative explanations are that (1) the nonreactivity of soft water with soap possibly hinders its ability to remove soap from the surface of skin or (2) when hard water is used, small amounts of insoluble residue possibly absorb oil from the skin to produce a greater drying sensation.

\section{Chloride}

The most substantial limitations and treatment requirements for groundwater use in the Virginia Coastal Plain likely are posed by $\left(\mathrm{Na}^{+}+\mathrm{K}^{+}\right)+\mathrm{Cl}^{-}$"salty" type water having large total ion concentrations in the eastern parts of deep aquifers (see "Major Ions") and at some locations in shallower aquifers. Localized changes in groundwater chloride concentration, including some exceeding the secondary maximum contaminant level of $250 \mathrm{mg} / \mathrm{L}$ (U.S. Environmental Protection Agency, 1990), are associated with possible movement of salty groundwater in response to withdrawals close to and within the saltwater-transition zone (see "Movement").

Salty groundwater in parts of the Virginia Coastal Plain is currently being increasingly developed as a water source. Brackish groundwater is withdrawn and treated as a means of addressing mounting water demands in rapidly growing metropolitan areas underlain by the saltwater-transition zone. As of 2007, five municipalities operate large-scale brackish groundwater development (BGD) facilities (table 3) as parts

Table 3. Municipalities operating brackish groundwater development (BGD) facilities in the Virginia Coastal Plain. ${ }^{1}$

[Mgal/d, million gallons per day]

\begin{tabular}{lcc}
\hline \multicolumn{1}{c}{ Municipality } & $\begin{array}{c}\text { Permitted } \\
\text { withdrawal } \\
\text { rate (Mgal/d) }\end{array}$ & $\begin{array}{c}\text { Withdrawal rate } \\
\text { during 2005 }\end{array}$ \\
\hline City of Chesapeake & 5 & 3.54 \\
Gloucester County & 8 & 0.66 \\
James City County & 6 & 1.50 \\
City of Newport News & 7 & 2.17 \\
City of Suffolk & 4 & 2.71 \\
\hline Total & 30 & 10.58 \\
\hline${ }^{1}$ J.P. Pope, U.S. Geological Survey, written commun., 2009. \\
${ }^{2}$ As of November 2007.
\end{tabular}

of their public drinking-water systems. Rates of withdrawal among the individual BGD plants during 2005 ranged from $0.66 \mathrm{Mgal} / \mathrm{d}$ to $3.54 \mathrm{Mgal} / \mathrm{d}$ and collectively totaled $10.58 \mathrm{Mgal} / \mathrm{d}$. Each municipality has received permits from the DEQ, however, authorizing greater withdrawal rates that total $30 \mathrm{Mgal} / \mathrm{d}$. BGD operation is expected to increase during the coming several decades. In addition, desalinization is known anecdotally through local well drillers to be increasingly used among small water-supply operations, such as centralized drinking-water systems serving residential subdivisions (T.S. Bruce, Virginia Department of Environmental Quality, oral commun., 2009). With desalination generally improving in efficiency and decreasing in cost, parts of aquifers containing salty water once thought to be avoided are increasingly viewed as favorable for development.

In addition to the direct withdrawal of salty groundwater by desalination facilities, other groundwater uses in the Virginia Coastal Plain are potentially affected by salty groundwater. Among these, essentially the entire water supply on the Virginia Eastern Shore is obtained from groundwater, because fresh surface water generally is unavailable (Sanford and others, 2009a). Additionally, in the city of Virginia Beach, numerous withdrawals are made from residential privately owned wells, many for seasonal uses such as watering lawns and gardens (Smith, 2005), because use of public water is restricted to consumptive purposes. In both areas, fresh groundwater is available only from the shallow and laterally constrained surficial and Yorktown-Eastover aquifers, beneath which salty groundwater occupies deeper hydrogeologic units.

Treatment and other resource-management options to address issues associated with salty groundwater in the Virginia Coastal Plain are varied. Municipal BGD operations are large and complex, and have only relatively recently been implemented in response to growing demands for public drinking water. Each BGD plant uses methods of desalination that include reverse osmosis and electrodialysis reversal, but also blends water from multiple wells having different chloride concentrations. Smaller distillation and reverse osmosis systems for privately owned wells and small community or commercial water supplies have historically been viewed as inefficient and costly (Parrott and others, 1999), but are improving and being increasingly used.

In addition to treating salty groundwater directly withdrawn, other measures can potentially minimize its movement. Where withdrawals are primarily of shallow freshwater, such as the Virginia Eastern Shore and city of Virginia Beach, groundwater development could be redirected by locating and operating production wells to maintain chloride concentrations below levels requiring treatment. In other areas where many production wells are already positioned close to and within the saltwater-transition zone, withdrawals of fresh groundwater could potentially be offset by withdrawals of salty groundwater to balance gradients across the saltwater-transition zone and thereby preclude saltwater intrusion. Areas of potential intrusion, however, are probably numerous, complexly distributed, and variable over time (see "Movement"). Hence, 
a program of conjunctive freshwater/saltwater groundwater development would require detailed hydrologic analysis of potential effects of proposed withdrawals, comprehensive coordination among the numerous and diverse water suppliers operating production wells, and an effective, long-term saltwater-intrusion monitoring network (see "Monitoring").

\section{Selected Constituents}

In addition to the major ions, some other chemical constituents can influence the suitability of groundwater in the Virginia Coastal Plain for various uses. Among these, fluoride is present in groundwater at concentrations exceeding primary and secondary drinking-water standards $(4 \mathrm{mg} / \mathrm{L}$ and $2 \mathrm{mg} / \mathrm{L}$, respectively) (U.S. Environmental Protection Agency, 1990), along a broad belt beneath the city of Suffolk that thins and tapers northward (see "Fluoride"). Because fluoride is chemically similar to chloride, it can be removed from groundwater using distillation and reverse osmosis systems similar to those used to remove chloride, but with the same shortcomings. Removal by ion exchange has also been suggested, alternatively using tricalcium phosphate, magnesium oxide, or magnesium hydroxide (Sinnott and Whetstone, 1962), hydroxylapatite (Zack, 1980), or "bone char" (Maciuika, 1992), a type of charcoal produced from animal bones.

In addition to treatment for removal of fluoride, blending of water from different sources can lower fluoride concentrations to beneficial levels (Sinnott and Whetstone, 1962). BGD operations in the city of Suffolk during 2007 (table 3) included blending of groundwater having large fluoride concentrations with water from a different well, from which essentially all fluoride had been removed as a result of desalination by electrodialysis reversal (J.P. Pope, U.S. Geological Survey, written commun., 2009). Deep groundwater in the city of Suffolk that underlies the high fluoride belt is also salty, requiring treatment for large chloride concentrations. At shallower depths, however, the Saint Marys aquifer can potentially provide a limited source of groundwater having smaller concentrations of both fluoride and chloride (McFarland and Bruce, 2006). The Saint Marys aquifer has so far only been very lightly used by a small number of private domestic wells.

Concentrations of iron and manganese in groundwater that exceed secondary drinking-water standards $(0.3 \mathrm{mg} / \mathrm{L}$ and $0.05 \mathrm{mg} / \mathrm{L}$, respectively) (U.S. Environmental Protection Agency, 1990) are at scattered locations throughout the Virginia Coastal Plain, but are more common to the west along the Fall Zone, across the saltwater-transition zone and eastward within the Potomac aquifer and lower part of the marine sediments, and within the shallow part of the marine sediments far to the east (see "Iron and Manganese"). Large concentrations of dissolved hydrogen sulfide gas also commonly coincide with those of iron and manganese (Ross and others, 2002) and can originate from dissolution of pyrite and decomposition of organic matter. Hydrogen sulfide is not associated with negative health effects and is not regulated by drinking-water standards (U.S. Environmental Protection
Agency, 1990), but can produce a strong objectionable odor and taste, and can induce corrosion in plumbing. Only 30 analyses of hydrogen sulfide are included among the tabulated groundwater-sample data (Attachments 1,2), which are inadequate to determine regional trends.

Removal of iron, manganese, and hydrogen sulfide are common necessary treatments of water from supply wells. One or more of these treatments are commonly used by major water-production facilities, but smaller systems are also designed for individual domestic wells and small community or commercial water supplies. Appropriate system design depends on the required water-production capacity and other considerations, including the level of treatment needed (Wilson and others, 1999b; Ross and others, 2002). Phosphate compounds chemically suspend iron and manganese at concentrations up to $3 \mathrm{mg} / \mathrm{L}$, but must be added while the iron and manganese are still dissolved and become ineffective at elevated temperatures (such as boiling). Water softening used to treat hard water (see "Hardness") can also remove iron and manganese at concentrations up to $5 \mathrm{mg} / \mathrm{L}$, but only by systems designed to do so. Hydrogen sulfide at concentrations less than $1 \mathrm{mg} / \mathrm{L}$ can be removed by activated carbon filters. Larger concentrations of iron, manganese, and hydrogen sulfide generally require some form of oxidation combined with filtering, either by chemical solutions, greensand, or aeration. These methods require varying degrees of pre- and post-treatment, and potentially intensive maintenance.

Concentrations of nitrate in groundwater that exceed the drinking-water standard of $10 \mathrm{mg} / \mathrm{L}$ (U.S. Environmental Protection Agency, 1990) are at widely scattered locations throughout the Virginia Coastal Plain, but mostly are limited to shallow depths (see "Nitrate and Ammonium"). Relatively large concentrations of ammonium are also present at somewhat greater depths and can transform to produce additional nitrate. Both constituents can be produced in some places by decomposition of sediment organic matter, but elsewhere possibly originate from site-specific human sources.

Removal of nitrate is a potential necessary treatment of water primarily from relatively shallow wells, which typically provide individual domestic and small community or commercial water supplies. Treatment options include distillation and reverse osmosis systems (Parrott and others, 2002) similar to those used to remove chloride, but with the same shortcomings. Alternatively, ion exchange can be used in a manner analogous to water softening, but configured to exchange nitrate anions for chloride anions. Such systems can require post-treatment to reduce corrosiveness, however, and their efficiency can be reduced by the presence of other anions, such as sulfate.

In addition to treatment for removal of nitrate, use of a different source can potentially provide groundwater having acceptably small concentrations. Wells producing water with relatively large nitrate or ammonium concentrations can often be in proximity to other wells exhibiting substantially smaller concentrations. In some instances where a specific source of nitrate and(or) ammonium is likely, a new well located 
and constructed to avoid the source is a possible long-term solution. Blending of water from a different source can also produce acceptable nitrate and(or) ammonium concentrations. Likewise, well siting and construction in areas undergoing new development can be undertaken to avoid previously existing and likely future sources.

\section{Summary and Conclusions}

Groundwater in the Virginia Coastal Plain is heavily used, and information on its chemical quality is critical to sound resource management. An investigation was undertaken during 2006-08 by the U.S. Geological Survey, in cooperation with the Virginia Department of Environmental Quality and the Hampton Roads Planning District Commission, to incorporate updated knowledge of groundwater quality into a newly developed regional perspective of the hydrogeology of the Virginia Coastal Plain. Results of the study include the following:

1. Data retrieved from multiple Federal and State agency databases represent 10,165 groundwater samples collected from 1,991 wells and boreholes during 1906 to 2007. Analytical results for 37 chemical constituents include 73,610 individual sample constituent values.

2. Chemical-constituent values and related data enable well drillers and owners, environmental consultants, and water-resource managers to address needs for local-scale information on groundwater quality. Use of the groundwater-sample data is supported by tables, summaries, location maps, and discussions of data quality and limitations.

3. A series of interpretive analyses of the sample data enable planners and policy makers to reach informed water-resource decisions, based on a conceptual understanding of spatial trends in groundwater quality and related processes at the regional scale. Maps, sections, and discussion describe concentrations of major ions, the configuration of the saltwatertransition zone, and selected other constituents of particular interest to resource management.

4. Based on concentrations of major ions that dominate the chemical composition of groundwater, most groundwater samples collected from water-supply aquifers are categorized as either

a. "hard" water, dominated by calcium and magnesium cations and bicarbonate and carbonate anions,

b. "soft" water, dominated by sodium and potassium cations and bicarbonate and carbonate anions, or c. "salty" water, dominated by sodium and potassium cations and chloride anions.

The chemical composition of groundwater in the deep Piney Point, Aquia, and Potomac aquifers evolves eastward and with depth, from hard to soft to salty. Chemical weathering of subsurface sediments is followed by ion exchange by clay and glauconite, and subsequently by mixing with seawater along the saltwater-transition zone. The chemical composition of groundwater in the shallower surficial and Yorktown-Eastover aquifers, and in basement bedrock along the Fall Zone, is more variable as a result of short flow paths between closely located recharge and discharge areas and possibly some solutes originating from human sources.

5. Groundwater chloride concentrations generally increase eastward and with depth, but are also displaced upward across the Chesapeake Bay impact crater and inverted across distinct downwarddecreasing vertical intervals. Although generally landward-dipping, the saltwater-transition zone is also convoluted where warped and mounded around the impact crater along the inverted zones. Fresh groundwater has flushed seawater from subsurface sediments preferentially around the impact crater as a result of broad contrasts between sediment permeabilities. Paths of differential flushing are also focused along the inverted zones, which follow stratigraphic and structural trends southeastward into North Carolina and northeastward beneath the chloride mound across the outer impact crater. Brine within the inner impact crater has probably remained unflushed, but its origin has also not yet been fully explained. Regional movement of the saltwatertransition zone takes place over geologic time scales. Localized movement has been induced by groundwater withdrawal, mostly along shallow parts of the saltwater-transition zone. Short-term episodic withdrawals result in repeated cycles of upconing and downconing, which are superimposed upon longer-term lateral intrusion. Effective monitoring for saltwater intrusion needs to address multiple and complexly distributed areas of potential intrusion that vary over time.

6. Groundwater fluoride concentrations exceed the drinking-water standard along a broad belt beneath the city of Suffolk that thins and tapers northward. Widespread small concentrations of fluoride probably originate by desorbtion from phosphatic sedimentary material. The high fluoride belt was possibly formed by initial adsorbtion of fluoride onto sediment oxyhydroxides, followed by desorbtion along the leading edge of the advancing saltwatertransition zone. 
7. Groundwater iron and manganese concentrations exceed drinking-water standards at scattered locations, but are more common to the west along the Fall Zone, across part of the saltwater-transition zone and eastward, and within shallow groundwater far to the east. Iron and manganese initially produced by mineral dissolution along the Fall Zone are adsorbed eastward and with depth by clay and glauconite, and subsequently desorbed along the leading edge of the advancing saltwater-transition zone. Iron and manganese in shallow groundwater far to the east are produced by reaction of sediment organic matter with oxyhydroxides.

8. Groundwater nitrate concentrations exceed the drinking-water standard at widely scattered locations, but are mostly limited to shallow depths. Ammonium is also present in large concentrations at some locations and can transform to produce additional nitrate. Although most nitrate and ammonium is naturally recycled near the land surface, some can be produced by decomposition of sediment organic matter, ion exchange along the leading edge of the advancing saltwater-transition zone, and possibly from site-specific human sources.

9. The chemical quality of groundwater determines its suitability for diverse uses. Soft water in deep aquifers is generally suitable for a wide variety of uses. Hard water at other locations can require treatment, most commonly by ion exchange. Salty water in the eastern parts of deep aquifers is undergoing increasingly widespread production for drinking-water supplies. Treatment operations use desalination and blending. Saltwater intrusion can potentially be mitigated by redirecting locations and operation of wells producing shallow freshwater and by conjunctive freshwater/saltwater groundwater development close to and within the saltwater-transition zone. In areas of large fluoride concentrations, blending of water from different sources is used as an alternative to removal. Large iron and manganese concentrations and associated hydrogen sulfide concentrations can potentially be mitigated by one or more method from an array of treatment methods, depending on the level of treatment needed. Large nitrate concentrations can potentially be mitigated by various treatment methods or withdrawal management.

\section{Acknowledgments}

This study was supported by the Virginia Department of Environmental Quality (DEQ) and the Hampton Roads Planning District Commission (HRPDC). Special thanks for program planning go to Scott Kudlas, Terry Wagner, Scott
Bruce, and Mary Ann Massie of DEQ, and to John Carlock and Whitney Katchmark of HRPDC.

Groundwater-quality data compilation was greatly assisted by database retrieval, organization, and transfer provided by Brad White, Todd Beach, and Beverly Quinlan at DEQ. Pore-water chemistry data from the inner Chesapeake Bay impact crater was provided by Ward Sanford of the U.S. Geological Survey (USGS) National Research Program.

Thanks also are extended to the many drillers and owners of water-supply wells, who have provided well data from across the Virginia Coastal Plain.

The quality of this report was aided greatly by Otto S. Zapecza of the USGS New Jersey Water Science Center, John S. Clarke of the USGS Georgia Water Science Center, and Rebecca J. Deckard, Kay E. Hedrick, and Jeffrey L. Corbett of the USGS Enterprise Publishing Network.

\section{References Cited}

Back, William, 1966, Hydrochemical facies and ground-water flow patterns in northern part of Atlantic Coastal Plain: U.S. Geological Survey Professional Paper 498-A, 42 p.

Back, William, and Barnes, Ivan, 1965, Relation of electrochemical potentials and iron content to ground-water flow patterns: U.S. Geological Survey Professional Paper 498-C, $16 \mathrm{p}$.

Barlow, P.M., and Wild, E.C., 2002, Bibliography on the occurrence and intrusion of saltwater in aquifers along the Atlantic coast of the United States: U.S. Geological Survey Open-File Report 02-235, 30 p.

Bell, C.F., 1996, Hydrogeology and water quality of the shallow aquifer system at the Explosive Experimental Area, Naval Surface Warfare Center, Dahlgren Site, Dahlgren, Virginia: U.S. Geological Survey Water-Resources Investigations Report 96-4209, 37 p.

Bradley, R.S., 1999, Paleoclimatology: Burlington, MA, Harcourt/Academic Press, 613 p.

Brown, D.L., and Silvey, W.D., 1977, Artificial recharge to a freshwater-sensitive brackish-water sand aquifer, Norfolk, Virginia: U.S. Geological Survey Professional Paper 939, $53 \mathrm{p}$.

Caine, J.S., Evans, J.P., and Forster, C.B., 1996, Fault zone architecture and permeability structure: Geology, v. 24, no. 11 , p. $1025-1028$.

Cederstrom, D.J., 1939, Geology and artesian-water resources of a part of the southern Virginia Coastal Plain: Virginia Geological Survey Bulletin 51-E, p. 123-136. 
Cederstrom, D.J., 1943, Chloride in ground water in the Coastal Plain of Virginia: Virginia Geological Survey Bulletin 58, $36 \mathrm{p}$.

Cederstrom, D.J., 1945, Geology and ground-water resources of the Coastal Plain in southeastern Virginia: Virginia Geological Survey Bulletin 63, 384 p.

Cederstrom, D.J., 1946a, Chemical character of ground water in the Coastal Plain of Virginia: Virginia Geological Survey Bulletin 68, $62 \mathrm{p}$.

Cederstrom, D.J., 1946b, Genesis of ground waters in the Coastal Plain of Virginia: Economic Geology, v. 41, no. 3, p. 218-245.

Cederstrom, D.J., 1957, Geology and ground-water resources of the York-James Peninsula, Virginia: U.S. Geological Survey Water-Supply Paper 1361, 237 p.

Cederstrom, D.J., 1968, Geology and ground-water resources of the Middle Peninsula, Virginia: U.S. Geological Survey Open-File Report 69-37, 231 p.

Commonwealth of Virginia, 1973, Ground water of the YorkJames Peninsula, Virginia: Virginia State Water Control Board Basic Data Bulletin 39, 74 p.

Commonwealth of Virginia, 1974, Groundwater of southeastern Virginia: Virginia State Water Control Board Planning Bulletin 261-A, 33 p.

Commonwealth of Virginia, 1975, Groundwater conditions in the Eastern Shore of Virginia: Virginia State Water Control Board Planning Bulletin 45, 59 p.

Drever, J.I., 1988, The geochemistry of natural waters: Englewood Cliffs, NJ, Prentice Hall, 437 p.

Ellison, R.P., III, and Masiello, R.A., 1979, Groundwater resources of Hanover County, Virginia: Virginia State Water Control Board Planning Bulletin 314, 130 p.

Fenema, R.J., and Newton, V.P., 1982, Ground water resources of the Eastern Shore of Virginia: Virginia State Water Control Board Planning Bulletin 332, 74 p.

Focazio, M.J., and Speiran, G.K., 1993, Estimating net drawdown resulting from episodic withdrawals at six well fields in the Coastal Plain Physiographic Province of Virginia: U.S. Geological Survey Water-Resources Investigations Report 93-4159, 21 p.

Focazio, M.J., Speiran, G.K., and Rowan, M.E., 1993, Quality of ground water in the Coastal Plain Physiographic Province of Virginia: U.S. Geological Survey Water-Resources Investigations Report 92-4175, 20 p.

Freeze, R.A., and Cherry, J.A., 1979, Groundwater: Englewood Cliffs, NJ, Prentice Hall, 604 p.
Ghyben, W.B., 1888, Nota in verb and met de voorgenomen put boring nabij Amsterdam: Tijdschrift van Let Koninklijk Inst. Van Ing.

Hammond, E.C., and Focazio, M.J., 1995, Water use in Virginia-Surface-water and ground-water withdrawals during 1992: U.S. Geological Survey Fact Sheet FS 94-057, 2 p.

Hammond, E.C., McFarland, E.R., and Focazio, M.J., 1994a, Potentiometric surface of the Brightseat-upper Potomac aquifer in Virginia, 1993: U.S. Geological Survey Open-File Report 94-370, 1 p.

Hammond, E.C., McFarland, E.R., and Focazio, M.J., 1994b, Potentiometric surface of the middle Potomac aquifer in Virginia, 1993: U.S. Geological Survey Open-File Report 94-372, 1 p.

Hammond, E.C., McFarland, E.R., and Focazio, M.J., 1994c, Potentiometric surface of the lower Potomac aquifer in Virginia, 1993: U.S. Geological Survey Open-File Report 94-373, 1 p.

Harlow, G.E., Jr., and Bell, C.F., 1996, Hydrogeology and water quality of the shallow aquifer system at the Mainside, Naval Surface Warfare Center, Dahlgren Site, Dahlgren, Virginia: U.S. Geological Survey Water-Resources Investigations Report 96-4055, 34 p.

Harsh, J.F., 1980, Ground-water hydrology of James City County, Virginia: U.S. Geological Survey Open-File Report 80-961, 73 p.

Harsh, J.F., and Laczniak, R.J., 1990, Conceptualization and analysis of ground-water flow system in the Coastal Plain of Virginia and adjacent parts of Maryland and North Carolina: U.S. Geological Survey Professional Paper 1404-F, 100 p.

Heath, R.C., 1983, Basic ground-water hydrology: U.S. Geological Survey Water-Supply Paper 2220, 84 p.

Heller, M.J., 2008, Trends in the depth, yield, and water quality of wells in Virginia related to geologic conditions: Virginia Minerals, v. 51, nos. 1 and 2, 16 p.

Helsel, D.R., and Hirsch, R.M., 2002, Statistical methods in water resources: U.S. Geological Survey Techniques of Water-Resources Investigations, book 4, chap. A3, 510 p.

Hem, J.D., 1985, Study and interpretation of the chemical characteristics of natural water: U.S. Geological Survey Water-Supply Paper 2254, 263 p.

Henry, H.R., 1960, Salt water intrusion into coastal aquifers: International Association of Scientific Hydrology, Publication 52, p. 478-487. 
Herzberg, A., 1901, Die Wasserversorgung einiger Nordsee bader: Journal Gasbeleuchtung und Wasserversorgung, v. 44 , p. 815-819.

Heywood, C.E., 2003, Influence of the Chesapeake Bay impact structure on ground-water flow and salinity in the Atlantic Coastal Plain aquifer system of Virginia, in Proceedings of the conference, MODFLOW and more 2003Understanding through modeling: Golden, CO, Colorado School of Mines, International Ground Water Modeling Center, p. 871-875.

Heywood, C.E., and Pope, J.P., 2009, Simulation of groundwater flow in the Coastal Plain aquifer system of Virginia: U.S. Geological Survey Scientific Investigations Report 2009-5039, 115 p.

Hubbert, M.K., 1940, The theory of ground-water motion: Journal of Geology, v. 48, p. 785-944.

Johnson, G.H., and Ramsey, K.W., 1987, Geology and geomorphology of the York-James Peninsula, Virginia, in Proceedings of the Atlantic Coastal Plain Geological Association, 1987 meeting: Williamsburg, VA, College of William and Mary, 45 p.

Jones, B.F., Vengosh, A., Rosenthal, E., and Yechieli, Y., 1998, Geochemical investigations, in Bear, J., Cheng, A.H.-D., Sorek, S., Ouazar, D., and Hererra, I., eds., Seawater intrusion in coastal aquifers - Concepts, methods, and practices: Dordrecht, The Netherlands, Kluwer Academic Publishers, p. $43-63$.

Kooi, H., and Groen, J., 2000, Modes of seawater intrusion during transgressions: Water Resources Research, v. 36, no. 12 , p. 3581-3589.

Lacombe, P.J., and Carleton, G.B., 2002, Hydrogeologic framework, availability of water supplies, and saltwater intrusion, Cape May County, New Jersey: U.S. Geological Survey Water-Resources Investigations Report 01-4246, $151 \mathrm{p}$.

Laczniak, R.J., and Meng, A.A., III, 1988, Ground-water resources of the York-James Peninsula of Virginia: U.S. Geological Survey Water-Resources Investigations Report 88-4059, 178 p.

Larson, J.D., 1982, Distribution of saltwater in the Coastal Plain aquifers of Virginia: U.S. Geological Survey OpenFile Report 81-1013, 25 p.

Lichtler, W.F., and Wait, R.L., 1974, Summary of the ground-water resources of the James River basin, Virginia: U.S. Geological Survey Open-File Report 74-139, 54 p.

Maciuika, P.A., 1992, Relation of groundwater fluoride concentrations to sediment mineralogy, Potomac Formation, southeastern Virginia: Norfolk, Old Dominion University, Master's thesis, $118 \mathrm{p}$.
Manheim, F.T., and Horn, M.K., 1968, Composition of deeper subsurface waters along the Atlantic continental margin: Southeastern Geology, v. 9, no. 4, p. 215-236.

McFarland, E.R., 1998, Design, revisions, and considerations for continued use of a ground-water-flow model of the Coastal Plain aquifer system in Virginia: U.S. Geological Survey Water-Resources Investigations Report 98-4085, $49 \mathrm{p}$.

McFarland, E.R., 1999, Hydrogeologic framework and ground-water flow in the Fall Zone of Virginia:

U.S. Geological Survey Water-Resources Investigations Report 99-4093, 83 p.

McFarland, E.R., and Bruce, T.S., 2005, Distribution, origin, and resource-management implications of ground-water salinity along the western margin of the Chesapeake Bay impact structure in eastern Virginia, in Horton, J.W., Jr., Powars, D.S., and Gohn, G.S., eds., Studies of the Chesapeake Bay impact structure-The USGS-NASA Langely corehole, Hampton, Virginia, and related coreholes and geophysical surveys: U.S. Geological Survey Professional Paper 1688, chap. K, 32 p.

McFarland, E.R., and Bruce, T.S., 2006, The Virginia Coastal Plain hydrogeologic framework: U.S. Geological Survey Professional Paper 1731, 118 p.

Meisler, Harold, 1989, The occurrence and geochemistry of salty ground water in the northern Atlantic Coastal Plain: U.S. Geological Survey Professional Paper 1404-D, 51 p.

Meng, A.A., III, and Harsh, J.F., 1988, Hydrogeologic framework of the Virginia Coastal Plain: U.S. Geological Survey Professional Paper 1404-C, 82 p.

Mixon, R.B., Berquist, C.R., Jr., Newell, W.L., Johnson, G.H., Powars, D.S., Schindler, J.S., and Rader, E.K., 1989, Geologic map and generalized cross sections of the Coastal Plain and adjacent parts of the Piedmont, Virginia: U.S. Geological Survey Miscellaneous Investigations Series Map I-2033, scale 1:250,000.

National Weather Service, 1996, Climatological data, Virginia, December 1996: National Oceanic and Atmospheric Administration, v. 106, no. 12,26 p.

Nelms, D.L., Harlow, G.E., Jr., Plummer, L.N., and Busenberg, Eurybiades, 2003, Aquifer susceptibility in Virginia, 1998-2000: U.S. Geological Survey Water-Resources Investigations Report 03-4278, 58 p.

Newton, V.P., and Siudyla, E.A., 1979, Groundwater of the Northern Neck Peninsula, Virginia: Virginia State Water Control Board Planning Bulletin 307, 48 p.

Onuschak, Emil, Jr., 1972, Deep test in Accomack County, Virginia: Virginia Minerals, v. 18, no. 1, p. 1-4. 
Parrott, Kathleen, Ross, Blake, and Woodard, Janice, 1999 , Household water treatment: Virginia Cooperative Extension Publication 356-481, 6 p.

Parrott, Kathleen, Woodard, Janice, and Ross, Blake, 2002, Nitrates in household water: Virginia Cooperative Extension Publication 356-484, 2 p.

Peltier, W.R., 1994, Ice age paleotopography: Science, v. 265, no. 5169 , p. $195-201$.

Phillips, S.W., ed., 2007, Synthesis of U.S. Geological Survey science for the Chesapeake Bay ecosystem and implications for environmental management: U.S. Geological Survey Circular 1316, 63 p.

Pinder, G.F., and Cooper, H.H., Jr., 1970, A numerical technique for calculating the transient position of the saltwater front: Water Resources Research, v. 6, p. 875-882.

Pope, J.P., McFarland, E.R., and Banks, R.B., 2008, Private domestic-well characteristics and the distribution of domestic withdrawals among aquifers in the Virginia Coastal Plain: U.S. Geological Survey Scientific Investigations Report 2007-5250, 47 p.

Powars, D.S., 2000, The effects of the Chesapeake Bay impact crater on the geological framework and correlation of hydrogeologic units of southeastern Virginia, south of the James River: U.S. Geological Survey Professional Paper 1622, 53 p., 1 pl.

Powars, D.S., and Bruce, T.S., 1999, The effects of the Chesapeake Bay impact crater on the geological framework and correlation of hydrogeologic units of the lower York-James Peninsula, Virginia: U.S. Geological Survey Professional Paper 1612, 82 p., 9 pls.

Powell, J.D., and Hamilton, P.A., 1988, Virginia ground-water quality, in Moody, D.W., Carr, Jerry, Chase, E.B., and Paulson, R.W., comps., National water summary 1986-Hydrologic events and ground-water quality: U.S. Geological Survey Water-Supply Paper 2325, p. 509-514.

Richardson, D.L., 1994, Hydrogeology and analysis of the ground-water-flow system of the Eastern Shore, Virginia: U.S. Geological Survey Water-Supply Paper 2401, 108 p.

Richardson, D.L., and Brockman, A.R., 1992, Hydrogeology and water quality of the shallow ground-water system in eastern York County, Virginia: U.S. Geological Survey Water-Resources Investigations Report 92-4090, $41 \mathrm{p}$.

Ross, Blake, Parrott, Kathleen, and Woodard, Janice, 2002, Hydrogen sulfide in household water: Virginia Cooperative Extension Publication 356-488, 2 p.
Sanford, Samuel, 1913, The underground water resources of the Coastal Plain Province of Virginia: Virginia Geological Survey Bulletin 5, $361 \mathrm{p}$.

Sanford, Ward, 2003, Heat flow and brine generation following the Chesapeake Bay bolide impact: Journal of Geochemical Exploration, v. 78-79, p. 243-247.

Sanford, W.E., Pope, J.P., and Nelms, D.L., 2009a, Simulation of groundwater-level and salinity changes in the Eastern Shore, Virginia: U.S. Geological Survey Scientific Investigations Report 2009-5066, 125 p.

Sanford, W.E., Voytek, M.A., Powars, D.S., Jones, B.F., Cozzarelli, I.M., Cockell, C.S., and Eganhouse, R.P., 2009b, Pore-water chemistry from the ICDP-USGS corehole in the Chesapeake Bay impact structure-Implications for paleohydrology, microbial habitat, and water resources: Geological Society of America Special Paper 458, p. 867-890.

Sinnott, Allen, 1969, Ground-water resources of the Northern Neck Peninsula, Virginia: U.S. Geological Survey OpenFile Report 69-259, 269 p.

Sinnott, Allen, and Whetstone, G.W., 1962, Fluoride in well waters of the Virginia Coastal Plain: Virginia Minerals, v. 8, no. 1, p. 4-11.

Siudyla, E.A., Berglund, T.D., and Newton, V.P., 1977, Ground water of the Middle Peninsula, Virginia: Virginia State Water Control Board Planning Bulletin 305, 90 p.

Siudyla, E.A., May, A.E., and Hawthorn, D.W., 1981, Ground water resources of the four cities area, Virginia: Virginia State Water Control Board Planning Bulletin 331, 90 p.

Smith, B.S., 1999, The potential for saltwater intrusion in the Potomac aquifers of the York-James Peninsula, Virginia: U.S. Geological Survey Water-Resources Investigations Report 98-4187, 24 p.

Smith, B.S., 2003, Ground-water flow and saline water in the shallow aquifer system of the southern watersheds of Virginia Beach, Virginia: U.S. Geological Survey WaterResources Investigations Report 03-4258, 67 p.

Smith, B.S., 2005, Simulated changes in water levels caused by potential changes in pumping from shallow aquifers of Virginia Beach, Virginia: U.S. Geological Survey Scientific Investigations Report 2005-5067, 25 p.

Speiran, G.K., 1996, Geohydrology and geochemistry near coastal ground-water-discharge areas of the Eastern Shore, Virginia: U.S. Geological Survey Water-Supply Paper 2479, $73 \mathrm{p}$. 
Subitzky, Seymour, 1961, Residual sea water in the basement complex of the Fall Zone in the vicinity of Fredericksburg, Virginia, in Short papers in the geologic and hydrologic sciences, articles 293-435: U.S. Geological Survey Professional Paper 424-D, p. D71-D72.

U.S. Environmental Protection Agency, 1990, Secondary maximum contaminant levels (section 143.3 of part 143, National secondary drinking water regulations): U.S. Code of Federal Regulations, Title 40, Parts 100 to 149, revised as of July 1, 1990, p. 674.

Wigglesworth, H.A., Perry, T.W., and Ellison, R.P., III, 1984, Groundwater resources of Henrico County, Virginia:

Virginia State Water Control Board Planning Bulletin 328, $118 \mathrm{p}$.
Wilson, Amber, Parrott, Kathleen, and Ross, Blake, 1999a, Water hardness: Virginia Cooperative Extension Publication 356-490, 3 p.

Wilson, Amber, Parrott, Kathleen, and Ross, Blake, 1999b, Iron and manganese in household water: Virginia Cooperative Extension Publication 356-478, 3 p.

Zack, A.L., 1980, Geochemistry of fluoride in the Black Creek aquifer system of Horry and Georgetown Counties, South Carolina - and its physiological implications: U.S. Geological Survey Water-Supply Paper 2067, 40 p. 
Attachment 2. Summary of groundwater-quality constituent values for hydrogeologic units of the Virginia Coastal Plain.

[minimum and maximum values are cited from Attachment $1 ; \mathrm{mg} / \mathrm{L}$, milligrams per liter; $\mu \mathrm{S} / \mathrm{cm}$, microseimens per centimeter; $\mu \mathrm{g} / \mathrm{L}$, micrograms per liter; $\alpha$, alpha; $\beta$, beta; $\mathrm{pCi} / \mathrm{L}$, picocuries per liter; —, no data]

\begin{tabular}{|c|c|c|c|c|c|}
\hline Constituent & Analyses & Minimum & Maximum & Mean & Median \\
\hline \multicolumn{6}{|c|}{ All hydrogeologic units } \\
\hline \multicolumn{6}{|l|}{ General parameters } \\
\hline pH (standard units) & 5,653 & 0.1 & 13.55 & 7.2 & 7.5 \\
\hline temperature (degrees Celsius) & 2,592 & 2.0 & 210 & 16.2 & 15.6 \\
\hline dissolved oxygen $(\mathrm{mg} / \mathrm{L})$ & 1,822 & 0 & 16.1 & 2.0 & .6 \\
\hline filtered residue $(\mathrm{mg} / \mathrm{L})$ & 3,073 & 12.0 & 470,000 & 2,130 & 351 \\
\hline \multicolumn{6}{|l|}{ Major cations (all mg/L) } \\
\hline calcium & 3,954 & 0 & 160,000 & 143 & 15.0 \\
\hline magnesium & 3,936 & .0006 & 1,110 & 21.9 & 3.9 \\
\hline sodium & 4,176 & .02 & 203,000 & 844 & 97.0 \\
\hline \multicolumn{6}{|l|}{ Major anions (all mg/L) } \\
\hline carbonate & 164 & 0 & 45,000 & 1,190 & 11.0 \\
\hline sulfate & 3,905 & 0 & 32,100 & 117 & 13.0 \\
\hline chloride & 6,650 & 0 & 55,560 & 587 & 37.0 \\
\hline \multicolumn{6}{|l|}{ Nutrients (all mg/L) } \\
\hline nitrate nitrogen & 2,711 & 0 & 30.25 & 0.61 & 0.05 \\
\hline ammonium nitrogen & 2,293 & 0 & 685 & 9.3 & .2 \\
\hline orthophosphate & 2,323 & 0 & 1,390 & 2.8 & .1 \\
\hline total dissolved phosphorous & 1,865 & .001 & 88 & .32 & .10 \\
\hline \multicolumn{6}{|l|}{ Secondary constituents } \\
\hline silica $(\mathrm{mg} / \mathrm{L})$ & 1,066 & 0.4 & 38,400 & 302 & 19.0 \\
\hline hydrogen sulfide (mg/L) & 30 & 0 & .51 & .04 & 0 \\
\hline \multicolumn{6}{|l|}{ Radiochemical constituents } \\
\hline gross $\alpha$ : uranium $(\mu \mathrm{g} / \mathrm{L})$ & 5 & 0.4 & 1.4 & 0.98 & 1.0 \\
\hline gross $\alpha$ : radium + uranium - radon $(\mathrm{pCi} / \mathrm{L})$ & 7 & .3 & 35.2 & 8.6 & 1.0 \\
\hline gross $\alpha$ : radium - uranium - radon $(\mathrm{pCi} / \mathrm{L})$ & 2 & .3 & .5 & .4 & .4 \\
\hline $\operatorname{gross} \beta(\mathrm{pCi} / \mathrm{L})$ & 9 & 2.5 & 12.4 & 5.2 & 3.7 \\
\hline gross $\beta$ : cesium ( $\mathrm{pCi} / \mathrm{L}$ ) & 7 & .6 & 12 & 3.8 & 2.6 \\
\hline gross $\beta$ : strontium $(\mathrm{pCi} / \mathrm{L})$ & 7 & .5 & 9.4 & 3.0 & 2.3 \\
\hline radon $222(\mathrm{pCi} / \mathrm{L})$ & 57 & 50 & 2,970 & 390 & 280 \\
\hline radium $226(\mathrm{pCi} / \mathrm{L})$ & 3 & 0 & .5 & .2 & .2 \\
\hline radium $228(\mathrm{pCi} / \mathrm{L})$ & 9 & 0 & 1.4 & .46 & .40 \\
\hline $\operatorname{uranium}(\mu \mathrm{g} / \mathrm{L})$ & 3 & .06 & .30 & .15 & .09 \\
\hline
\end{tabular}


Attachment 2. Summary of groundwater-quality constituent values for hydrogeologic units of the Virginia Coastal Plain.-Continued [minimum and maximum values are cited from Attachment $1 ; \mathrm{mg} / \mathrm{L}$, milligrams per liter; $\mu \mathrm{S} / \mathrm{cm}$, microseimens per centimeter; $\mu \mathrm{g} / \mathrm{L}$, micrograms per liter; $\alpha$, alpha; $\beta$, beta; $\mathrm{pCi} / \mathrm{L}$, picocuries per liter; - , no data]

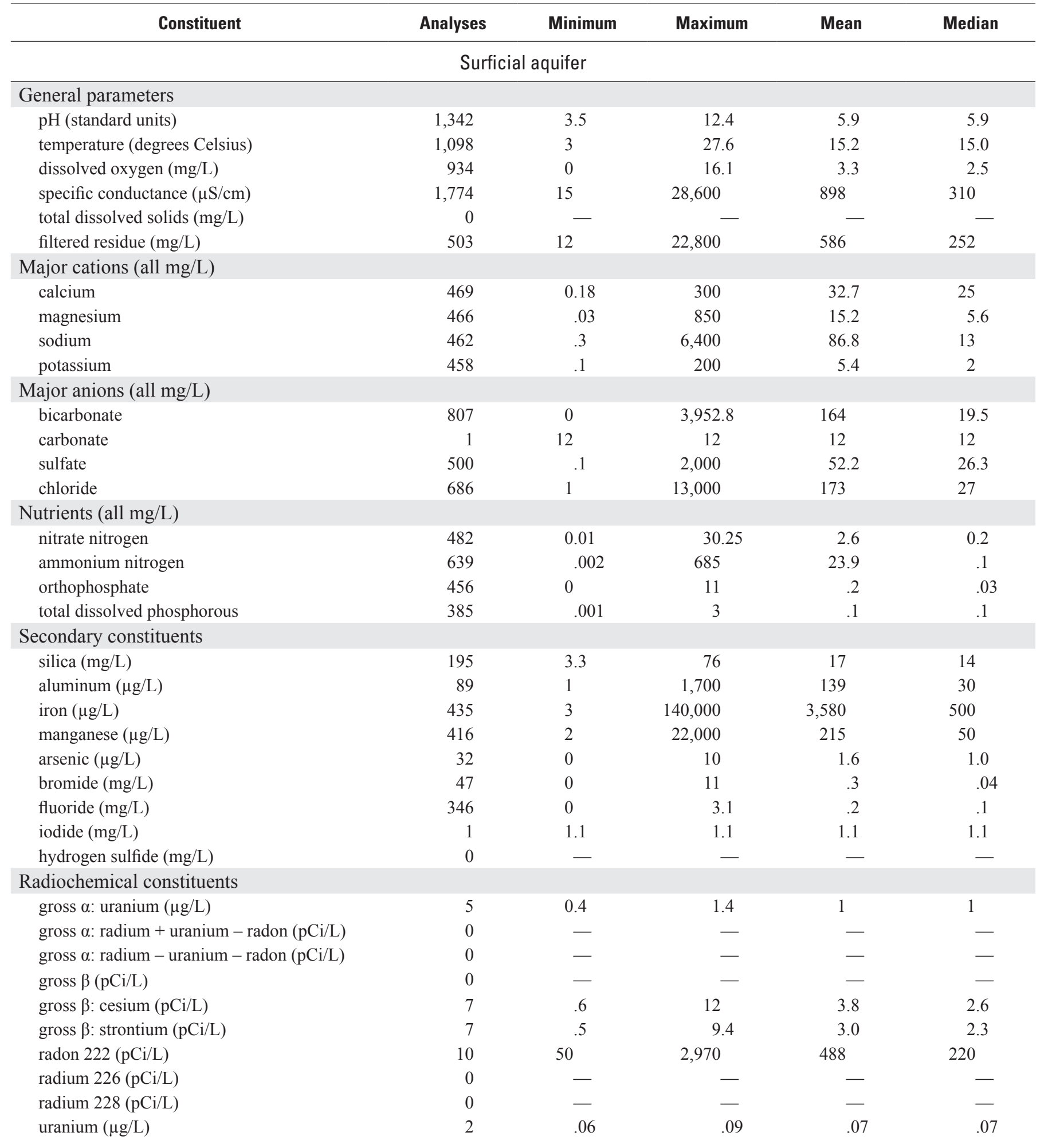


Attachment 2. Summary of groundwater-quality constituent values for hydrogeologic units of the Virginia Coastal Plain.-Continued

[minimum and maximum values are cited from Attachment $1 ; \mathrm{mg} / \mathrm{L}$, milligrams per liter; $\mu \mathrm{S} / \mathrm{cm}$, microseimens per centimeter; $\mu \mathrm{g} / \mathrm{L}$, micrograms per liter; $\alpha$, alpha; $\beta$, beta; $\mathrm{pCi} / \mathrm{L}$, picocuries per liter; —, no data]

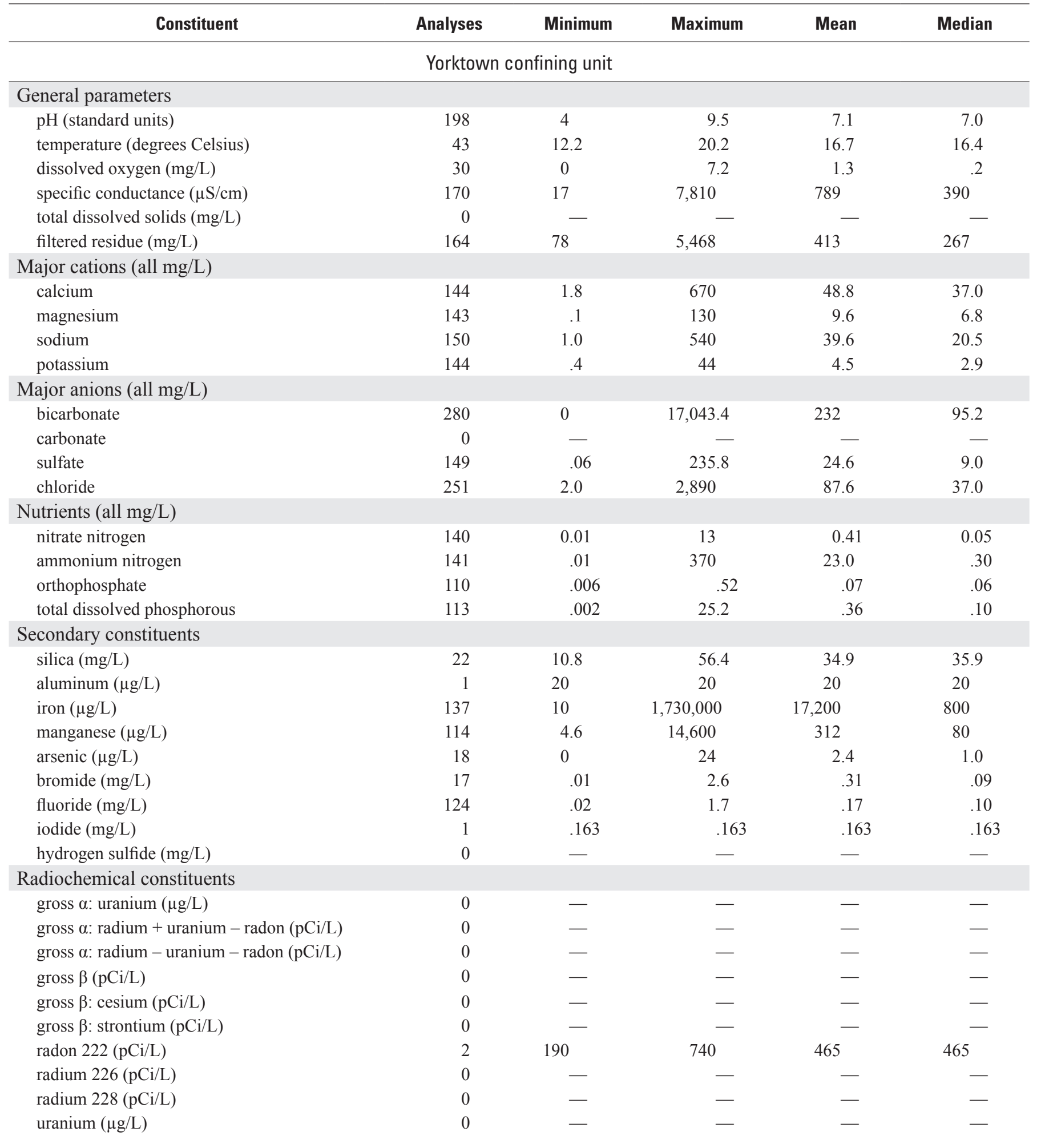


Attachment 2. Summary of groundwater-quality constituent values for hydrogeologic units of the Virginia Coastal Plain.-Continued

[minimum and maximum values are cited from Attachment $1 ; \mathrm{mg} / \mathrm{L}$, milligrams per liter; $\mu \mathrm{S} / \mathrm{cm}$, microseimens per centimeter; $\mu \mathrm{g} / \mathrm{L}$, micrograms per liter; $\alpha$, alpha; $\beta$, beta; $\mathrm{pCi} / \mathrm{L}$, picocuries per liter; —, no data]

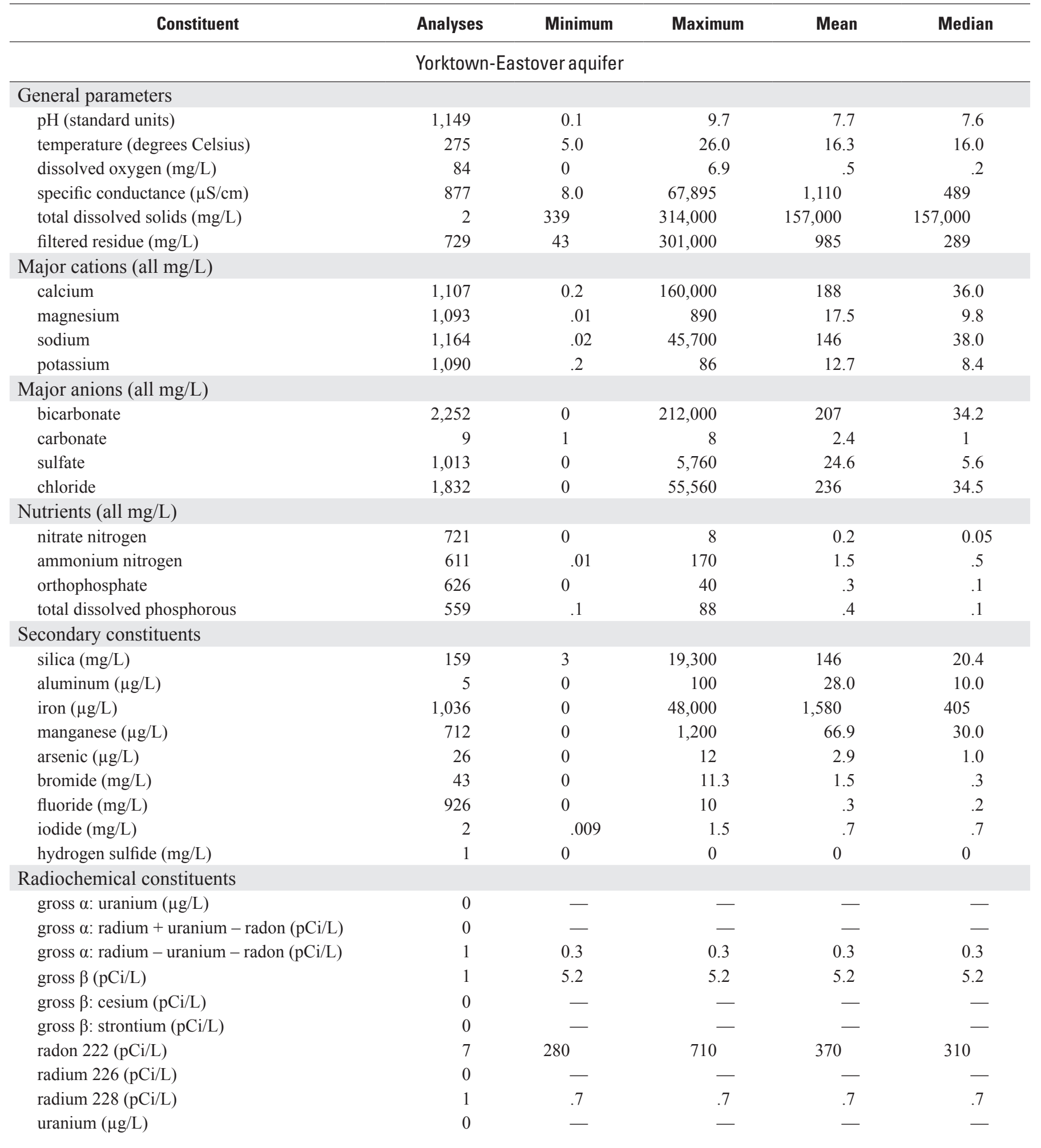


Attachment 2. Summary of groundwater-quality constituent values for hydrogeologic units of the Virginia Coastal Plain.-Continued

[minimum and maximum values are cited from Attachment $1 ; \mathrm{mg} / \mathrm{L}$, milligrams per liter; $\mu \mathrm{S} / \mathrm{cm}$, microseimens per centimeter; $\mu \mathrm{g} / \mathrm{L}, \mathrm{micrograms}$ per liter; $\alpha$, alpha; $\beta$, beta; $\mathrm{pCi} / \mathrm{L}$, picocuries per liter; —, no data]

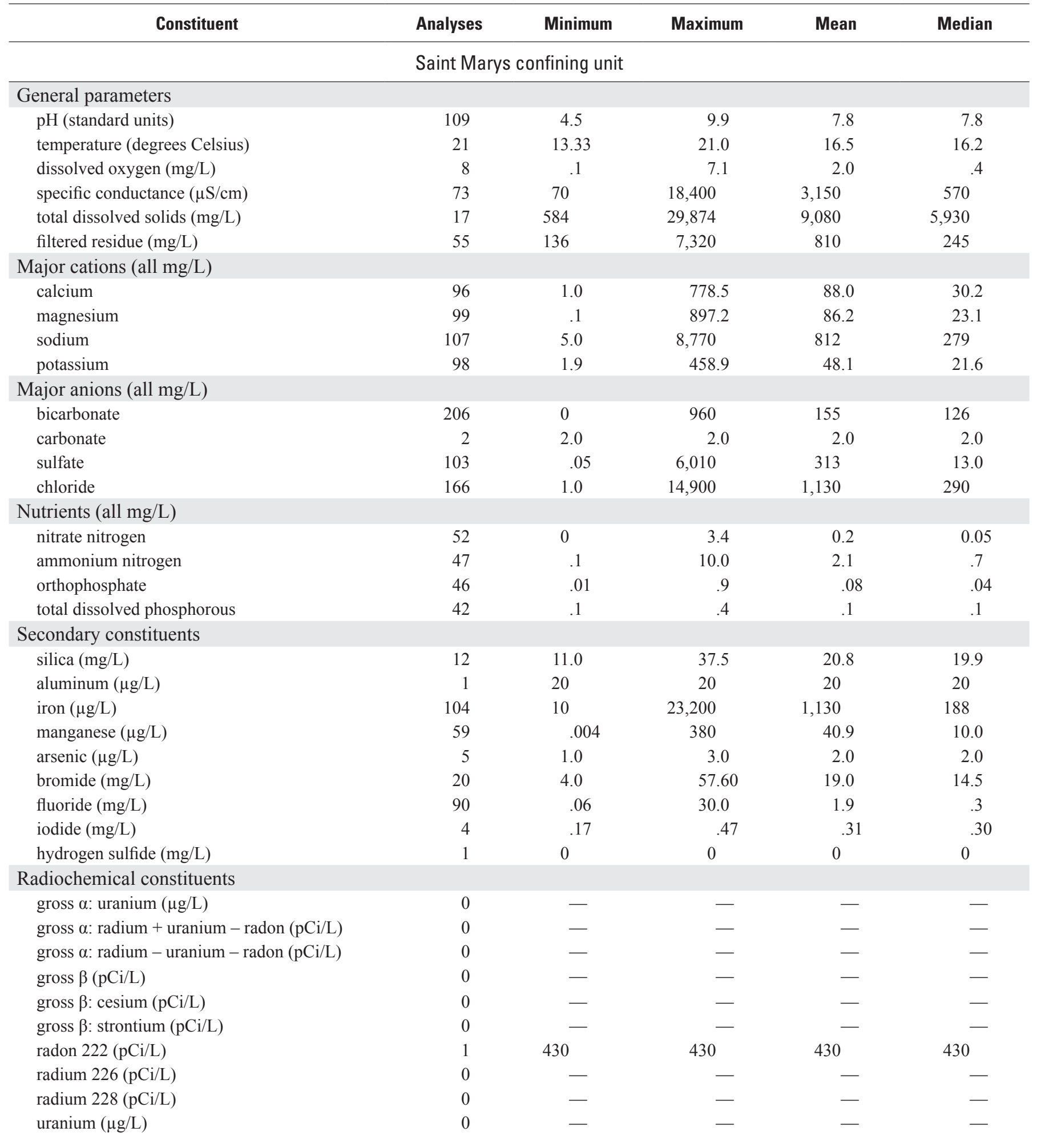


Attachment 2. Summary of groundwater-quality constituent values for hydrogeologic units of the Virginia Coastal Plain.-Continued [minimum and maximum values are cited from Attachment $1 ; \mathrm{mg} / \mathrm{L}$, milligrams per liter; $\mu \mathrm{S} / \mathrm{cm}$, microseimens per centimeter; $\mu \mathrm{g} / \mathrm{L}$, micrograms per liter; $\alpha$, alpha; $\beta$, beta; $\mathrm{pCi} / \mathrm{L}$, picocuries per liter; - , no data]

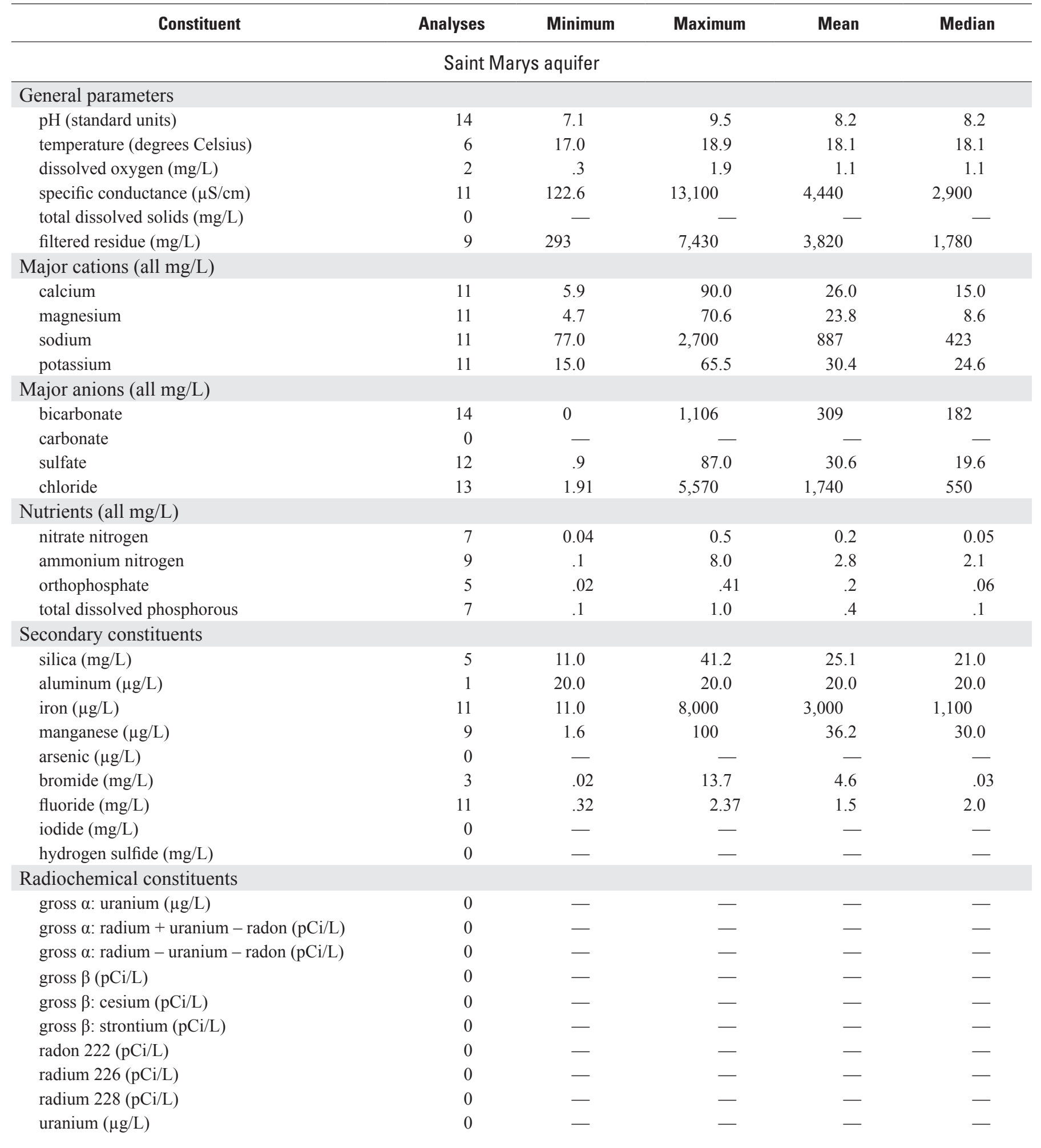


Attachment 2. Summary of groundwater-quality constituent values for hydrogeologic units of the Virginia Coastal Plain.-Continued

[minimum and maximum values are cited from Attachment $1 ; \mathrm{mg} / \mathrm{L}$, milligrams per liter; $\mu \mathrm{S} / \mathrm{cm}$, microseimens per centimeter; $\mu \mathrm{g} / \mathrm{L}, \mathrm{micrograms}$ per liter; $\alpha$, alpha; $\beta$, beta; $\mathrm{pCi} / \mathrm{L}$, picocuries per liter; —, no data]

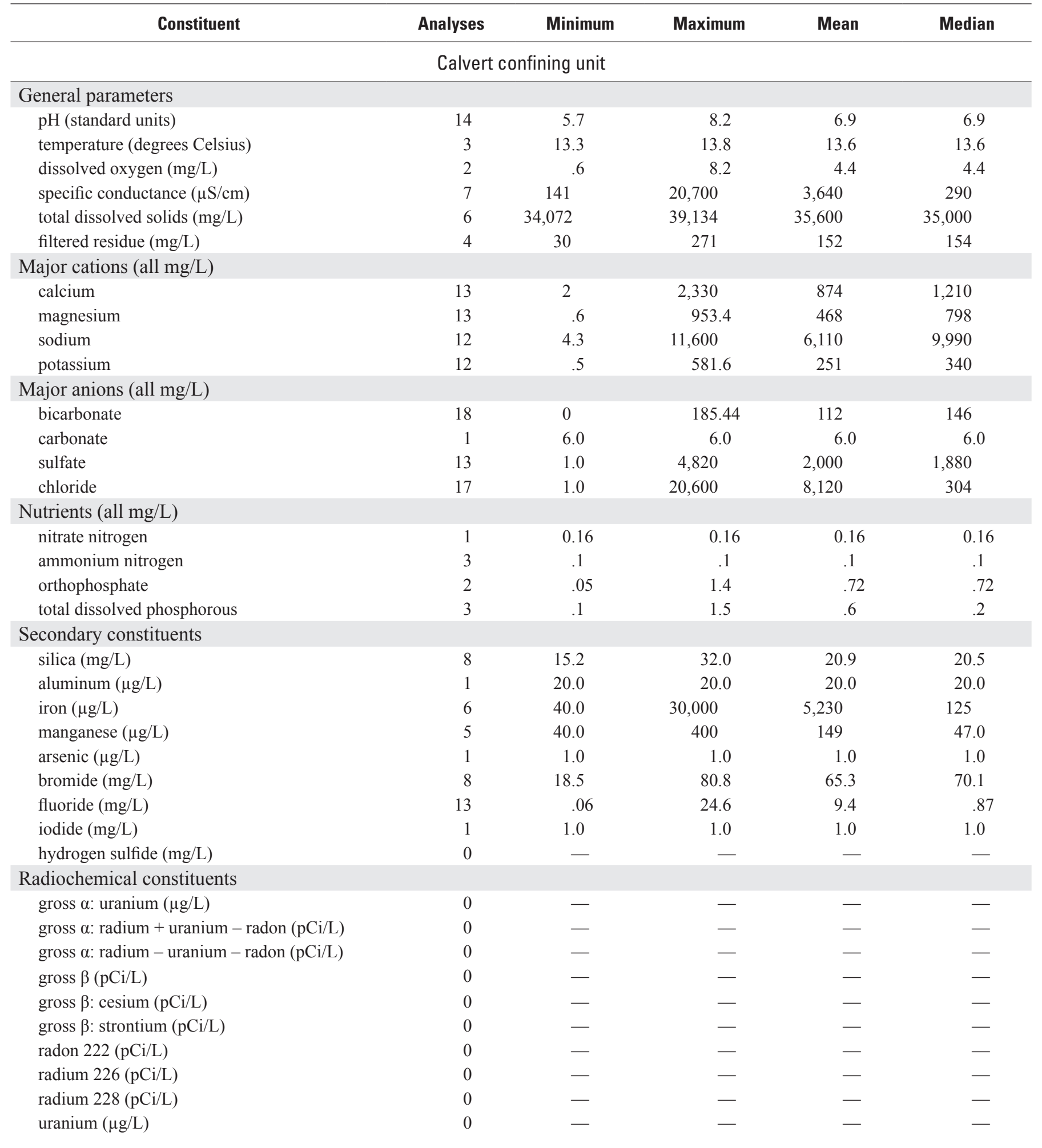


74 Groundwater-Quality Data and Regional Trends in the Virginia Coastal Plain, 1906-2007

Attachment 2. Summary of groundwater-quality constituent values for hydrogeologic units of the Virginia Coastal Plain.-Continued

[minimum and maximum values are cited from Attachment $1 ; \mathrm{mg} / \mathrm{L}$, milligrams per liter; $\mu \mathrm{S} / \mathrm{cm}$, microseimens per centimeter; $\mu \mathrm{g} / \mathrm{L}$, micrograms per liter; $\alpha$, alpha; $\beta$, beta; $\mathrm{pCi} / \mathrm{L}$, picocuries per liter; - , no data]

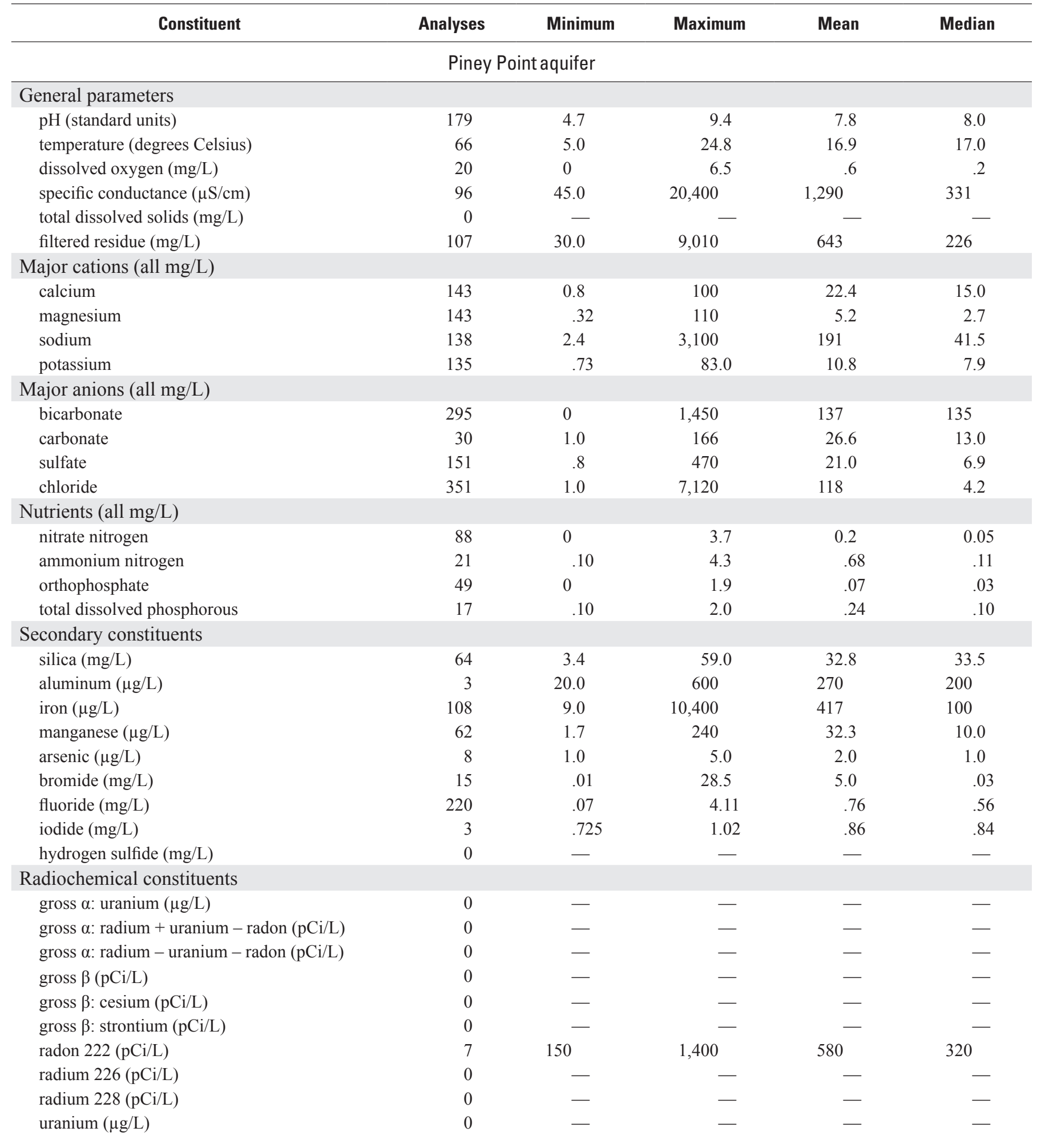


Attachment 2. Summary of groundwater-quality constituent values for hydrogeologic units of the Virginia Coastal Plain.-Continued

[minimum and maximum values are cited from Attachment $1 ; \mathrm{mg} / \mathrm{L}$, milligrams per liter; $\mu \mathrm{S} / \mathrm{cm}$, microseimens per centimeter; $\mu \mathrm{g} / \mathrm{L}, \mathrm{micrograms}$ per liter; $\alpha$, alpha; $\beta$, beta; $\mathrm{pCi} / \mathrm{L}$, picocuries per liter; —, no data]

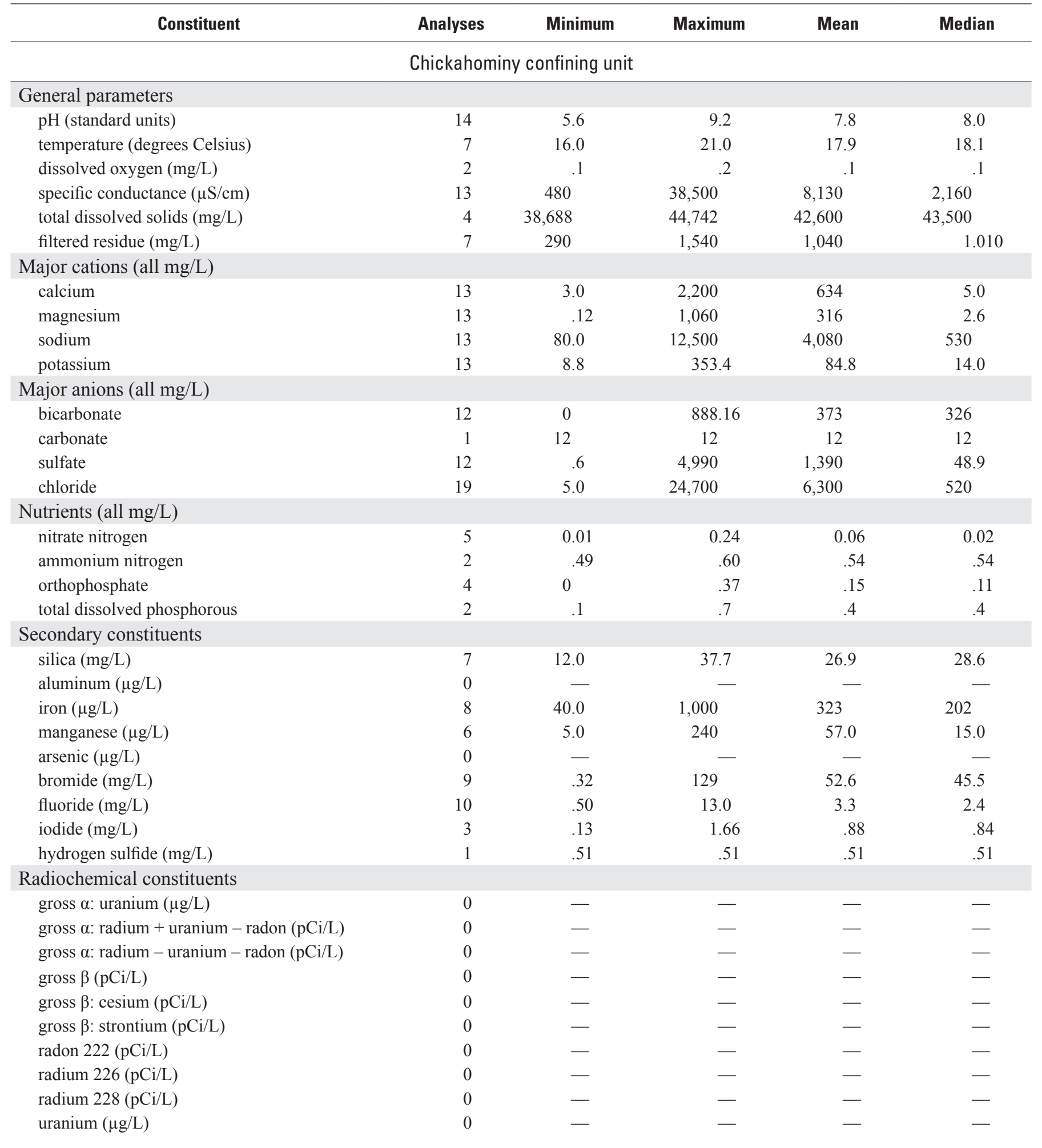


Attachment 2. Summary of groundwater-quality constituent values for hydrogeologic units of the Virginia Coastal Plain.-Continued [minimum and maximum values are cited from Attachment $1 ; \mathrm{mg} / \mathrm{L}$, milligrams per liter; $\mu \mathrm{S} / \mathrm{cm}$, microseimens per centimeter; $\mu \mathrm{g} / \mathrm{L}$, micrograms per liter; $\alpha$, alpha; $\beta$, beta; $\mathrm{pCi} / \mathrm{L}$, picocuries per liter; —, no data]

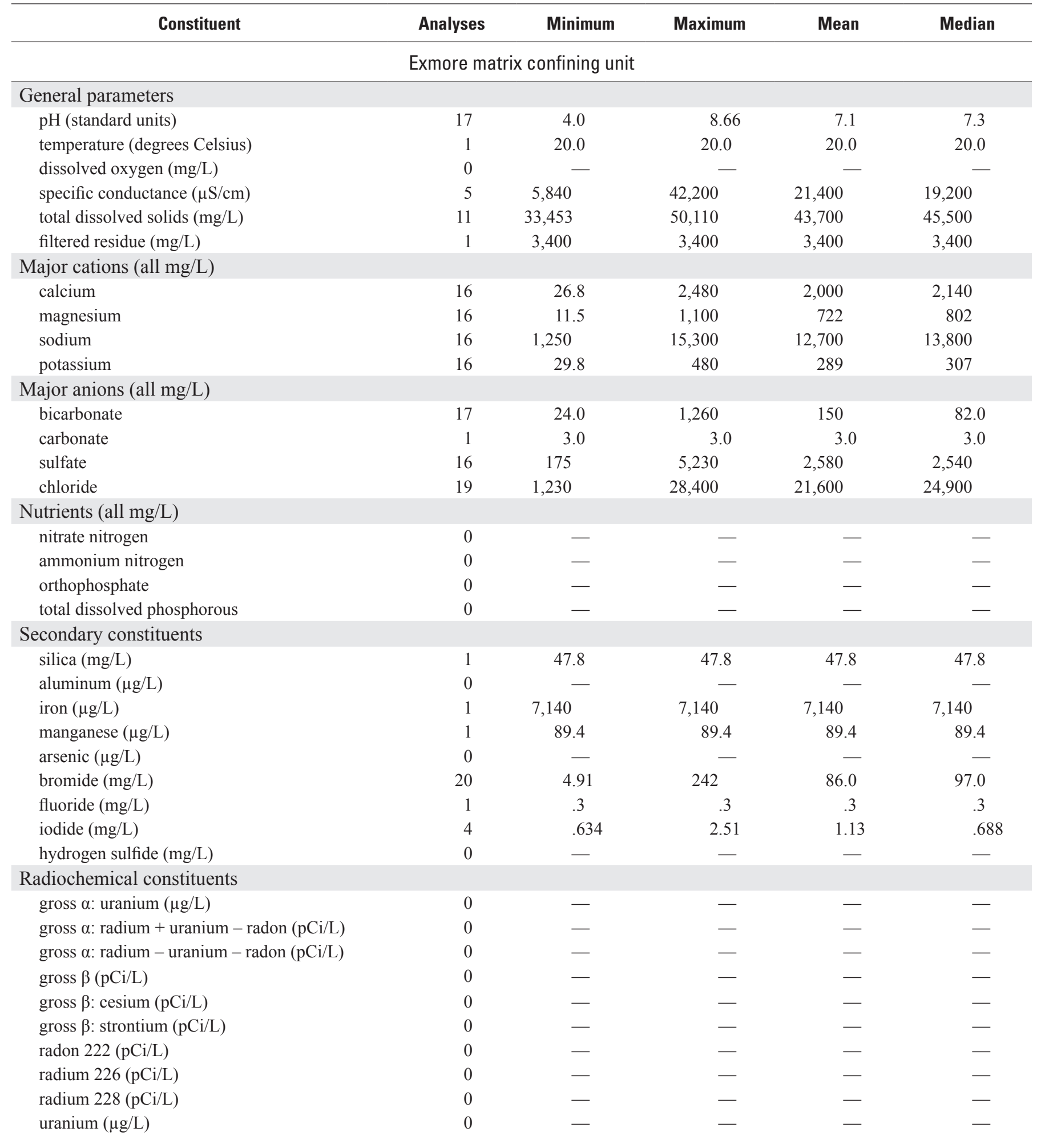


Attachment 2. Summary of groundwater-quality constituent values for hydrogeologic units of the Virginia Coastal Plain.-Continued

[minimum and maximum values are cited from Attachment $1 ; \mathrm{mg} / \mathrm{L}$, milligrams per liter; $\mu \mathrm{S} / \mathrm{cm}$, microseimens per centimeter; $\mu \mathrm{g} / \mathrm{L}, \mathrm{micrograms}$ per liter; $\alpha$, alpha; $\beta$, beta; $\mathrm{pCi} / \mathrm{L}$, picocuries per liter; —, no data]

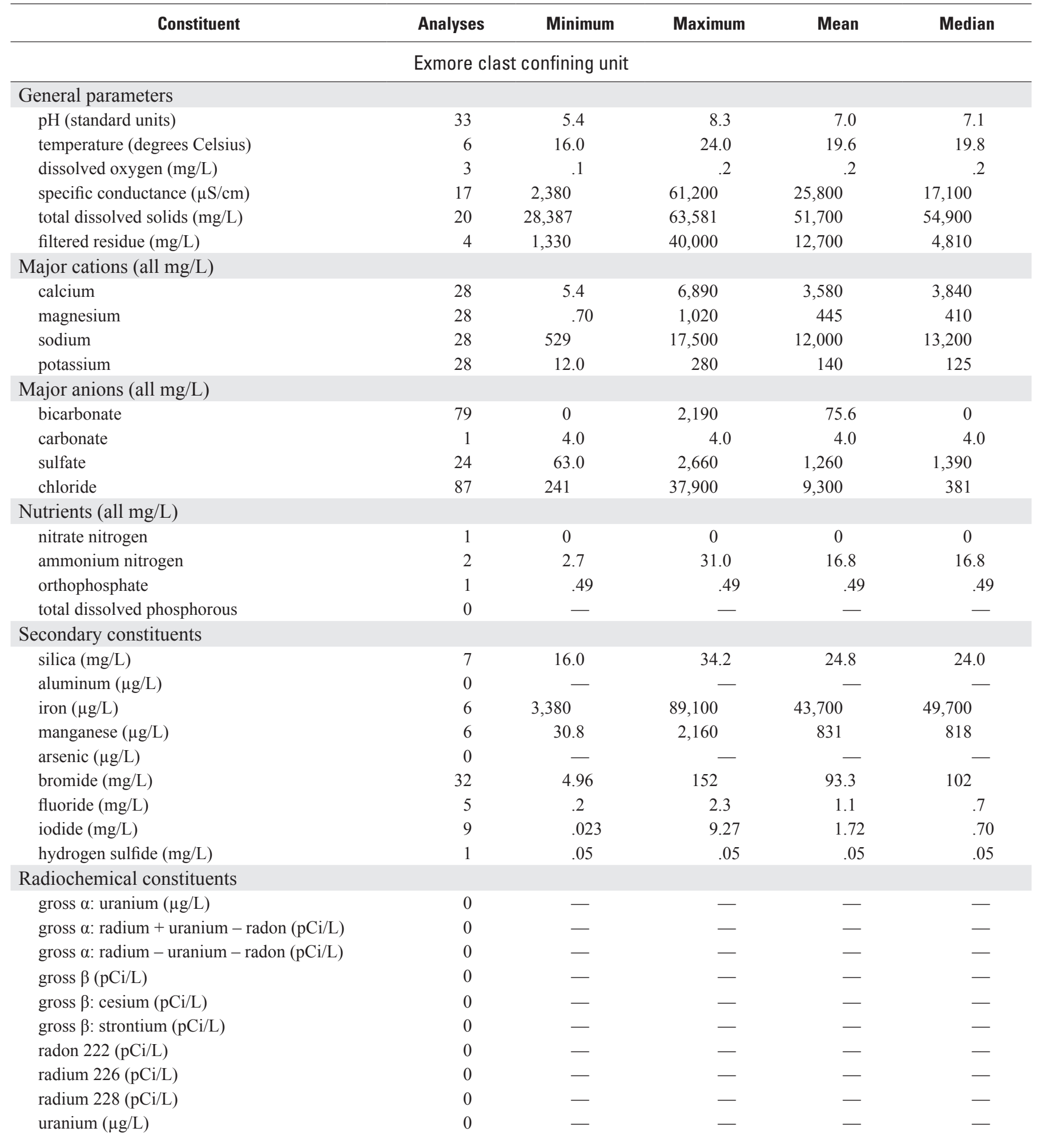


Attachment 2. Summary of groundwater-quality constituent values for hydrogeologic units of the Virginia Coastal Plain.-Continued

[minimum and maximum values are cited from Attachment $1 ; \mathrm{mg} / \mathrm{L}$, milligrams per liter; $\mu \mathrm{S} / \mathrm{cm}$, microseimens per centimeter; $\mu \mathrm{g} / \mathrm{L}$, micrograms per liter; $\alpha$, alpha; $\beta$, beta; $\mathrm{pCi} / \mathrm{L}$, picocuries per liter; —, no data]

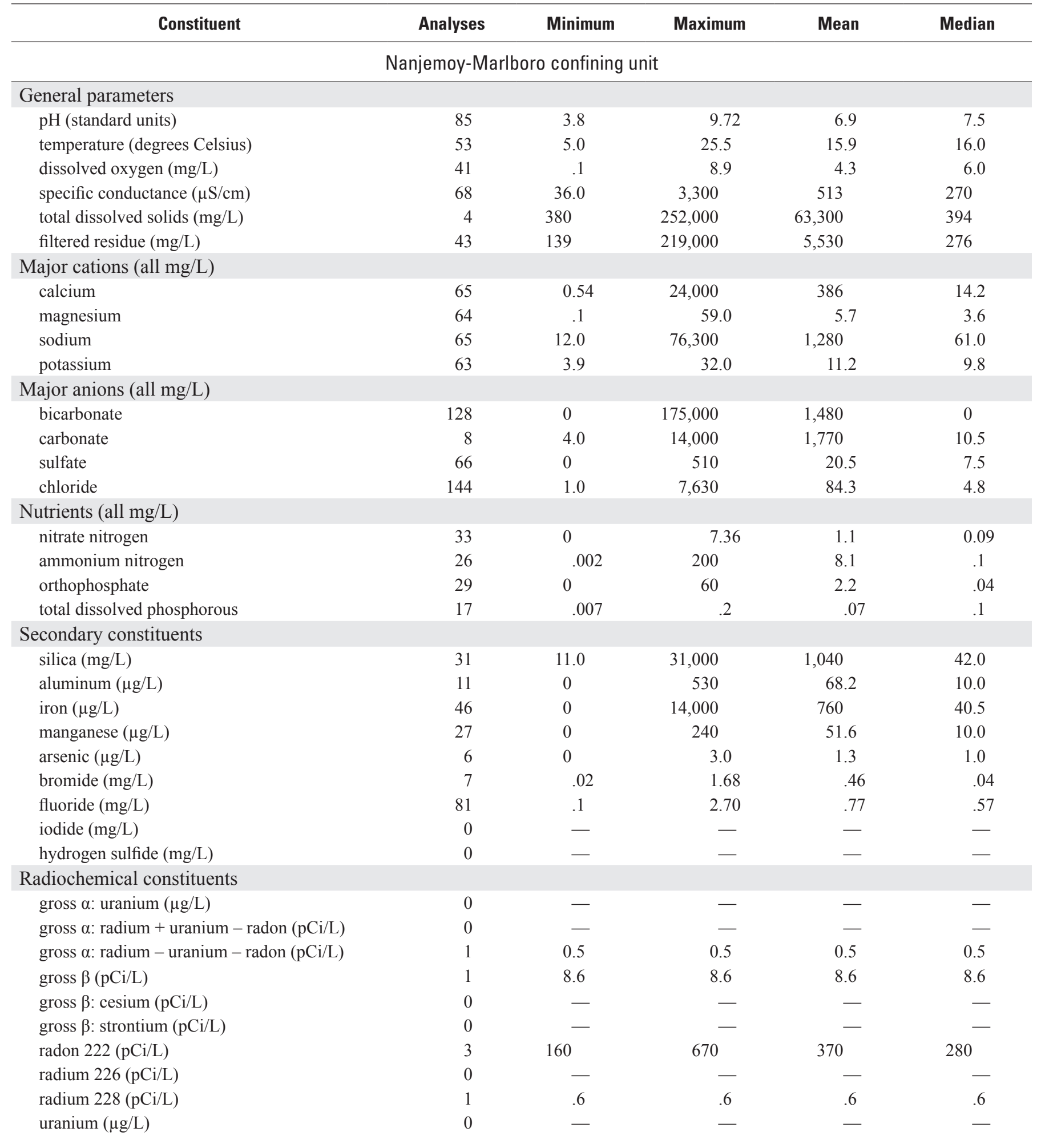


Attachment 2. Summary of groundwater-quality constituent values for hydrogeologic units of the Virginia Coastal Plain.-Continued

[minimum and maximum values are cited from Attachment $1 ; \mathrm{mg} / \mathrm{L}$, milligrams per liter; $\mu \mathrm{S} / \mathrm{cm}$, microseimens per centimeter; $\mu \mathrm{g} / \mathrm{L}, \mathrm{micrograms}$ per liter; $\alpha$, alpha; $\beta$, beta; $\mathrm{pCi} / \mathrm{L}$, picocuries per liter; —, no data]

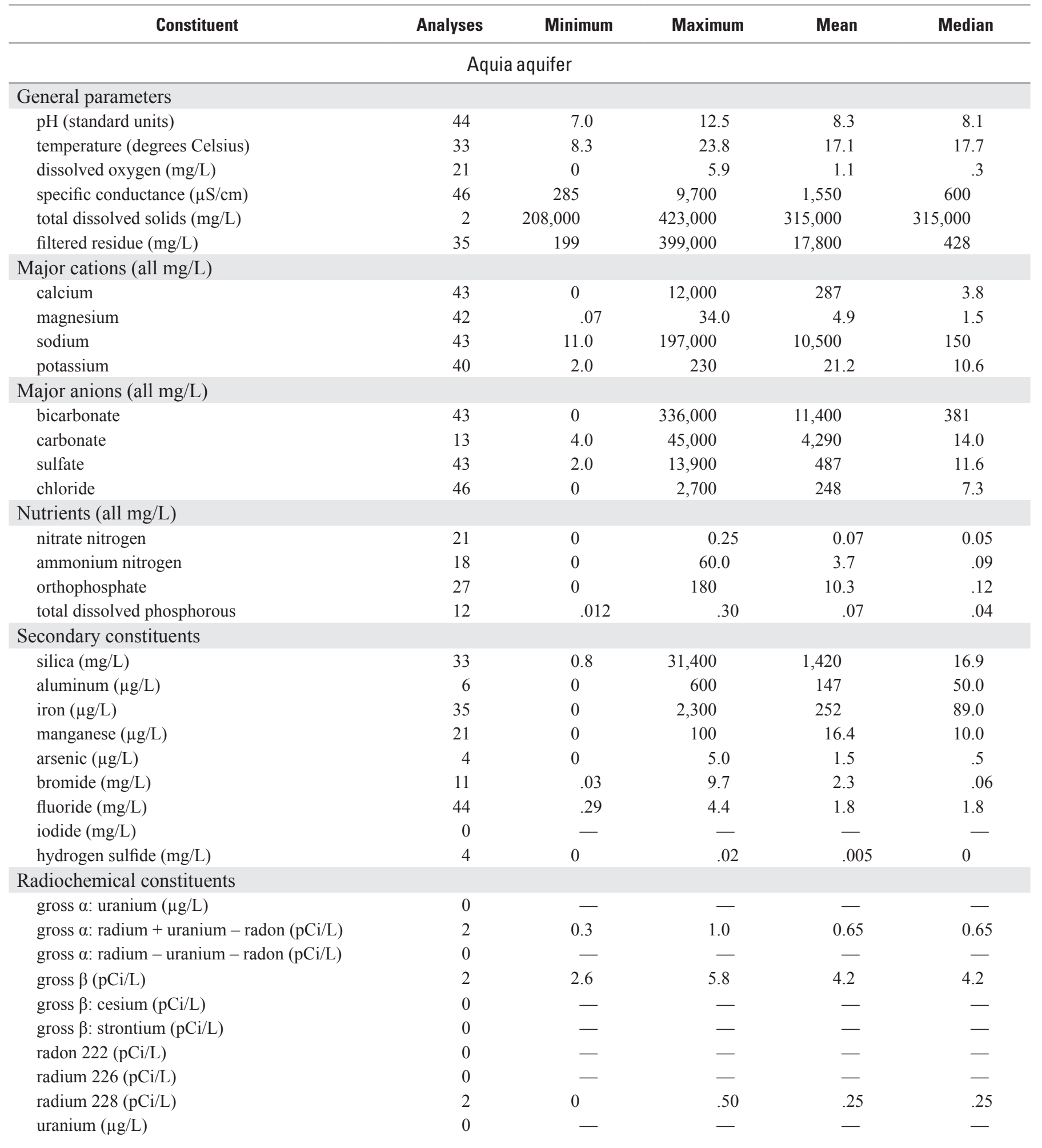


Attachment 2. Summary of groundwater-quality constituent values for hydrogeologic units of the Virginia Coastal Plain.-Continued

[minimum and maximum values are cited from Attachment $1 ; \mathrm{mg} / \mathrm{L}$, milligrams per liter; $\mu \mathrm{S} / \mathrm{cm}$, microseimens per centimeter; $\mu \mathrm{g} / \mathrm{L}$, micrograms per liter; $\alpha$, alpha; $\beta$, beta; $\mathrm{pCi} / \mathrm{L}$, picocuries per liter; - , no data]

\begin{tabular}{|c|c|c|c|c|c|}
\hline Constituent & Analyses & Minimum & Maximum & Mean & Median \\
\hline \multicolumn{6}{|l|}{ General parameters } \\
\hline $\mathrm{pH}$ (standard units) & 6 & 7.8 & 10.0 & 8.4 & 8.2 \\
\hline temperature (degrees Celsius) & 2 & 17.5 & 18.4 & 17.9 & 17.9 \\
\hline dissolved oxygen $(\mathrm{mg} / \mathrm{L})$ & 2 & .1 & .3 & .2 & .2 \\
\hline filtered residue (mg/L) & 3 & 2,226 & 2,490 & 2,360 & 2,370 \\
\hline \multicolumn{6}{|l|}{ Major cations (all mg/L) } \\
\hline calcium & 5 & 7.7 & 12.0 & 9.3 & 8.0 \\
\hline magnesium & 5 & 8.2 & 10.7 & 9.8 & 10.0 \\
\hline sodium & 5 & 70 & 940 & 673 & 780 \\
\hline \multicolumn{6}{|l|}{ Major anions (all mg/L) } \\
\hline carbonate & 1 & 7.0 & 7.0 & 7.0 & 7.0 \\
\hline sulfate & 5 & 68.2 & 175.7 & 135 & 149 \\
\hline chloride & 5 & 32.0 & 876 & 696 & 860 \\
\hline \multicolumn{6}{|l|}{ Nutrients (all mg/L) } \\
\hline nitrate nitrogen & 3 & 0.05 & 0.10 & 0.07 & 0.05 \\
\hline ammonium nitrogen & 3 & 1.5 & 1.7 & 1.6 & 1.7 \\
\hline orthophosphate & 3 & .05 & .20 & .13 & .13 \\
\hline total dissolved phosphorous & 3 & .20 & .20 & .20 & .20 \\
\hline \multicolumn{6}{|l|}{ Secondary constituents } \\
\hline silica $(\mathrm{mg} / \mathrm{L})$ & 2 & 10.7 & 12.0 & 11.3 & 11.3 \\
\hline hydrogen sulfide (mg/L) & 1 & .224 & .224 & .224 & .224 \\
\hline \multicolumn{6}{|l|}{ Radiochemical constituents } \\
\hline gross $\alpha$ : uranium $(\mu \mathrm{g} / \mathrm{L})$ & 0 & - & - & - & - \\
\hline gross $\alpha$ : radium + uranium $-\operatorname{radon}(\mathrm{pCi} / \mathrm{L})$ & 0 & - & - & - & - \\
\hline gross $\alpha$ : radium - uranium - radon $(\mathrm{pCi} / \mathrm{L})$ & 0 & - & - & - & - \\
\hline gross $\beta(\mathrm{pCi} / \mathrm{L})$ & 0 & - & - & - & - \\
\hline gross $\beta$ : cesium $(\mathrm{pCi} / \mathrm{L})$ & 0 & - & - & - & - \\
\hline gross $\beta$ : strontium $(\mathrm{pCi} / \mathrm{L})$ & 0 & - & - & - & - \\
\hline radon $222(\mathrm{pCi} / \mathrm{L})$ & 0 & - & - & - & - \\
\hline radium $226(\mathrm{pCi} / \mathrm{L})$ & 0 & - & - & - & - \\
\hline radium $228(\mathrm{pCi} / \mathrm{L})$ & 0 & - & - & - & - \\
\hline $\operatorname{uranium}(\mu \mathrm{g} / \mathrm{L})$ & 0 & - & - & - & - \\
\hline
\end{tabular}


Attachment 2. Summary of groundwater-quality constituent values for hydrogeologic units of the Virginia Coastal Plain.—Continued

[minimum and maximum values are cited from Attachment $1 ; \mathrm{mg} / \mathrm{L}$, milligrams per liter; $\mu \mathrm{S} / \mathrm{cm}$, microseimens per centimeter; $\mu \mathrm{g} / \mathrm{L}, \mathrm{micrograms}$ per liter; $\alpha$, alpha; $\beta$, beta; $\mathrm{pCi} / \mathrm{L}$, picocuries per liter; - , no data]

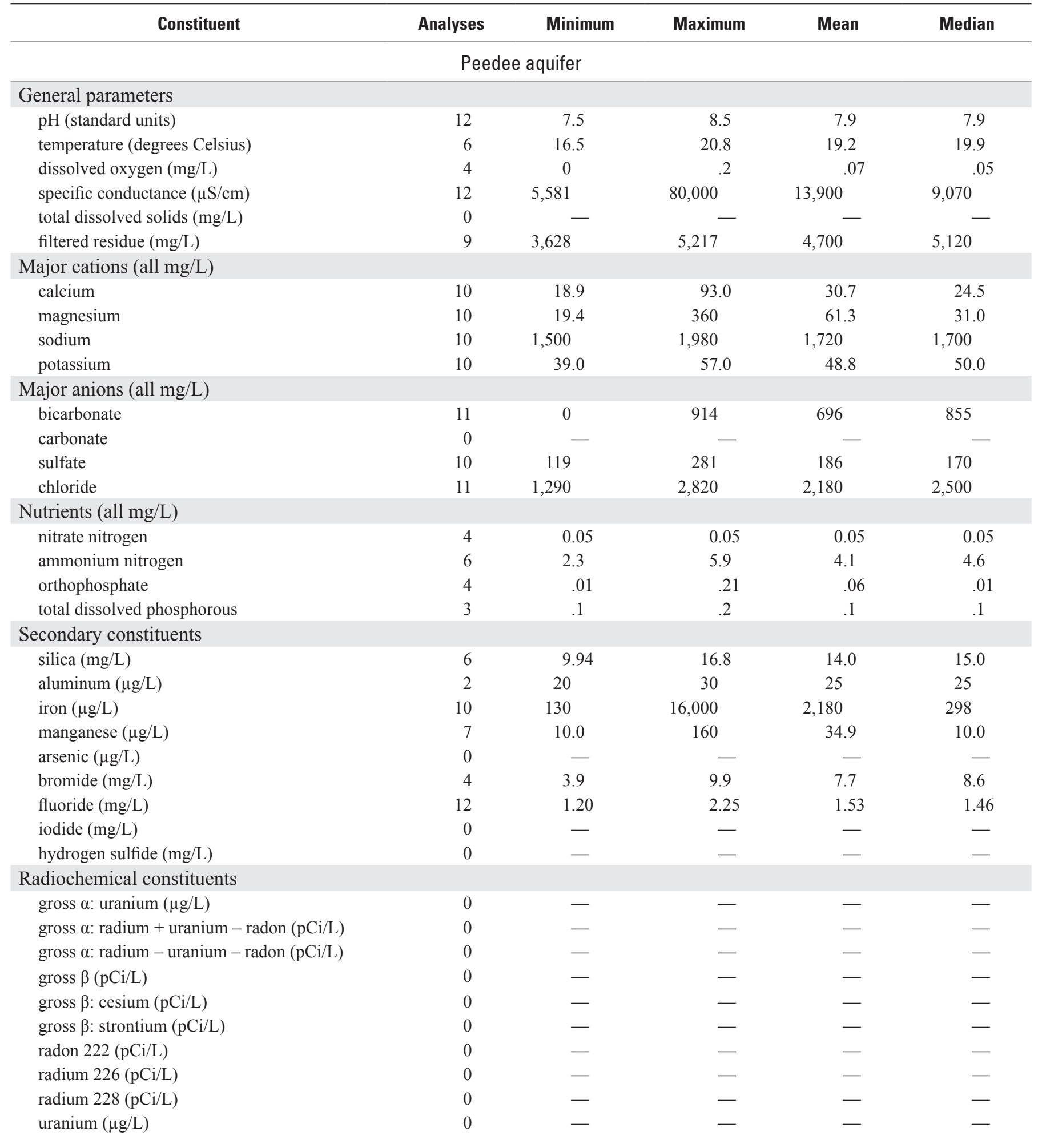


Attachment 2. Summary of groundwater-quality constituent values for hydrogeologic units of the Virginia Coastal Plain.-Continued

[minimum and maximum values are cited from Attachment $1 ; \mathrm{mg} / \mathrm{L}$, milligrams per liter; $\mu \mathrm{S} / \mathrm{cm}$, microseimens per centimeter; $\mu \mathrm{g} / \mathrm{L}$, micrograms per liter; $\alpha$, alpha; $\beta$, beta; $\mathrm{pCi} / \mathrm{L}$, picocuries per liter; —, no data]

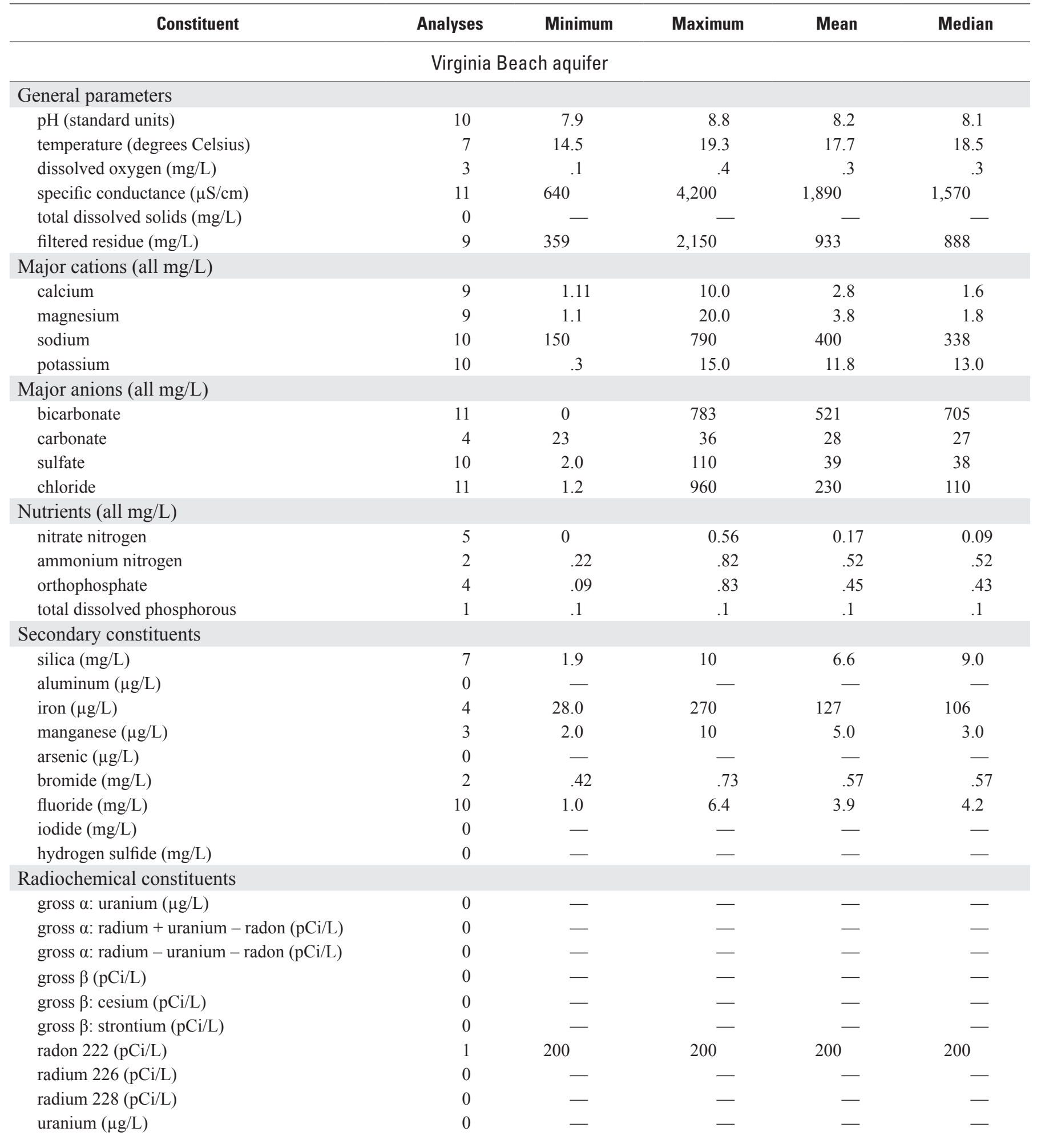


Attachment 2. Summary of groundwater-quality constituent values for hydrogeologic units of the Virginia Coastal Plain.-Continued

[minimum and maximum values are cited from Attachment $1 ; \mathrm{mg} / \mathrm{L}$, milligrams per liter; $\mu \mathrm{S} / \mathrm{cm}$, microseimens per centimeter; $\mu \mathrm{g} / \mathrm{L}, \mathrm{micrograms}$ per liter; $\alpha$, alpha; $\beta$, beta; $\mathrm{pCi} / \mathrm{L}$, picocuries per liter; —, no data]

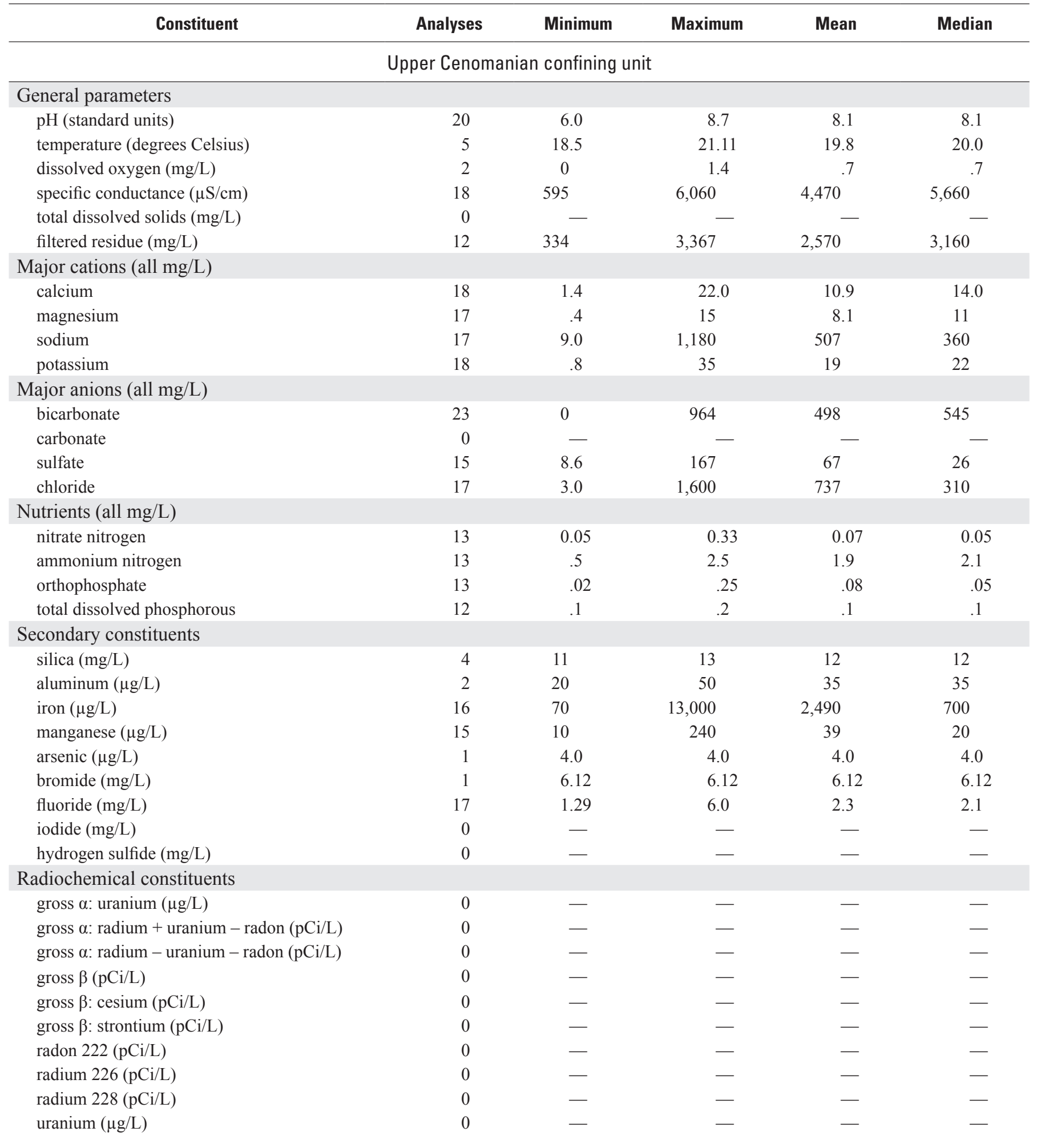


Attachment 2. Summary of groundwater-quality constituent values for hydrogeologic units of the Virginia Coastal Plain.-Continued

[minimum and maximum values are cited from Attachment $1 ; \mathrm{mg} / \mathrm{L}$, milligrams per liter; $\mu \mathrm{S} / \mathrm{cm}$, microseimens per centimeter; $\mu \mathrm{g} / \mathrm{L}$, micrograms per liter; $\alpha$, alpha; $\beta$, beta; $\mathrm{pCi} / \mathrm{L}$, picocuries per liter; —, no data]

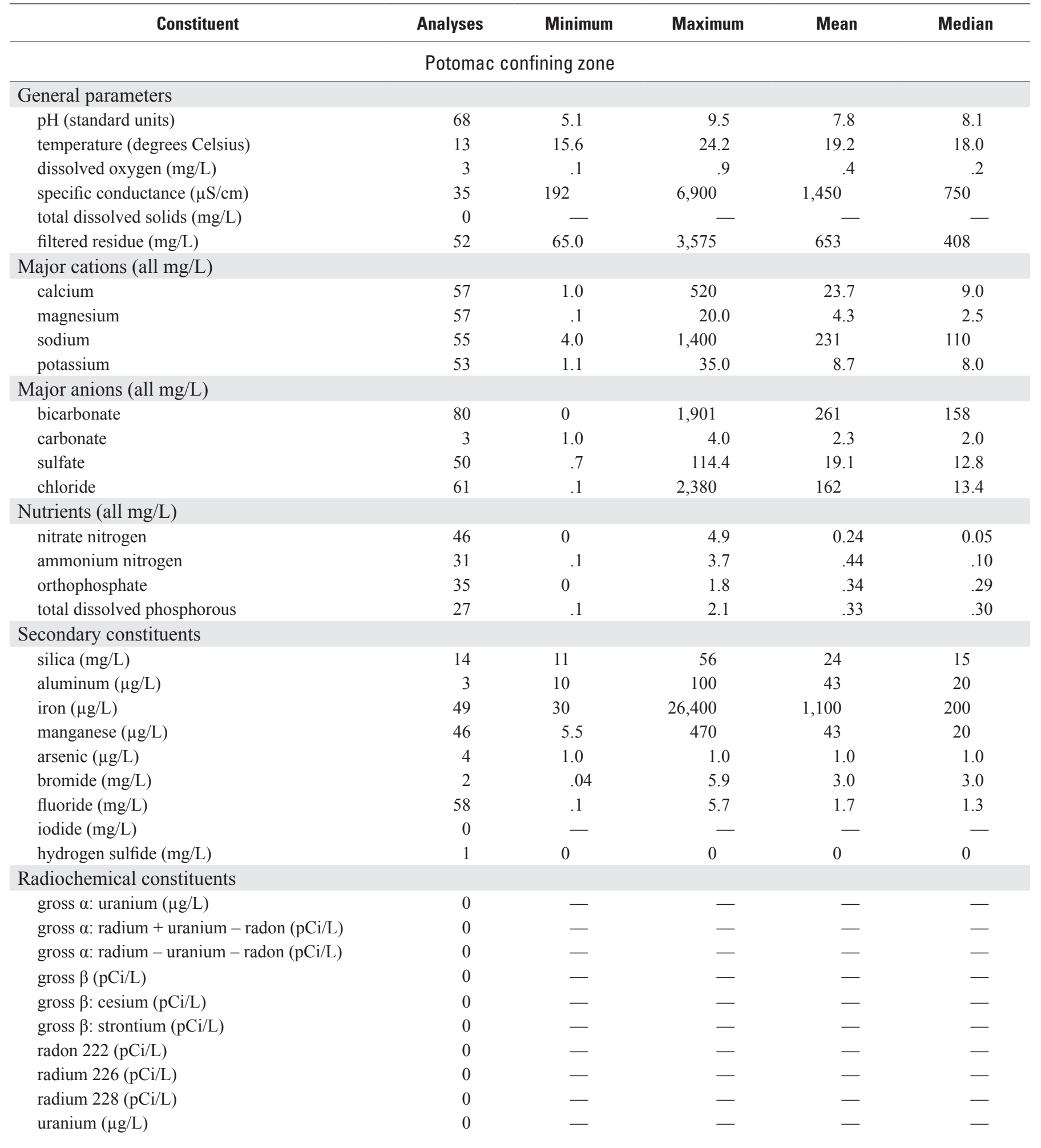


Attachment 2. Summary of groundwater-quality constituent values for hydrogeologic units of the Virginia Coastal Plain.-Continued

[minimum and maximum values are cited from Attachment $1 ; \mathrm{mg} / \mathrm{L}$, milligrams per liter; $\mu \mathrm{S} / \mathrm{cm}$, microseimens per centimeter; $\mu \mathrm{g} / \mathrm{L}, \mathrm{micrograms}$ per liter; $\alpha$, alpha; $\beta$, beta; $\mathrm{pCi} / \mathrm{L}$, picocuries per liter; —, no data]

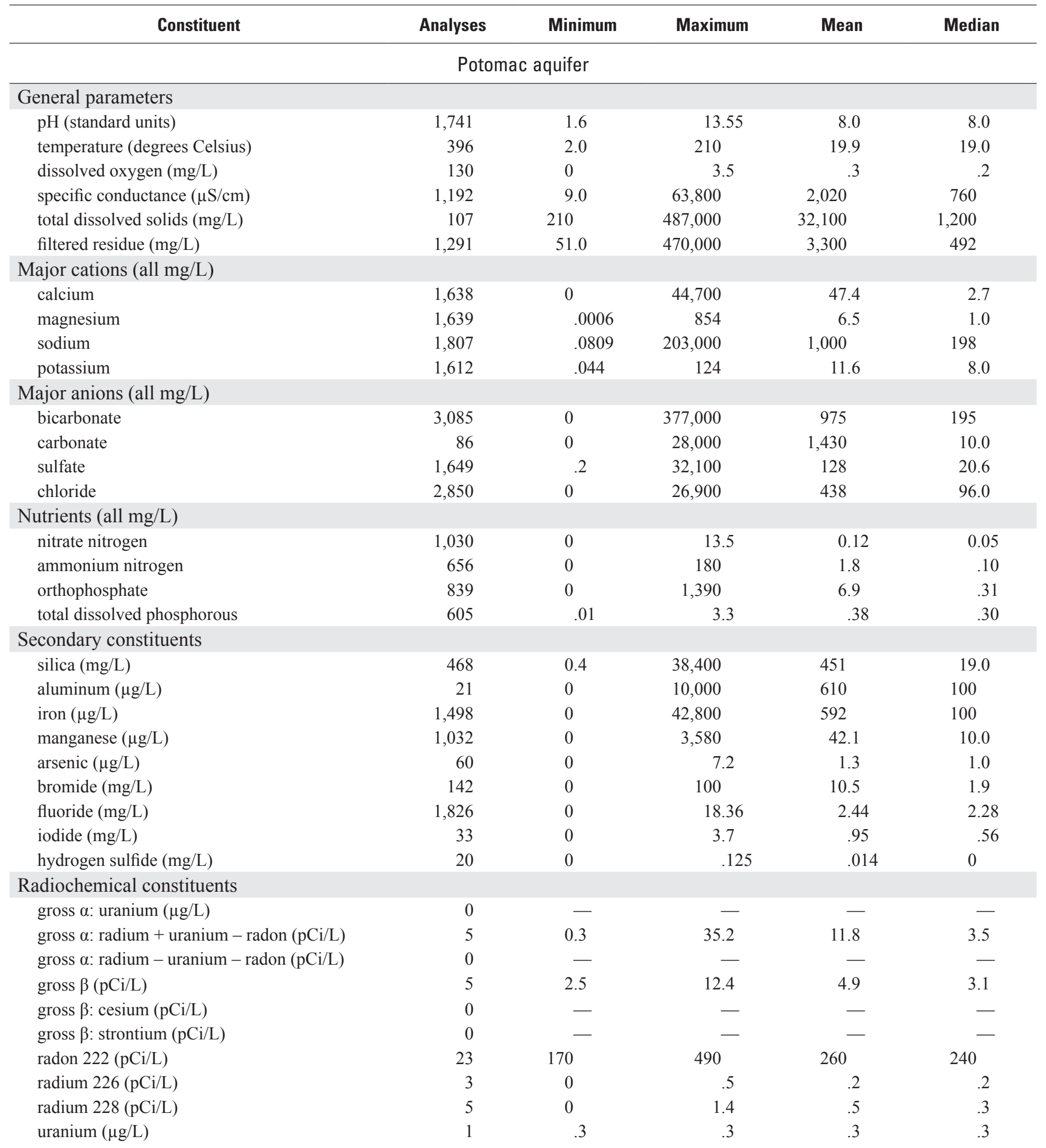


Attachment 2. Summary of groundwater-quality constituent values for hydrogeologic units of the Virginia Coastal Plain.-Continued

[minimum and maximum values are cited from Attachment $1 ; \mathrm{mg} / \mathrm{L}$, milligrams per liter; $\mu \mathrm{S} / \mathrm{cm}$, microseimens per centimeter; $\mu \mathrm{g} / \mathrm{L}$, micrograms per liter; $\alpha$, alpha; $\beta$, beta; $\mathrm{pCi} / \mathrm{L}$, picocuries per liter; —, no data]

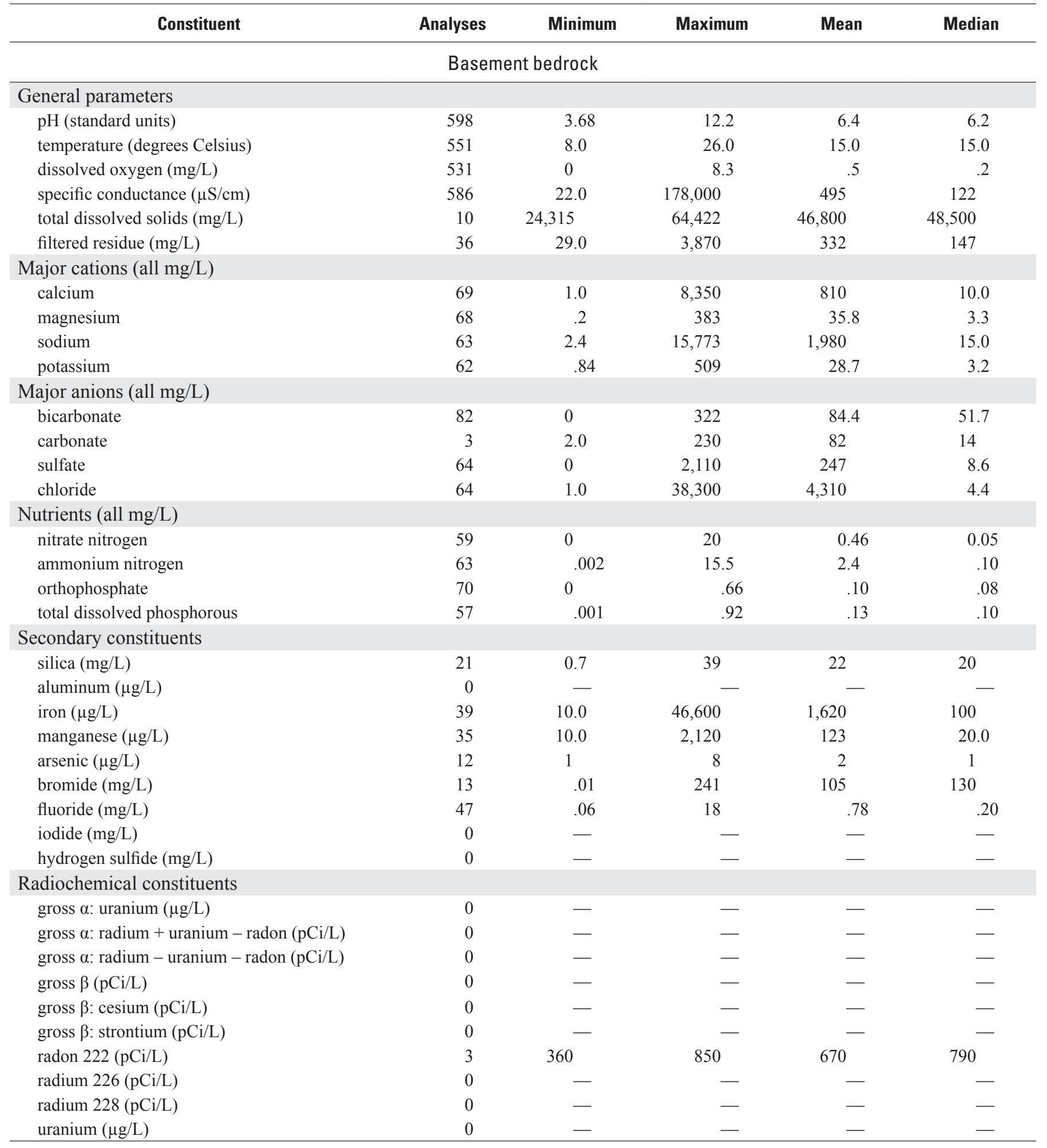




\section{Prepared by:}

USGS Enterprise Publishing Network

Raleigh Publishing Service Center

3916 Sunset Ridge Road

Raleigh, NC 27607

For additional information regarding this publication, contact: Director

USGS Virginia Water Science Center

1730 East Parham Road

Richmond, VA 23228

phone: 1-804-261-2600

email: dc_va@usgs.gov

Or visit the Virginia Water Science Center Web site at: http://va.water.usgs.gov 
